\title{
MARKING SPACE: A LITERARY PSYCHOGEOGRAPHY OF THE PRACTICE OF A NURSE ARTIST
}

\author{
By \\ Heather Edwina Martin
}
A thesis
submitted to the Victoria University of Wellington
in fulfilment of the requirements for the degree of Doctor of Philosophy In Nursing

\author{
VICTORIA UNIVERSITY OF WELLINGTON \\ NEW ZEALAND
}

2006 


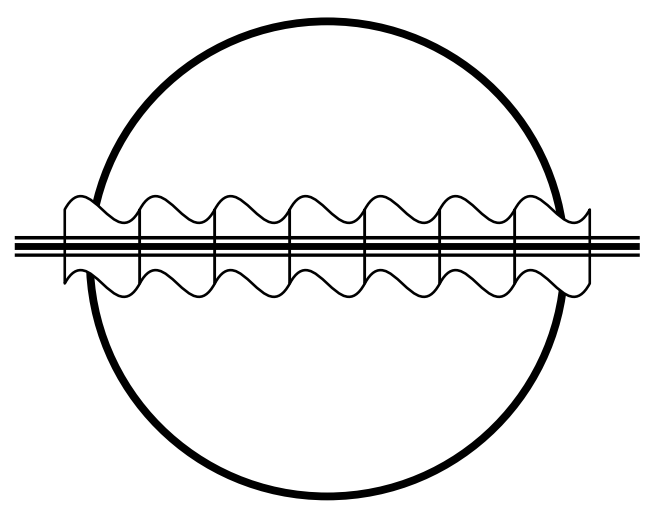




\section{ABSTRACT}

The thesis as a production of disciplined work presented in a creative style is congruent with performance and presentation best practice in community arts. As a practising nurse artist I create spaces of alternate ordering within the mental health field environment.

I also inhabit the marginal space of the artist working in hospital environments. This Other Place neither condones nor denies the existence of the mental health field environment as it is revealed. Yet, it seeks to find an alternative to the power and subjectivity of the [social] control of people with an experience of mental illness that inhabit this place both voluntarily and involuntarily.

I have used a variety of texts to explore the experience and concept of Otherness. The poems are intended to take you, as a reader where you could not perhaps emotionally and physically go, or might have never envisaged going. They also allow me as the author to more fully describe the Otherness of place that is neither the consumer story nor the nurse's notation, but somewhere alternately ordered to these two spaces.

Drawing on the heuristic research approaches of Moustakas and literary psychogeography, particularly the work of Guy Debord, this thesis creates the space to explore the possibilities of resistance and change and the emergence of the identity of the nurse artist within the mental health field environment 


\section{ACKNOWLEDGEMENTS}

Out beyond ideas of wrongdoing and rightdoing, there is a field. I'll meet you there.

When the soul lies down in that grass, the world is too full to talk about. Ideas, language, even the phrase each other doesn't make any sense.

Rumi.

I dedicate this thesis to my friend Ronald Albert Brewer. Ron was sent to Seacliff Asylum when he was fifteen, and when I met him in his seventies he had been in one Institution or another, all his life. He had a brilliant attitude and enormous capacity to overcome his situation in creative ways. All his treasured possessions and correspondence he carried safely in his coat, which weighed about seven kilos. Ron would write short stories about himself and send them off to radio announcers or politicians. As he chortled while posting the letter he'd say "That'll make em think"... Ron, and others like him, have taught me everything I know about forbearance.

I give my heartfelt and humble thanks to the many people that have helped in the writing of this thesis...Christine Alavi who said the magic word psychogeography and brought my life's work and passion into focus and into text, for sharing your wisdom and deep knowledge with me, while all I had to do was write. My beautiful sisters Colleen MacGregor and Margi Martin who are cornerstones of my world. Ina Martin my mother for her unflinching belief in me, and my whole family who always and ever have faith in me. Phyllis Tangitu and Po Te Atatu for welcoming me in and letting me go again. Kerry Watson and Michele Don for being my support crew on location. Rebecca Fraser, Mere Marshall and Prue Muschamp for being mentors and cheerleaders to my dreams. Marilyn Webb for the aesthetic as it relates to justice. Jan Duke who encouraged me to achieve something I thought was unobtainable. Friends and colleagues who followed my progress and cheered me on. Guru Mayi for keeping me safe. Most of all, thanks to Pat Irvine, Monty, Del and Lunar who with patience, sojourned with me. 


\section{TABLE OF CONTENTS}

PROJECT LOGO . . . . . . . . . .

ABSTRACT . $\quad . \quad . \quad . \quad . \quad . \quad . \quad . \quad . \quad$. .

ACKNOWLEDGEMENTS . . . . . . . . . . .

TABLE OF CONTENTS . . . . . . . . . . .

NOTES ON THE TEXT $\quad . \quad$. $\quad . \quad$. $\quad . \quad$. $\quad$ viii

GLOSSARY . $\quad . \quad$. $\quad . \quad$. . . . . .

LIST OF ILLUSTRATIONS . $\quad . \quad$. $\quad . \quad$. $\quad . \quad$ xii

LIST OF TABLES . . . . . . . . . . . .

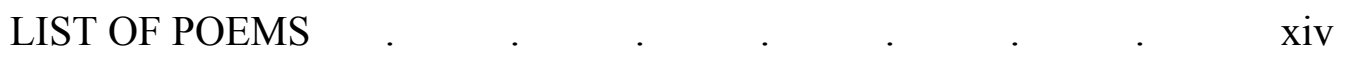

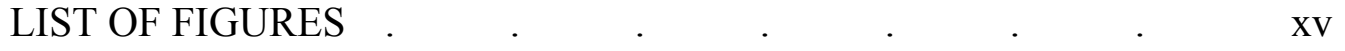

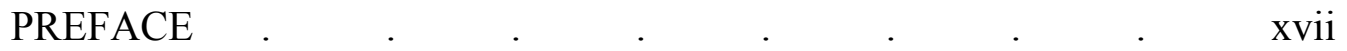

ART INTERVAL . . . . . . . . . . 
CHAPTER ONE: Mapping Identity and Environment

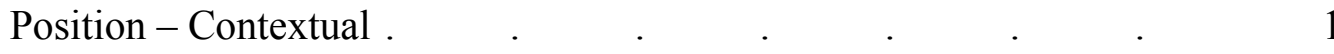

CHAPTER ONE: Mapping Identity and Environment $\quad$. $\quad$. 1

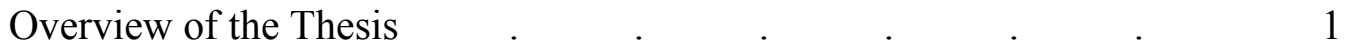

CHAPTER ONE: Mapping Identity and Environment $\quad$. $\quad$. 1

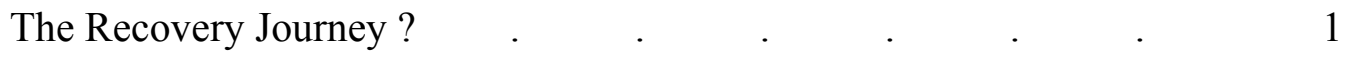

CHAPTER ONE: Mapping Identity and Environment $\quad$. $\quad$. 1

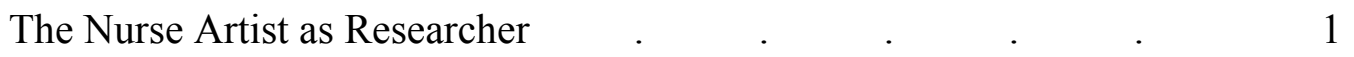

CHAPTER ONE: Mapping Identity and Environment $\quad$. $\quad$. 1

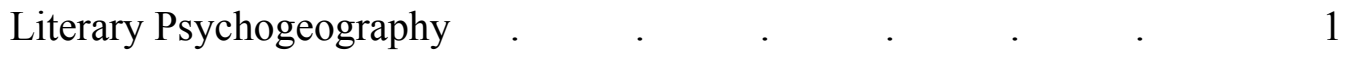

ILLUSTRATION: Thesis As Cognitive Map. $\quad$ · $\quad$ · $\quad$ · 20

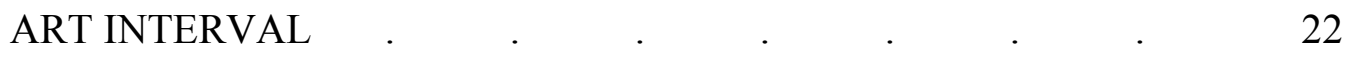

CHAPTER TWO: The Mental Health Field Environment 1

Placement In The Consumer Domain: A Strategy of Inquiry. $\quad$ · 1

Creative Arts in the Mental Health Field Environment: Mental Health

Side By Side Practice in the Community Arts Model . . . 23 
CHAPTER THREE: Theoretical and Philosophical Understandings of the Mental Health Field Environment . . . . . . 46

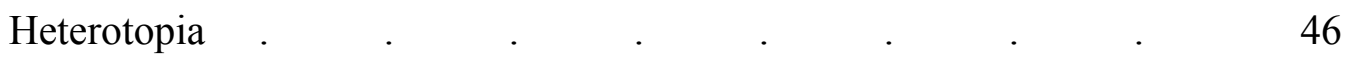

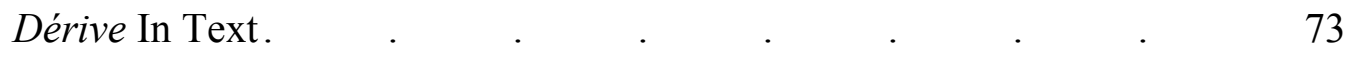

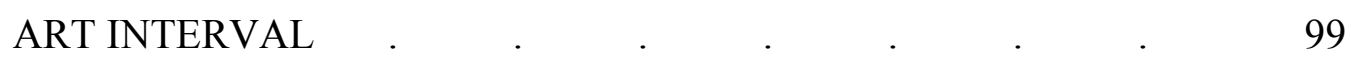

CHAPTER FOUR: Theoretical and Philosophical Understandings

of the Mental Health Field Environment - Another Way 100

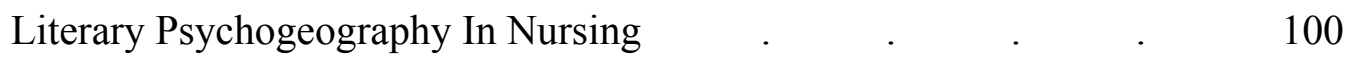

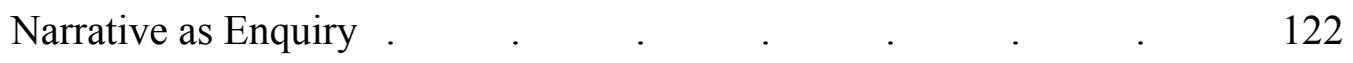

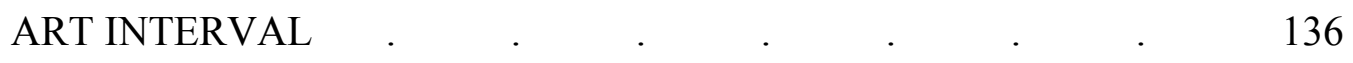

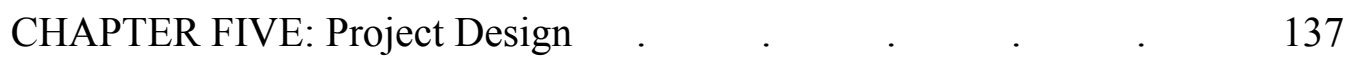

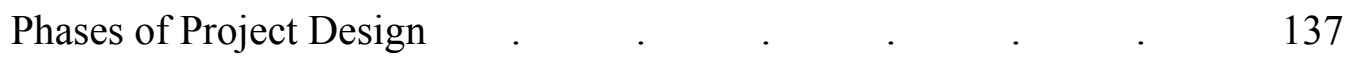

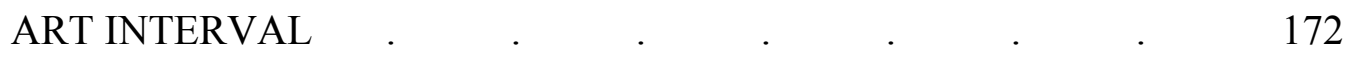

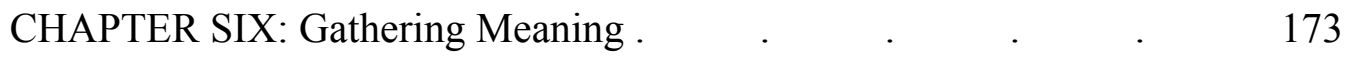

Map Fragments - Literary Psychogeographical Method $\quad$ · $\quad$ · 173

Map Fragments - Cognitive Mapping of the Mental Health Field

Environment . 


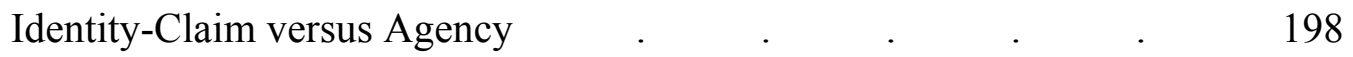

Meaning Making, Expose of Data, Detail and Relevance . 203

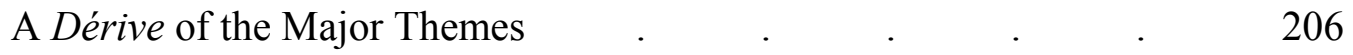

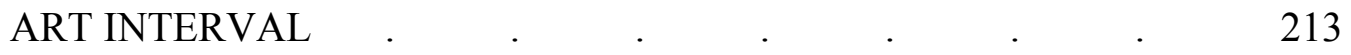

CHAPTER SEVEN: Conclusion and Recommendations for Practice 214

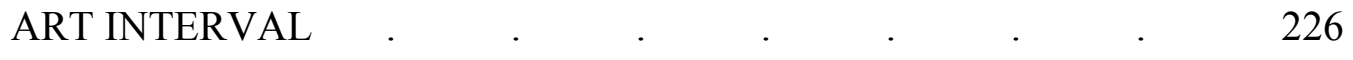

APPENDICES

Appendix 1: Letter From Cathy Cooney $\quad$ • $\quad$. $\quad$. $\quad$. $\quad 227$

Appendix 2: Letter from Jacqui Akuhata-Brown $\quad . \quad$. $\quad$ • $\quad 228$

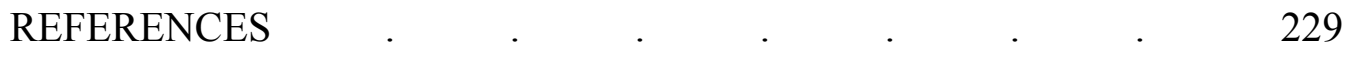

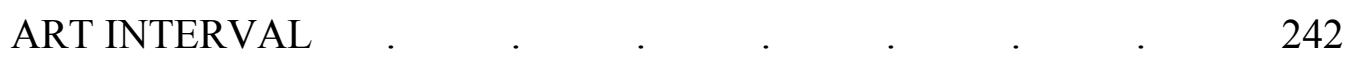

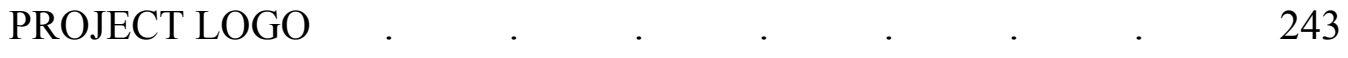




\section{NOTES ON THE TEXT}

1. Moustakas, Goffman and Laing use the male pronoun throughout their work, however I would rather use a more feminine-gendered discourse and so where I use their quotations I am placing their pronouns in \{\} curly brackets.

2. [ ] square brackets in the remaining text are an indication of an insertion of détournement which gives an opportunity for a new eventuation to arise in meaning and interpretation. This is the voice of resistance and movement.

3. Where I have capitalized words such as People and Things, my intention is that the reader recognises these terms as specific subjects of interest in the context of their presence in the mental health field environment.

4. The Internationale Situationniste was a review published by the Situationists in Paris in the 1950s and 1960s and is sometimes referred to as The Situationist International. The revolutionary movement of the The Situationists was also sometimes referred to as the Situationist International. My quotations in text have attempted where possible to follow the chosen form of reference by the author of the quote.

5. All poetry (and paintings) unless otherwise attributed, are the original works of the author of this thesis Heather Martin.

6. All textual material unrepresented in this thesis but written in support of it has been forwarded to Boroko, Papua New Guinea, as an illustration of dètournement. 


\section{GLOSSARY}

\section{People/Person}

Any reference made to an individual or individuals is with a citizenship approach as opposed to a rehabilitative approach or custodial approach (Liddy, 2004)

\section{Consumer}

Consumer movement generated meaning past experience of a mental illness and experience of hospital treatment (Liddy, 2004)

\section{Patient}

Used by medical staff and other health professionals to denote the person who receives treatment in open or locked hospital environments. A patient receives care and the term implies a duty of care provided by the health service but also implies passive involvement in health illness process and care (Liddy, 2004)

\section{Client}

When I use the term 'client' generally as a nurse artist, I refer to the person/s who may participate in various activities of creative expression within the mental health field environment. However, for the purposes of this thesis, when I use the term 'client' I am referring only to consumers / tangata whaiora of mental health services and generally people experiencing severe and enduring mental illness.

\section{Community Arts}

Community arts, refers to art in a Community Arts context that supports an individual's right to personal creative expression. Overcoming social injustice caused by power imbalance, poverty and discrimination, individuals reach their creative potential by active participation in the visual and performing arts. In a health context the intention is to achieve creative expression not use art as a therapy. However where a Client acknowledges the therapeutic quality of this experience for themselves, this is acknowledged. 


\section{Institutionalisation}

"The warehousing or placing of people together in institutions for long periods of time, sometimes for life" (McKewen, 2001, p. v).

\section{Villa}

"Separate accommodation, which enabled small groups of patients (sic) with similar needs to be managed together". (Mckewen, 2001, p.vi)

\section{Maori Translations}

Hangi - traditional maori steamed food cooked in underground oven

Hapu - sub-tribe

Hikoi - special journey; usually a walk

Iwi - the people of the local area (tribe)

Kaumatua - male elder; wise and experienced older members of the whanau

Kaupapa - principles recognised nationally by Maori

Kaupapa Maori - for Maori by Maori; Maori centred services which are offered within a Maori cultural context

Kawa - protocol

Kia Ora - hello; thanks; good health

Kimi Ora - "search for life or good health'

Korero wairua - reference to the spiritual realm

Mai i Maketu ki Tongoriro - from Maketu to Tongoriro (place names) describes the geographical boundary of the Te Arawa Canoe

Marae - focal point of settlement for Maori

Ngati Whakaue - people of the Whakaue tibe

Oranga - health; wellbeing

Pakeha - non-Maori

Po Te Atatu - "from the darkness into the light"

Pohiri Poutama - A Maori model of best practice. Powhiri is the ritual associated with welcoming people. Poutama is likened to a stairway that transcended the heavenly realms 
Pukeroa - place name located in Rotorua, site of the Rotorua Hospital

Rotorua - place name

Taha Hinengaro - mental and emotional realm

Taha Tinana - physical realm

Taha Wairua - spiritual realm

Taha Whanau - family realm

Tangata Whaiora - person/s seeking wellness

Tangata Whenua - local people; people of the land of a locality; hosts, the indigenous people of New Zealand (Maori)

Тари - sacred

Te Arawa - The Arawa tribe

Te Tiriti o Waitangi - The Treaty of Waitangi

Tikanga - The practice of Kawa, rules

Tikanga Whakamua - A framework of Maori health practice

Tino Rangatiratanga - self-determination; reclaiming identity

Tuku iho - passed down

Tumuaki - Senior Manager

Tupuna - ancestors

Waka - vehicle

Wairua - spirit, soul

Wero - challenge

Whakatane - place name

Whakatau - welcome 


\section{LIST OF ILLUSTRATIONS}

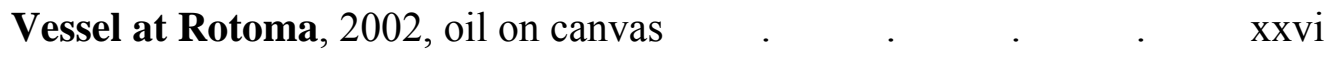

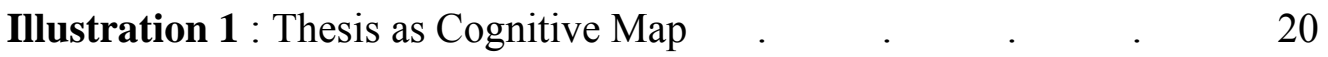

Porcelain Hospital Jug at Tarawera, 2002, oil on canvas . 22

Deinstitutionalised Hospital Jugs, 2001, acrylic on canvas. 45

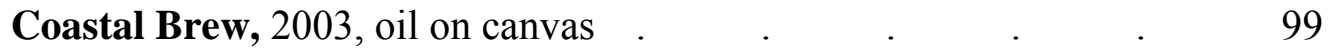

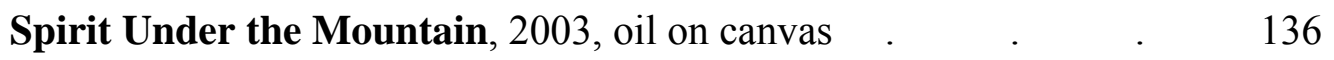

Illustration 2 : Conceptual Map of Positioning of Researcher $\quad$ • 161

Illustration 3 : Psychogeographical Map of the Thesis Design $\quad$ • 170

Illustration 4 : The Necklace, Psychogeographical Map - Another Way 171

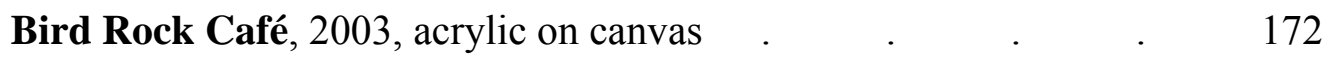

Illustration 5 : Cognitive Map of the Poems - 2002 . $\quad$ • $\quad$. 195

Illustration 6 : Cognitive Map of the Poems - 2005 _ . . 197

Moving On, 2003, acrylic on canvas _ . $\quad$. $\quad$. $\quad$. $\quad 213$

Open Hearted Phase I, 2003, mixed media . $\quad$ • $\quad$. $\quad$ • $\quad 226$

Open Hearted Phase II, 2003, mixed media $\quad$. $\quad$. $\quad$. 242 


\section{LIST OF TABLES}

Table 1 : Mental Health Field Environment Heterotopic Juxtapositions

Table 2 : Key to Research Journal $\quad$ c $\quad$. $\quad$. $\quad$. $\quad$. 143 


\section{LIST OF POEMS}

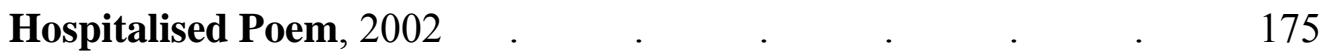

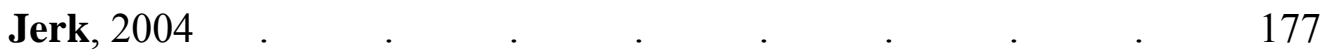

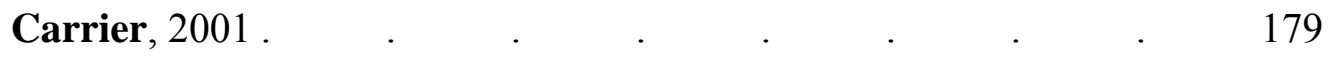

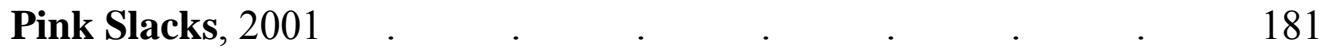

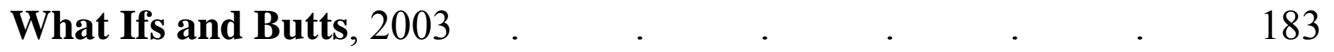

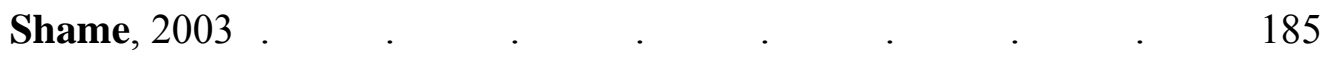

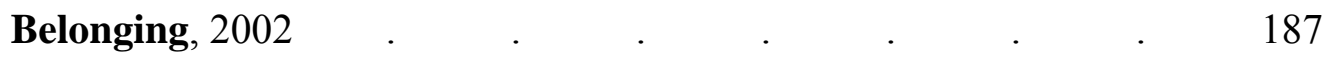

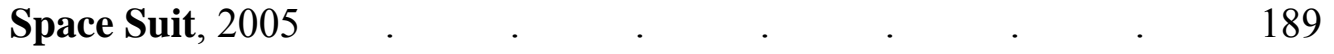

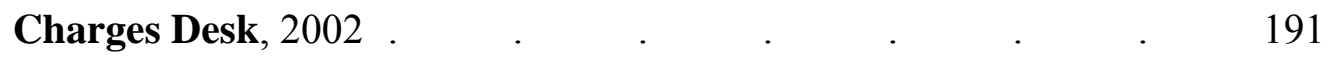




\section{LIST OF FIGURES}

Figure 1 : Conceptual Map of Parallel Practices - Art, Ethnicity and Recovery

Figure 2 : Nursing Practice Development Tool . . $\quad 148$

Figure 3 : Thesis as Mountain - Side View . $\quad$. $\quad$. 153

Figure 4 : Mental Health Field as Mountain of Separation -

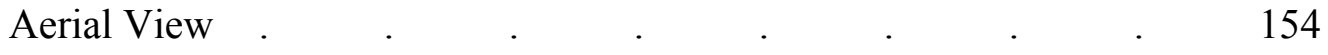

Figure 5 : Mental Health Field as Mountain of Separation -

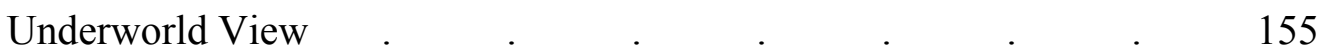

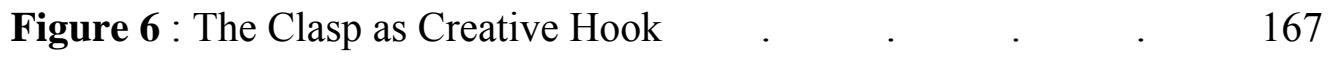

Figure 7 : The Clasp as Synthesis Eye $\quad$. $\quad$. $\quad$. $\quad 169$

Figure 8 : Cognitive Site - Map Fragment . $\quad$. $\quad$. $\quad 176$

Figure 9 : Cognitive Site - Map Fragment . $\quad$. $\quad$. $\quad$. 178

Figure 10 : Cognitive Site - Map Fragment . $\quad$. $\quad$. $\quad$. 180

Figure 11 : Cognitive Site - Map Fragment . . . . . 182

Figure 12: Cognitive Site - Map Fragment . $\quad$. $\quad$. $\quad$. 184

Figure 13 : Cognitive Site - Map Fragment . $\quad$. $\quad$. $\quad$. 186

Figure 14 : Cognitive Site - Map Fragment . $\quad$. $\quad$. $\quad$. 188 
Figure 15 : Cognitive Site - Map Fragment .

Figure 16 : Cognitive Site - Map Fragment . 192 


\section{PREFACE}

As a reader, you are invited to consider the wanderings and musings of the author, as new possibilities are sought to refine practice positions that nurses can work from. The experience may challenge both perceptions of practice and thesis presentation, although the research project itself follows a traditional route.

The method used initially to enter the research field was Reflective Topical Autobiography, which draws on the heuristic research approaches of Moustakas (1990). Steps are described as immersion, incubation, and illumination, which produce a high level of critical self-reflection and a total immersion in the topic. This journey is documented using poetry, text, cognitive maps and visual art images.

The presentation challenges the notion of reading a document sequentially from the start to the finish in order to pursue the idea of textual play, and seek freedom from the situating of the narrative in an historical and lineal assembly. As Soja (1989) states "sequentially unfolding narrative predisposes the reader to think historically, making it difficult to see the text as a map, a geography of simultaneous relations and meanings that are tied together by a spatial rather than a temporal logic" (p.1).

This element and challenge is central to this thesis.

This thesis is, in essence, the creation of a heterotopic site where neither the ordering nor freedoms of artistic expression are given central or marginal positions. The place of alternate ordering of the unfolding narrative is an Otherness, and is based upon the author's idea of the possibility of social improvement through nurse artist theory development in nursing practice. A place of Otherness is a site constituted in relation to other sites by its difference.

The thesis, as a production of disciplined work presented in a creative style, is congruent with performance and presentation of best practice in community arts. As a practising nurse artist I create spaces of alternate ordering within the mental health field environment. 
Geographical, as well as socially constructed notions define the studied environment and this is best presented in poetry. A poem, as a device, also allows me as the author to more fully describe the experience of being there. Poetry has been recognised by Watson (as cited in Chinn \& Watson, 1994) as a method of truth where unconcealment occurs through language from the inside out. I am able to "(re)write the Self as well as to unite people's (inter)subjective experiences with individual interpretations" ( p.12). The process of bringing words from my inner experience into hard copy on a page, is for me, a truth that very much comes from the inside out. The poems have been written so that they can be read as part of this document, although ultimately I would prefer them to be spoken so that you, as my audience, could hear them. If however the poems touch you in some way, you may yet hear my voice.

\section{The Nine Poems}

Nine poems are included in this thesis that provide the reader with a unique opportunity to access, rather than be shut out of the mental health field environment. These poetic texts reveal the environment and the author in a performance phase. They bring together shuffled, juxtaposed - torn up and rearranged - eyewitness account and nurse artist practice conducted and systematically documented in practice projects and commissions over a period of fifteen years from 1986 - 2005. The project and process most closely resemble that described as Literary Psychogeography which is a method drawn from text which is descriptive of an age or an era. In particular, I am drawing from this period of time 1986 to the present, 2005, in which I have been nursing and/or making art in the mental health field environment. The poetry and art produced in practice are the data of the research project, which underpin the thesis. The practice then becomes available in new and specific ways as revealed in the thesis.

\section{The Environment}

Privacy laws and security measures prevent access to the geographical environment of mental health service hospital environment. They are not open to general 
disciplines or lay people who have no direct business there. The social construction of this environment creates a division amongst the population of people that have experience of mental illness, and people that imagine they will never have experience of mental illness, to the degree that they hold stigmatising and discriminatory views of the environment. Also the media may present this environment of the mental health field with a stereotypical view that may not resemble actual physical knowledge or experience.

\section{Practice Stories}

The poems are each accompanied by a practice story, which describes some aspect of the practice of the nurse artist, or some critical observations made by the nurse artist during practice. The stories are an echo of the poem, and do not seek to pull the poem apart analytically by offering explanation. The practice stories are the poem, presented in another form, and each story has art forms that are also interconnected.

\section{The Paintings}

The nine illustrations of paintings, (with one painting transforming into two modes) are intended to be read as text within the context of this thesis. Nurse Karen Breunig (as cited in Chinn \& Watson, 1994) has discovered in her own practice of painting in a health setting what Heidegger calls Aletheia or unconcealment. She quotes him as saying that "art reveals to us not knowledge about any thing but the highest form of knowledge, knowledge of the truth (Chinn \& Watson, 1994, p.194).

In producing these paintings I attempted, through the materials of art, to immerse myself in the process of research. The challenge of creating the paintings became incubation and finally an illumination of my inner truth.

Traditionally, art historians and critics have interpreted the works of an artist for the benefit of the viewer. Artists on the other hand can remain silent upon the subject of 
their own works. I prefer not to describe the content of these works other than to say they are all based upon the theme of the individual's desire to be free.

I invite you as the reader to enjoy and view these works in this thesis as if you were in a gallery, wondering and musing at their content.

\section{The Five Chapter Ones}

To read this thesis requires engaging in expedition mode. Discover your own entry point into the passage that suits you best by selecting from the five Chapters One.

As a reader you are invited to literally experience the thesis at work by engaging in the structured method of psychogeography. The language revealing the method becomes signposts, or features of the traversed environment, in the experience of the journey.

\section{Dérive}

For instance the Dérive, literally translated as 'drifting', allows you a passage through the varied ambiences of the five Chapters One. Dérive involves playful constructive behaviour and awareness of psychogeographical effects. These effects that you may notice are constant currents, fixed points, psychogeographical contours and vortices that strongly discourage entry into or exit from certain zones (Debord, 1958). Let yourself be drawn by the attractions of the textual terrain and the geographical features that you discover there.

Psychogeography involves an element of letting-go which is required if you are to keep from the urge to follow the chapters in their chronological order. It also involves a necessary contradiction to letting go, a "domination of psychogeographical variations by the knowledge and calculation of their possibilities" (Debord, 1958, p.1). This is an insight that you may gain into what I

discover as I dérive in the mental health field environment, and the knowledge and calculation that I make as a nurse artist of the possibilities for practice development. 


\section{Détournement}

The second part of the psychogeographical method of which I have made use is Détournement which is literally translated as 'turning around'. This is the integration of present or past artistic productions into a superior construction of a milieu (Internationale Situationniste \#1, 1958). Here, you as the reader, have the opportunity to utilise the five Chapters One, to set the scene for your progress through the thesis. The elements of the poetry, text, and illustrations of paintings no matter which Chapter One they were taken from, will serve in making new combinations. "The mutual interference of two worlds of feeling, or the bringing together of two independent expressions supersedes the original element and produces a synthetic organisation of greater efficacy" (Debord, n.d., p.1). Détournements have particular categories that are further explained in the body of the thesis. Postmodern embracing of the notion of multiple truths is most noticeable in the détourned element as rather than seeking to absolutely state categorical fact. I, as the author, allow the opportunity for a new eventuation to arise in meaning and interpretation and am able to be inclusive of you, the reader, in anticipation of your varied reaction to this work, as well as being inclusive of the People and Things that inhabit the mental health environment with me.

\section{The Chapters Two to Seven}

Chapter Two gives the reader a view of the consumer domain as a distinct aspect or Other site within the mental health field environment, and informs the reader about art as a means to mental health recovery. Divided into two parts, this chapter firstly considers placement within the consumer domain as a strategy of inquiry including the narrative positioning of the nurse artist; and secondly, considers creative arts in the mental health field environment. Side-by-side practice, which is the name given by me to describe the aspects of my practice as a nurse artist, is portrayed. Two comparative examples are presented: one exemplifies the negative possibility of causing or prolonging mental illness through stigmatisation of art and artists and the 
other exemplifies the positive promotion of art and artists; on the recognised margins of mainstream art as 'outsider art' or 'outsider artists'.

Chapter Three considers the theoretical and philosophical understandings of the mental health field environment through consideration of heterotopia, loneliness and isolation as an investigation of human experience, and habitus. Heterotopia or counter-sites, reveal the depth and breadth of ordering and classification of those People and Things that inhabit the mental health field environment. Habitus as a set of acquired characteristics is revealed as having a generative capacity that is inherent in struggle and competition, which centre on economic, social, cultural and symbolic capital.

Chapter Four explores theoretical and philosophical understandings another way, through literary psychogeograhy as a form of mapping of the mental health field environment. The reader is enabled, in exploration of this field, by a description of the movement of People and Things, in space, over time, and in place particularly where People and Things contribute to the constructed nature of the environment. This section of writing is followed by an explanation of narrative as enquiry and introduces the writer, in the form of the voice that speaks, to the reader. I also demonstrate that the mental health field environment, as a source of textual data, is also a place where the narrative of Others is colonised by the practises of staff. I explore the possibilities of reflective topical autobiography as a narrative method and use a description of the phases of this method to introduce the reader to the next chapter, which demonstrates my use of these phases of immersion, incubation and illumination.

Chapter Five begins by giving a detailed description of the origins of the logo and its placement within the thesis. The various phases of project design that were generated by narrative methodology are as follows: development of scholarship in writing; practice stories; partnership and consultation as design; writings of others; conceptual positioning of self; and finally locating meaning by design. These phases also give examples of the experience of immersion, incubation and illumination. The 
thesis design is illustrated and described which allows the reader access to the framework that was used to carry the research question, and emergent supposition, from the period of inception of the thesis to the period of conclusion.

Chapter Six entitled Gathering Meaning employs literary psychogeography method as a means to positively influence the mental health field environment. Poetry as textual data, exemplifying locations and their attributes, allows the transfer of information about the mental health field environment from myself to others, for the purpose of influencing, resisting or rupturing passivity and acceptance of mental health services that cause or prolong mental illness. The poetry, as a source of literature, then becomes a further field of exploration in the psychogeographical method. Developing minor and major themes shows the expansive possibilities for exploration of the environment, and the introduction of the intervention of movement as an antidote to stasis, isolation, separation and passivity in, and of, People and Things. The reader is invited, after appraisal of two examples of a literary psychogeographical analysis in the form of a cognitive map fragment, to consider further possibilities. This research method leads me to the creation of cognitive maps as a result of my exploration. A map, from my earlier insights, records the primacy of identity-based claims as a key to recovery and can be compared in stark contrast, to a map from the end period of research which records more accurately subtle differences and explorations of space of the Other from a view that promotes agency beyond identity-claims as accountable reason. Non-literary texts such as paintings, which are displayed as illustrations between the seven chapters of the thesis, are also presented as data with the poetry, since a psychogeographical element exists within them, which describes physical surroundings and their impact on the mind.

Chapter Seven presents conclusions and recommendations for practice that are captured initially in a restating of the research question: is it possible to describe what environment contributes to mental health recovery? This question arose because a government document (Mental Health Commission, 1998) pointed out that the concept of recovery often lies in the beliefs about the origins and nature of mental illness. Where some people believe the origins or the prolonging of mental illness 
does not lie in the person, but in the world around them, what part does the mental health field environment have to play in this? The possibility of unresponsive services being the origin or the cause of prolonging of mental illness is not only abhorrent to me as a human being and a nurse but also part of my experience of the past twenty years in this environment. This is what I seek to change.

The choice to respond to the possibility of resistance and change that is inherent in marginality and struggle is made. Rather than being a catalogue of frustration I intend that this thesis provide some insight into the what and why of unresponsive services, and suggest practical methods for mental health workers who have reduced or lost the capacity to accurately see the mental health field environment due to the effects of their institutionalisation. Side-by-side practice is restated as a means to allow the speech of the Other and the possibility of a reply. I provide space for the emergence of an identity-claim of artist that leads, through community arts practice, to agency in creative expression. This change of level in addressing myself as a nurse artist to a layer of material previously having no pertinence to medical model subjective surveillance makes the previously invisible person seen. This artist recognition is an alternative to patienthood and diagnosis. Furthermore, the description of my position as geographer of mental health field environment throughout the thesis, gives the reader a view of my acute awareness of the possibility of opening up and expanding the scope and critical sensibility of my spatial or geographical imagination. Where the material world is focused on the real and then this reality is interpreted in the imagined, a Thirdspace as a multiplicity of real-and-imagined places provides the opportunity for deconstruction or radical restructuring of modes of knowledge formation that perpetuate stigma and discrimination against those people with experience of mental illness. Chapter Seven concludes with a statement of the impossibility of speaking for others and openendedness of this research in its intention to not create a final statement, but importantly to promote further discussion. 


\section{Thesis Design: The Necklace}

I have used the metaphor of the necklace to assist in the early stages of the research to link the research question and the research framework. This consciously constructed element of design made the research framework very visible. The framework/necklace has a beginning stage [introduction] and end stage [conclusion], and when seen as a whole, the framework clasped can be said to encircle a field of knowledge. When observing the research the necklace is linear and able to be handled. When engaged with the research, as the subject of the enquiry, the necklace is metaphorically worn about my neck and close to my heart as a body adornment. The practice is the framework and vice-versa. Practice is embodied and, in my case, highly visible.

The stranded design of the necklace, metaphorically and actually, allowed an ebb and flow of growing awareness about the mental health field environment without prejudgement. I could place the poems as data into minor themes and major themes in some context which did not define them prematurely, but let them float.

\section{The Legacy of the Situationists}

The Internationale Situationniste were published works with an explicit anticopyright notice which states that the writings may be "freely reproduced, translated, or adapted without even indicating their origin" (boy, a.h.s., Anti-Copyright 1996, p.4).

Although I am guided by the practices of the Graduate School of Nursing and Midwifery as a School of the Victoria University of Wellington, I acknowledge the intention of the Situationists. By allowing full copyright they hoped to create a challenge to further Spectacle (see Chapter Three) by freeing information intended for not-for-profit purposes, from capitalist influence. In my judgement, advancing nursing practice should be a not-for-profit venture. 


\section{Art Interval}

Vessel at Rotoma, 2002, oil on canvas, 500mm x 600mm 


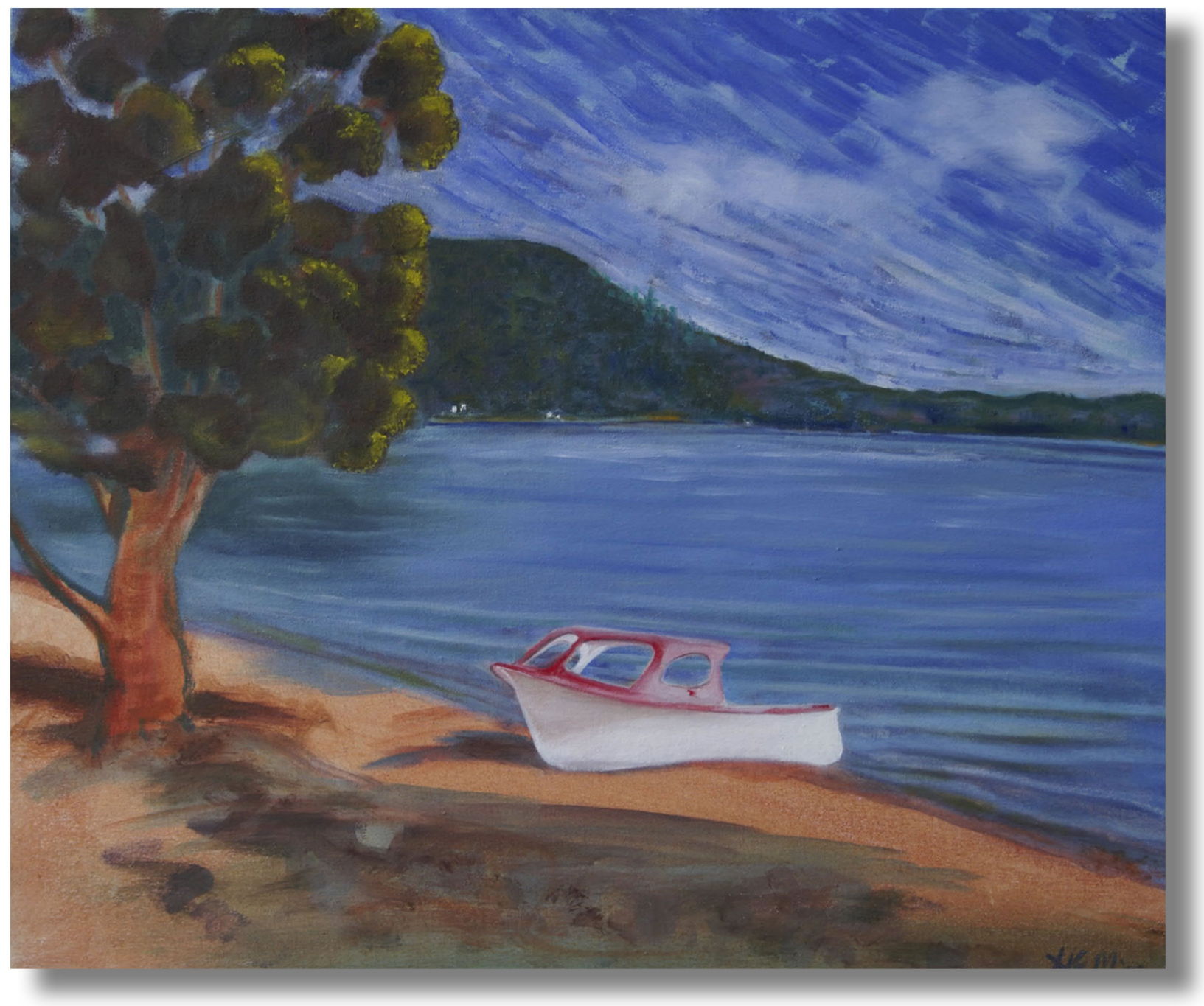




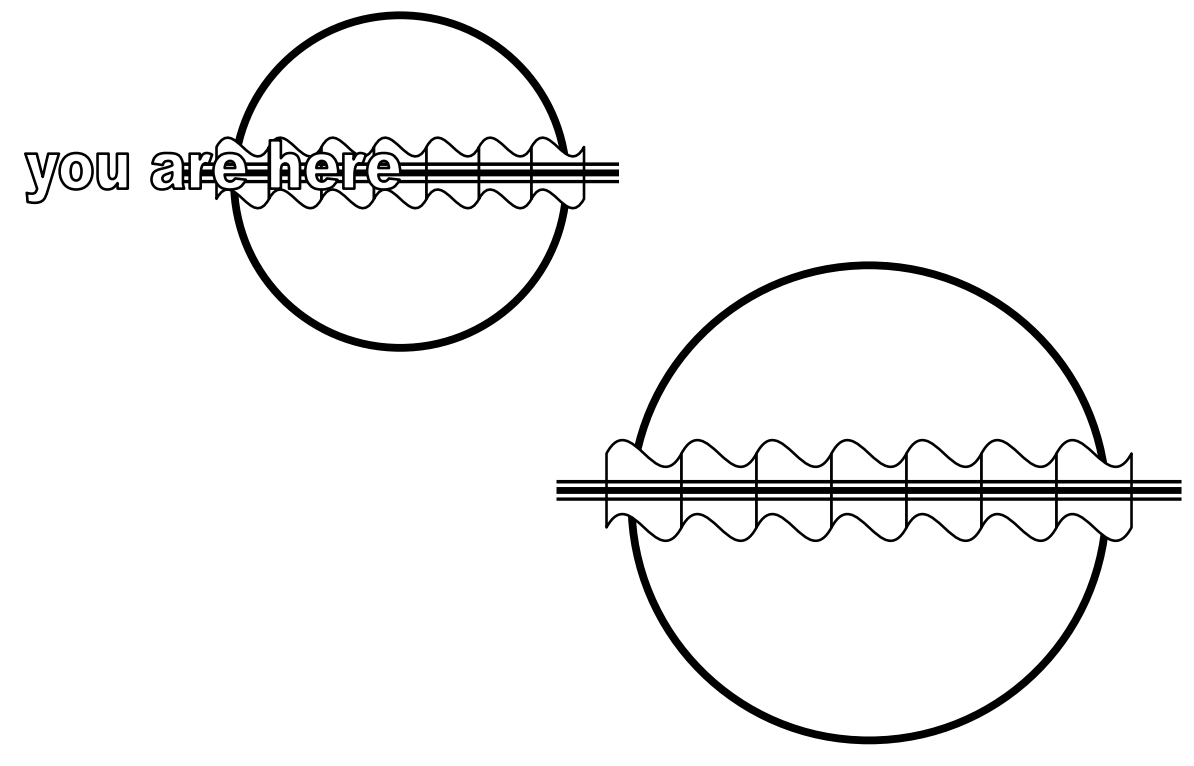




\section{CHAPTER ONE}

\section{MAPPING IDENTITY AND ENVIRONMENT}

\section{Position - Contextual}

In considering the context of this thesis I will describe three interrelated aspects of mental health practice [although there are some aspects] that are unique to New Zealand and myself as a Nurse Artist, [they could be applied on a global basis] and are part of my ongoing exploration of what facilitates creativity in the mental health field environment. These aspects are:

Celebrating recovery-focused mental health workers

Partnership in Maori [culturally based] models of best practice

Nurse Artist practice in the mental health field environment - the inner artist

I share a standpoint with other New Zealand Mental Health Workers, Maori Health Practitioners and Community Artists: that services should be targeted to the individual, and have a wellness and healing approach as distinct from one of illness and disease (Tangitu \& Cooney, 2002). These three distinct groups of people working in the community have very individualized models of practice and yet share a common philosophical approach - that of Recovery.

\section{The New Zealand Context}

It has been estimated that $20 \%$ of the population has a diagnosable mental illness, including alcohol and drug disorders, at any one time. Three percent of these people will have a serious, ongoing, and disabling mental illness (Mental Health Commission, 1998). 
The Mental Health Commission (MHC) was established in late 1996 and one of its three key tasks was to strengthen the mental health workforce by working with key agencies. Its vision statement included the notion of a range of appropriate services being provided by the right combination of people (MHC, 1997).

Since 1994 the New Zealand National Mental Health Strategy sought to close the gap in access targets by addressing the needs of these " $3 \%$ of the population who will need publicly funded specialist mental health services in any six month period" (MHC, 1998, p.109). This target was to be achieved by 2002 and by 2004, "access declined from $1.7 \%$ to $1.6 \%$ of the total population over six months against the national target of 3\% in any one month" (MHC, 2004a, p.7). "Despite increased funds, growth has slowed and access to services remains pretty much unchanged" (MHC, 2003, p.3.). Furthermore, the type of measures valued in the past, such as "monitoring beds numbers and funded full time equivalent positions"(MHC, 2003, p.3.), are not keeping pace with the shifts in philosophy and practice of the people who are involved in the sector. The numbers of contracted supported accommodation beds provided, cannot describe the quality of care and support for recovery that goes with that bed, or the lack of it.

In 2005 workforce issues are critical with poor recruitment and retention of staff numbers being one of the major barriers to an effective and safe national mental health service. It has fallen more and more to a core group of staff that is dedicated to delivering services to do more with less, despite attempts to reverse this trend.

The challenge for these staff is to develop strategies to enhance and capture the capabilities and potential of the teams that are present. Where a range of services has not been achieved often what makes the difference, in my experience, is the skill of staff in being able to put together the right combinations of people to achieve diversity and choice. The flexibility and ingenuity of mental health staff in working with consumers has never been more challenged, and this has created a demand for creative solutions to every day problems. The dynamic capacity of the arts to respond 
to clinical and environmental challenges experienced by people in mental health crisis produces both a solution and resolution all at once.

The challenge for key staff motivators is to overcome the inertia of people seeing themselves as human beings limited to a self or professionally-prescribed role, which has inherent inadequacies and inhibitions. This potential for self-limiting applies both to professionals and to service users treated by those professionals.

Where people see themselves as small and uncreative, change towards recovery is less likely to take place. To this end the Mental Health Commission, in a series of planned steps, has worked towards the development of a workforce that embodies a recovery approach with the knowledge and attitude that people can get better. As one Mental Health Commission poster says: "encourage people to believe in themselves and their future and believe in your own power as a mental health worker to make a positive difference" (Huia Communications, 2001).

Initial 'recovery approach' principles were set out in the Blueprint for Mental Health Services in New Zealand in 1998, which proposed that both more effective and better services were required. The Blueprint states:

Historically, mental health services have failed to use a recovery approach. Recovery could never take place in an environment where people were isolated from their communities and cultures, where power was used to coerce people and deny them choices, and where people with mental illness were expected to never get better. Some people have experienced recovery without using mental health services. Others experienced recovery in spite of them. But most will do better if services are set up and delivered to facilitate their recovery. Virtually everything the mental health sector does can assist or impede recovery

(Mental Health Commission, 1998, p.1).

The Mental Health Commission introduced detailed recovery-based competencies in March 2001 to provide educators with guidance on the inclusion of 'recovery' 
content in programmes. This was the implementation phase in the education and creation of a competent workforce.

A comprehensive set of information includes: a paper called "Recovery Competencies for New Zealand Mental Health Workers", a teaching resources kit also available on $\mathrm{CD}$, posters, a book of collected articles, collected biographies celebrating recovery-focused mental health workers, and a series of four consumer group experience booklets. This material is available on application to the Mental Health Commission free of charge; and other named books are priced with all publications backed up by a user-friendly list of electronic sources.

The Mental Health Commission intends that these competencies apply to service users of all ages and cultures and to all people working in services whether they are mainstream, Maori, or service-user run. They also apply to all mental health workers, in all occupational groups and cultures.

"The attitudes, skills, knowledge, and behaviour required of the mental health workforce" (MHC, 2001, p.3). are defined in the listed ten major categories and subcategories, however the examples given in each competency show that the emphasis is on "attitudes and knowledge rather than behaviour or skills"( p.3).

In defining recovery Mary O'Hagan, a prominent consumer advocate, says: “ Most of the literature on a recovery approach for people with major mental illness comes from the United States and has three ideological sources" (MHC, 2001, p.2.). These are: the generic recovery or the self-help movement, the mental health user movement, and psychiatric rehabilitation with a community integration focus (MHC, 2001).

The authors of the New Zealand recovery competencies assert that rather than a rewrite of the current literature they have made an attempt to define recovery in a “contemporary New Zealand context" (MHC, 2001, p.2.) with an emphasis on service user movement experience. The training standards and curricula for 
psychiatrists, comprehensive nurses, social workers and mental health support workers, are enriched by the inclusion of 'recovery' content that sits alongside existing professional and clinical course content. No professional ethics, or strictly therapeutic or technical competencies are included, rather, the clinical workforce, having acquired the ten competencies, is more likely to experience their clinical or therapeutic support leading to recovery (MHC, 2001).

I will focus on the ways in which my experience of practice with a recovery focus promotes the individual's search for self-determined, cultural and creative identity illustrated by my conceptual map below. The important establishment of identity in a recovery environment, in my judgement, leads to the assertion of Self and the reinstatement of Wellbeing.

The conceptual model shows the parallel practices of Recovery, Ethnicity and Art.

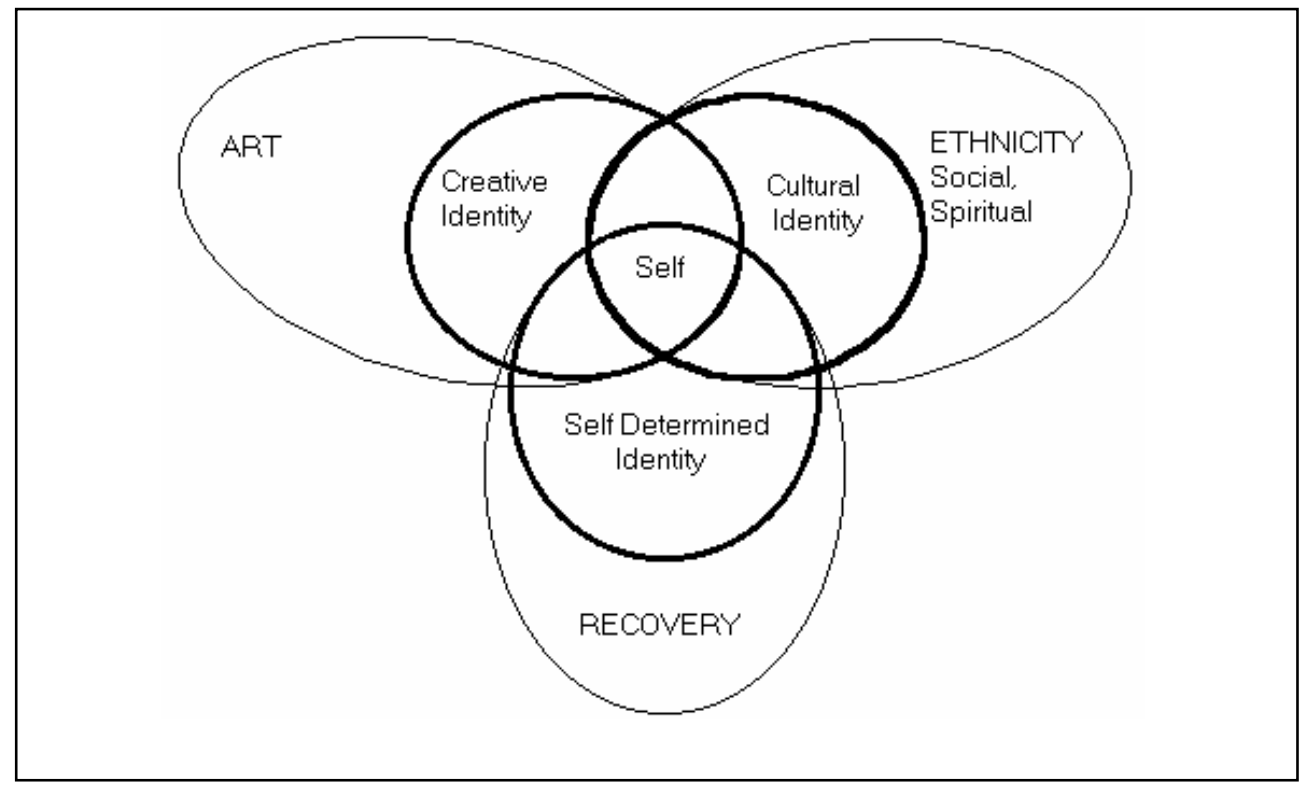

Figure 1: Conceptual Map of Parallel Practices - Art, Ethnicity, Recovery

\section{Celebrating Recovery-Focused Mental Health Workers}

In the past it has been recognized that tasks and actions were often defined and limited by professional boundaries. Mental health services functioned on the multidisciplinary team approach, where staff opinion and comment were prioritised 
and not informed by a shared appreciation of the consumer goal of recovery, as defined by the consumer.

Differences of opinion between treating clinicians created confusion for the consumer and their family. Consumers coined the phrase "nothing about us, without us" to emphasise their grievance, and to bring justified political pressure to bear on staff that they should be physically present, and the central focus, of meetings involving their lives.

The Blueprint focused on a recovery approach in service delivery. This recognition of the capacity of everyone present to mobilize current resources and develop new ones within the mental health field and community was a unique recovery approach in the 1998 environment of the Lakes District Health Board services in Rotorua, New Zealand where I worked (permission given to use this area names, see Appendix One).

The employment of a second Consumer Advisor in an operational management group role in Rotorua at this time brought a strategic Consumer perspective to business plan writing and service vision. As Arts Consultant I was also included in this dynamic management group with a direct report to the Service Manager.

This role as an Arts Consultant or Nurse Artist with special project responsibilities within an acute hospital and community mental health setting is, to date, unique within New Zealand. I continued to maintain a current Comprehensive Nurse practice certificate and to apply the skills of a nurse when I met and cared for individuals, but the [healing-treatment] [restoration towards health] that I created was based in the skills of a practising community artist.

The Arts Consultant/Nurse Artist role was established in 1998 by the determination and vision of the Service Manager as an organizational response to the Blueprint for Mental Health Services In New Zealand. The recovery approach requires "mental health services to develop and draw on their own resources, but it also requires they 
develop and draw on the resources of people with mental illness and their communities" (Mental Health Commission, 2001, p.1).

This recovery approach is upheld by the meaning of recovery as defined in the Blueprint, which is "when people can live well in the presence or absence of their mental illness"(Mental Health Commission, 1998, p.1)..."or whatever people choose to name their experience" (Mental Health Commission, 2001, p.1).

Mental Health Services in the past have seen the individual with an experience of mental illness only in terms of when and where it necessitated clinical intervention. In other words when the notes are in the file room the person ceased to exist to the services.

Whilst accepting the notion of people living well in the "presence or absence of illness", this was perhaps interpreted at first by mental health workers as just another way of saying admission or discharge, from the services' perspective. The mental health services have never really had a notion of the person that had continuity and much less a consistent quality of life, that persisted outside of the influences of cyclic illness and clinical intervention. The more important declaration I would argue is the self-determination reflected in the statement "or whatever people choose to name their illness". Many health care workers have overlooked this to date. Certainly the collective consumer movement voice and the production of texts such as "The Gift of Stories" by Julie Liebrech (1999) in New Zealand, detail the experience of individuals who have traumatically had the right to name their own experience removed whilst receiving mental health care.

This statement "or whatever people choose to name their experience" is, I believe, the key to understanding the essence of the recovery approach. My experience is that in the past the illness/experience was defined and managed by hospital-based and community services staff; the definitive opinion of the individual experiencing this phenomenon was usually considered last, if at all. As an example of this - the hospital services provided the containing and defining institutional environment, the 
patient was said to 'exhibit behaviours' which were then interpreted from which their 'problem' was deduced. This was then fed back to the patient in medical-ised language as a formal diagnosis. More importantly, the patient was asked to corroborate this by stating what they thought their problems were, and where it agreed with 'our' summation it was re-stated in the notes that the patient had insight into his or her problem/s. Thus the health service's naming of the mental illness was re-sanctioned and the person was further removed from owning their experience.

Some health professionals in the past five years have not embraced recovery as a principle in New Zealand health care policy service delivery because of a reluctance to forfeit, as they see it, any power or influence to the consumer. Consumers agree that:

We do not want more of the same. We want services led by us that enhance our autonomy, recognise us as whole human beings, expect our recovery and offer us a broad range of solutions and resources. We want a society and whanau that value us as fully participating members, with the same rights and opportunities as other citizens

(MHC, 2004b, pp.7-8).

It should be noted that none of the recovery-focused interventions are designed to take importance or relevance away from the existing medical and allied health practitioners but to elevate the status of the consumer to an equal importance in the quest for Wellbeing. Existing services, where they are designed and delivered to facilitate recovery, can only add to the availability of choice that a person has when confronted with the experience of mental illness. It is a matter of moral import that everything the service does should assist recovery and not impede it.

Tania in her recovery story relates her naming of illness:

I first used mental health service in 1992. After my first episode I found my way back home to the far north where I'm from. Back to my whanau (family). I'd been 
quite distant from my whanau and felt like a stranger. I had another episode there but I hesitate to call it mental illness. I experienced an emotional and spiritual and psychological upheaval. I choose to call it a healing crisis because it brought my attention to things in my life I needed to change in order to heal and move on

(Fenton \& Te Koutua, 2000, p.13).

When recovery, as defined in the 1998 Blueprint, stated that " people with mental illness need to find their own understanding of mental illness and mental health issues" (p.16) or, that the illness experience may be named and defined by the individual, a new platform for the context of my previous work in the arts and health became apparent. Here is the key to my work, which I now am able to describe and classify in relation to recovery. My focus as a nurse artist is that I seek to change the status quo; so that it is not about the mental health services' perception of the person who is ill, but the perception of the person who is ill, as to how or what the hospital services can do to assist in the naming, or making sense of, this illness experience. Thus the hierarchical direction of care as it was from 'top down' or physician down is reversed to, 'client up', or in fact, the client takes the central position of focus and others gather around. Where status quo decisions and actions do not have a recovery focus, the individual often experiences this as a form of oppression.

Significantly, in New Zealand, organizational charts of mental health services have begun to feature the parallel streams of knowledge and expertise that are present in service delivery broadening, from being management only to include Consumer, Ethnic or Cultural group and Whanau/Family representation. This is about the naming of the illness by the client, and part of that process may be by necessity and choice, accessing what resources the mental health services can offer.

I believe we face a new challenge in New Zealand because, whilst we have stated we give encouragement to the individual to name their own illness experience, mental health services seem to have been slow to match these words with actions. Documentation of the processes of access, entry and journey of the client through the 
service leading to discharge, otherwise known as the 'client pathway', continues to be written and couched in the 'top down' management hierarchical language of the hospital.

The journey remains difficult for the client to negotiate despite their readiness to participate and help write the story. The gathering generations of trained and competent mental health workers will make a difference. In the meantime we celebrate the mental health workers who are recovery-focused and build the capacity of others in this approach.

\section{Partnership in Maori Models of Best Practice}

The Maori experience of the search for identity is a reintroduction to, or discovery of, ties with family and the land. The Treaty of Waitangi is the founding document of New Zealand and lays out in three articles the contract made between the Crown and Maori. The Treaty implications incorporated in all aspects of health services for all New Zealanders are:

Article One: Consultation and collaboration with Maori in order to determine their attitudes and expectations with regard to the functions of 'good government'.

Article Two: To give protection to things valued by Maori of a physical and spiritual nature. Self determination and jurisdiction for Maori communities and organizations to manage their own property, assets and resources.

Article Three: The development of partnership under the rights and obligations of the Treaty of Waitangi (Cunningham, 1998). Equal rights of access and equal health outcomes. Equity of participation, access and outcomes (MHC, 1998, p. iii).

The New Zealand health sector acknowledges Maori health as a priority since statistical evidence shows overwhelmingly the relatively poor health status of Maori compared to other population groups. Particularly worrisome in mental health is the high rate of readmission, which suggests that Maori are unable to access services relevant to their needs (Mental Health Commission, 1998, p.12). Public sector agencies are now required to be responsive to the needs and expectations of Maori in 
carrying out their business (Cunningham, 1998). Only by contact with Maori Health Team members can a person choose a Kaupapa Maori (for Maori, by Maori) service, and be assisted in their search for cultural identity which may be a factor in recovery.

The Maori historical worldview of wholism centres on concepts of connectedness and interdependence, on the personal and the collective, and on the relationship between $\{\operatorname{man}\}$ and the environment, both physical, spiritual, emotional, and as expressed through family ties (Cunningham, 1998). Contemporary challenges for Maori have been the social and cultural diversity with which the Maori worldview is now seen and experienced. Past colonisation policies of integration and assimilation over the years and increasing urbanization have had a damaging effect on the health and Wellbeing of Maori. Acknowledgement of Treaty responsibilities has resulted in the crown making moves to redress Maori grievances.

In New Zealand for the past fifty years Maori-specific interventions have been developed within health services. In recent years the well-being of Maori is assisted at a practical level and by acknowledgement of the significance of offering a "for Maori by Maori" approach in the healing process (Tangitu \& Cooney, 2002). Maori state the need for "quality services as determined by Maori, with Tangata Whaiora or the "person seeking wellness", retaining the right to choose kaupapa Maori services, mainstream services, or a combination of both" (Milne, 2001, p.6).

As Treaty partners in the delivery of health care, non-Maori now have the unique experience of the integrated practice of Maori as the indigenous people of this country, within acute and community mental health services alongside mainstream psychiatry.

Maori are traditionally tribal and although contemporary lifestyles have produced detrimental effects, there remains a strong connection to the land and to customary ancestral areas. Within the central regions of the North Island of New Zealand is Rotorua, the place where I worked from 1999 to 2004. Being there, as distinct from being in any other region, has uniquely influenced and shaped my Nurse Artist 
practice. As a nurse artist this has meaning for me as my practice will always be shaped by the kawa (protocol) of the local people. I work equally with Maori, pakeha (non-Maori) and other ethnic groups, but I look to Maori professionals within my workplace to guide me and keep me safe in the cultural laws and expressions of everyday life and mental health practice that are paramount to Maori. The Tangata Whenua or local people of Rotorua are of the tribe Te Arawa. Particular protocols and traditions are practised within this region, which are unique to this tribe's inheritance. The unique relationship with Maori in Rotorua is further enhanced by the gift of the land by Te Arawa on which the Hospital stands, to the people of Rotorua and surrounding districts for the provision of health services. This provision is closely monitored and reported between the Lakes District Health Board and the tribal governors of this land. This strengthens the potential of Maori influence in positive Maori health outcomes and potentiates the Board's role as a good partner in health outcome delivery.

'Po Te Atatu'(“from darkness into the light") is the Maori Mental Health Team in Rotorua. Tikanga Whakamua, is the name given to the framework by which Maori health workers practice. This innovative best practice model is represented by seven upward reaching steps which describe tikanga (the practice of kawa, rules). These seven standards represented by each step, are part of a progression of engagement with the client on a holistic basis and 'in community'. This model draws on Kaupapa or principles recognized nationally by Maori, and interpreted differently by various tribes. The maintenance of the well-being of an individual relies on the balance of four aspects of the Self - physical, social, spiritual and mental. Tikanga Whakamua, in including these four aspects, is a living evolving expression of Te Arawa's way forward for their people.

It is important that I recognized my degree of dependency on the Maori Mental Health Team -Po Te Atatu- who were present in my Rotorua work setting for Maori cultural nourishment, as this need to learn and understand is continuous in this and many other health care settings. This creates situations where not only Tangata 
Whaiora (person/s seeking wellness) but also the staff are drawing on the finite resources of this and other comparatively small teams.

I am empowered as a New Zealand Health Care worker by the National Mental Health Sector Standards (Ministry of Health, 2001) to contribute to this cultural richness. I consciously seek information and learn so that I do not repeat actions in error or without thought. For example, as a nurse, I may at one time have utilized a pillow intended for the head to place under someone's feet. Now I am aware that the head is considered sacred and it is not culturally appropriate to use things intended for the head in any other way.

I was also instructed by Arama Pirika kaumatua (personal conversation, March 20, 2003) that traditional Maori artists do not generally portray the precise form of the body, as this creation of purity is thought to be exclusively the domain of God. Therefore, as an artist, I would be mindful not to produce or display a life drawing in my work settings.

Detailed awareness of another culture cannot occur without recognition of my own identity. When I have begun to understand who I am and where I have come from, I can relate to the significance of this for others. Identity and cultural origin matters in this mental health field environment, perhaps above all other contexts, because it is recognized that the principle tool of practice is the Self. My personal demonstration of Partnership according to the Principles of the Treaty of Waitangi as the founding document of New Zealand goes beyond understanding, to an embodiment of Partnership which guides my everyday thinking about, feeling about, and actions, with Maori and other peoples.

I see that there are parallels between Maori models of best practice, of which there are many examples (Milne, 2001), and my own as a Nurse Artist. The principal efforts of the Maori model of practice are directed towards recognizing, creating, and securing identity. Te Hinengaro (mental and emotional realm) are the thoughts the emotions, the deep mind. The Wairua (spiritual realm) is the belief and connections 
between people, the land and the atua (god) "The journey towards reclaiming oranga hinengaro, oranga wairua begins with reclaiming ourselves, our identity" (Milne, 2001, p.8).

In consumer models of recovery, identity is described in terms of personhood and is the beginning of the personal journey through reinstatement of hope to autonomy (Wells, 2001). The Community Arts model of practice is what I, as a Nurse Artist, bring to my work environment where art is not viewed as a treatment and the environment is seen as a creative space.

The Community Arts Model asserts:

The arts, creativity, and self-expression are part of the wholistic concept of health and an essential part of every person's emotional, physical and spiritual wellbeing. Clients should be given access to, the means and the opportunity for, involvement in the arts to enable them to realize their full potential

(Cooper, 1992, p. 2).

Identity or personhood is secured by the re[dis]covery of the inner creative self. When this inner artist begins to create using art materials, in the presence of another person who importantly acknowledges their inner artist, the person can see themselves as someone other than patient or diagnosis. From this place of 'other', identity recovery begins. "In order to take responsibility for the "work of recovery" there has to be a sense of personhood outside of the disability, no matter how small or limited it may be initially, to provide the person with a place from which to begin to address the illness itself" (Davidson, 2004, p.12).

Therapeutic value, where it arises, is claimed by the individual who retains ownership of the tangible artwork and the meaning of the artwork as defined by them. These actions, when introduced by myself as a companion artist, bring reinstatement of the Inner Artist. 
As a Nurse Artist I assert that arts practice that reinstates creative identity, based on a recovery approach within a mental health field environment, is an integral part of the healing process of the Self. Something that can only be achieved in the 'by artists for artists' approach, as part of the wholistic and self-defined healing process of the individual. 'By Artists for Artists' reinstates the natural birthright of the individual to be recognized as a creative being and to have the means to creative expression in whatever medium or form the individual chooses (Butcher, 2003).

In this way I see my work closely aligns with Maori models of best practice and 'Tino Rangatiratanga' or reclaiming identity. Maori have said "There is healing within our language. It is in the way we speak and the spirit in which it is spoken. Let us use language to massage our spirit/soul and our emotions" (Milne, 2001, p.7). Likewise, there is healing in the materials of art, and the way we choose to use these materials and the spirit with which we use them has the potential to massage our spirit/soul and our emotions.

\section{Nurse Artist Practice in a Mental Health Field Environment}

As a nurse artist one of the significant positive transformations that I can make is to the physical environment. When entering the hospital environment it is quite clearly a place that supports a western, masculinist and medical model of care, and may be entirely inappropriate for Maori and other ethnic/cultural groups.

The environments of acute mental health inpatient facilities are perceived as fearful places of illness, and loss of control, by society. Sometimes they are referred to, as a town's 'local nut house'. Conditioning gossip and media sensationalism bring about a situation where individuals fear the consequences of the onset of mental illness because they share the same negative perceptions that society does. When a person enters the service they enter the group that is stigmatized and discriminated against by others in the community at large. 
In the presence of this overwhelming barrier of prejudice, arts solutions can create connections and reduce barriers where no other solution can be found. As a Nurse Artist I encourage change that brings about a positive perception of this mental health field environment where individuality and creativity are celebrated as an aspect of personhood, and not relegated to a lesser domain in the presence of mental illness and diagnosis. This change is multidirectional and begins with the recognition of the presence of an abundance of creative possibilities within the Self and is not confined to the Client group but also includes staff, family and community. A creative space is equally about the establishment of a creative space within a given environment, and the creative space within a human being, because, from here, an individual's journey of recovery begins and ends.

Within a Mental Health work field, I assert three fundamental aspects to reclaiming Wellbeing for the Self. The first is that every individual has the right to personal expression. The second is that you embody an Artist that dynamically contributes to your Wellbeing. The third, that you can initiate Wellbeing in another person or other people, by making a creative connection from your artist to their artist.

It is a matter of social justice that every individual has the right to creative expression. Just as we know that people, especially newborn children wither and die for lack of touch, so does the spirit suffer denied its birthright of self-expression. If we can't outwardly communicate who we are in the world in the style that suits us best we are experiencing oppression.

An important aspect of recovery is our ability to make autonomous choices: to create a self determined identity. Where choices can be made freely about what we wear, eat, where we live, and whom we socialise with, they become so familiar to us that we carry them out unconsciously. However these seemingly insignificant daily choices directly shape the building of Self. This 'art of Self' has critical influence on Wellbeing because when it is performed in freedom, and with infinite variety, a health response arises. This is where hope is born. 
For people who face the dilemma of "lives and dreams being shattered in the wake of mental illness" (Deegan, 1996, p.75), the ability to creatively find ways to move on and foster hope is craved and can become essential to survival. Through art new possibilities are found. This process can be begun by experiencing art in a context where creativity and mastery emanate from the Self rather than it being removed and made exclusive to only a few special others.

Our own inner artist possesses an anticipatory readiness and all that is within us and outside of us becomes the potential materials of this artist. The art/fullness is an innate permission that we feel in potentially and actually engaging with these materials in a creative way. As Cameron states in her book "The Artist's Way":

In short the theory doesn't matter as much as the practice itself does. What you are doing is creating pathways in your consciousness through which the creative forces can operate. Once you agree to clearing these pathways, your creativity emerges. In a sense, your creativity is like your blood. Just as blood is a fact of your physical body and nothing you invented, creativity is a fact of your spiritual body and nothing you must invent

(Cameron, 1995, p.xiii).

My observation has led me to believe that people, who are involved in the period of recovery after acute illness and discharge from acute psychiatric care, see themselves as being in a period of rehabilitation that is 'learned'. A medicalised paternalistic view gives rise to certain language, behaviours and enforced protocols that promote this notion. The stance of community mental health and support workers may reinforce this, as things are 'not quite stable' yet, therefore the person is not allowed to return to the 'normal' world. This can be seen also as a period when rights of 'full citizenship' are suspended and the legal conditions of a community treatment order mean the relinquishing of a drivers license and, in the past, temporary removal of voting rights.

We can make a comparison with the very different experience of a patient with a fracture that heals and the person with mental illness by noting that when someone is 
released from hospital after orthopaedic treatment they are generally restored to 'normal' personhood as they step out of the hospital building.

Another example of this constructed notion of helplessness and enforced rehabilitation period that I observed was when a person left the ward without permission from a doctor to visit a hotel bar. The practice of the mental health service is to perceive and document this act as medical non-compliance. However as I observed, when this same choice of action occurred in a social context one New Years Eve, the inpatient 'behaviour' in breaking out to visit a bar is not seen or talked about as non-compliant, but perceived as normal. I saw that the staff were quite supportive of this in a "good on you" sort of way.

If this is in fact true, that mental health workers and clients cooperate in a period of rehabilitation or prolonged helplessness that is 'learned', this may mean that intervention at this stage in providing, or working towards, rehabilitation is expected by both the provider and the client. It is as if, in some way, self determination is automatically negated by inpatient status.

The time when providing a sense of personhood may have the most impact, is when the client in fact least expects it, based on their inclusion in a social construction of what admission to an acute psychiatric facility may mean. Having become unwell enough to require hospitalisation the person is at their most disbelieving of their worthiness to be reinforced with a sense of personhood. When acts of labelling and medicalisation occur personhood disappears at a greater rate. If ever there was a teachable moment it must be in the acute phase of illness; it must be when people are at a loss to explain the disappearance of their identity through the dehumanising process of experiencing the onset of mental illness. I believe this is the time when most energy goes into reinforcing the illness role through required compliance, rather than it being recognized that this is the prime opportunity for development of the Self, through establishment of a multiply defined identity. 
Maori have identified the critical nature of this time and insist that if they are to offer a culturally appropriate service it must begin at the same time as the person approaches the door. The culturally appropriate moment is lost if the person is not offered this choice at this time and they are effectively harmed by this oversight.

This is also the exact right moment when the creative identity of the individual may be located to assist the journey of addressing the illness itself. This moment is the moment for the individual because, as health services take these notions on board, services react in a service way and attempt to create policies to enforce practices. These words explain the different approach of the Nurse Artist. " Service providers must be cautious about "recovery programs". Recovery-supporting policies and practices cannot simply be tacked on to existing programs and services. Supporting the recovery of others means fundamentally doing differently that which we do every day" (Curtis as cited in Wells, Competency One- p.24).

What might it be like if instead of asking people who experience a mental illness to name and focus on their problems, we invited them to see themselves from upside down or from any other angle in fact than the way the medical model insists, which is to "get things straight" or reduce symptomatology.

Might it be a way of unlocking the mystery of this very personal challenge? My work as a Nurse Artist does just this. Instead of pronouncing patienthood and then referencing everything from this perspective I refer to the Client as Artist and so we see the physical, spiritual, social and mental self from an entirely different place.

My journey is to find what it is within me that I bring to this place and how I should express myself. I must be able to gather my past experience into one form, a composition of knowing, being and doing. There is also the influence of time and from this I am able to relate elements of past experience to my present and future experience. When I have gathered this form together, in its enlivened state, it is known to me as my wairua or soul. From this wairua that flows through me in all my actions, expression and decisions, I can begin to find my identity and my voice. My 
wairua/soul is my being fully present at any given moment in time, for the benefit of others.

What can we offer in terms of self-discovery by the provision of art materials in hospital environments? I am interested in the broad field of research into the effect of art. When artistic-creative contributions are brought into the clinical field by the nurse artist, recognizable changes can be seen in the recovery of clients without them having to correspond to strict evidential criteria.

This 'arts oriented' practice has its roots in 'life orientation' as changes begin with the acknowledgement of the autonomy of the client of the presence of their inner artist. A student nurse Lorraine told me of her primary school experience. When Lorraine was asked to draw something one day in class she complained..."oh I can't draw'. Her teacher replied..."You've been drawing breath since the day you were born so do not think that you can't draw".

This story so aptly illustrates my connection with Maori in my nurse artist role. For Maori drawing breath (and exhaling) is an art, that expresses the life force, and art is as close to a person as their breath is. Life and art are inseparable and there is a natural acceptance of individual personal creativity in Maori culture. In this way we are working in parallel, as I also believe in the inalienable right of the individual to creative expression. I believe that the inner artist exists for every one of us and that it can be a powerful and positive force in mobilizing hope and personhood in the presence of mental illness. 

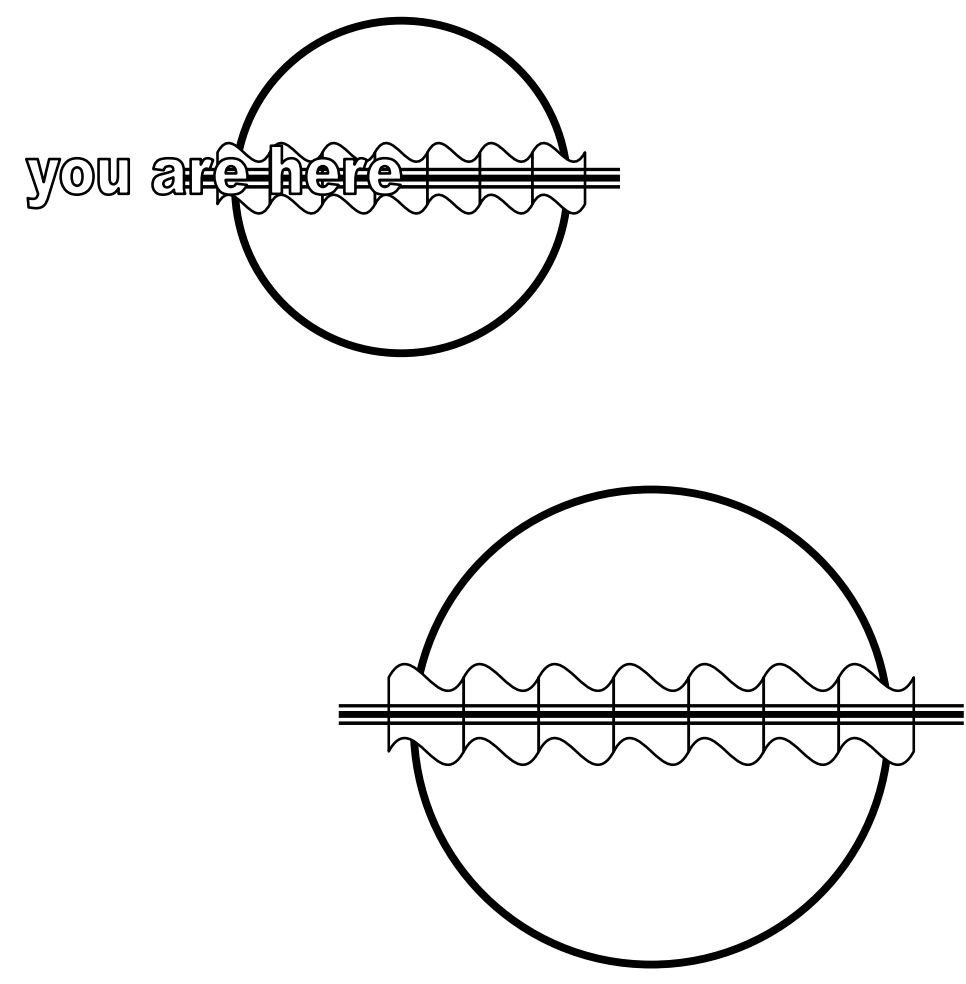


\section{CHAPTER ONE}

\section{MAPPING IDENTITY AND ENVIRONMENT}

\section{Overview of the Thesis}

This thesis is about the experience of nursing in the mental health field in Aotearoa New Zealand from my unique perspective as a Nurse Artist.

The overarching style of the study is in the framework of narrative enquiry. This has been defined as the:

stories that create the effect of reality, showing characters embedded in the complexities of lived moments of struggle, resisting the intrusions of chaos, disconnection, fragmentation, marginalisation and incoherence, trying to preserve or restore the continuity of life's unity in the face of unexpected blows of fate that call one's meanings and values into question

( Ellis \& Bochner, 2000, p.744).

Ellis and Bochner (2000) describe my position in terms of the narrative genre," I refer to these personal stories as evocative narrative where the author writes in the first person, making herself the object of research and thus breaching the conventional separation of researcher and subjects" (p.744).

Evocative stories activate subjectivity and compel emotional response. They long to be used rather than analysed; to be told and retold rather than theorized and settled; to offer lessons for further conversation rather than undebatable conclusions; and to substitute the companionship of intimate detail for the loneliness of abstracted facts

(Ellis \& Bochner, p.744). 
This overview puts my writing into a context for the reader. The search for the more precise method of describing Self-experience does not however end here. The research project became part of this reflective cycle of telling and retelling that uncovered deep insight and experience in describing the complexities of the mental health field environment.

Where another person may describe mental illness as their lived experience, I am able to express my view as a nurse and an artist - describing my lived experience of stepping into the physical and psychic space where the illness is taking place. I am aware of also being able to choose to step outside of this physical and psychic space where the person with an experience of mental illness may not have this luxury.

I agree with Ellis and Bochner's premise (2000) that “the investigator should always be implicated in the product. So why not observe the observer, focus on turning our observations back on ourselves?"(p.747). I find this to be a very challenging and interesting question when so much of mental health care relies on the detailed observation of the nurse upon, or over, her patient.

It seems right that I not only have the capacity to observe myself in great detail, but in a sense it is an empowering step to subject myself to the very gaze to which I subject others. In its most benevolent sense the nurse's gaze is the softness of view in which I hold my client with unconditional positive regard. In its malevolent sense it is the gaze of surveillance and the all seeing eye that monitors and reports during containment. The gaze that constructs self-monitoring. How do I begin to tell my own story when it may be the story I have been trained to tell?

I write from a place of deep introspection but also sinking down into myself so that my inner self-life-story (autobiography) becomes more apparent, even to myself. I value the intention and capacity that I create in my writing, that the text be felt by the reader as a genuine expression of my self and that it is also real for the other person whilst remaining real for me. Ellis and Bochner (2000) ask "And why not write more directly from the source of your experience? Narratively. Poetically. Evocatively" (p. 
747). I too, want to answer the questions that Ellis and Bochner have asked themselves, to come " to address deep and troubling questions about how to live a meaningful, useful, and ethical life" (p.747).

I entered the nursing profession with a sense of wanting to do some good in the world. The position I find myself in, as a nurse artist in the mental health field environment, is often troubling to this rudimentary ethic. I invite other people to see some of the world of mental health as I witness it, with all its paradoxes and controls. I am making my way through a world that "poses obstacles, interruptions, contingencies, turning points, epiphanies and moral choices" (Ellis \& Bochner, 2000, p.748).

Often, the quality of choice and the consequent experience that I am able to offer the client, is directly relevant to choices that I have previously or simultaneously made in response to this dilemma of being in the mental health world. Sometimes the choice is not there for the other person, as my turning point does not occur until after the critical event. This produces a reflective tension where I could perhaps do better the next time when faced with similar challenge, but on this occasion my practice lags behind the presenting challenge. The mental health nurse, as practitioner, becomes an expert when praxis allows good decision making in future events based on past knowledge. The challenge inherent in this is to not become a repetitious performer of the past into the future as 'empty tasking'.

Ellis and Bochner (2000) write " personal narrative matters because we live within the tensions constituted by our memories of the past and anticipations of the future" (p.746). He however rejects the question: Does this story reflect my past accurately? I have also rejected this question, as I do not attempt to represent, by holding a mirror to my past. I share the mental health field environment with people who have been constrained and prevented from representing themselves, and therefore their future is forever affected by a view of their past which was not of their own design or making. In losing hope for oneself, the impetus to anticipate the future is lost. In my judgement this form of oppression over personal narrative, creates a cycle of 
dependency upon the mental health system. I also recognise that I cannot separate myself either from the effect of this or from being in the position of contributing to this effect. I need to be able to re/create myself in the telling of my story in such a way that allows me to see a future with new possibilities.

Ellis and Bochner (2000) say "The work of self-narration is to produce this sense of continuity: to make a life that sometimes seems to be falling apart come together again, by retelling and restorying (restoring) the events of ones life" (p.746). They encourage the question "What are the consequences my story produces? What kind of person does it shape me into? What new possibilities does it introduce for living my life?" (Ellis \& Bochner, 2000, p.746). I also ask the question what new possibilities does it introduce for my nursing practice? What are the consequences my story produces for other nurses and for clients of the mental health services? What barriers do other nurses have to being able to relate to my story? What can you read about me that I couldn't say? What are the forces at work that make me voiceless?

The goal is to encourage compassion and promote dialogue. Actually I would be pleased if we understood our whole endeavour in the face of all the barriers and boundaries that make conversation difficult. The stories we write put us into conversation with ourselves and with our readers. In conversation with ourselves, we expose our vulnerabilities, conflicts, choices, and values. We take measure of our uncertainties, our mixed emotions, and the multiple layers of our experience...often our accounts of ourselves are unflattering and imperfect, but human and believable. The text is used then, as an agent of self-understanding and ethical discussion

(Ellis \& Bochner, 2000, p.748)

This thesis uses three devices: literary psychogeography as narrative, text as data, and creative arts in the mental health field environment to present a new position to consider mental health nursing, and to illustrate my experience of sustaining personal hope and resilience in a mental health field environment. It illustrates the potential 
for hope and resilience to be [adopted and] practised by other health professionals. Using the recovery-focussed approach hope and resilience will be demonstrated consistently toward clients in every interaction [possible]. The three devices are explained in the next three sub-sections.

\section{The first is literary psychogeography as narrative}

This thesis offers a free option for change that doesn't separate us as human beings. Literary Psychogeography practice doesn't cost anything. It has potential for saving everything from quality of lived experience to time, personal energy, to money, autonomy, and resources. It is playful, creative and able to be shared with health professionals and clients rather than separating views through lack of common ground. It gives an opportunity for a mutual health view, without having to refer to politicians or financiers.

\section{The second is text as data}

This thesis offers an alternative to the creation of the health industry as a commodity and the mental health service as a product within a consuming society. I endeavour to assist nurses and health care workers to recognise and avoid health care delivery as a form of business at the point of delivery. The mental health worker is challenged to an alternative position of observation that produces reflection on practice, from a position unaffected by the insidiousness of habitual and empty tasking

\section{The third is creative arts in the mental health environment}

Opportunity to engage with good quality and freely available art materials in the mental health field environment can serve to address the negative effects of receiving a diagnosis. Due to the primacy of the bio-medical model a diagnosis comes to stand in place of the person as an individual. This is a matter of social injustice. The diagnosis then, as a particular and narrow view of the person, creates the model for how this person 'should exist' in the world, and replaces the individual's potential for self directed and ongoing development of creative and unique identity. People are robbed of the opportunity to freely express themselves creatively as all expression is fed through this same particular and narrow view of the diagnosis. For example artworks made by people with an experience of mental disorder are displayed in a 
medical journal as 'psychiatric art' (See Chapter Two). A mention is made of the individual artist who is psychoanalysed through his work rather than described as a working artist. The medical doctor is however mentioned in recognition of his large collection of these works, and is acknowledged for his description of the motifs in the painting, described by him, as he explains, in relation to the illness and the person's use of artwork as an unconscious 'working through' of their disorder.

Creative arts enable me to form a theory of nursing creatively and definitively, identifying possible ways to change practice using, for example, cognitive mapping in order to create the possibility of change and space for Other. The importance of identity and environment might be established in the ongoing search for methods, path(s)/way(s) to reduce stigma and discrimination against people with an experience of mental illness. To show reality through my eyes and all of my other senses and consider another person's reality is...the truth on one day, or in the quality of the light in one clearing in the forest...to be a nurse in a mental health field environment and, where possible, to use my voice to speak about the circumstances of health care as we know it which delivers a service to people who do not always have the freedom of being able to articulate their presence in this field.

This thesis seeks for change in some mental health practice and mental health field environments. To offer other nurses and health professionals an innovative form of practice that enables them the choice to think strategically and originally as an individual, and with personal integrity as required by the Recovery Competencies for Mental Health Workers of Aotearoa New Zealand, unaffected by the subtle pressures of conformity and institutional thinking. Professionals must act as a team not in 'group think', but rather in using their individual thoughts in conjunction with others. " the term recovery provides a container for the competencies to sit in. But we could equally label that container as the competencies service users most value, and sometimes find most lacking, in mental health workers" (Mental Health Commission, 2001, p.2) 
This thesis asks to consider the grass roots thinking of worrying about caring, it seeks to consider the ethical and moral dilemmas and reaches out to all nurses and mental health workers who lie awake at night and worry that they made the wrong choice for someone else, forced treatment on someone, or feel lost from their principles as a human being. For the person who goes home and transforms into a human being but goes to work as a machine. For the person that sees them self in every medicalised description of depressed mood.

This thesis may provide a point of arrival or departure for a person as a health practitioner who may be interested to know if their practice has become affected by institutional thinking. Psychogeography enables a self check and also an environmental check to if there is a self perception or observation of custodial and forcing practices. Practitioners can illustrate identity and environment aspects that they have identified as being non-recovery focused.

This thesis illustrates new ways of change. Change is possible because we can use what already exists in new ways. The possibility for creating change doesn't have to overwhelm us. To "reuse pre-existing artistic elements in a new ensemble" is possible (Hetherington, 2002, p.1).

I attempt to suggest a tonic for the empty hearted and the empty soul, whose goodness has been poured out into the mental health field environment and, in particular institutions, without a source of renewal. To be filled with hope and possibility for other people's recovery one must have the means to consider/reflect and renew one's own perspective, which must be hopeful and filled with possibilities.

This thesis is written by an artist who has forthright ideas on being artistic recognising the talents and potential every one of us has as a birthright. Danger may be a reality in the form of experiencing verbal and physical acts of aggression, but attempt not to lose sight of the possibilities of renewal and a good ending in the midst of all the chaos and fear. 
I consider what occurs when we are practising with dread. This thesis is for the weary and beleaguered: the nurses and mental health workers who have given all of their energy away. For those who wake each morning with a dread to return to the workplace, it is offered as an option for an overworked marginalised and stigmatised workforce.

This thesis is written as a gift for big heartedness - the key to thriving creatively. A gift for all the nurses who have left nursing...down hearted, angry and frustrated at a system that has them beaten them into a shape they didn't want to become. To tempt people with good hearts back to nursing to show them the place for them is there and that the attitudes of others in the workforce will support them and encourage recovery-focussed practice. If I can do it this way you can too. It is to relieve nurses and health care workers from being agents who are sent out to deliver treatment as a form of social oppression.

In order to consider my relatedness with art and people I had to begin with my own environment. This then enabled me to consider the central questions that provide my practice alternatives. I want to know where I am standing. What ground does a person who is labelled mentally ill in the presence of mental illness stand on? What ground does a person who is labelled health professional in the presence of mental illness stand on? What ground do we take up?

Can I hold onto my integrity in all circumstances of presentation of illness? Can I keep my integrity in the face of overwhelming challenge or subtle insistence to join in a round of cynicism, or to help deliver the drug by force today in the hope it will bring relief from mental suffering tomorrow.

My knowing and practice knowledge provide a way to conceive of communicating toughness. I know art can carry me through. I know art can carry us through - the creative act of making a tangible product that sits outside of you and me and gives another more understandable reason .... a commonality to us. 
This commonality or finding common ground is critical, since the irony is that the forces of stigma and discrimination, rather than the illness, itself separate us. Why and what brings us together?

\section{Considerations}

Is this about Society and Mental Health or Mental Health in Society or Mental Health through our Society? Could descriptions of what is occurring in nursing practice and environments of health alert us to both mental health as we know it to be, and the elemental form of our society.

These considerations throw up the following concerns that enable me to focus on the environment I find myself in:

I want to know if other people who struggle and leave the workforce would feel some strength and truth as I do when I work as a nurse artist.

Is being a nurse artist legitimate? Should art space be set up outside of the institution that can offer people a place to go to, rather than giving away sanctions to treatment that is forced to be close to mental health services?

What is the purpose of this cycle known as the 'revolving door'? Maybe, the 'level of wellness' (because we never say wellness per se but always qualify it) that we as health professionals think is so great, isn't all that great for the person who experiences it. Why do people who have been on a medication regime and are reasonably well begin to refuse treatment and get sick? Then, after hospitalisation, when they do take medication and return to 'wellness' we as health professionals all agree this is good. Clients may agree too. Is this a ritual of attachment or dependence that we generate as part of the function of the mental health services as a system of care? Maybe people just decide they want to change something...rather than the 
awful sameness, isolation and stasis that other people in society, with greater resources, are able to sustain as part of the spectacle of capitalism.

What do we do to set up the system of re/cycling that creates the need in people as the client to return under duress, and the need in the health professional to accept the client (with the system so overloaded, others are sent home before they are ready) under duress. Why after all these years, since the Mason Report (1996 Ministerial Inquiry of availability and delivery of mental health services in New Zealand related to semi-acute and acute mental disorder), is the mental health service still something, as the saying goes, that is hard to get into and hard to get out of? 

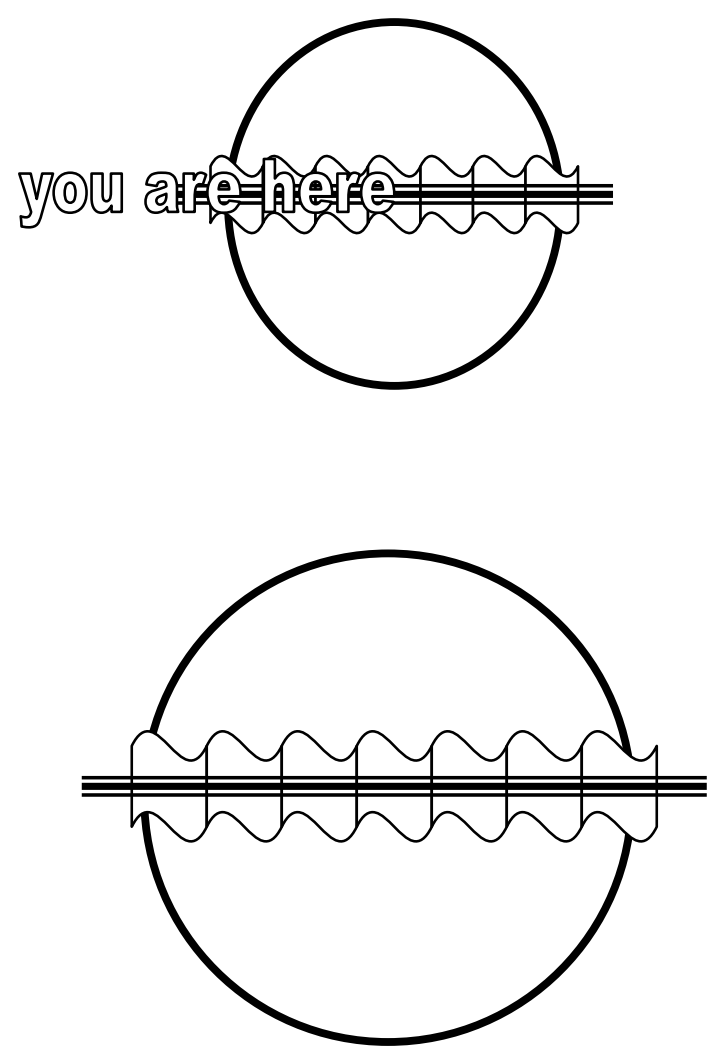


\section{CHAPTER ONE}

\section{Mapping Identity and Environment}

\section{The Recovery Journey?}

The background to this thesis is based in the challenge to mental health workers to meet the requirements of Aotearoa New Zealand health legislation. "The Government in June 1994 launched the National Mental Health Strategy. The strategy has two key goals:

1. To decrease the prevalence of mental illness and mental health problems within the community

2. To increase the health status and reduce the impact of mental disorders on consumers, their families, caregivers and the general community"

(Mental Health Commission, 1998, p.5).

The "Blueprint for Mental Health Services in New Zealand: Working Document" published by the Mental Health Commission in November 1997 and then revised in November 1998. The Blueprint is the National Mental Health Service Development Plan and in this plan the strategies specify that all Mental Health Workers be required to practice from a Recovery Approach. The 1998 Mental Health Commission document states:

\section{The Recovery Approach}

Recovery is a journey as much as a destination. It is different for everyone. For some people with mental illness, recovery is a road they travel on only once or twice, to a destination that is relatively easy to find. For others, recovery is a maze with an elusive destination, a maze that takes a lifetime to navigate. 
Recovery is happening when people can live well in the presence or absence of their mental illness and the many losses that may come in it's wake, such as isolation, poverty, unemployment, and discrimination. Recovery does not always mean that people will return to full health or retrieve all their losses, but it does mean that people can live well in spite of them.

Historically, mental health services have failed to use a recovery approach. Recovery could never take place in an environment where people were isolated from communities, where power was used to coerce people and deny them choices, and where people with mental illness were expected to never get better (Mental Health Commission, 1998, p. 1).

Policy and practice models which enact the Recovery Approach are increasingly audited for inclusion of the ten recovery competencies which direct individuals, mental health support workers, and mental health services. The 1998 Mental Health Commission document goes on to say;

\section{Recovery In Action}

The concept of recovery can be applied to most beliefs about the origins and nature of mental illness - biological, psychological, social, or spiritual. It can also be easily applied to holistic approaches such as the Whare Tapa Wha model which identifies four dimensions of health - taha wairua (spiritual), taha hinengaro (mental and emotional), taha tinana (physical), and taha whanau (family). Some people believe the origins (or at least the prolonging) of mental illness does not lie in the person with the illness but in the world around them. It may be their family, social injustice, unresponsive services, or a traumatic event. In these cases recovery does not just need to happen in the individual; the people and systems that contribute to a person's illness also need to change to enable that individual to live a better life

(Mental Health Commission, 1998, p. 15). 
The background to this thesis is a sense of sadness and anger that I have within me. During my direct experience of more than twenty years as a nurse artist working in the mental health field I believe I have witnessed the prolonging of people's illness due to the world around them, which is the mental health field environment, rather than any manifestation of mental illness due to an internal cause. Given different circumstances of living, and a different world experience, people can and do get better.

My focus became further exploration of accurately describing people and systems that might contribute to a person's illness.

Many descriptions and personal stories have been told from a consumer perspective. Much has been expressed of the experience of being at the receiving end of 'contributions' to ones illness or the prolonging of it.

Lapsley, Nikora and Black (2002) in "Kia Mauri Tau: Narratives Of Recovery From Disabling Mental Health Problems" discuss this phenomenon:

accounts of illness based on the experience of the sufferer have become a popular genre and are the stuff of memoirs, films, television dramas, documentaries and talk shows. They have become so common that they could be said to form part of the literary genre: the illness memoir. This is not a new phenomenon, but the huge growth in interest recently suggests that there is a ready audience for "illness stories”, in contrast to earlier times where suffering in silence was seen as appropriate

There is not however the same wealth of information in various mediums giving us an account of what it is like to be a part of the body of a profession or system that is charged with making this 'contribution' to the causation or prolonging of a person's mental illness. Not because as consumers have, nurses or hospitals at an organisational level have "suffered in silence". More because they are held up as 
being the source of cure and it would be inappropriate, and certainly politically incorrect perhaps, to speak of individuals or systems of health causing or prolonging illness. The public sees nurses as the embodiment of Florence Nightingale qualities, which bring us close to sainthood. Hospitals are seen as lifesaving places where one must go to access the finest expertise and most up-to-date technology. Nurses at a personal level have suffered in silence, in the same way that consumers did or still do. Unfortunately though the illness memoir of the 'nurse in the system' or the 'mental health system in the health system' have not been voiced in such a multiplicity of mediums or been subject to such avid demand.

Why are we so quiet? If the Mental Health Commission can publish a document in 1998, which states that "the origins (or at least the prolonging) of mental illness does not lie in the person with the illness but in the world around them"..."the people and systems that contribute to a person's illness also need to change to enable that person to live a better life" (Mental Health Commission, 1998, p.15). What are we doing to change?

I posit that the individuals and the systems that operate within the mental health field environment, when considering themselves, honestly believe that they are doing the right thing. In a lot of situations they are. They go to work to make a positive difference. The difference lies however in the morality of the method of healthcare that we offer in the mental health environment.

If a person in a surgical ward has a wound that will not heal it is not thought to be the fault of the person. It is seen to be their body (separated from their mind) not responding to proffered treatments, even though their will is happily engaged in this healing process. They are rewarded for this by subtle 'system things' like getting to chose one's meals from a daily menu.

Conversely, if a person in a mental health ward will not heal, it is often thought that it is their fault since the mind is not responding to treatment and there in the mind lies the seat of the will. The body floats along behind the mind in this circumstance, 
attached by a coat hanger like some forgotten dry-cleaning in its plastic bag. These patients are not thought to be cooperative for which they are punished in 'subtle system' things like having to chose between two meal types that arrive, the first clients who get to the kitchen get their first choice, the rest miss out. Herein lies the difference between mental health and general hospital practice.

Is it the fast clients' fault that they get their first choice?

Is it the slow clients' fault that they get the second choice meals?

Is it the nurse's fault there are only two meal choices?

Is it the kitchen's fault that the ward turn-over is considered too fast to offer choice?

Is it the hospital's fault that mental health services buildings are located in isolation within the community and far from the main hospital kitchens?

Is it the system's fault that people with a mental illness get no choice and other types of patients can choose?

So why don't we say something about this treatment that has the potential to cause or prolong mental illness?

We don't speak due to fear of losing employment and nursing registration that some individuals have experienced when this silence has been broken. Some nurses have been made examples of as particular codes of silence prevail in legislation and behind closed doors. When the public of New Zealand are assured that dedicated amounts of our economy are devoted to the staffing, support and systems resourcing of adequate mental health services to people perceived of as antisocial, dangerous and unpredictable, it is difficult to speak out in opposition to these assurances that make people feel comfortable and safe. The common term for someone who does speak out is "whistle blower"(legal terminology in Protected Disclosures Act, 2000). Hardly encouraging of the person, with something critical to say about a government or private service.

I hope to be able to make a contribution to the body of knowledge that describes this unique and somewhat difficult position from a nurse's perspective. To explore, 
through my reflective practice in this field, the contributors or contributory system manifestations that may cause or prolong a person's illness. To feel the fear and do it anyway...to try to describe an illness memoir and to have the courage to change it to a memoir of recovery using what I have as my skill, my creative self.

My intention is to explore this field using literary psychogeography, examining the contributors or contributory system's ability or inability to recognise when and how they (or it), cause or contribute to the prolonging of another person's illness.

My hope is to explore social and system change that my creative arts and nursing practice could contribute as an antidote or 'good medicine' to enable individuals to live a better life. To make a contribution to nursing practice through finding another space for developing practice outside of causing or prolonging mental illness.

The statement in the Mental Health Commission Document of 1998 is that "historically, mental health services have failed to use a recovery approach" (p.1).

I question if in fact we really have the comfort of being able to assert that this is an historical fact. I do not believe we have come far enough away from "an environment where people" with an experience of mental illness "are isolated from their communities", "where power was used to coerce people and deny them choices" and "where people with a mental illness are expected to never get better" (Mental Health Commission, 1998, p.1).

A person may have the inherent potential and find this inner strength to overcome for example the huge challenge of family abuse or rejection, social injustice, or traumatic events, but they will never be able to achieve this if the individuals, or the system, from which they seek help is unresponsive or even sick-making.

Despite the best intentions and the clear directives of the ten Recovery Competencies for Mental Health Support Workers in Aotearoa New Zealand, these do not affect essential practice at the point of delivery in terms of the attitude and behaviour of the 
individual practitioner. This is the practice that no audit can accurately measure as what goes on behind closed doors inside of defensive practice is where the damage can occur.

Nevertheless I believe that causing or prolonging a person's mental illness by individuals or systems can be remedied. I am interested in the potential that individuals have to make a positive difference in the lives of people with an experience of mental illness, through reflective and creative practice that acknowledges the identity of the individual and the environment of the mental health field.

Here I give an example from my own practice, which I was able to reflect upon. This example highlights the contribution of me as the individual and the system within which I work, in potentially causing or prolonging a person's illness.

\section{Practice Example of a Contribution to a Person's Illness}

A family meeting was occurring in an inpatient acute ward. The Youth Specialty Service worker arrived to see the Client not having been informed of the family meeting. She asked to see the client's notes which she could not locate in the usual place. I offered to help to find them and then realised when I looked through a glass window in a side room a meeting was taking place which involved the Client and the notes were actually in the hands of the Consultant Psychiatrist at that moment and he was referring to them. I offered to interrupt the meeting to ask if the worker could join in this apparent family conference. I knocked on the door, opened it and in full view of everybody present who were seated in a circle - medical staff, family members and client- I asked the Consultant if the nurse could join the group.

I knew my mistake as I walked away.

The client was a body on the couch, her face out of sight behind her mother's shoulder. I didn't even make eye contact with her, let alone speak to her to ask her if she would like her Nurse to attend. 
Whose meeting is it?

From a Recovery Approach it is definitely the client's meeting. My attitude and knowledge at that moment in time was a bio-medical model response. It caused me to decentralise the client and place the consultant at the centre of the group. In the bio-medical model hierarchy the doctor would always lead, and permission for this sort of intrusion would be directed to him. I acted, at this time, as an envoy and a mouthpiece for the consultant and thus disempowered and disenfranchised the client.

I try to be so aware and yet in the busyness and atmosphere of the ward I don't always get it right. This isn't so much of a confession as it is a realisation of the insidiousness of not wanting to, but somehow ending up deferring to the doctor over the client.

In my head I can rationalise the knowledge that the client will go home perhaps, but on a heart or emotional level I know I will have to stay here at the ward with the doctor. So the question is what will I do as a reflex action in my own struggle to be in this place? How will I respond at any given moment? Who do I want to think well of me and help me and protect me? ...If I have to stay here ...then it is the doctor whose approval I seek and whose protection I need. This is the exact desire of the client, except that they seek this approval and protection from the doctor(s) for the purpose of being released from this place. I seek it to keep my job and my position as a registered nurse. It is the doctor whom I prioritise over the client.

So with this realisation I can see what is really at stake because I need the doctor to look after me if something goes wrong. I may need the doctor more than the clients do.

When I enter this environment I am personally exposed in ways I cannot predict [as future events may provoke certain irregular behaviour and response in people] and ways that are very familiar to me because they happen regularly. It's the knowing 
and the not knowing - it's the unpredictability of it. It is raw emotion and physical state. I know I am just the same as the client group because ultimately we are all judged - approved of and not approved of by the same model and by the anointed head of this model's group of practitioners... the consultant.

Conformity is paramount as that is how I can prove my sanity where all around me people are being judged insane. That is how I prove my normality to everyone else. It is ultimately what we pass judgement on our fellow human beings about - in order that they might proceed in freedom to move in society once more... or not.

We call the team meetings multidisciplinary because it sounds fair and good, but by law, and in actuality, we all implicitly look to and hope for final and difficult decisions to be made by the head doctor [small pun].

Who decides who gets to live outside these walls, keep their child, receive medication or ECT, go home for the weekend despite the risks and unwelcoming community... and so many other life changing decrees.

I don't want it to be me... How do I combat this 'leave it to someone else' while I walk through my working day like a ghost of my real self. I want to have my "human journey through authentic life" (Hetherington, 2002, p.17) and I want other people to have their human journey through authentic life. What is the key?

I want to be able to make an individual difference, join up with someone else's individual difference and so on until like a beautiful strong matrix we become resilient together and yet maintain our essential freedoms. To bring authentic experience and thus human authenticity to our actions - these are recovery actions. 


$$
\theta^{\ominus}
$$




\title{
CHAPTER ONE
}

\section{Mapping Identity and Environment}

\author{
The Nurse Artist as Researcher: Demonstration of Credentials in a Narrative \\ Style
}

Self As Nurse?

Burns (as cited in Burns \& Grove, 1997) is quoted as saying:

In the methods section, the researcher documents his or her credentials for conducting the study. This documentation is valuable in determining the worth of the study, since the researcher serves as a primary data-gathering instrument and the data analysis occur within the reasoning processes of the researcher

This thesis uses literary psychogeography alongside my workday role as a nurse artist and features literary and artistic works made over time. Poems and paintings elucidate my exposure to, and growing awareness of, the mental health environment.

This literary psychogeography method enables me to be present as a nurse and artist without exerting undue pressure as a researcher or appropriating another person's experience for the purpose of my research. I draw from and develop description or identity of things and people in response to, and as a conclusion of, reflective processes to my own sense of being drawn to, repelled or excluded from the mental health field environment. I may generate a fresh view or another practice space from which to be able to provide recommendations for modifying this environment so that it might reduce harm to individuals and create recovery in mental health. 
The link between research and practice is in literary psychogeography. "It is the method to bring all those scattered images within reach, it enables people to wander freely through space and time with eyes and ears/ looking and listening" (Shaw, \& Van Tijen 1991, p.3).

The Situationists of the 1950s and 1960s importantly used psychogeography not just as a means to look, or a fresh eye, but also to expose what effects we might otherwise be unaware of, and to carefully detail them to form a basis for resistance. "Part of its purpose lay in allowing participants to drift from their usual activities and to become more aware of their surroundings while simultaneously seeking ways of changing them" (Pinder as cited in Ungar, 2002, p.1).

Guy Debord was a Situationist who identified that "people suffered from an extreme alienation to the extent that they had become mere spectators of life, without any real sense of taking part, being involved, or interacting. We experience all of our life as a kind of 'spectacle'; we are passive spectators with no real involvement in events" (Ungar, 2002, p.1). Debord's contention was that this spectatorship had resulted from "modern cities that had become centres of capitalism where life was reduced to mere production and consumption" (Ungar, 2002, p.1).

To write poetry as a form of literature crystallises my experience. I take this small grain of mineral crystal and show you the surface of it; the quality, and the character that you might better know the rock. This grain of crystal is truth, it is my truth.

This study is the story of my nurse artist practice within this land that I love, Aotearoa New Zealand. I will not abandon my creativity to tell you about myself in a bookish style but instead fully embrace the potential of the arts to more fully record my being and to invite your participation as a reader of prose and poetry, and as a viewer of the painted surface.

You stand in your place in the world with all of your understanding that you might judge me. In the same way that I practice I do not force your participation, but invite 
you, indeed entice you to participate for some part of our journey together. For a short while we are artists and comrades in exploration of ourselves and meaning in a new medium. This new medium is my research, which is as experimental as the first fresco. The wonder of exploration in substances that might stick to walls, stand the test of time, and whose colours still glow through heat and cold and dust. The fresco has the daring of the big work that moved outside of a frame, all the better to tell its wonderful story.

This study is also about my work-life path that, quite surprisingly, erred from the very straight and easy street that I imagined in my twenties to become a winding roller-coaster ride. I sit in the seat of my Self, with nursing as my vehicle on the creativity tracks - what a ride! Together we have been places, seen things and come to know people that have enriched me and potentiated my expertise propelling me onward to be a better me.

This journey has brought me to a position of combining the theoretical and practical fields of art and nursing within a New Zealand health care system. In this system the human spirit seeks to express itself in its unique state and is helped or hindered in it's striving to be healthy and free. I find myself now, in my forties, as an advanced practitioner of the skills required to light the inner flame of the person who is demoralised; lover of the ostensibly unlovable; and shelterer of the person whose spirit is homeless.

When I presented a portion of my work to the Clinical Council of the Lakes District Health Board on the $6^{\text {th }}$ April 2004 one of the comments offered to me by a member of the council was that " you are in touch with your wairua (spirit, soul), and I believe people with a mental illness are too. They, will see that in you and be drawn to you" (Council member, personal communication, April 6, 2004).

What do people see in me? What do I see as I look around me? This is about the looking out and the looking in of the nurse and the artist within an environmental context. I am not separate from this environment, as I am a researcher I am also the 
researched. What am I drawn to? What is it about me that draws others? What am I repelled from? What do I repel?

Psychogeography, has been defined as "the study of the specific effects of the geographical environment (whether consciously managed or not) on the emotions and behaviour of individuals" (Internationale Situationniste, 1958, p.1). I have reasoned that the environment goes beyond what I can perceive with my eyes and other senses. In its gross presence it goes out into the universe and in its minutae it penetrates my skin and enters my very cells. The energy that makes me a living being does not draw boundaries between people, other living things and matter, but is the make up of all and gives us an undeniable commonality.

This is the moral basis of my practice and an underpinning of the thesis. I believe all to be equal in our energetic state. The cicada frozen into no flight by the cold wind needs a place of safety in which to warm its body. I lift it from the footpath. The woman curled in her blanket on 10/60s (10 minute nursing observations), I engage with her to speak rather than merely passing by with the clipboard satisfied she is not acting on her thought of self-harm. I can't stand on the cicada one day and then ask someone if they are safe with heartfelt care the next. My world is connected. Yet I see examples of people accepting mental health care, and people giving mental health care with complete disconnection to each other. This disconnection ruins lives and lives are lost. Nurses give up and capitalism wins over authentic human relationship [potential]. As a nurse and an artist this motivates me to create connections within individuals and between individuals.

This study is a narrative, a story of the way in which I have begun to speak, to open the photograph album of my life as a nurse artist and to share this with you the reader. I offer a view bound by a particular time in which I began to be employed in mental health settings first as an artist, and then a nurse from 1986 until the present. My observations are not limited to place because, in hindsight, I have found through the years and across the various employment environments that the themes, problems and solutions have been similar. I interact with humankind - people, and personify 
objects - the spirit of humankind with which I fill inanimate objects - things, within this environment that we share and in which my practice is revealed.

As human beings we are subject to a certain burden of fate, and none more so than people who carry the stigma of mental illness or mental disorder. The human spirit varies in its response to a diagnosis of mental illness. It may be perceived by the person who bears it as either a great affliction or as a determining gift. Many people I have worked with shoulder the burden of the experience of mental illness all of their life and suffer the blows of social discrimination. They continue on with this great collection of confusing objects pressing on their shoulders and bowing their head under its weight accepting this particular burden of fate. Another person however, shoulders the burden but having carried it for a period hoists it down off their shoulders and, having considered its components, proceeds to make a bicycle out of the various parts and cycle away.

Is it possible to describe what environment contributes to mental health recovery?

\section{Partnership in Nurse Artist Development}

\section{Tribal Land as Environment}

As in Maoridom everything in the past is acknowledged in the present, in order to progress forward, I stand from this present place and look backward and forward and this gives me the authority of the personal pronoun 'I' (A. Perika, personal communication, March 20, 2003). As Arama Perika, kaumatua (male Elder) informs me, my being is a gift of my ancestors and yet I have authority over my own destiny, as I am free to interpret my being within the context of my own generation, my own time. Everything around me is thus interpreted in this generational context as a gift from the past but seen through my eyes in the present time: colour, hue, shape and design are all present in works of art and daily life and are available to me. They give me authority over my own perception and description. I face my own life as I embrace it, and therefore embrace the authorship of my own narrative. 
The conditions and circumstances of this project are exciting, in that where previously in Western medicine it may have not been considered to be the core work or interest of the nurse to use the arts as a tool of practice, now the scope for this is widening and health administrators value skill in creative expression. This is demonstrated by my having been employed as an Arts Consultant nurse/artist in the mental health service context. In short, organizations are becoming more positively disposed to practices that engender health and wellbeing that include the visual and performing arts.

Study involving environment however, can only proceed when I have first considered my partnership responsibilities under the Treaty of Waitangi. I will begin by first locating myself within a context from which I can describe my position. My title for a time was Arts Consultant to the Mental Health Service Lakeland Health Limited, Rotorua. The Mental Health Service buildings are situated at Pukeroa (place name), on land gifted by Ngati Whakaue ( people of the Whakaue tribe). The land was given for the purpose of housing the facilities and workforce that delivers health care to the people of Te Arawa (The Arawa Tribe) who settled on this land, Mai i Maketu ki Tongoriro (from Maketu to Tongoriro - place names, geographical boundary).

The creation of an Arts Consultant position within a mental health service had important cultural ramifications. The position included aesthetic and artistic aspects of service development, and had the potential to convey Maori aspirations of mental health and wellbeing to the Mental Health Services target population. This position also had the potential to deliver information that changed social attitudes. My grasp of the context in which I worked, and the conveying of this health message, would have been different had I been of Maori descent. I acknowledged the limitations I had in regard to the Clients' right to treatment for Maori by Maori. I also acknowledged the influence that I was able to have in potentiating Maori arts and health programmes in partnership, by my willingness to embrace my obligations and desires for equality of resource and opportunity. 
As a Pakeha ( non- Maori) woman writing and observing within an environment that had a treatment programme called Pohiri Poutama (A Maori model of best practice) which is practiced in a uniquely Maori way, I could not fully know all there is to know about the Maori view. I did, however, critique the presentation of the environment and practice where I was present and involved and I hoped to eventually make a significant contribution as a means of directly improving mental health practice and the environment in general. I recognise that in critiquing this environment by my observation, practice and influence of my experience I have entered a constitutional debate, and this is an action that is advocated by Mason Durie pre-eminent writer and speaker on behalf of Maori and a mental health expert:

At a National level the Government has accepted Te Tiriti $O$ Waitangi as New Zealand's founding document. There still remains the need for constitutional debate so the position of Maori and the position of other New Zealanders might be secured within a climate of consensus

(Durie, 1994, p.215).

Therefore, I put forward my opinion with respect and as part of the wider debate and search for consensus.

Understanding of the context within which I worked was promoted by the generosity of spirit and wisdom expressed to me by the Late Kaumatua Tutanekai Kinita. Tutanekai described the origins of the buildings that house the hospital-based mental health services and beyond, that the people that lived and fought here tupuna (ancestors) shaped this land. Phyllis Tangitu - Tumuaki of Te Whakaruruhau (Senior Manager of the Cultural Safety Service) guided me in the understanding of Tutanekais' words. The staff of Po Te Atatu ('from darkness into the light'), the Maori Mental Health Team extended their support to me. I asked them questions as a Pakeha woman, which I carefully thought about before I spoke. Then I listened to their responses as Maori, and realised there was always more for me to understand than just the words of the reply. Within this exchange is the conversation of the Treaty partners and something I am constantly learning to do. I developed a 
relationship based upon my acceptance into Te Arawa kawa (protocol) and received a whakatau (welcome) on my first day of setting foot on this land. This enabled me to proceed safely with the state of tapu (sacred) lifted. Once having received my whakatau and having been welcomed into this tribal area to work with the people, this relationship continues despite having left this place and these people. Even though I write in the past tense of our dialogue together, our connection does not end and will not end. My responsibility to these people of this place and to this land remains an unbroken thread no matter how far away I might travel.

This research may further people's understandings of the value of and ability in, nurse/artist practice in a clinical environment which already acknowledges the need for client-centered activity, education and recreation.

Problems that may be encountered are where it may be perceived that medical/technical practice, that is the predominant form of practice employed by staff in this study context, is being threatened by my practice as a nurse/artist, which emphasizes nurse oriented and led clinical practice. There could be negative reaction to the aims of this study, where other Nurses perceive that I have a 'privileged position' of contact with Clients based on our creating art; my use of techniques of reflecting on practice and using art as a tool of practice that give rise to well-being. Where people do not perceive this as a worthy direction for placement of time, resources and intent of our organization criticism and anger may result. Institutional racism, where it exists, will resist forms of practice that are seen to be sympathetic or parallel to Maori health practice.

In matters of Client voice, with freedom and power to speak of their own experience, my work could be challenged as being merely the opinion or view of the health professional. This can be overcome by power differentials being reduced by the presentation of my Self as artist and my connection with the Client's artist. Therefore the ground that we meet on and explore is more level. 


\section{Leavening}

Like air folded into dough the rise of a career and a place in the world is a series of enfoldments of the basic ingredients over time. First mixed in correct proportions and then wetted like being exposed to the juices and waters of life in a varied degree at certain stages. The eye of the baker sees and knows not to wet too much or too little as the dry ingredients need not to drown or cloy. Exposed to life's waters or, as Patch Adams says, "the elixirs of life; wonder, nutrition, humor, love, faith, nature, exercise, and community" (Adams \& Mylander, 1993, p.21) the binding of the ingredients of the soul, environment, personality and inheritance as intrinsic nature transform into human dough. Once we have a sense of our own raw state 'the dough of Self' we enfold ourselves, and are folded by experience into the bread of life. I believe I am on a journey of grand design. I have a sense of my purpose but also wonder at past experiences I may have taken for disaster but which inevitably turn into design. This 'Self in pain' must be the rising agent because as bland and unpalatable as yeast is in its raw form combined with life's waters, sugar as love, and warmth, over time it creates height and levity - the palatability of life. This is the bread of my life. My story in the present, and the flavour of my life is in the eating of the bread - the reading of my story. I offer the bread of myself in sustenance and ceremony for the support and transformation of others on this journey.

All energetic matter strives to reach its potential. Like a blade of grass through concrete, and like water falling to the lowest point, the inevitability of personal self expression is apparent in the most mundane tasks of daily living or the most acute circumstances of self preservation. People live out the potential of their lives uniquely and even seek to end this life uniquely by welcoming death in personal ways.

We live in societies that conform to the cultural norms of the dominant voice of power who choose what is 'normal' behaviour. People are persecuted and put to death because of their individuality where it is seen to be outside the norm. The people I choose to be with in this life as a nurse, woman and artist, are people who 
because of their difference in presentation or self-expression have in the past risked having their personality surgically excised.

Although psychosurgical means, such as lobotomy, are now not popularly used as a form of restraint on the human spirit there are many other more subtle ways that are equally effective to limit or 'treat' the individual. The categorisation of individuals into diagnosed mental disorder by use of the Diagnostic and Statistical Manual of Mental Disorders $4^{\text {th }}$ edition (American Psychiatric Association, 1994) known as the DSM IV, the isolation of acutely unwell individuals in purpose built facilities called 'seclusion', and the use of chemical restraint, are all methods used in New Zealand today.

I believe that far more damaging and marginalizing effects, which can be brought to bear on an individual by a disapproving society, are achieved by the removal of that individual's right to creative expression. When this happens in a mental health environment, where the individual has received a diagnosis of mental disorder, the person suffers from a double disadvantage.

When the further disadvantage of homelessness; dislocation from family/Whanau; negative physical effects from drug therapies; unemployment; no life partner; subjection to public ridicule/violence; damning media coverage of an amorphus group called 'mental patients'; or 'the insane'; the need to form trusting relationships with paid professionals; lack of privacy; threat to personal property and wealth accumulation by circumstance; lack of a place to store personal treasures; wearing clothes someone else chooses; receiving budget haircuts; being excluded from the celebration of and property and wealth gains secondary to birthdays, weddings and anniversaries; denied inheritance on parent's death by siblings, families who would rather see them incarcerated, and the list goes on...the creative essence of a person seems like a luxury to seek, when the essential person is lost.

I have found my being a witness, or a participant, in the mental health field very quickly compelled me to want to change many things. To change conditions within 
my direct sphere of influence, and outside my sphere of influence, such as: policy, facilities, practice, behaviour, justice, fair play and human rights, and through time into the future.

While I write about people who share this environment with me, I seek to express myself for the benefit of the one who is not allowed to speak, or through oppression, has lost their voice. In some studies this is considered to be a contribution to the social justice aim, of expression of the viewpoint of the subaltern. I do not use the direct voice of experience of a consumer of mental health services. I use the voice of the one who stands beside as witness. I am part of the system that oppresses, and recognise and acknowledge my power as an employed staff member. But I am also the one who, by studying the precise effect from the place of commonality of being another human being, exposes this and seeks change.

The unique environment that is the mental health services has some barriers to people seeing it for themselves. The clinical and community settings for mental health care are not like a wild game park situated in a heavily populated city where one might walk through and see captured examples of lived experience. I cannot place you in the room and wouldn't want to. Most people have played the game of 'what would you rather be if you had to...blind or deaf?' but not many people play the game of "what mental illness would you rather have... schizophrenia or depression?' I have been in a room that was like many other rooms all used for the same purpose: that of containment. I must also protect the person who suffered in that room from your knowledge of them. I have seen many people suffer and the suffering is so much the same. These experiences fall one on top of another like leaves falling off a tree and I want to honour each leaf even when I am not free to describe the intricacy of each.

The perceptions and context of the presence of others in the environment is presented in the literary psychogeography style, of flashes of awareness, essence of experience and drawing to or being repelled by. Whilst the reader may seek to detect a place in time or a person, the people I come into contact with are a representation of 
themselves and their circumstances rather than their direct presence. This is in keeping with the psychogeography method and also as a protection against revealing identity or breaking a confidence. It is also as a result of my exposure to this environment over years. We have been presented a picture of a renaissance in mental health care in the community as deinstitutionalisation has taken place, and yet I have observed the plight of the mental health consumer remaining the same or becoming worse. The rhetoric and the politics and settings have changed but essentially the lives of individuals are compressed by circumstance, and dollar driven into being the same. The observations I made that contribute to poems from the past are the same observations I can make today.

\section{Experiences Involved}

The analogy of the bicycle first as a burden of fate and then as a means of escape is one I think of because of the actual experiences that I have had which no one else could fabricate even in their wildest dreams. There was a character from my past working life who had no means of transport except the use of an abandoned bike. You could always hear this transport approaching on the asphalt bearing my friend before you could see the bike, because the dazzling entrepreneur lacked the rubber tyres for the wheels but rode the bike anyway. With no chain guard to hand, a hospital staff locker door had been tied to the side of the bike to protect the rider. Various found objects swung off the handlebars to carry pipe tobacco and matches one memorable one was an empty feminine hygiene product plastic bag. The carriers changed depending on their durability, likely adaptation to the task, and outright style. The apple box tied to the back completed the picture. The fascinating thing is that no attempt was ever made to offer the rubber tyres and maybe this would have created an investment in the bike by staff that would have been unwelcome, because without the tyres no one cared about the ownership of the bike but if it had been refurbished some boundaries, or even rules around its use, would have followed which would have shifted the ownership from entrepreneur to staff member- more than likely to the Charge Nurse. 
Having begun an arts studio for Mental Health Consumers called Artsenta in 1991, I began to feel the need to be with nurses and find out more about what nurses experience of creativity in their practice. I devised a plan to begin the "Heather Martin Express School of Art for Nurses" (2002) and then realised that I was in fact seeking my own understanding of myself as a nurse artist within the mental health field. This is where this study begins. 


\section{The Nurse Artist as Researcher: Demonstration of Credentials in a Literary Psychogeography Style}

\section{Self as Artist?}

My first sense of personal creativity - of texture, colour and shape was fused with the generosity of spirit and love given by my namesake Grandmother Edwyna. Her house was at the end of a short drive on the farm where I lived. I sought her out each day sometimes staying until sunset. She had a hall cupboard, which contained treasures, which were kept there especially for me, guarded by lion door handles. Books new scented with thick rough paper and glossy covers, special scissors and crayons from her pen pal in America in a tiered box with a pencil sharpener built into the back. Cutouts and colour in books of an infinite variety and unlimited amount. Nana Martin style omelettes and bacon, homemade milk powder lollies in lunch paper wraps.

All of these memories are of the years before five because at that time my parents moved into town. I don't remember spending so much time with her after that but it was a formative experience of a sense of the generosity that one person can have for another, a delight in abundance of art materials that trigger the desire to be involved in things creative. Later, I would come to understand how powerful a figure in my creative life this Grandmother had been and how close to my senses she has stayed.

I didn't have a 'life as an artist' or anything like it, until I was challenged by a disability. I had nursed for only two years past my registration with a sense of having 'made it' to my chosen career when one day it slipped through my fingers. I was diagnosed with a spinal deformity called spondylolisthesis and sent home with an orthotics appointment to be fitted with a body brace. I couldn't get through a half hour with out being gripped with sciatica, a white hot pain that seared down the back of my legs and rendered me incapable of movement and speech until it passed. That 
was the end of my nursing I believed, and so at 23 years of age I searched for a new beginning.

I moved cities and became very despondent and miserable, I felt useless. My sister suggested an art class at the local college as I was really lost, and so art was more like an activity than a true direction. My search was really in desperation and I tried to hide my nervousness in fronting up at school again as an adult student of the art department. The teacher asked me what I did and I said nothing really. I was sent home to make something - anything, and bring it back the next day.

In the depths of that night I agonized over the blank page. I don't recall specifically asking anyone for help but I do remember calling on help for my dejected and lonely situation and my need to produce something. Finally with an eerie feeling of disassociation from my arm, from about the elbow down... I began to draw my own face from a mirror propped up in front of me. There I felt my grandmother's presence as I had when I was a child. She was at my elbow infusing my arm with a before unused ability. She said nothing but I could feel her strength and love for me in my need and she 'drew the lines' where my courage and self-belief failed me.

I was exhausted and jubilant the next day as I displayed these powerful line drawings of my likeness to the teacher. 'Just keep going' he said, make anything you can... make anything you want and with that my art folder was born and I produced material that, when sent in photographic form to the Dunedin Polytechnic School of Fine Art, allowed me a place in the School of Fine Art which I took in 1983.

In 1985 I graduated with a Diploma in Fine arts majoring in sculpture and was approached by the Arts Access sector of the Queen Elizabeth II Arts Council of New Zealand to undertake an Artist-in-Residency in Seddon Memorial Hospital in Gore. It was one of the first hospitals hit by the push to centralize surgical services to the cities, and an arts solution was sought to highlight the presence and benefits of the hospital in the community. This was the first time that Arts Access had been able to place an artist within a public hospital in New Zealand, and it was thought that I 
would survive the experience as an artist from my previous experience and knowledge as a nurse, thus overcoming difficulties and risks of installing a layperson in a clinical area.

This was a successful partnership venture and I was again employed by the QEII Arts Council to undertake a residency at a large rural mental health Institution called Lake Alice Hospital. It was for a six-week period and I was to live in at the Nurses Home. Nothing in my life except my love of people from all walks of life, could have prepared me for what I saw and experienced in that time. I was made to access my own conscience to the plight of the mental health consumer in New Zealand society and, more than that, to people living in inhumane conditions in rundown and condemnable buildings with custodial care at best, and brute force at worst. I felt as an artist hugely challenged by what I saw and as a Nurse I was politically activated and lost faith and trust in the 'system' to provide for people in a way that I had taken for granted. I had taken "To Do No harm" to heart and here was a place of supposed care where harm was all around. Certainly my exposure as a nurse to peoples' misery perpetuated by the Institution, had been sheltered and limited up to this point.

After completing this residency, I found that I was fit enough to return to clinical practice in the Ear Nose and Throat ward at Dunedin Hospital. Employed as a Staff Nurse I was noticed by the Head of Department for Inservice Education and Orientation for Nursing Staff and became a staff Nurse with that team and eventually Charge Nurse of Orientation.

I became a committee member of a group called the Creative Arts Trust, which provided access to the arts within Cherry Farm Hospital, a rural mental health facility. In 1989 I eventually became the Arts Manager of the Creative Arts Trust on site at an abandoned Villa within the hospital complex called Villa A.

My job was to provide opportunities for access to the arts for the hospital clients, who numbered some 1200. The Hospital was in the process of being deinstitutionalised and where the focus had been arts access, it changed to being an 
arts solution for the problems that were envisioned from the slow death of the site, and removal of its residents over a two-year period.

I enacted a performance piece involving the last 200 people on the last day of the hospital's official life before it was closed in 1991. In the process of consumers moving into town, the Creative Arts Trust also opened a city-based workshop that I also managed, providing access to, and opportunity for, mental health consumers in the visual and performing arts. I was responsible for the development and commissioning of this project. This Studio called Artsenta has had four moves since its beginnings and now occupies space in the central business district of Dunedin City with dedicated workshop and exhibition space for some 400 participants annually.

After a ten year period as Manager, then Creative Director, for this growing enterprise I left to return to my home town of Whakatane (place name). I was immediately engaged to carry out a three-month artist in residency for the acute and long-term inpatient areas of mental health services in Rotorua (place name). Following this successful project I was employed by this service as Arts Consultant and facilitated programmes that addressed the creative and developmental needs of a large vibrant and busy community-based mental health service.

My personal artistic endeavours have now expanded to include painting in oils and acrylics on canvas. Where I had created art as a community enterprise I am now considering the journey of the nurse/artist and am working towards a solo exhibition.

I came back to nursing; I also came back to back with nursing.

Nurses stay away from the nursing profession in New Zealand because of low wages compared to overseas opportunities and, lately, an increase in the litigiousness of the environment. When I first started nursing and for some ten years after that, the catchcry of many women who pursued other life paths such as motherhood or private business, is their desire to one day "go back to nursing". It is seen as a stalwart friend 
and a good vocational standby to reinvest in one's practising certificate and again enter the profession. It is interesting to me to realize that despite not consciously identifying as a nurse when I went to art school I never let my registration lapse in all those years 1983-2000. In a sense it was not back to nursing but that I had been in a stance of back to back with nursing.

\section{Back to Back With Nursing}

The establishment of the artist role within me allowed a process of observation of what nurses were doing in practice. I was in a health environment in another guise as artist but with my nurse present. I could quite dispassionately look, dissect and analyse critical areas of nursing expertise that, from the perspective of an artist, were either making or breaking the patient who was the focus of the nurse's attention. I was in this position of observer, from my first artist-in-residency job in 1986 at Seddon Memorial Hospital in Gore, and I believe I still carry this enhanced and extended ability to view nurse practice from a place which is other than purely nurse or purely artist.

I gained this valuable experience as an artist-in-residence in hospitals and then as an arts director of a non-governmental organization. This service was set up to deliver a participant directed programme to consumers of mental health services. I believe I was able to move ever increasingly closer in understanding and opinion of what the day-to-day experience of a person who suffers severe and enduring mental illness is, as I was in very close contact and communication with the people who both attended the programme, and were recipients of mental health system care. I was able to articulate this negative effect of the health care system, via provision of an arts programme that clients quite clearly stated had become their antidote to the health care system. The more I did this, the closer I was able to stand with people whose illnesses were prolonged, or caused by people or systems. I became someone who was able to articulate the rights of people with an experience of severe and enduring mental illness, despite not having experienced this myself. I was respected enough by 
people to speak for them, and I was encouraged and supported to do so within and arts and mental health contexts.

It was not a matter of anyone confiding in me. It was always known that I had no personal experience of mental illness myself (or that I had never come out as a consumer) I would never pretend that. I consider that such an action would be the ultimate betrayal. I could however be physically and psychically close, and look without causing shame or offence, to not avert my eyes or have the other person shy from me. I had reached a place where I could simply be there in acceptance of me. A place a nurse is never permitted to sit. 

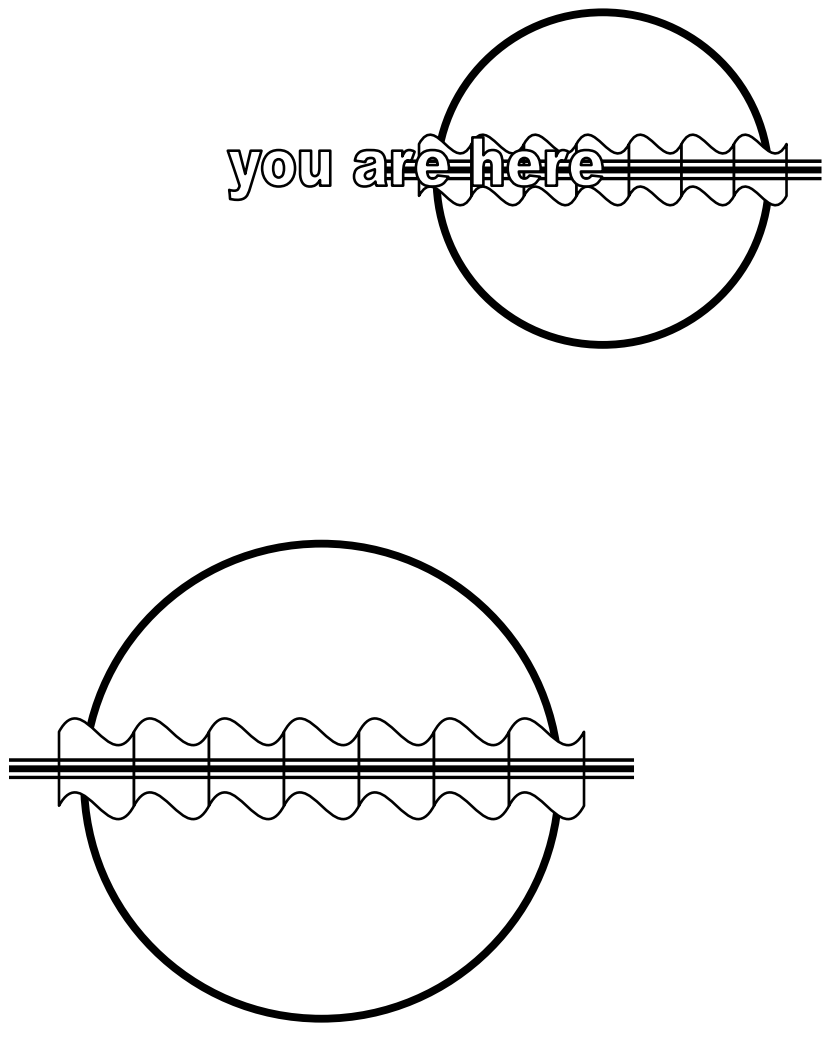


\section{CHAPTER ONE}

\section{Mapping Identity and Environment}

\section{Literary Psychogeography}

\section{The Outside and Inside of Narrative Psychogeographical Positions}

The beginning paragraphs of this chapter are in the manner of numbered theses in "The Society of the Spectacle" by Guy Debord (originally published in France in 1967).

1.

Psychogeography is a method of studying environment. The external environment that I encounter as a human being in the world, and the internal environment that I encounter as a human being with behaviour driven by an inner world of emotions.

Psychogeography is subjective geography, the art that endeavours to record the influence of the outer environment upon the human mind, as well as reciprocally, world view, the phenomenal creative mental emotional process of meaningful association in memory to locale and environment

$$
\text { (Agassi, n.d., (C) 2001-2005, p.6). }
$$

Literary psychogeography is the study of the environment based on textual sources. It is described as "the authorship of setting" (Agassi, n.d., (C) 2001-2005) p.8.).

The progression of psychogeographical research is usually, but not exclusively, from the dérive, to the practice of psychogeography by mental mapping or the production of mood-based maps, to détournement. "To dérive then, is to rediscover an existential relationship with place. To analyse this subjective relationship is to practice psychogeography. To distort - and therefore subvert the attributes of the 
spectacle (or mental health field environment) itself was to détourne" (Hussey, 2001, p.2).

In this chapter I intend to introduce Psychogeography as research method that enabled me to be author of my own nurse artist chronological past, as I perceived it when beginning this research. Then, to demonstrate the use of Literary Psychogeography as the specific data gathering method, which allowed levels of introspection that were not simply limited to chronology and historicism. This located a written record of my evolving historical and spatial experience of the setting that is the mental health field environment; into prose, poetry, paintings and narrative which the reader of the thesis, is then free to access.

I will discuss the theory of the dérive, which is one of the basic Situationist practices in psychogeography. My discussion of the dérive will explain the use of this technique, literally meaning 'drifting', in playful-constructive behaviour and awareness of psychogeographical effects observed in the mental health field environment (Debord, 1958). This discussion will be accompanied by vignettes from my practice as a means of allowing the reader intermittent access to the environment of study.

I will illustrate to the reader the various types of mood-based maps that can be created, and will make comparison between cartography, conceptual and cognitive maps. This section of writing features a cognitive map of the mental health field environment of a studied major city in the psychogeographic style, as a guide for the edification of the reader.

I will describe Détournement, literally meaning 'to turn around'. Détournement is defined as "short for détournement of pre-existing aesthetic elements. The integration of past artistic productions into a superior construction of a milieu" (Internationale Situationniste, \#1 June 1958). This description will also be accompanied by vignettes from my practice as a further means of allowing the reader intermittent access to the environment of study. 
Finally I will show that psychogeography, as the basis for literary psychogeography, allows progression to textual forms which record a more dynamic range of experience of the nurse artist, than perhaps is afforded solely by mood-based maps per se. Literature is taken in its widest possible sense it is "any writing that manages to capture the influence of a particular part of the city or landscape on the human mind, or a person's projection of inner feelings or moods on to the outer environment" (Tijen, n.d., p.2). Textual sources mentioned by Tijen can include, poetry, fiction, journalistic writing, plays, novels, songs and films. "Any fragments or passages that capture psychogeographic moments in descriptive texts" (Tijen, n.d., p.2). For the purposes of this research I have also chosen to include works of visual art as another form of text.

2.

\section{Psychogeography}

"Psychogeography was developed as a critique of urbanism by the Lettrist International and then by Situationist International in the late fifties. Today it is pursued by artists, radical thinkers and, on an academic level, geography researchers." ("What is,". n.d.).

A definition of psychogeography is identified in the published articles of the Paris based revolutionary group Internationale Situationniste from the $1^{\text {st }}$ June 1958 and is described thus, "The study of the specific effects of the geographical environment (whether consciously organised or not) on the emotions or behaviour of the individual” (Internationale Situationniste, \#1 June 1958).

A more precise definition of the concept of psychogeography was later developed. It too was published in the Internationale Situationniste: "The search for the exact laws and effects connected with the influence of geographical surroundings, whether or not arranged consciously, on the instinctive behaviour of individuals"(Shaw \& Tijen, 1991, p.5). 
3.

\section{Dérive}

A list of definitions, printed in the Internationale Situationniste \#1 on the $1^{\text {st }}$ June 1958, which was the central bulletin published by the sections of the Situationist International and edited by Debord (translated by K. Knabb), describes dérive as "An experimental mode of behaviour linked to the conditions of urban society: a technique for hastily passing through varied environments" (Internationale Situationniste, \#1 June 1958).

4.

As a nurse artist, I have adopted this method as a means to analyse the mental health field environment for the purpose of this research. The use of psychogeography is a means to reflect on the environment of nursing/practice in nursing/nursing as an environment that creates a new field of dialogue and insight for the Nurse Artist (and Client). The dérive as playful creation with critical notice shifts the locus of control back to the observer by allowing fresh in/sight of the mental health field environment.

This experimental mode of research behaviour is linked to conditions of the urban society healthcare delivery system. Nurses in mental health settings have been portrayed as saint-like or brutal. The graphic images of two quotes from the same author (Helm, 2004) exemplify this split:

The first time I was bathed after the barbarity of seclusion a young, dark-haired endorsed nurse (one step above a nurse-aid) gently washed my hair, touching my scalp with delicate massaging fingers. The simple experience of that act of caring was immensely powerful, as human touch had been denied me. I lay in the bathtub as I looked up at her I felt I was in the presence of a different kind of human being all together. She was an angel, and goodness was in existence in the world

and,

The practice of the day meant she had been given initial sedation of 
paraldehyde, which left her struggling like a wounded animal to even pick up her body from the cold lino floor. Heavy brown brogue shoes offat-calved charge nurses periodically pushed food in plastic bowls towards her. No one spoke, no one told her where she was, and the only touch given to her was the prizing open of the jaw to pour the thick brown anti-psychotic syrup down the throat

The overwhelming implication that springs from these quotes, is that when I begin as a nurse in this environment I might still have an intact humanity and regard for my fellow human being, as I progress in length of service or seniority in this environment, this humanity is lost to me and is replaced by monster-like characteristics. In my judgement, the socially acquired, embodied systems of dispositions and or predispositions which enable collusion by nurses within the healthcare system, of which they are members, are an 'ontological complicity' between embodied history and objectified history in institutional roles. These saint/monster roles are complicit in maintaining the discriminatory producing views of mental illness as being based in either biological disease or psychological dysfunction. Furthermore they actively promote discrimination against people with experience of mental illness. In all of these effects, the nurse who engages in some activity of psychogeography, becomes aware and able to recognise and resist flawed practice. More importantly the nurse possesses the opportunity, through détournement of these existing elements of practice, to create a superior and health giving exchange between herself and the client.

5.

Situationists used one main method of study of the urban geography - the dérive. They believed that:

in our everyday lives, we tend to become unaware of the effects that the city has upon us. These effects need to be exposed and carefully detailed to form a basis for resistance; for forming a new way of living in cities

(Ungar, 2002, p.1). 
The Situationists of the 1950s found it possible to use this method to become aware of the conscious and unconscious laws and effects of the geographical surroundings on people who lived in the city. I propose that using this method it might also be possible to become aware of the effects of the mental health field environment on myself, as a nurse, and others who are subjects of treatment within this environment. "From a dérive point of view cities [mental health field environments] have psychogeographical contours, with constant currents, fixed points and vortices that strongly discourage entry into or exit from certain zones" (Debord, 1958, p.1.)

This description of being drawn or repelled by the attractions of the environment and the encounters I may find there is an important match with my presence as a nurse artist in the mental health field environment. "The dérive also includes a letting-go and its necessary contradiction: the domination of psychogeographical variations by the knowledge and calculation of their possibilities" (Debord, 1958, p.1.).

6.

Another example in practice is the general view that might be held as a nurse within an institution, that all is right and good by virtue of the provision of a service which specifically supports people with an experience of mental illness. The ability to continue to perceive this environment as separate from my being begins to fade over time. It begins to become an extension of my ability to practice, and then an extension of myself. The power that I have as a key-holding staff member, to manipulate the environment, enter or exit at will, and to deny this power to a person who is a patient or visitor is absolute. Being repelled by the male patient toilet and shower facilities or drawn to the areas of the building that give comfort such as the staff-only coffee making area and seminar room creates a 'them and us' culture, which is equally mirrored in community residential facilities and in the social psyche. We might judge a patient who is similarly drawn to these staff-only areas of comfort as being 'nosey' or 'attention seeking'. So that I might accurately perceive my own practice within this environment, and the practice of others, I must adopt a position of letting go and concurrent critical notice. Through this Otherness of critical spatial awareness, I can begin to seek, and create change. 
7.

Knowledge and calculation of the possibilities of the setting arise as an external and internal response to my exposure to the setting. Part of the derive's purpose is in allowing me to drift from my usual activity (habitual activity) and to become more aware of my surroundings. Simultaneously I will seek out ways of changing my surroundings. In engaging in dérive I actively attempt to disrupt existing representations and convey different visions of the mental health field environment. "Not as an entirely new product but as an integration of past or present artistic production into a superior environmental construction" (Ungar, 2002, p.2). Fragments of existing works, in the literary form that is text, are "taken and rearranged or juxtaposed to produce new meanings" (Ungar, 2002, p.2)

In this mental health field environment, habitual influences, and stigmatising, and harmful effects, provide a basis for disruption and resistance and creation of social change that holds the belief that people with mental illness can get better.

As Debord says: "The objective passional domain of the dérive must be defined in accordance both with its own logic and with its relations with social morphology"...or another example he gives: "an urban neighbourhood determined not only by geographical and economic factors, but also by the image that the inhabitants and those of other neighbourhoods have of it" (Debord, 1958, p.1.).

Interestingly, Debord rejects the natural association that people may make between drifting and chance. Chance has the propensity to create something that is merely a new trend and thereby reducing the psychogeographical observations to those things that we notice, only seen through habit. It can also limit what happens, to alternation between reduced numbers of variables. Debord imparts that progress is made in psychogeographical observation where we are able to break through the hold that chance may have upon our attentions. There is more to be gained in creating conditions favourable to my purpose as a researcher when I can reject the very first 
geographical attractions, which I may naturally create into habitual axes (Debord, 1958, pp.1-2.).

The mental health environment, by definition, has a diverse and polarising set of geographical attractions. It would be too easy to constantly be drawn to, or repelled by the things that are inherently attractive or repugnant, such as laughter in the nurses station, or crying and banging from seclusion rooms.

7.

Another example of habitual notice would be the tendency I may have as a staff member to associate all dérive beginnings with the turn of the key to open and all dérive endings with the turn of the key to close. I may consider that the dérive that is initiated by the turning key is legitimate, however I am apt to begin to only observe the psychogeographical elements in association with the key and not in association with other fixed points or vortices. The observation of 'using the key' once may have been seen as directed by chance, but it then becomes embedded in my habitual tendencies preventing me from accurate observation of my passage through the setting.

Debord's (1958) insight in the matter of "this letting-go and necessary contradiction" (p.1) is critical in the mental health field environment as it points to the way in which we remove the creative 'playful-constructive behaviour', true-nature of chance, from our own and other people's lives by reducing it to habit. Once habitual, these are the things that we are aware of and all else goes unnoticed.

The conditions that are favourable to my purpose are those settings rich in natural elements of chance. Debord thus preferred the city to the countryside as he saw the potential for capitalist driven transformation of living spaces to be the richest centres of possibilities and meanings. Therefore environments of community residential housing and hospital or institutional environments provide a rich source of material for me as a dériver. 
Some of the techniques of the dérive that are suggested I have used directly and others I have adapted. It is possible to dérive alone but Debord suggests the fruitfulness of several small groups of two to three people who have reached this similar level of awareness. Crosschecking of impressions can then take place. The composition of the groups should change from one dérive to the next. Ten or twelve people would be the maximum. I was interested in this description as it closely aligns with groups of mental health support staff members that are allocated to shifts across the day and rostering produces the desired effect of changing group composition.

The average duration of a dérive is one day between sleeps, although taking time out to attend to activities of daily living (to use a nursing term) is considered unavoidable. The last hours of the night, or when a person is fatigued, are considered undesirable times to dérive. Dérives can last for moments, or days and it can be difficult to distinguish between dérives unless an interruption of a particular type occurs such as taking a car ride to relocate between sites. In the situation of a series of dérives' it becomes almost impossible to differentiate the state of mind peculiar to one dérive and the next. Prolonged rain is a significant factor in influencing dérives, although storms or other types of precipitation are considered favourable. Snow produces an interesting effect on dériving in South Island New Zealand settings.

The goal of the dérive is to either study a terrain or emotionally disorientate oneself. These two aspects, however, are considered to overlap in so many ways it becomes difficult to distinguish either one of them in its pure state. If I was to particularly study a chosen terrain however, this research is then considered to be primarily about psychogeographical urbanism. In the case of the mental health field environment I am studying a particular terrain and I wonder if the term psychogeographical mental [health] consumerism might be applicable.

In every case the spatial field depends on the point of departure and although one can dérive to the extent of the size of a city it is also possible to dérive in a small selfcontained area. "The exploration of this fixed spatial field entails establishing bases and calculating directions of penetration" (Debord, 1958, p.3.). 
The final technique of the dérive is the "possible rendezvous". Here I am released from the usual burdens of showing up at a particular time and place to meet a particular person although a particular person may arrange a "possible rendezvous". It is assumed that somewhere, somehow, I will meet a person whose identity I have no way of knowing. Because I have been relieved of the usual pressure to know or recognise this person, I am more likely therefore to speak casually to passers-by. I may meet no one or I may meet by chance the person who has arranged the "possible rendezvous".

8.

It is worthwhile at this point to recount a "possible rendezvous" experience I had in 2003 where I went from New Zealand to Madrid in Spain, as a first time international traveller to a "possible rendezvous" with my thesis supervisor. Not knowing features of the city we arranged to meet at a chocolate shop recommended in a New Zealand bought travel guide. I did not know how to use the Metro so I dérived across the city asking directions from passer-by to passer-by with very little Castillan, attempting to walk closer to a tall building, that in the backstreets I could no longer see. I emerged at a central location, then asking the newsagent who gave me wrong directions and I was late. I entered a deserted street with boarded-up shops to see a lone figure at the opposite end of the street. We approached each other and it was she, my "possible rendezvous" at a place where we had not arranged to meet

As Debord (1956) observes "one can see the virtually unlimited resources of this pastime" (p.3). I am also very aware of the similarity I have in possible rendezvous in the mental health field environment. The approach Debord describes has the manner of unconditional positive regard (Rogers, 1961) understood and used as a nursing term. This respectful attribute of a mental health worker is very important and noticeable in practice when it is not present. I have been at work when a name of a prospective person for admission is mentioned, and everyone in the office groans. 
What must it feel like to arrive in an environment to be cared for when it is apparent that you are not wanted? I value the opportunity to meet with another human being in this setting, the "unexpected turn" of mental disorder or circumstance that brings a person on a path that intersects with mine. I hold a place in my practice as a nurse artist for the "possible rendezvous".

9.

Maps may be cartographic, conceptual or cognitive. I will describe below the use of maps by the Situationists and their essential differences and similarities. This is an interesting point of study as Debord says "ordinary, ecological and psychogeographical" (Debord, 1958, p.3.) maps can then be utilized along with the détourned (see following description ) counterparts, which are maps that are made as superior constructions of the originals with elements of the originals remaining.

Psychogeography was proposed as a means of investigating the effects the city has upon us. With some basic recommendations for beginning, such as time of day and weather, original and unique responses and actions were created. Considered to be a form of cognitive mapping these effects that we may be unaware of, can be elucidated and used in the context of social change:

the sudden change of ambience in a street within the space of a few metres; the evident division of the city into zones of distinct psychic atmospheres; the path of least resistance which is automatically followed in aimless strolls (and which has no relation to the physical contour of the ground); the appealing or repelling character of certain places

(Debord as cited in Ungar, 2002, p.2).

Where conceptual maps may have lines that represent the relations between boxes and circles, psychogeographically connected sites were represented more by flowing shaped arrows creating indications of the psychogeographical effects noticed, such as vortices or exclusions. 
Conceptual maps are artefacts for organising and representing knowledge. Their origin lies in the theories about psychology by David Ausubel enunciated in the 1960 's. Their objective is to represent relations between concepts in the form of propositions. Concepts are included within boxes or circles whereas the relations between them are explicated by means of lines connecting their respective boxes. The lines, in turn, have associated words describing the nature of the relation that links the concepts

(Dürsteler, 2004)

While conceptual mapping has some elements in common with psychogeography, cognitive mapping is more closely aligned to psychogeography in that not only the nature of the relationship between sites is defined but also their attributes.

The connection between cognitive mapping as it is described below and psychogeography as a form of cognitive mapping, is the decoding of information about the relative locations and attributes of phenomena in their everyday spatial environment. The similarity between psychogeography and cognitive mapping, is that drift and awareness are the key principles as opposed to acquiring and storage of information. Also that recall and decoding of information represented by the conceptual map, does not have the social justice developmental edge that the Situationists had, in the exposure of these effects and careful detailing of them to form a basis for resistance (Ungar, 2002).

Cognitive mapping may be defined as a process composed of a series of psychological transformations by which an individual acquires, codes, stores, recalls, and decodes information about the relative locations and attributes of phenomena in their everyday spatial environment

(“Intraspec.ca", 2005)

10.

Prior to this study, my exposure to the geographical/spatial effects of the hospital and community health services was based on personal experience, consumer experience 
through personal conversations, being witness to events, and government opinion expressed in legislation. It could be said that I was using a 'conventional' map that conveyed a kind of truth about the mental health field environment. Psychogeographical mapping, as cognitive map, conveys a "social, experiential or existential truth" (Ungar, 2002, p.2) that may reveal the forces that are at work in this setting.

Cognitive mapping is ideally suited for study of the mental health field environment. It allows me to create an impression of the physical and historical context of this setting that are the usual phenomenological viewpoints for interpretation. Alongside these viewpoints I will also consider the spatial context where the mental health field environment, containing people and things is a construction of social "structural determinacy" (Bourdieu as cited in Scahill , n.d., p.3)

(The thesis as cognitive map is represented on page 20.)

Historical and structural viewpoints provide a double methodological concern. At times this thesis is concerned with history as is recorded in text, and/or social structural determinacy as recorded in text and at times they cross paths (Marin, 1984). At other points in the thesis map, the three devices of literary psychogeography, texts as data, and creative art in the mental health field environment, provide layering of observation and zones of distinct psychic atmosphere, and appealing or repelling narrative.

11.

\section{Détournement}

The Détournment of elements, no matter where they are taken from can contribute to the generation of new combinations. Debord discusses the discoveries of modern poetry in the late 1950s (regarding the analogical structure of images), which demonstrate that "when two objects are brought together, no matter how far apart their original contexts may be, a relationship is always formed". 
Debord does not feel it is necessary however, to restrict oneself to the use of words as a convention of the practice of détournement, that more than words " the mutual interference of two worlds of feeling, or the bringing together of two independent expressions, supersedes the original elements and produces a synthetic organization of greater efficacy. Anything can be used" (Debord, n.d., p.1).

Debord defines the two main categories of détournement as minor détournements and deceptive détournement:

Minor détournement is the detournement of an element which has no importance in itself and which thus draws all its meaning from the new context in which it is placed. For example a press clipping, a neutral phrase, a commonplace photograph...

Deceptive détournement, also termed premonitory proposition détournement, is in contrast the détournement of an intrinsically significant element, which derives a different scope from the new context

(Debord, n.d. p.2).

12.

As an example of the deceptive type, I replaced the roman numerals that denote the fourth edition of the American Psychiatric Association Diagnostic and Statistical Manual of Mental Disorders, the DSM IV with the date 9/11 which has become a journalistic reference to the act of the destruction of the Twin Towers in New York City in 2001 .

DSM 9/11 then, becomes a détourned element that brings together two separate elements leading to a new scope. The effectiveness of this type of détournement is greater when the source of the original con/text is able to be recognised. The new element then is the significance of American influences in foreign countries, namely psychiatry in New Zealand and the politics of the war in Iraq, and the volatile outcome of both. (Debord, n.d., p.1). Extended works of detournement will be composed of one or more sequences of deceptive and minor détournement. 
An example of détournement in the mental health field environment would be the notice boards in locked hospital environments which display New Zealand Health and Disability Commission Patients Rights and Responsibilities posters (humanitarian) beside the ward-generated rules of the ward (domestic), pages of drug information (code of belief) and various other hospital pamphlets (usually not relating to mental health circumstances). These are détourned with graffiti, stickers, artwork and pen marks by clients of the ward, into new elements.

Another example of détournement was the closure ceremony of Cherry Farm Hospital in 1991 that I directed as a performance art piece. Approximately two hundred people who left there on the last day gathered in a huge circle and were given a brown paper bag each. I invited people to yell all of their "dread/ful stuff" associated with this place into their bag. They then crumpled them up and posted them into the top of a large sculptural three-dimensional hollow peace sign that was lit. Music "peace in the city, peace in the valley" played whilst the paper burnt away as a form of cleansing. People then gravitated to flags representing the buildings that they had the most feeling for and association with, and taking the flag and whitewash with them, these groups went and painted peace-signs as symbols of closure, on windows and doors of the locked villas and support buildings - dining room, garage, workshop, physiotherapy department.

13.

Laws, according to Debord on the use of détournement, can suggest the activity that will elicit the most impact.

- "It is the most détourned element which contributes most sharply to the overall impression, and not the elements that directly determine the nature of this impression" (Debord, n.d., p.3)

- "The distortions introduced in the détourned elements must be as simplified as possible, since the main force of a détournement is directly related to the conscious or vague recollection of the original contexts of the elements" (Debord, n.d., p.3) 
- "Détournement by simple reversal is always the most direct and the least effective" (Debord, n.d., p.3)

The first law is essential and applies universally, the other three are only practically applicable to deceptive détourned elements. Other forms of détournement relating to titles of works, architecture, cinema, urban society, paintings, metagraphic writing and restoration of museum paintings are all suggested as fertile areas for détourned elements.

15.

Two other forms deserve special mention, the first called ultradétournement. This is the détournement of gestures and words and meanings in everyday social life. It is so close to the notion of the construction of mental illness, and the search for mental health through the exhibition of acceptable behaviours judged by health professions as being normal or abnormal. If the individual is not able to exhibit normalized socially acceptable matched social behaviours they are judged against the DSM IV Diagnostic and Statistical Manual of Mental Disorders published by the American Psychiatric Association, as previously mentioned. An example of this in my practice was the placing of flowers and small decorative lemons on a nurse's station desk each morning, as a means of bringing some colour and softness to a symbol of power. What I didn't know was that there was a client inpatient at the time that had also done the same thing in times past. When I was not observed as the placer of these objects it was assumed to be behaviour of a sick person. A sign of the presence of a mood disorder, such as mania. When I was seen, and it was realised that I, as a senior member of the management staff, was placing the objects, the notion of illness and behaviour was challenged. What happened next was that I was accommodated into the habitual institutionalised view and labelled 'a little bit mad' as a joke. Rather than the patient being seen as a 'little bit more normal'.

The second form, which is also very closely related to mental health industry is outside of language, and involves the possibility of using the same methods to 
détourn clothing with all its strong emotional connections. "Here the notion of disguise is closely linked to play" (Debord, n.d., p.5).

In many situations the element of clothing that contributes to diagnosis is not associated with mental illness but with poverty. Some people have to dress 'normally' to be able to get leave from locked wards. This ability to 'dress-up to get out' could be taught as a skill to those people with an experience of severe and enduring mental illness and resultant poverty. I have heard of a scheme where office workers donate used business suits to people who are unemployed to attend interviews. This is an example of a détournement. One could conceivably 'play at and wear the disguise of' the normal to escape diagnosis. This begs the question of how many people who are completely mad are disguised as normal? And how many people who are normal are disguised as mad? What sort of disguise do we dress people in when we give them a diagnosis? I would suggest the disguise that has the most effect is to arrive at the mental health services wearing pyjamas and handcuffs.

16.

Debord (n.d.) reaches the apex of détournement in the suggestion of "the ultimate goal of all our [Situationist] activity" (p.5) which is to construct situations, to open to everyone the opportunity to détourne entire situations by deliberately changing this or that determinant condition of them. This is where I see the ultimate applicability of this method in the mental health field environment rests in terms of its ability to contribute to nurse practice. Everyone should look for the possibilities and conditions of a determined situation discovered by dérive and thus having noticed the elements, seek to change them in a manner that causes resistance to environments and behaviours that prolong or cause mental illness.

For example as a nurse artist, I am aware of the 'closed' nature of the hospital environment contributed to by society, which supports the segregation of people who are considered to not behave 'normally'. These are held beliefs of stigma and discrimination against people with experience of mental illness. I considered the closed mental health service environment an entire situation that could be détourned. 
I therefore convinced my colleagues of the possibility of holding an Open Day, which celebrated this environment and literally reversed the closed view by providing welcomed access. The opening was in the form of a mini festival and invited the public to come and see the buildings and a representation of the service for themselves. Whilst there wasn't a great influx of people on the day, (most people spent their Saturday shopping or at sports events) the preparations made by staff to open this environment, ruptured some long held beliefs about the necessity for the veiling of this care facility from the public view. It was very interesting to present this service to about sixty or so curious members of the public and more interesting to present it in an open way to each other. The rationale given by a few unhappy staff for not having this Open Day proceed, was that patients should be kept in private and out of the view of the voyeuristic public. This idea of continuous necessary privacy when presented to the Client group was not supported. They felt that people should see the ward as it might help them in the future if something happened to them or their family. Clients said if they felt they didn't want to be seen at the time of the visit they would go for a walk.

On the day, nobody could tell the difference between patients and visitors anyway, which was another interesting dérive in terms of the branding of people with experience of mental illness as different from others. This 'branding' was a feature of populations of large hospitals and institutions of the past, and particularly in people with experience of severe and enduring mental illness. However, with the advent of deinstitutionalisation and medication that has reduced extra-pyramidal [outward] side effects such as excessive salivation or involuntary movements, 'branding' is not always born out in physical appearance or behaviour. The outcome of this détournement was that an annual Open Day event was adopted. 
17.

\section{Literary Psychogeography}

Literary psychogeography brings history to life, enabling an audience to wander freely watching, listening, and examining the influence of physical surroundings upon the instinctive behaviour of individuals as recorded in the written records left behind by a people or an era

(Agassi, n.d.,(C) 2001-2005. p.6).

Literary psychogeography then, is a source of awareness that is generated from studying textual expressions of an age or an era. This is a method that brings a particular awareness of the effects of the institutional health services in general and particularly mental health services, upon me as a person who performs as a nurse artist in this field.

I utilize text in the form of painting, poetry, prose and personal narrative that has been generated by me as a result of direct and indirect personal experience. I utilize text that has been generated by people with an experience of mental illness, and text generated by their whanau/families, as well as texts generated by government agencies, private organisations, media sources, authors, and others who have a particular stake or interest in the mental health field environment. 


\section{CHAPTER ONE}

\section{Illustration: Thesis as Cognitive Map}

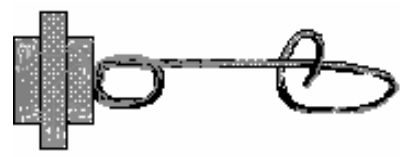

Creative

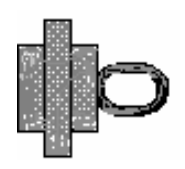

Synthesis

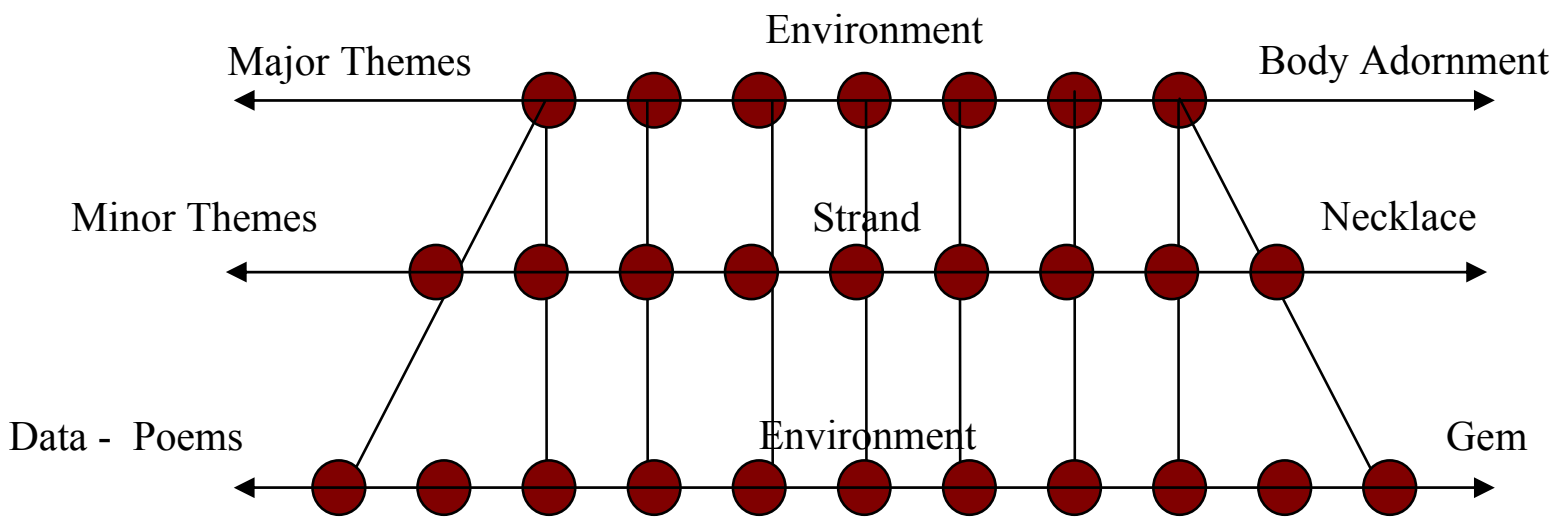

Illustration 1: Thesis as Cognitive Map 


$$
\theta^{\ominus}
$$




\section{Art Interval}

Porcelain Hospital Jug at Tarawera, 2002, oil on canvas, 300mm x 400mm 


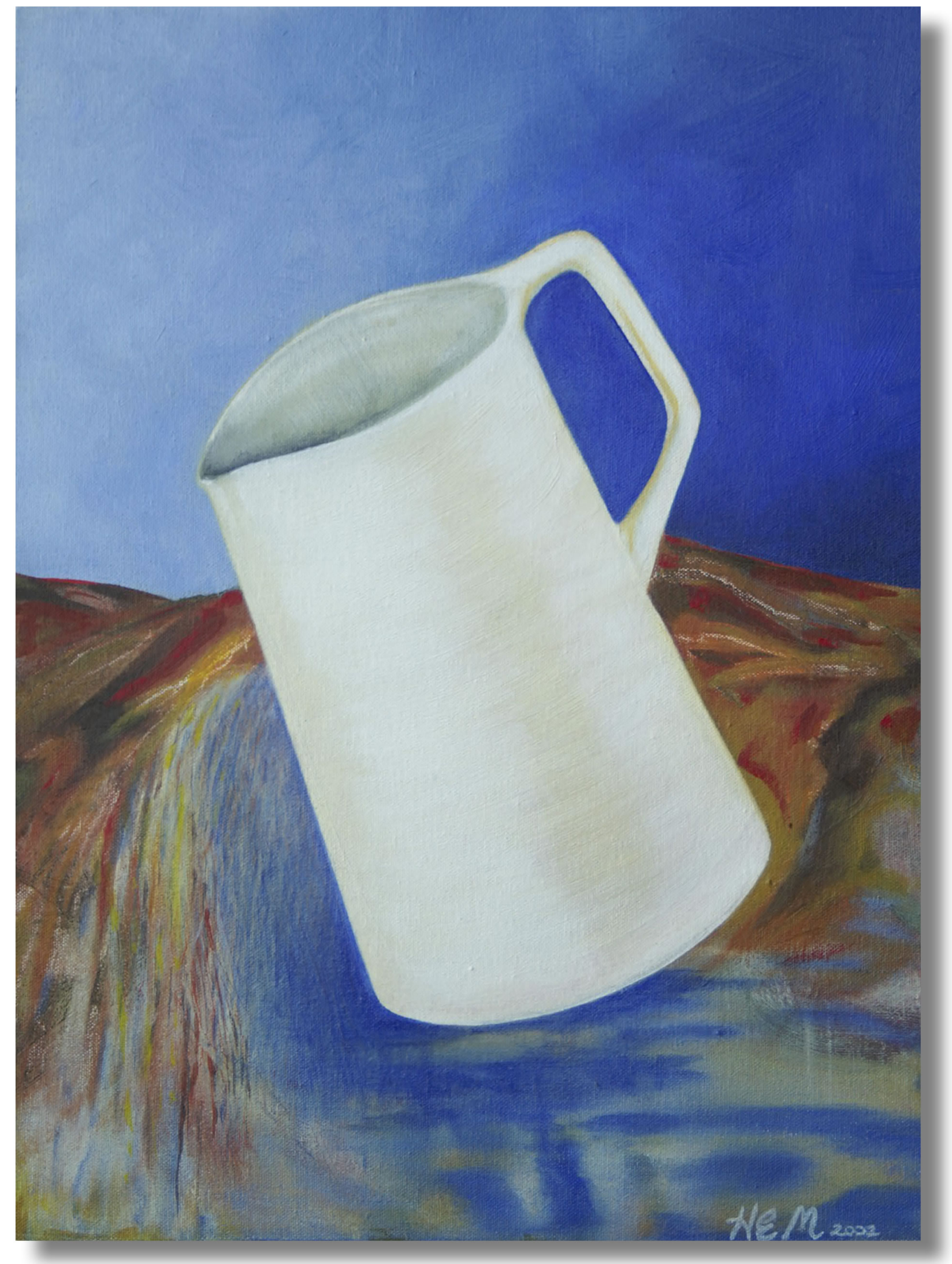




\section{CHAPTER TWO}

\section{The Mental Health Field Environment}

\section{Placement In The Consumer Domain: A Strategy of Inquiry}

My body is healed, my mind is healed, my writing flows

My body is healed, my mind is healed, my writing flows

My body is healed, my mind is healed, my writing flows

My body is healed, my mind is healed, my writing flows My body is healed, my mind is healed, my writing flows

My body is healed, my mind is healed, my writing flows

The sun sets...

My body is healed, my writing is healed, my mind flows

My body is healed, my writing is healed, my mind flows My body is healed, my writing is healed, my mind flows My body is healed, my writing is healed, my mind flows

My body is healed, my writing is healed, my mind flows

My body is healed, my writing is healed, my mind flows

(Martin, H., 2005)

What delineated area of the mental health field environment could be said to be the consumer domain?

I propose that the consumer domain is in fact a health professional domain in which the consumer is constructed in particular ways. This construction is then represented to the consumer as "this is how we (health professionals) find you (consumers) to be". The context in which the consumer who experiences severe and enduring mental illness is held within is the biomedical model, the basis of its function being in assessment, diagnosis and psychopharmacological treatment. Any attempt on the 
consumer's part to exist outside the construction of their assessment and diagnosis is re-labelled "non compliant". In order for consumers to 'get along' with health professionals who have ultimate power and control over their personal freedom, they must in turn project their constructed face. This construction of the consumer experience as domain, is then represented to consumers newly experiencing the mental health domain as patients, and also to new health professionals who are experiencing the mental health domain as practitioners. What both groups find is a construction, which they believe to be the domain of the consumer and so the edifice and the development and maintenance of it remain.

\section{Consumer Domain Dialogue - Speaking to? Or Speaking with?}

Fundamental questions need to be asked about the nature of the place I stand in relation to the consumer and in relation to the consumer domain, and the way in which I speak with, describe, and understand people with experience of mental illness. Alcoff (1991-2) follows Foucault in discussing the "rituals of speaking" as "who is speaking to whom turns out to be as important for meaning and truth as what is said; in fact what is said turns out to change according to who is speaking and who is listening" (p.12). These rituals of speech then constitute meaning in terms of the words spoken as well as the meaning of the event. Alcoff goes on to say that rituals of speaking are politically constituted by power relations of domination, exploitation, and subordination. The implication is that speakers may lose control over the meaning and truth of their utterances as the context of the person listening is partially determinant and the speaker "is not mistress"(Alcoff, 1991-2, p.15) of the situation. As a nurse I may attempt to take control over what is said in a defined situation where the rituals of speech are so extreme that, as the speaker, what I say predetermined by the power relationship, and what the person hears is fully determined by their domination.

An example of this is when I observe some clients being offered the supposed 'choice' of taking control over their own behaviour within an environment. The action takes place in a locked ward following the loss of privilege of personal freedom due to Compulsory Treatment. The client is offered the choice of oral or 
injectable medications that they violently oppose. As a result of this no win situation for the client often verbal and physical threats of violence are directed at staff and sometimes other clients. From the staff group's perspective, the client is expected to take control of their own threatening behaviour.

The client is offered the choice of the comparative freedom of the locked ward environment and oral medications or the locked seclusion environment and injectable medications dependent on their ability to comply with the request to take control of their own behaviour. The individual desire by any staff member to offer some choice to the consumer is overwhelmingly affected by the underlying threat, that if the client does not, or cannot take control, the consequence will be removal to the seclusion room. Should the client choose to not utter any assurance that the unsafe behaviour displayed will stop, their silence is further construed as expression of threatened violence and can result in the election of the more confining of environments and the more invasive of treatments.

Regardless of the national Recovery Approach and The Health and Disability Code of Consumers Rights and policy and procedures that surround and support the client's right to choose, the version of the truth, and meaning of the situation which is given more weight is firmly placed in the field of the staff member and therefore the structure of oppression is maintained.

Alcoff (1991-2) suggests that for the speaker, or staff member in this case, "a partial loss of control does not entail a complete loss of accountability" (p.16). The problem of the nurse speaking for the client as illustrated by this scenario exemplifies the concern with accountability and responsibility that this action creates. The nurse may feel compelled to speak for the client as the accountability is placed upon them by the context of the action and by law, and yet the responsibility is for the staff member to listen and allow the other person to speak. More importantly is the creation of the possibility of space for the answering back. Alcoff asserts:

we should strive to create wherever possible the conditions for dialogue and the 
practice of speaking with and to rather than speaking for others. If the dangers of speaking for others result from the possibility of misrepresentation, expanding one's own authority and privilege, and a generally imperialist speaking ritual, then speaking with and to can lessen these dangers

The most powerful task set for me is, as Spivak (1988) suggests, that the intellectual must learn that their privilege is their loss. "Unlearning" my privilege as my loss then means "working critically back through one's history, prejudices, and learned, but now seemingly instinctual, responses" (Landry \& MacLean, 1996, p.5). The intention of Spivak's words interpreted in my context, means that if it is possible to learn to discriminate against and stigmatise people with experience of mental illness, then it is possible to unlearn these behaviours. If I were to retain my assumptions, that are as deep in me as instinctual responses, then this has the potential to close down creative possibility, to create loss of options at the cost of other knowledge. To unlearn privilege means to be able to learn things that are outside of what is fed to me in my health professional position; primarily to become aware of Other knowledge than what is based purely on biomedical model clinical assessment and diagnosis. This is not simply that which I haven't yet learnt as a deficit in my nurse education but knowledge that "I am not equipped to understand by reason of my social [and professional] position" (Landry \& MacLean, 1996, p.4).

Landry and MacLean further interpret Spivak's teachings as learning to "work hard at gaining some knowledge of the others who occupy these spaces most closed to our privileged view and attempting to speak to those others in such a way that they might take us seriously and, most importantly of all, be able to answer back” (p.5).

One position might be to accept the consumer domain as an ever-filling, resourcepoor and solution-less place, and avoid any dialogue or comment since I have no personal experience of mental illness, or that I cannot speak as I am a nurse and not a patient. If I were to adopt the position of not being able to speak, because of my privileged position in the world: because I grew up in a middle class family, and I 
went on to a nursing education, and I practice as a health specialist in my field, this is only manoeuvring to excuse myself from becoming involved and doing what I need to do to reach out to others.

Spivak insists, however, that if I make it my primary task to learn what is going on in the consumer domain, through language, research and study, but also through a historical critique of my position as the investigating person, then I will have "earned the right to criticize and be heard" (Spivak, 1990b, p.62).

\section{The Dialogue of Silencing, The Dialogue of Speech}

Spivak (1990b) suggests that to criticize something which is Other is to take a certain risk. On the other hand to say I won't or can't criticize is to salve my conscience and ultimately contribute to the notion that nothing can be done to change the consumer position. It also allows me to escape the work of investigation necessary to uncover what silences me, and what silences people with experience of mental illness.

An example of this silencing in the Mental Health Field Environment was when I represented the mental health service in gaining the use of a client's artwork for a hospital project. I was aware of the dual position I was in - an employee of the institution and also attempting to represent the client's interest in having artwork acknowledged financially. Early in the project I suggested that the health professional organisation might compensate this client for the use of the work. I was later censured for attempting to manage a situation that involved a monetary sum when I did not hold the hierarchical office to do so. The matter was taken out of my hands and some food vouchers were issued to the client, a payment which was as small as possible was the most desirable outcome from the organisation's perspective.

The voice of the artist was lost in the consumer domain as he was not recognised as a craftsperson able to ask a fair price for a fair product. The outcome was that the business manager decided the value of the product. The manner in which it would be paid was also decided since we, as health professionals, display a paternalistic 
attitude to consumers' use of money. Therefore, in this instance, it was arranged that only items from a certain store were to be purchased. This displays the many layers of silencing that the person who made the art was subject to. First as an artist, secondly as a consumer and thirdly as a consumer who makes art. Are there any more that I cannot see because of my privilege?

As a nurse I am represented as the person who will de-escalate and problem solve to reduce the risks involved in the mental health field domain. As a nurse I am powerfully persuaded and legally required to do the thing that is considered to be 'most safe', as implication in the deterioration of a client's mental state would bring a charge of misconduct. As a clinician member of the group in the face of senior management I was also reduced in my power to speak my mind. As an artist, however, I felt compelled to support the fair price for creative endeavour. I too was effectively silenced.

Further uncovering of these layers shows the ways in which mental health services recognise the value of the consumer voice, in this case as artistic text, which becomes valuable to the construction of the representative voice of the health service/consumer partnership in recovery principles. Representative stories by some people with experience of mental illness are picked up and supported by health services and drug companies as the voice of Others to legitimate their position of "valuing the consumer voice". It becomes a question of what occurs in terms of representation. In terms of a representative consumer voice, is it better for the consumer group to be represented by someone able to speak for them who has experience of mental disorder, or by a radical critic of the system that causes client oppression in speaking for them.

To not speak becomes as problematic as to speak 'in the name of' which brings me to my discussion of the term subaltern.

Gayatri Spivak's essay “Can the Subaltern Speak?” poses the question about whether the subaltern woman can speak for herself. And she asks "What must the elite do to 
watch out for constructions of the subaltern?" (Spivak, 1988, p.294) Her formulations on the subaltern describe "that constituency which remains most excluded from the circuits and possible benefits of socialized capital" (Landry \& MacLean, 1996, p.5) When she claims that the subaltern cannot speak, she doesn't mean that the person cannot utter a sound to speak but that the person is prevented from speaking because the person with whom she might converse cannot hear her because of their cultural capital.

What Spivak calls for is a clear understanding of representation in its two-fold expression. First is that of "stepping into someone's place" (Spivak, 1990a, p.108).

The mental health field equivalent of this is the formal manner in which the health professional is charged with representation of the consumer. This can be as basic as acting on behalf of the patient to decide how many blankets go on their bed to prevent them from feeling cold, to formal contexts such as representation in court to argue for or against the constraints of the Mental Health Act compulsory assessment and treatment period. It also occurs in the myriad ways in which the mental health professional makes decisions for the consumer based on their belief that they are acting as if they are walking in the other person's shoes, and would prefer this or that to happen.

The second form of representation is the proxy and portrait. This is the representation by "placing there" (Spivak, 1990a, p.108). Its most recognisable form in the mental health field environment is the place of the Consumer Advisor, who is employed by the institution as a representative voice for all consumers in matters of policy and practice. Spivak (1990a) explains that in political representation "placing there" (p.108), we also include in this representation a portrait of ourselves and the institution as we set about appropriating their name and assuming solidarity with consumers which benefits the institution and not the consumer.

Consumer representation presumes that this one person speaks for and represents all consumers/patients and, in doing so, represents herself as consumer/patient. In fact in 
the mental health field environment it has become almost imperative for the consumer representative to present stories of their own patienthood as a means to authenticate the positions of representation to which the institutions have appointed them, and that they have put themselves forward for appointment to. The advisor attends the meetings and sessions that are dictated by the running of the health institution and must do so to be able to locate a forum to be a representative at. No other representation is encouraged at levels where one consumer might speak to the other consumer, as advisor to patient, as this is firmly dictated to not be the role of this particular consumer proxy. The consumer representative represents what the institution allows.

I will now proceed to discussion that considers my representation in both of these forms and to also uncover what I may perceive of representation that is made on behalf of the consumer who is placed in the consumer domain. I consider that nurse and consumer are both present/captured in this constructed domain, nurse as powerful and consumer as powerless.

\section{Narrative Positioning}

What position do I hold in the mental health field environment in carrying out a narrative study? More importantly perhaps is what contribution I can make to this community? This is a challenge as Beverley (2000) notes in learning to distinguish between "desire for solidarity and the desire for objectivity" (p.555). I seek to bring my experience to this story as an artist in solidarity with other artists and as a nurse in my desire for practice development. Beverley (2000) describes such writing as testimonial narrative or testimonio. Myself, as the narrator and also the witness of the events that I recount, tell the narrative in the first person. Very importantly I am not narrating as a re-enactment of the consumer experience in the mental health field environment, rather, "involving a problem of repression, poverty, marginality, exploitation or simply survival that is implicated in the act of the narration itself" (Beverley, 2000, p.556). 
Beverley goes on to make comparison with the 1960's-born importance that is given to oral testimony or consciousness raising. I particularly relate to Beverley's reference to the Chinese Cultural Revolution practice of "speaking bitterness" (p.556). This has a consumer parallel in 2005, in the formation of a restitution panel for people with experience of mental health services from the past and in whose care very many people have experienced trauma. It has worried me that much of my speaking in this narrative has a bitter taste which you, as the reader, may also taste.

In general Beverley tells us that "testimonio could be said to coincide with the feminist slogan 'the personal is the political"' (p.556) and this has become true for me throughout the process of this project. I also recognise that within the mental health field environment any feature of the personal that separates one from society by bestowing a diagnosis of mental illness becomes the politics of subalternity, a political struggle for the individual to exist as burdened and outcast. To exist, but also repel the construction becomes an unbearable burden. The personal is indeed the political because, as a nurse, I occupy a position of privilege and power within the group that is constructed as normal - that is the group not attributed with a diagnosed mental disorder.

Testimonio demands from the narrator that self-identity is not separate from the subaltern or class situation that I narrate. I am however, in a position to separate myself from this subaltern or consumer class both as a nurse and a student in order to write a scholarly text, and therefore I move from a "culture of primary and secondary orality to writing: from a traditional group identity to the privatised, modern identity" (Beverley, 2000, p.557) of academic nurse student.

I could describe myself as taking up two positions: my authority in the clinical field as a nurse gives me power and privilege over those referred to as patients, and the voice I use in this position is one that has the potential to misrepresent the voice of others, or to represent others as a means to misrepresent myself. An example of this is the way in which mental health professionals are extolled for their virtue in being able to 'look after those people' (sic). 
In the same relative sense as patients are to nurses, I also assume the position of the excluded, the marginal, the subaltern in relation to the biomedical model which would have female nurses as handmaidens in a masculinist medical profession carrying out the dispensing of treatment as ordered. As a nurse I am also beholden to my employer. This carries political and economic demands and relegations. As an artist in a medicalised setting it is often assumed I would, in compatibility with the medical model, take an arts therapist role. I choose however, to reject this and work as a community artist.

In this sense my voice within this narrative as a nurse artist, is not silenced or defeated despite my being subsumed by the health institution of power and privilege and may give the reader a sense of the "real, rather than fictional person" (Beverley, 2000, p.556).

Maybe this is the challenge of embracing my dual presence in the mental health field environment in that testimonio is involved in, and constructed out of, opposing terms nurse/artist, nurse/patient, community/inpatient, sane/mad, centre/margin, us/they. Testimonio does involve a new way of articulating these oppositions; it represents symbolically a relationship of solidarity between nurse and consumer. Or perhaps even a nurse as carer of a consumer, and a nurse as witness for a consumer.

As a nurse artist, I am trying to see things with an eye - but I can't ever be there. I can't speak, for those people with experience of mental illness. Yet I do speak of experiencing the mental health field as first-person witness narrator.

This chapter explores the issue of the importance of listening in its most simple elucidation, which is to pay attention, to hear a voice. Listening for something or someone is as Spivak (as cited in Beverley, 2000) shows:

That behind the gesture of the ethnographer or solidarity activist committed to the cause of the subaltern in enabling or allowing the subaltern to speak is the trace 
of the construction of another who is available to speak to us (with whom we can speak or whom we feel comfortable speaking), neutralizing thus the force of the reality of difference and antagonism to which our own relatively privileged position in the global system might give rise [or mental health worker as activist committed to anti-discrimination and consumer as subaltern].

The comparison could be made of the mental health worker committed to antidiscrimination in enabling or allowing the consumer to speak. In this event I think that the emphasis on anti-discrimination in the workplace can be a construction of the group of privilege (that is the health care provider) in an attempt to make more favourable the reality of the life of experience of mental illness and less derogatory the actions of the people that discriminate (health care staff). The device has created second-class consumers as some are said to be the voice for discriminatory experience and some are not. Some people are also paid for this experience and some are not.

\section{Consumer Domain-Context}

The New Zealand Mental Health Commission was given the mandate in 1996 to reduce stigma and discrimination on the grounds of mental illness. This initial development was amongst other "laws, policies, agencies" and "initiatives" that were set up at the same time, often without knowledge of, or connection to each other (MHC, 2004c, p.iv). Efforts to counter discrimination came to be known as 'antidiscrimination work' and, whilst laws and policy changes have been crucial in workforce and service development, effective anti-discrimination work is really about the change in behaviour and attitudes in community citizens that can be brought about on a day-to-day basis (MHC, 2004c). I posit that, despite a decade of major work in New Zealand to counter discrimination, the domain that people with experience of severe and enduring mental illness are permitted to move within continues to be delineated by others. It is not consumers who name their domain of 
influence, but the discriminatory practices of others by which consumers are constrained.

The isolation of various anti-discrimination work efforts is described as being a feature of the early years and it has been noted some ten years on, by the 2004 document “Journeys Towards Equality: Taking Stock of New Zealand's Efforts to Reduce Discrimination Against people With Experience of Mental Illness", that this still remains a feature of today's efforts with leadership and coordination of work lacking (MHC, 2004c, p.iv). What this document calls for is leadership from those with "experience of madness" (MHC, 2004c, p.iv). Is this an expectation that could lead to re-discrimination of consumers who fail to step up as leaders? And from what consumer domain could consumers be expected to emerge who have the voice besides the experience of madness? Is it the experience of madness or the experience of discrimination that we should be asking for, when an experience of madness voiced on behalf of all consumers may be hard to capture without causing divisive dissent amongst them. However all may describe the experience of discrimination.

This chapter considers the implications of the nurse artist within the socio-political landscape. It explores the privilege of the position of mental health worker within the mental health field environment, beside the different experiences of prejudice and exclusion that prevent consumers from participating as equal citizens. I also consider what ethical responsibility I have as a mental health worker to create space for the recovery of others within what is referred to as the 'therapeutic relationship' even as the processes of social exclusion proliferate around us.

What do I, as a nurse artist, bring to the mental health field environment that draws me, repels me or excludes me from recognizing and acknowledging the domain of a person with experience of mental illness?

There are considerable efforts towards reducing stigma and discrimination against people with an experience of mental illness made by the public health sector, the human rights sector and the disability sector. However, for the purposes of this 
chapter, I have focussed my attention on the mental health environment that is addressed by the mental health sector (as distinct from public health, human rights or disability sectors) through biomedical model and recovery approaches and the service user movement (MHC, 2004c).

In previous Chapters One, I have discussed elements of the bio-medical and recovery approaches that reveal the ways in which the mental health sector approaches antidiscrimination work. Service user organisations and regional networks are reported by the Mental Health Commission to use "the politics of identity to locate themselves" (MHC, 2004c, p. xi) and direct the work that is done which can "often focus on direct discrimination through activism and education, as well as internalised stigma through peer support" (MHC, 2004c, p. xi).

At this point I ask the question: Can the politics of identity adequately represent the individual or locate the individual when she is placed in the consumer domain?

\section{The Consumer Domain}

The following two statements, the first by Judge Mason who headed the 1996 Inquiry into Mental Health Services in New Zealand and the second by the Mental Health Commission sum up the opposing forces which, in my judgement, contribute to the geography of the mental health field environment, and which in turn shapes the consumer domain.

We support a public awareness campaign- it is a must. It is fundamentally wrong that a vulnerable group in our society should be continually subjected to comments and actions of those who possess an outcast mentality...We are optimistic enough to believe that a well informed New Zealand public will then realise that the mentally ill [people with a mental illness] are people whom we should nurture and value

(Mason, Johnston \& Crowe, 1996, p.164). 
One of the most painful, widely felt, and insidious problems for people who experience mental illness is social exclusion. The direct effect of mental illness may contribute to social exclusion in some cases and at some times, but the major contributor is discrimination

(MHC, 2004c, p 1).

I believe that these statements hold the fundamental realities of the creation of the consumer domain; that people who do not have experience of mental illness create the consumer domain for people who do have experience of mental illness. They do this, first by social exclusion, then by definition of the needs of this marginalised and rejected group without recourse to, listening to, or allowing the voice, of the disenfranchised individual to be heard.

The very information that seeks to resolve issues of discrimination carries within it the seeds of the basis of discrimination. The defining by one social group of the other, in terms of "outcast vulnerable group" becomes more than an observation; it is an act of oppression. These statements do not allow for the right to be heard of the so-called "outcast vulnerable group" yet the New Zealand public is exhorted to mobilise itself for the sake of a "group in our society" whom they "should nurture and value"(Mason et al., 1996, p.164). I propose that when people who have no experience of mental illness are given this challenge to nurture and value they have no real motivation, regardless of being well informed, to allow the inclusion of someone affected by the direct or indirect effects of mental illness to enter their dominant group; a group that has the social practice of creating social exclusion. If a member of the dominant group creates inclusion then they risk being subjected to the direct or indirect effects of discrimination themselves.

With the greatest of respect for Judge Mason and his colleagues, whom I had the privilege of addressing personally in the form of oral submission (Mason et al., 1996) I do not consider that an "optimistic belief in a well-informed New Zealand public" (Mason et al., 1996, p.164). will ever change the fundamental way in which well- 
informed New Zealanders respond to being confronted by the deinstitutionalisation process of forcing people from previously segregated institutions into local communities. The life events of a person with experience of severe and enduring mental illness continue to be dictated to that person, by their very definition, within our society regardless of what information people have about the illness. The asylum has always been a place of segregation of the mad, as "well-informed" (Mason et al., 1996, p.164) people, or the bourgeoisie as we might more readily recognise them, did not want someone from the "vulnerable group" present within their living environment. What New Zealand community can we identify which does not have an outcast mentality and what community exits for people to be deinstitutionalised into? 'Communities' no longer exist for them to be part of.

Society can accept the face of mental illness as it is portrayed through national mass media campaigns such as the 1998 Like Minds, Like Mine: Project To Counter Stigma and Discrimination Associated with Mental Illness but cannot readily accept the actual person. The findings of the evaluations of the mass media advertising campaign show that:

One area of concern was that although attitudes toward mental illness generally improved, attitudes towards people with schizophrenia did not. The likely reason is that schizophrenia was not targeted in the advertisements, part of a deliberate decision in the first phases to avoid a focus on diagnostic labelling

(MHC, 2004c, p.12).

In my judgement this occurred because people who are depressed may be able to make it, but others who involuntarily gesticulate and rant, and respond to stimuli unseen by others, can't get by.

Such an important national campaign must realise that, from the perspective of the mental health sector, diagnostic labelling is a norm and, for the consumer, forms the basis upon which they engage with the mental health services. As long as we utilise the biomedical model this will not change. 
The Mental Health Commission (2004c) says in summing up their campaign efforts to reduce discrimination against people with experience of mental illness: "One area of potential conflict with rights based approaches to anti-discrimination activities is that the ministry develops and administers mental health legislation authorising compulsion against service users in certain circumstances" (p.vii). This coercion is essentially the experience that people with experience of severe and enduring illness have 'in certain circumstances'.

Avoiding a focus on diagnostic labelling is not a real world solution. Following high profile media releases the national campaign said feedback indicated that where "famous people" and "ordinary people" are portrayed as having experience of mental illness, this can promote recall of key messages and association of mental illness with leading a normal life (MHC, 2004c, p.11).

In my judgement this new public knowledge however, is not transferable to more deeply rooted discriminatory beliefs held by society about the likelihood of people with mental illness to transgress social norms. In other words if the consumer looks like the people seen on TV in a warm supportive work and family network, society may concede and allow a normal life. But if you don't look like that projected image because of homelessness, family rejection, poverty, drug dependence and/or have schizophrenia you will continue to be discriminated against. The anti-discrimination work of the past decade has educated people to not say "the mentally ill" (Mason et al., 1976, p.164) instead; we use the more correct term of "people who experience mental illness"(MHC, 2004c, p.v). In either case, I suggest that society continues to regard mental disorder as something that powerfully separates 'them' from 'us'. This is supported by the arguments of Peter Barham in Schizophrenia and Human Value (1984). He writes:

Community conceived of as a mere site, without reference to the forms of social relationships that are embodied there and to the constraints on those relationships, certainly offers no guarantee whatsoever of any improvement in the 
form and quality of our moral relationships with psychiatric patients (sic)

He refers here to an insistence on the centralisation of a wide range of complex issues, in which the community might contain people who suffer from schizophrenia and other severe mental disorder. Insistence in framing these myriad and complex issues to two polarised terms such as mental hospital versus community compounds the confusion. Here the implication is that the opposing conditions apply; "exclusion from moral community (i.e. mental hospital)" and "inclusion within moral community (i.e. community)" (Barham, 1984, p.178) [or in recent New Zealand terms institutionalisation and de-institutionalisation]. Barham warns though that:

we err if we suppose that administrative changes in the form of the transfer of those people from one category of sites to another necessarily indicate a deeper social change in the terms on which such people are to be regarded and permitted to participate in social life

Where the threat of social proximity to the dominant group is apparent, society continues to push for mini versions of the previous institutional environment that can give some village or cluster housing quality to peoples' existence, and which removes the greater possibility of someone with experience of severe and enduring mental illness living next door, or being housed in 'normal' urban communities. So the administrative changes that support a swing back to 'mental hospital' as preferred containment begin.

This movement is highlighted in the very interesting kernel of information declared as the future needs of the sector engaged in mental health anti-discrimination activities. The key statement is "Service user leadership in this work will be key, as "nothing about us without us" must be a central principle of anti-discrimination work". In other words, the essential message since a concentrated effort of antidiscrimination work by thousands of people in multiple sectors since 1998, still in 
2004 alludes to the primary difficulty of definition and exclusion of the "service user" by the wider social group (MHC, 2004c, p.xiii).

\section{My Placement In the Consumer Domain}

This section of writing further explores the consumer domain including my presence as a nurse researcher where I have the privilege of access to the mental health field environment, and personal experience of the defining and perpetuating of the 'service user' label by the wider social group. Recognition of my placement and view affects the outcome of the study in terms of the lens with which I look.

I am interested in researcher credibility, as described by Polit and Hungler (1997). This is also described as the faith that can be put in the researcher. In this research I am "the data collecting instrument - as well as the creator of the analytic process" (Polit \& Hungler, p.306). In this way this work reflects, where possible, my training, qualifications and experience. Here the personal connections that the researcher has to the people, topic, or community under study, have an effect on the relevancy to the reader. It is argued that the researcher may have a "negative or positive effect upon data collection, analysis and interpretation" (Polit \& Hungler, 1997, p.306). This is an academic description of what Spivak (1988) describes as privilege and is an integral part of my placement in the consumer domain.

I must travel back to the beginning of my desire to be a nurse in this health environment, offering my Self to people who needed my help, my competencies, my understanding that the other person also has a place in which their presence in this environment began for them. This relationship response is the completion of the transaction between speaker and listener (Landry \& Maclean, 1996). As Spivak ( cited in Landry \& Maclean) argues "ethics are not just a problem of knowledge but a call of relationship (p.5)...The ethical stance of making discursive room for the Other to exist" (Kilburn, 1996, p.1). Spivak (as cited in Kilburn, 1996) describes that this ethical relationship is like an embrace where each learns from the other, which is "not at all the same thing as wanting to speak for an oppressed constituency" (p.5). 
'Nurse training' can bring us to a position where beliefs, prejudices, understandings and assumptions have arisen and become naturalised into the processes of our construction of what we consider to be therapeutic. In general the Mental Health (Compulsory Assessment and Treatment) Act 1992 has signalled a move towards individual rights. Along with the Health and Disability Act 1992 and Privacy Act 1993 these statutes protect, in legislation, the rights of all people who receive health services in Aotearoa New Zealand.

In mental health services, where the person is being compulsorily assessed and treated under this Mental Health Act, the difference, especially in comparison to other health services, is that the person we act upon as patient often strongly disagrees with our notion of what is therapeutic. You can't always go on in harmony when the other person with whom you expect to harmonise is there under coercion. At this point the ethical stance of the embrace may become a two or more person restraint hold.

Perhaps the felt nature of the consumer domain is summed up in these words expressed by someone with first hand knowledge. A friend with experience of severe and enduring mental illness once explained to me, "its like a carpenter talking to a carpenter or a plumber to a plumber" (name withheld, personal communication, January 3,2005 ) there is a common knowingness which creates an understanding. It will never be possible for a nurse to talk with full understanding to a person with experience of mental illness no matter how intensely she may dedicate herself to this task. It will never be possible either, for a nurse with an experience of a mental illness such as bi-polar disorder to include her insight of her own illness into care for people she has responsibility for, in a healthcare setting. What my friend suggests the nurse does have is a wide range of knowledge of interventions that can limit the harm of bi polar (sic) highs and lows (name withheld, personal communication, January 3 , 2005). 


\section{Placement In The Consumer Domain-A Privilege or a Loss?}

This project must acknowledge the fundamentally different positions of power and understanding of self, and the boundaries that exist between the nurse and the patient in the mental health field environment. The rights of appropriation of knowledge from the other person by the institution are all encompassing and penetrating.

For me to assume knowledge of a consumer domain, as defined by consumers, is impossibility because even with this attempt to locate myself within a place of Otherness I am using words, or signs in text, of the power filled establishment. "Stigma and discrimination are social processes that lead to the exclusion of certain people or groups from their usual and rightful participation in their communities" (MHC, 2004c, p.V). Being a nurse in a healthcare setting with someone who is labelled consumer is also a constructed position.

I cannot attempt to describe someone else's position using a framework of sociohistorical definition which applauds my own position, as a woman, nurse, care-giver employed, economically viable [contributing and consuming], law abiding and 'normal', even as it stigmatises another's position as for example; young, male, unemployed, no fixed abode, diagnosis of mental illness, previous hospital admissions, medication resistant, and with anti-social traits. Between 'applauded position' and 'discriminated and stigmatised position' such labels become selffulfilling prophecies.

Landlords, restaurateurs, banks, and hire car firms demonstrate their preference for dealing with people who have applauded positions. The more acceptable person gets more acceptability and the least acceptable person gets ever reducing levels of acceptance. This tends to become a self fulfilling prophecy because if society pays you no respect, the sense of needing to fit in to society by acting in socially acceptable ways becomes less and less of a motivation. The less you fit in as a citizen, the more likely you are to be excluded from 'normal' and rewarding 
lifestyles such as homeowner, car owner, and family member, and the more likely you are to rely on social services such as benefit payments, food banks, night shelters, prison, and mental health services.

One might say the that payment society makes for the luxury of excluding some people from being considered normal, is the provision of social and health services which are paid for by taxes. This is an anonymous way for the model citizen to contribute and for the state to acquire the administration costs because it is not about the dishevelled young man who stands on the main street on a Friday night gesticulating strangely but, a rather faceless mass that must be treated by services, which are run as economic units.

\section{Patient File As Constructed Consumer Domain}

It is a strange feeling to see the eyes of a person follow their name written on the side of the "notes" as the folder disappears down a corridor or into an office tucked under someone's arm, and when we have a Clinical Review meeting and carry these folders to the closed discussion to present their contents, we leave the actual person on the ward.

People who work in the healthcare system, enacting the bio-medical model, and backed up by hospital policy, assume the immediate collection of information from the patient following admission and from previous admissions covering their lifespan. A legal notation in the patient file takes precedence, in terms of the treatment model, over the lived experience of the person, because the lived experience of the person is being constantly viewed by health professionals who couch their observations in medical terminology. This has been reinforced by high profile events in recent New Zealand mental health history, where individual health practitioners were intensively scrutinized and censured in the coroner's court following the release of a patient from hospital treatment who then committed homicide against his mother. 
The patient consents to this information collection, or is said to have given informed consent, and the file is the patient's own file. However, should the patient wish to see it, they must first apply to see it and partial or full access may be denied. Information about the patient regarding, for example, the chemical make up of their urine, traumatic childhood experience, and their latest sexual encounter, all may become part of the file. The right of appropriation of the other person begins even as the person is admitted to hospital.

This is not a domain for consumers, but a medical history that becomes changed or constructed in particular ways, and which may blur a sense of ownership of the self. In his classic work Stigma, Goffman (1961) explains this subtle but important phase in creation of the 'inpatient person':

If the custodial faction in the hospital is to succeed in managing \{his\} daily round without complaint or trouble from $\{$ him $\}$, then it will prove useful to be able to point out to \{him\} that the claims about \{himself\} upon which he rationalises $\{$ his\} demands are false, that $\{$ he\} is not what he is claiming to be, and that in fact $\{$ he\} is a failure as a person. If the psychiatric faction is to impress upon $\{$ him\} \{his\} views about \{his\} personal make-up, then they must be able to show in detail how their version of $\{$ his $\}$ past and their version of $\{$ his\} character hold up much better than \{his\} own....No segment of \{his\} past or present need be defined then, as beyond the jurisdiction and the mandate of psychiatric assessment. Mental Hospitals bureaucratically institutionalise this extremely wide mandate by formally basing their treatment of the patient upon \{his\} diagnosis and hence upon the view of \{his\} past. The case record is an important expression of this mandate. This dossier is apparently not regularly used, however, to record occasions when the patient showed capacity to cope honourably and effectively with difficult life situations

The borrowing of others' words within an environment such as this, where the person's story becomes patient medical history, asks the question what dangers are 
there then in the borrowing of others' experience? Is it possible as a nurse exploring this mental health field environment to construct the consumer experience as a contributory element of what makes up a [good] mental health worker? How can recovery competencies for New Zealand mental health workers guide and contribute to the making of discursive room for the Other to exist?

The risks of speaking for Others are great as are the risks of speaking words that come to stand for consumer experience when representation is the cultural norm. If it is an impossibility to speak for Others then in what way can I contribute to making discursive room for Others? As Spivak (1990b) would say, I must make room, clear the space to allow Others to speak.

\section{Creative Arts In The Mental Health Field Environment}

\section{Side-By-Side Practice in the Community Arts Model}

Artforms such as sculpture and paintings, ceramics, drama, and music can make us gasp with their beauty and cleverness. Many people feel it is something beyond them to be involved in the making of art. The presentation of 'high' art in museums and galleries, and the hushed and reverential tone used in its presence tells us 'we must not touch'. This however, is only one view of art, and one way to view art.

There are other ways to appreciate, create and display art. One of these is the making and appreciation of 'raw' art in the Community Arts context. "Often created from inexpensive everyday materials the work can reflect aspects of popular culture and everyday life" (National Gallery of Australia, n.d. p.1). Work made in the politic and approach of the community arts model "significantly draws no distinction between well-known and unknown artists and instead focuses on the strengths and inventiveness of the art" (National Gallery of Australia, n.d., p.1). This is made art or pure expression, which is not measured by the constructed notions of artists celebrated by a public that holds artistic, cultural and monetary valuing over one person's work and not another person's work, simply because of the aesthetic 
construction. "Expression in art may be experienced as inherently rewarding and healing, instead of the main focus being on the technical virtuosity or artistic merit of the product" (Freeman, Epston, Lobovitts, 1997, p. 149). In the [mental] health field environment, rather than being employed for objective diagnostic and interpretive purposes, the visual and performing arts in a community arts and personal creative expression context can invite people to make meaning of their own expressions. The nurse artist takes a stance of curiosity, and facilitates the expansion of preferred meanings for the person, rather than offering an expert opinion on her artistic productions (Weller, 1993).

\section{Uncovering the Politic of Side-By-Side Practice Compared to Hierarchical Practice}

How does art help people? How can art in the mental health field environment be (mis)used to further reduce the space for Others to speak? How is art used to represent the consumer voice and as a construction of consumer experience?

I intend to demonstrate my socio political stance as a nurse artist within the mental health field environment by aligning my own ethical conduct and practice with one of two comparative examples taken from contemporary arts practice. The correlation with the mental health field and, in particular, the view that we as an audience are encouraged to take of the work in these two examples, largely contributes to the view that we hold of the artist.

In the first example the work becomes synonymous with illness and we are invited to join in the spectacle and analysis of the subaltern. In the second example we are invited to view the works on exhibition, and elucidation of the work is oriented towards inclusion of the artist and viewer in a mutually open space that invites matters of contemporary artistic and social exploration. In the first example the person is mute. In the second example the powerful difference is the way in which the person who acts and struggles speaks. These comparisons draw out the manner in 
which a reader or audience is led to construct privilege and ultimately decide to privilege what is truth for them, over another persons' experience of truth.

Deconstruction of my position of privilege as a nurse artist within the mental health field environment is important in this thesis if I am to avoid making claims that are merely personal, and thus interpreting or encouraging the reader to interpret this narrative as the truth and experience of Other:

Deconstruction does not say there is no subject, there is no truth, there is no history. It simply questions the privileging of identity, so that someone is believed to have the truth. It is not the exposure of error. It is constantly and persistently looking into how truths are produced

(Landry \& MacLean, 1996, p.9).

\section{Context of the Comparative Examples}

I will show the stark contrast between the privileging of identity of a health professional and the privileging of identity of a working artist with experience of disadvantage within society. My work and presence within the mental health environment is often uniquely focussed on the simple matter of privileging the identity of the person who has experience of mental illness, where the constructed nature of the environment gives me that privilege as of automatic right. "Deconstruction opens up the personalist belief in identity-as-origin not by denying experience, but by insisting upon the need to examine the processes whereby we naturalize personal experience and desire into general truth" (Landry \& MacLean (Eds.), 1996, p.10).

I will now make a comparison between the collections and public displays of art made by people who have been described as being "disadvantaged within society" (National Gallery of Australia, n.d. p.1). The first group are identified by the disadvantage of their medical diagnosis and represented by the medical field; the second group are identified by the disadvantage of their status in society and 
represented by the arts field. In both instances however the particular disadvantage shared by all in the medical field, and some in the arts field, is the experience of a mental disorder. In this way both groups are present in the mental health field environment.

\section{Example One}

\section{The Cunningham Dax Collection [of Psychiatric Art]}

The medical field example is a drug company sponsored regular display of work from the Cunningham Dax Collection - Art Creativity and Education in Mental Health on the back page of a medical journal. Doctor Eric Cunningham Dax amassed the collection of some 10,000 artworks in over fifty years of his practice in psychiatry in the treatment of psychiatric illness (sic). In my judgement, the artwork is reduced in its authorship and celebration of the artist. The artist with experience of mental illness and/or psychological trauma is summarised by the dissection of the work through the bio-medical model eye, which reduces the person to symptomatology and the work to a conduit for inspection of the disorder. A psychiatrist who addresses the readership of the journal beginning with "Dear Colleagues" makes the commentary on the mental state of the patient by analysing the imagery that he can see in the paintings that are displayed in every issue of the journal. Highlights recorded by the Collection in the website of The Mental Health Research Institute of Victoria for the 2003 year were:

The Collection has begun a process of reframing its direction. This reframing has seen a change in its emphasis and accessibility - from a collection that has been viewed with an almost exclusive clinical emphasis, with consequent limited clinical audience, to one which considers the creative works of people with mental illness to be art as well as clinical record, and therefore accessible to a broader audience. Accordingly there has been a name change from 'The Cunningham Dax Collection of Psychiatric Art' to 'The Cunningham Dax Collection - art, creativity and education in mental health

(Mental Health Research Institute of Victoria, 2004). 
Whilst the Collection assures its viewers that its mission is to promote a greater understanding of mental illness and that the works are preserved and ethically presented, it also assures us "that the value of the collection extends beyond its aesthetic appeal; it is also a significant teaching, research and public education tool. The works are intriguing not just as art but also insights they afford into mental illness" (Mental Health Research Institute of Victoria, 2004, p.1). The touring exhibitions of the Collection are said to explore the experience of mental disorder, for example an exhibition entitled 'Still Lives - between creativity and shadowland' "explores the experience of depression and mania" (Mental Health Research Institute of Victoria, 2004, p1).

My extreme sense of outrage at the suggestion that this work 'amassed' in another context should be then regurgitated as a public education tool to illustrate categories of mental disorder is overwhelming. What of the individuals who were analysed some fifty years ago? What opportunity do they have to voice their experience of depression and mania, if in fact that is what their intention was, in what the work was saying. By what method was the work 'amassed' by Dr Cunningham and with what thought to preservation and ethical presentation? Early copies of the medical journal reveal the absence of the artist name and the renaming of the work with the title 'schizophrenic art'. Viewing art is a very personal experience and to suggest that a large body of works is definitively about a given diagnostic event also reduces the capacity of the viewer to consider allowing the Other person to voice their experience. The exhibition viewer may be led by 'experts' in both medicine and art into believing what they have been supplied is an accurate and global view of the experience of the consumer. If you visit the exhibition and see the homogenised and representational view of depression and mania, [one may assume to] never have to meet a person with this experience to know what it is all about. On what basis does one label art to be about depression or mania? My contention is, that to call the colour black sadness and the colour red frenzied is an oversimplification of emotional response to colour, and an undervaluing of the meaning of creativity in human endeavour. 
Within art history painstaking effort is put into understanding the whole world view of the artist in context of the artwork and despite this effort the descriptions one hears in galleries of what the artist intended are tentative and contextualised to the historian making the claims. The Cunningham Dax Collection of Psychiatric Art, to go by its old name which continues to be used in the medical journal, confidently states the committee consisting of representatives of several government departments, philanthropic organisations, academics and [representative] consumers and chaired by former state health ministers has gained funding to allow the psychology school's programme a comprehensive teaching module in association with the Collection. Through the amassed artwork of largely unnamed and unconsulted peoples, psychologists are to be trained in professional development, which fosters their own insight into the work. On the basis of this I would presume they would practice psychology on another generation of consumers and even encourage the amassing of further works.

Bruce Doyle, who has his identity and diagnosis revealed and creator of an illustrated work in the medical journal, has this said of him/his work:

\section{Dear Colleagues,}

Many artists have painted birds in their cage as viewed from outside the cage. In this vibrant work the artist painted the view from inside the cage. Did the artist identify himself more with the caged birds than the viewers on the outside? Was he trying to express his sense of entrapment by his schizophrenic illness or to express his feelings of isolation and rejection by those around him?

Dr Eugen Koh

\section{Director, The Cunningham Dax Collection}

(Zoo from inside the parrots cage, 1991, p.957).

Here the artist, addressed as a schizophrenic, and the art as "psychiatric art" are subjected to constructed notions of the consumer who is described in his problematic place in the world' by a person of privilege. 
What must it feel like to see one's own work displayed in such a manner? Works are said to be procured from the Collection for the publication, with the permission of the consumer or their family. What capacity does the consumer have to refuse this request? Or rather what pressure is exerted by the power differential between patient and doctor that results in permissions to print?

\section{Example Two}

\section{The Peter Fay Collection}

The arts field example of work is part of The Peter Fay collection and travelling exhibition to national and international galleries entitled "Home Sweet Home". Peter Fay in asking the fundamental question: "Why is that art and that not?" (National Gallery of Australia, 2003, p.1) or why is that person given permission to pass in our society and that person not? 'Outsider' artists have as much to give as established or 'insider' artists" (National Gallery of Australia, 2003, p.1). This is the essential premise of the Community Arts model that I will discuss in more depth later in this section of writing

Peter Fay's impulse to become a serious collector of art originates in his own sense of immersion and empathy for other worlds. He recalls the experience of reading Dickens when he was a child and says "for me it was real, I was in that world... when the art kicked in, it built on the same foundation, the same passion" (National Gallery of Australia, 2003).

Hart, senior curator of the National Gallery of Australia writes:

This exciting [Home Sweet Home] show of predominantly Australian and New Zealand contemporary art is about a collection that comes from a domestic context and examines the way the idea of 'home' - and by extension our hearts and minds - can be transformed by art

(National Gallery of Australia, 2003, p.1). 
This exhibition reveals Fay as a collector who has supported emerging and outsider artists as well as others who are well known. In the Community arts context 'Outsider Artists' became a term used to describe those artists who have not received formal art training, or attracted mainstream arts funding, and who experience marginalisation not only in an arts context but also in a societal context, as distinct from mainstream artists who are revered in our society. This term was particularly adopted by a gallery space in Wellington, New Zealand, that supports the display and sale of works by people with experience of mental disorder.

In contrast to the medical field example of display and commentary on the patient/artists work, the Peter Fay Collection includes commentary about art by artists, rather than commentary about art by doctors.

Ricky Swallow, who is named as artist and born in Australia in 1974 has his work described in its construction, and then it is noted that this work is reproduced courtesy of the artist and also courtesy of a gallery by which perhaps the work is owned. Of him it is said:

\section{Ricky Swallow is a Melbourne-based artist who has received international recognition in recent years. His best-known works are a series of models in which tiny people inhabit grey landscapes no bigger than the portable record players that power their perpetually revolving dramas. In Clockman , a tiny model man appears to dangle out of a clock - or is he himself the clock? The clock is literally his face, hands and body. The scale of the figure generates a sense of being observed from a distance. When looking at Clockman, phrases such as 'body clock', 'watching the clock' or 'every minute counts' come to mind. Question: What does this work of art say about contemporary society?}

(Home Sweet Home, n.d.)

This is exemplary of a genre of statement that accompanies the artist's works in the Peter Fay Collection in complete contrast to the statement made by the Cunningham 
Dax Director. It questions and extends our thinking about our own curiosity and awareness in the work and the artist is applauded and recognised fittingly. The artist is neither identified as a patient or outsider artist [unknown] nor well known, so that we are not privy to the associations that the artist has by which he came to be included in the collection other than his talent.

\section{Key Research Insight}

It is impossible to compare these two examples of the collections of art without acknowledging the dedication and decency of this man Peter Fay. He has quite clearly chosen to use his personal resources and influence to make a collection of works, with the essential elements of the artist and their work being presented, as the artist would wish. Despite his powerful position in holding and displaying these works he has not misused or distorted the artist with this power, rather he has brought recognition and pride to the artist that perhaps may not have been there. $\mathrm{He}$ has brought this genre of expression societal acceptance and a social position and perhaps acceptance and social position for the person as well. This is in contrast to Doctor Eric Cunningham Dax who has used his influence and power to further create a barrier between those that experience mental illness and those that do not which makes the artist a medical curiosity and the work a product of illness. His intention may not have been to create this barrier but his method of examination of the work and the artist through the biomedical model lens has resulted in this dehumanising display.

Here, in essence, is my own acute awareness and practice ethic, that notices and utterly rejects this medical typecasting of people, dependent on the position of the speaker, into a marginalised and stigmatised existence. An answer to the question how does art help people might be: Art in itself is a medium that a person can use to express herself. The critical element of nurse artist practice then, is to receive this expression [or speech] by Other, into the power filled and constructed framework of the mental health field environment in such a way that honours the Other person and does not attempt to twist or reinterpret their original meaning of their creation to 
my/our purpose. This extends to every visual and performing art but also to the ways in which people come to understand, and recover from, their own experience of mental disorder in their life.

More accurately stated perhaps is, How does art help me? Cardinal's (National Gallery of Australia, 2003) comment points to this revelation " The art offers us the prospect of an alternative and potentially revolutionary way of seeing" (p1). As a nurse artist, then, I am able to search for connections with the Other person as I become aware of my own search for meaning and connections that arise from my life time of intimate encounters, personal associations and love of things invested with time and memory (National Gallery of Australia, 2003). Thus tentative statements can be made about how 'I find myself in relation to Other', rather than 'I find Other to be', which tends to be a fait acompli from a professional nurse perspective when Other is a person with experience of mental disorder. This is the mechanism in the mental health field environment for disallowing the subaltern speech and which my research is attempting to disrupt and challenge.

Fay was influenced in 1997 by the 'Arts Project Australia' in Melbourne. The Arts Project is an organisation dedicated to the creative development of artists with disabilities. Studio space is where artists can work and a gallery, with exceptional archives of the artist's works (National Gallery of Australia, 2003). Another similar organisation's influence was also a turning point for me as I was funded by the Queen Elizabeth Arts Council of New Zealand in 1991 to research the Melbourne based Arts Access programmes for the benefit of New Zealand based programmes. The grant was under the auspices of the Professional Development Programme for Arts Workers and Arts Administrators. I was eligible for this as a Community Arts Worker responsible for programme development in Cherry Farm Hospital Creative Expression Unit where I was the Arts Director of the hospital-based creative expression unit Kimi Ora ('search for health'), and city based studio gallery space Artsenta. Studio space dedicated to outsider artists [with an experience of mental illness] was the model that I used to develop the studio space called Artsenta in Dunedin New Zealand when Cherry Farm Hospital closed in 1992 and every one of 
the residents was deinstitutionalised. This studio met the creative needs of some 400 artists in any given year after its inception and still thrives today.

Art is inherently therapeutic and need not be interpreted. Some clients have described as: "Its like if you keep pulling up a plant to inspect its roots!" (Hall, 1987). In my judgement the arts therapy's practice of utilising the finished art piece made by a person, for the purposes of interpretation of their mental state (or art expression for diagnostics), significantly discriminates against, and gives rise to, stigma in people with experience of mental illness by exclusively referencing every other aspect of their life from the centrally constructed position of the diagnosis. If a person sings, gazes at things in wonder, writes words on paper, moves their body in a way other than sitting, lying, standing or walking, this is all described and recorded in terms of the illness often without any recourse to the person or their intended actions. A good example of this is the way in which a young Maori man had been taught by his elder to use a mirror as a means to address his inner voices so that he could make a comparison with what he heard and what he observed about his own body. This was a suggestion that used the environment creatively to assist in the reduction of distress from hearing voices. When this technique was not understood by other staff, the young man's actions in looking into outside window reflections and holding a dialogue were interpreted as being psychotic phenomena out of control. He was never asked about this and the clinicians in a position of power could, or would, only assume as far as they could apply their own understanding to this situation.

\section{Mental Health Nursing as Dialogue or Side By Side Practice}

In the previous section I considered the domain of the consumer and some of the ways in which it can be constructed and recognised. I also included examples from practice to illustrate the ways in which the consumer domain silences people with experience of mental illness. I will now describe how I address the harm done by this environment, and the ways in which health gains can be made by making space for Other. This is a developing art, or in practice terms, it is a performance competency. 


\section{Iatrogenic Harm Done To People In the Mental Health Field}

\section{Environment}

Privileging occurs in the mental health field environment in response to drivers that dictate the ways in which people are held. In London in 1576 the Bethlehem Asylum was prison-like and patients were chained to the walls. Profits of running asylums such as this, were reaped by the proprietor of the institution (Brookes \& Thomson, 2001). In the early 1990s, in New Zealand's history, the realisation of the financial burden of the nation's healthcare resulted in health reforms that had economic goals; those of creating a competitive environment with the expectation that this would create better efficiencies in health care (McKewen, 2001). The result of this medical consumerism in today's context is that the individual is considered a type of shopper who consumes services. Perhaps it is no accident that patients became known as consumers or service users. Strong criticism of medical labelling is voiced by those who reject being referred to by their diagnosis, yet there is little or no criticism of health services commodity labelling which overvalues a measurable outcome, and the true transaction of human care risks being lost.

I was present when a person was newly admitted to a locked mental health unit. She stood at the desk and in an angry tone asked for her 'nut papers'. Through recognition of the derogatory term 'nut' I immediately understood what she was alluding to, and as I had made a connection with her before this, I asked her about using the words 'nut papers' in reference to herself. She said (name withheld, personal conversation, September 14, 2005) "I used to be a fruit loop but now I'm in here (under a section of the Mental Health Compulsory Assessment and Treatment Act) I must be a nut, so give me my nut papers"(she was alluding to patient's copies of legal papers relating to placement under section papers).

Goffman (1961) describes "the privilege system and the mortifying processes to which the inmate (sic) [patient] must adapt" (p.61). Goffman (1961) notes that often the first response is "situational withdrawal" (p.61) which in the mental health service context that I am familiar with, is often described by the staff as the person 
exhibiting isolative behaviours. Secondly Goffman describes "the intransigent line: where the inmate [patient] intentionally challenges the institution by flagrantly refusing to cooperate with staff. In the mental health setting this can be very damaging. Any compulsory treatment prescribed, or unsafe behaviour exhibited, can result in forced treatment, and thus the process of mortification of the individual is amplified. Staff and patients may be seriously hurt in verbal and physical acts of violence, and the person is viewed, and recorded, as having the potential to be dangerous which profoundly affects their ability to access further services with neutrality.

The third standard alignment in the institutional world according to Goffman (1961) is "colonisation: where the sampling of the outside world provided by the establishment is taken by the patient as the whole and a stable relatively contented existence is built up out of the maximum satisfactions procurable within the institution" (p.62). This often produces a mixed attitude towards the person by staff. On one hand staff are comfortable that the person no longer presents a risk to themselves or others, but on the other hand staff are also suspicious of the patient's relaxed presentation as they are viewed as becoming institutionalised or it is seen that they were/are a malingerer.

The fourth mode of adaptation to the setting of total institution is "conversion: the patient takes over the official or staff view of himself and tries to act out the role of the perfect patient" (Goffman, 1961, p.63). Goffman also describes the mental hospital conversion as creating two possible scenarios. That the patient adopts the psychiatric view of themselves after an inner struggle which results in them "gaining insight" (p.63) to what is wrong with them and secondly, by the adoption of manner and dress and behaviours of the nurse in managing other patients and aspects of the physical environment.

In my judgement the experience and expression of the person I referred to earlier who asked for her 'nut papers', exemplifies this mortification process. It illustrates the way in which a person's view of herself changes from socially acceptable to 
socially unacceptable after being exposed to the mental health field environment. A 'fruit loop', in every day language, may be someone who is zany and unpredictable in a soft way. One can even 'go on a fruit loop' which is a temporary display of funny or unusual behaviour. However, a person who uses the terms 'nut', 'crackers' or 'mental' is thought to be describing a person who is certifiably mad. Consumers have begun to also question what recovery can exist in the presence of the Mental Health Compulsory and Treatment Act 1992 and in the presence of the Community Treatment Order?

\section{Iatrogenic Harm Reduction In the Mental Health Field Environment}

This poem was written for me by a person who was struggling to come to terms with the implications of needing to take medication on a long-term basis. Stopping consuming medication has resulted in a distressing involuntary admission to hospital where she experiences extreme agitation. She writes:

\section{To Heather}

We Must Remember that,

The Sun Does Not Always

Shine and that is When

We Need You Most.

(name withheld, 30.8.05)

Here the person, in a poetic form, speaks to me about her need for help from someone who can bring back the light. This expressive work likely came as a result of my past association with her in the context of witnessing her struggle and receiving other works of creativity. These became a means to her gaining some personal insight which led to a feeling of gaining personal control in a situation which was, for her, out of control. 
Where this process of mortification, or learned helplessness, may be taking place in varying stages with every person that I make contact with in my role as mental health worker, what forms of practice can I enact which enable the person to speak, and to speak with me? As a staff member I am somewhat cast in the role of the oppressor, unless I am able to conduct myself, in my work, in such a manner that it does not contribute to this process of mortification.

I will now begin to describe the elements of the art of practice which I employ and which I have come to name "side-by-side" practice. As a nurse artist it is possible to describe the steps that are part of the formation of a space for dialogue. This space for dialogue takes many forms and can encompass all of the visual and performing arts. Sometimes the side-by-side practice is purely about talking and listening. For the purpose of explicating the process in this thesis however, I will first describe those events that take place while painting on canvas in acrylic or oils. This process is, importantly, within the community arts model framework and not in association with art therapy. The differences between these will be illustrated.

The process of engaging in creative art making which not only reduces the mortifying processes of patienthood but also redresses some of these effects. The making of art creates space for a dialogue in alternative textual modes, that is, not necessarily in the dialogic form of the spoken word.

Much of the expression of people who are being assessed and treated for mental disorders is required in spoken form between doctor and patient, or nurse and patient. Any other expression is observed and interpreted by staff. The client does not have a choice as to the means of their expression of their mental distress, or their expression of accomplishment for that matter.

Side by side nurse artist practice is possible individually or in groups. A purely institutional view of client participation can be that mental disorder, such as the experience of hearing command hallucinatory voices, acute mania or acute depression, are not conducive to active participation in creative processes although 
people experiencing these phenomena may be able to be present where art making is taking place. Modern settings produce barriers to participation, and risk management directives preclude people handling certain equipment, whereas older style environments of asylum did not often create these barriers.

The first element in nurse artist practice is the preparation stage, which applies to the physical environment, the artist's readiness to begin, and the materials present. The provision of good quality materials that honour the work that will come to be made by or on them is critical. In the past I have witnessed work done on newsprint that is then put in the bin by the mental health worker after the session. Where an individual reveals an image that is part of/generated by their internal and external process of creativity, what the mental health worker then does with the work is often indicative of the respect, or lack of it, with which the person is held.

People in the mental health field environment watch what happens to the work they make and I know that they form an opinion of themselves based on this, as the positive, and sometimes negative, identification between artwork and person is often unique and powerful. People have commented when I care for their work, that it has previously been trashed.

The second element is the progression of what the work is made of, from raw materials to composition of materials in technique and image. How the work is made is honoured. This is a mutual process of personal experimentation and arts technique, which is a teacher/learner project.

The third element is that the work must be entirely free of staff interpretation and must be upheld as a work of unique creativity. Where an artist chooses to freely interpret the work as an expression of her own mental state, which is then integrated into their recovery journey, then the work could be said to have contributed to a therapeutic outcome for that individual. Therapeutic intention in the community arts model is not restricted to the product but, most importantly, to the process of creativity where nurse artist and client artist work side-by-side. As Krasner and Joyce 
(cited in Freeman, Epston, \& Lobovits, 1998) state: "It is the dialogic process between two people of significance to each other rather than the relationship between clinician and client that is regarded as the primary agent of healing"(p.8). This is revealed in the dialogue which reflects on the process and hands back rising health status or reassures the Other that indeed they have succeeded or been heard.

The fourth element is the product which must also receive the same consideration in being given safe storage, and in being able to be accessed by the artist for the purposes of future decisions as to the display or sale of the work. This view of the work, as a product with the potential of being a commodity which might be sold by the artist, is very important as often work made in the mental health field is seen only as an expression of the illness and is interpreted in art therapy in the bio-medical model. This further mortifies the individual.

\section{Arts Therapist Practice and Nurse Artist Practice - A Comparison}

The following steps were illuminated as part of the process of reflection on my practice and as a result of comparing my process to the documented process of an occupational therapist in the mental health field (Weinstein, 1998).

The Therapist appears to have prioritised these 'interventions' with the prior notion of the person as being in some way degenerate or showing behavioural signs of having become completely mortified into the role of mental patient. The decision making process begins and ends with the powerful position of the therapist in charge of the beginning and ending of the intervention. The power differential remains undisturbed and the patient is said to have received therapy.

\section{Occupational Therapist as Art Therapist}

a.) Decisions about where to start the intervention

b.) Skilful adjustment of activities to provide the "just right" challenge;

c.) Creation of activities that tap the client's inner drive while promoting selfdirection and growth; 
d.) The transition or flow of one activity to another;

e.) The therapist's relationship with the client; and

f.) Decisions about when to discontinue intervention.

(Weinstein, 1998, p.580)

In comparing my practice to that of Weinstein, writing on Arts Therapy I have indicated the reorganisation of the therapist's priorities as they arise in my practice. This reorganisation of the therapist's intervention in nurse artist practice terms creates discursive room for the Other person.

\section{Nurse Artist}

e.) Relationship with nurse artist self must be established/engaged/conscious, then

f.) I may be rejected or unwanted at this point so it is not really about discontinuing the intervention but asking permission for it to begin, then

b.) As a result of sensing the relationship and the permission, different possibilities begin to connect between us. In a way I feel, I hear and see the activity as a result of the fusion of our presence. The materials help to guide the process of launching an idea, although importantly there must be a vision of a finished product to help initiate the project.

This is an important point, as often clients are led through creative processes by therapists in a controlled step-by-step way without giving them a clear idea of the product. The emphasis for monitoring their capacity is on their ability to accomplish the phases of the task, and there is less value placed on the final product because then no-one knows what to do with it; it has no intrinsic value to anyone as its real purpose was to judge the mental state, the psychosocial and psychomotor skills. The client's ability to complete the steps is recorded and this is what they get positive feedback on. I also believe that it is morally right to privilege the process and the product otherwise how can the other person make an informed choice as to their participation and how can true permission to continue be gained.

The image that I have of this mutual formation of a project idea, is two synapses coming closer together until the electrical impulse jumps the gap and the vision of 
what we could do is in front of us. For me the vision of the form is almost holographic as I always see a finished three dimensional product... this must be important as I 'carry' an image of the finished item where sometimes the other person cannot support the whole. My vision of the product is a means to developing believability in the other person, that indeed we can achieve this together. This is also modelled practically in my side-by-side process of making my own piece of art

c.) I describe the inner artist who always has and does know what to do, and will continue to inform us whatever happens, then

d.) Permission to begin in the here and now, combined with my previous discussion of natural permissions of creative birthright produce a sudden flood of ideas...I could then do this and this and this... and I give the individual creative process over. It's a bit like attaching creative jumper leads from my battery to the other person's battery.

a.) Where to start becomes our end point, but at a higher level due to our achievement with new found creative recognition of each other, the making of a work of art becomes external and concrete proof of this experience. Something you can look at and touch and return to, which is less elusive than a thought or a feeling. So it is open-ended, has oxygen in it, and is about future possibilities. The initiation of a creative response spirals upward in growth and points to future connections.

Further to these reflective insights I then synthesised a client session to more fully explicate the method. This is written in a style that shows the meditative reflective focus of the directed nurse artist practice.

\section{Nurse Artist Practice Space As Dialogical Creative/Creating Space}

- I prepare myself as I prepare the space. A welcome is made, allowing for settling in, drink/food, exchange of 'daily' information

- We work side by side on a form of art making, mutually agreed as being a positive direction based on previous work or interests. We agree on personal goals that can include working towards an exhibition or show, experimental 'making' or making art in the company of another artist.

- Quality materials are an important part of the process of directing the outcome as they contribute to the overall quality and a successful realisation 
of ideas. Artists feel honoured when able to freely select or are offered use of good materials and it produces an enticement or lust for the task. Art materials invite the materialisation of art.

- My experimentation as an artist is visible as is the client's. No marks made are considered mistakes. All work becomes part of the artist's diary. We consciously look for the opportunity presented in surprise elements. Recognising / accepting accidents of design in art builds confidence, supports risk taking and gives a sense of freedom from being 'wrong'; adding to a personal resource rather than taking away

- Themes and elements of expression are brought forward into images that tell stories in all forms of visual and performing arts. Where a poem has been written it may find its way into paint on canvas, or a song. There is no limit to the possibilities for expression except congruence with health and safety (some materials are toxic or sharp to use) and obvious budgetary constraint.

- We have creative goals, which we agree to, set, and meet. We begin sessions with recapping from discussion, reflection, and reviewing art's diaries, 'art visits' to galleries and places of intrigue, and current works. These discussions may include touching on the connections between the progress of artwork and personal progress. Fear of beginning, fear of failing, putting images into context and framing works all can be metaphors for living with the experience of mental disorder. This connection as an underlying theme is not laboured but touched on lightly and with positivity and is available to each participant as an expression of search for mental health, rather than exposure of one person's mental illness. Insights are given time and respect.

- Our session ends as it began, in discussion, goal setting, and agreement for progress and when to meet next. Information that is mutually agreed upon about the session, is passed to the key worker where appropriate. This is important because progress in the creative field can be the only positive thing brought before multidisciplinary groups of staff that often focus on and report only failure. As a nurse artist contribution to the multidisciplinary team can provide a view of what dialogue has occurred, and provide an entry point for the other clinicians who previously held an opinion that the client was 
unreachable. Consideration is given to gallery visits or art events which can include key worker, family/whanau, as the client wishes to include others in his /her artist's life.

In summary then, the contribution that side-by-side practice makes in the mental health field is a new way to look at things and tasks. Spivak (1988) asks "How can we touch the consciousness of the people, even as we investigate their politics? [their mental health?] With what voice consciousness can the subaltern speak?"( p.285).

I am able to recognise my own experience but also recognise that there is, further to my own story, a place of sitting quietly and listening to Other. In this recognition a profound change takes place in the mutual experience of the mental health environment that I share with the person that also listens to me. I create and protect the place where "oppressed peoples speak, act and know for themselves which leads to essentialist, utopian politics" (Spivak, 1988, p.276). Spivak (1988) says that Foucault is correct in suggesting:

To make visible the unseen can also mean a change of level, addressing oneself to a layer of material which had hitherto had not pertinence for history and which had not been recognised as having any moral, aesthetic or historical value

(Spivak, 1988, p.285).

Where the person who has experience of mental illness is unseen and not valued morally, aesthetically or historically, nurse artist practice in psychogeography makes visible the unseen by addressing a layer of material that generally is not recognised. Spivak (1988) notes that the real challenge inherent in this recognition of the " "true' subaltern group whose identity is its difference" (Spivak, 1988, p.285) and moving from there to "rendering vocal the individual" in both is to avoid the possibility of "any kind of analysis of [the subject] whether psychological, psychoanalytical or linguistic" (Spivak, 1988, p.285). My challenge is in rendering visible the mechanism that creates or prolongs mental illness for people with experience of mental illness (not the identity or experience of the patient as we would prescribe it) 
and then to move to creating an open space for Other in which she might be vocal. In achieving this level of practice [change of level] I must be aware of the constant internal and external pressure that I am under to analyse [the subject] person from the constructed position of nurse artist:

whenever we set about reading our "texts" and find them leading obsessively back to ourselves, it is a good idea to not stop there, with ourselves as centres of meaning, but rather to go on and think through the possibility that the personal might necessarily lead us outside "ourselves" to the political

(Landry \& MacLean, 1996, p.12). 


\section{Art Interval}

Deinstitutionalised Hospital Jugs, 2001, acrylic on canvas, 900mm x 300mm 


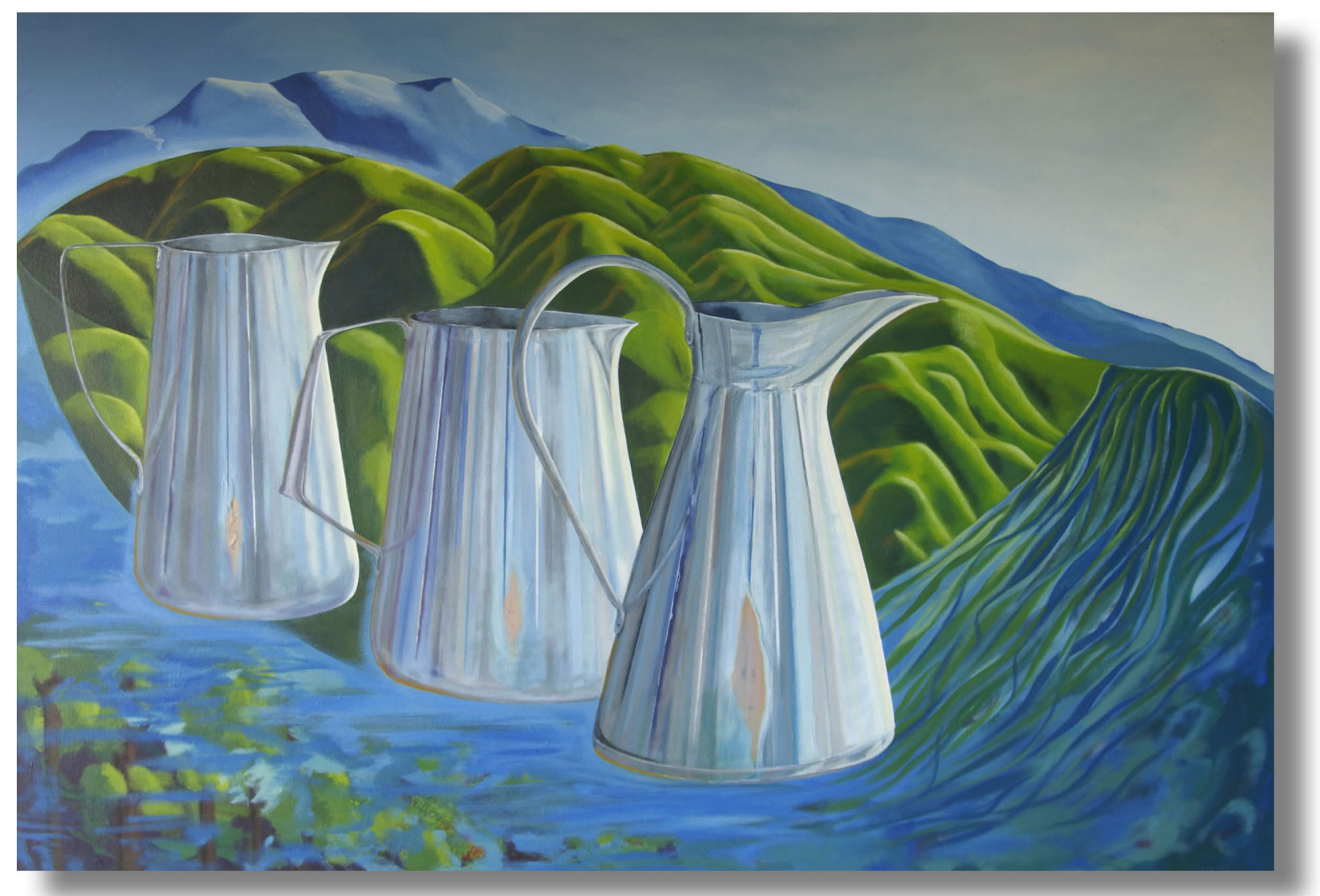




\section{CHAPTER THREE}

\section{THEORETICAL AND PHILOSOPHICAL UNDERSTANDINGS}

\section{Heterotopia}

\section{Heterotopia as Places of Excluding}

Heterotopia means 'places of otherness'. These are real places that are formed in the founding of society - and are counter-sites. Other real sites that can be found in culture, are simultaneously represented, contested and inverted. Places of heterotopia are outside of all places, even though it may be possible to indicate their locality in reality. Two main categories of heterotopia are identified in all cultures: the heterotopia of crisis and the heterotopia of deviation. These are spaces in which those whose behaviour is deviant from 'required' behavioural norms are placed, and include rest homes, psychiatric hospitals and prisons. This is the nature of the mental health field environment in which this study takes place.

"Heterotopia do not exist in the order of things, but in the ordering of things"

(“Theoretical Spaces", 2001, p.13)

In this section of this thesis I am exploring the feeling of being an outsider, as a nurse artist, within the mental health field. I sense that I am in the position of Other, not as nurse or artist, or client, but occupying a place of Otherness. As Hetherington (1997) says "the position of the Other and the validity of difference, hybridity, transgression and uncertainty have become significant political as well as academic issues" (p.7).

Such positioning is delicate since, as my intentional act to build on it is the very act that would make it no longer an outsider position. Every act of certainty towards a position creates a stance, which becomes fixed and this emulates the social order of the institution from which I hope to stand differently/apart. 


\section{Heterotopia as Places of Transgression Into Resistance}

Heterotopia are not quite spaces of transition - the chasm they represent can never be closed up - but they are spaces of deferral, spaces where ideas and practices that represent the good life can come into being, from nowhere...heterotopia, therefore, reveal the process of social ordering to be just that, a process rather than a thing.

(“Theoretical Spaces”, 2001, p.12)

Cultural geographical notions of margins have recently made heterotopia important as sites of resistance, where people's voices can be heard. People live different and alternative lifestyles and hope to be accepted for their difference and their uniqueness (Hetherington, 1997). My recent experience of this is the rising awareness and voice of transgendered peoples who are profiled by the media. They are portrayed as finding both acceptance and marginalisation as political figures in this country's present-day government. Notions of resistance, protest and transgression are found in this group of people who take up, or inhabit, a margin of our society. Another group of peoples on the margin are those clients of the mental health services who have recently begun to voice their experiences of abuse at the hands of staff employed by named institutions. These people have recently been invited by the Mental Health Commission (Mental Health Commission, 2005, p.1) to attend hearings known as the Confidential Forum for Former In-patients of Psychiatric Hospitals where they might voice their individual stories.

Hetherington (1997) sees a certain danger in this, where "the image of counterhegemonic margin that acts as a site of resistance, offers us an image that oversimplifies, through a process of polarization, the issues of marginality, difference and Otherness" (p.7). There is a very good argument for individuals having a voice from the margin but then we must never assume we have understood or heard the margin in its entirety or its unique difference. What of gay men and lesbian women? For whom does the politician who is a transgender-identified person speak, when an argument against hate actions develops on prime-time television. What of people 
with an experience of institutions, who are not able to verbalise their abuse, who were not abused at any one person's hands, but institutionalised as a form of abuse? The polarization of people from the order of the centre to the resistance of the margin is a process of ordering and not an order. Very soon the politician who is transgendered appears on a ballroom dance show called "Dancing with the Stars" (TV One, April, 2005) raising money for charity and dancing the light fantastic for the public vote, and all the historic consumers of mental health services who suffered abuse, who appear at the confidential forums, will be a differentiated and ordered group from those other consumers who did not attend, or are yet to attend services, or are yet to be diagnosed.

This next section of writing explores some of the historical background of the development of ideas about heterotopia. It is not meant to be an exact record of the unfolding of history, rather a dérive that allows the writer and the reader to explore space. As Foucault writes:

Perhaps our life is still governed by a number of oppositions that remain inviolable, that our institutions and practices have not yet dared to break down. These are oppositions that we regard as simple givens: for example between private space and public space, between family space and social space, between cultural space and useful space, between the space of leisure and that of work. All these are still nurtured by the hidden presence of the sacred

(Foucault, 1967, p.2).

Finally this section attempts to explore the mental health field environment through the six principles as defined by Foucault (1967, pp. 4-7) that are the traits of heterotopia. 1.) The constitution of heterotopia, 2.) Heterotopia as unfolding history, 3.) The juxtaposing of incompatibilities in heterotopia, 4.) Heterotopia's links to slices of time 5.) The opening and closing of heterotopia, which create isolation and penetrability, 6.) And finally the function that heterotopia have in relation to all the space that remains. I will begin with a dream sequence as a means to carry you, the reader, into another space and time. 
I had a dream that I was teaching a large group of twenty or so performers who were forming a performance troupe. I led them along the side of the canyon, near where we were staying, in a cabin-style hotel somewhere in the American desert canyon area. It was approaching nightfall and the way was rocky and steep. We threaded our way around and over boulders with the red sand soft beneath our feet. Each of these women [womin] of all ages and strengths followed me single file to a vantage point at the top of the lip of the canyon.

On the left of where we crouched was a highway busy with traffic. The headlights of oncoming cars and taillights of cars driving away from us formed streams of light that hung in the air like coloured ribbons. The perimeters of the road stretched out to infinity with road signs and a disappearing median line in the fading evening light. Here everything was directed, directional and with speed.

To the right was the yawning open chasm of the canyon, filled with night air and space, freedom, possibility and challenge, welcoming, but tricky, slow, and a great teacher.

I showed the women [womin] that the key to their practice was somewhere between these two spaces. If they wanted to be really great performers they would have to perform on the highway of human experience but draw from the canyon, from where wisdom and creativity flow. As I woke I knew all of these women [womin] were aspects of me and I was describing to myself the heterotopia of the nurse artist.

\section{Mental Health Environments as Places Of Otherness}

The method chosen for researching the mental health field in which I work as a nurse artist is literary psychogeography. This method produces a style of narrative and observation of my experience that cannot accommodate the bio-medical model, nor appropriate the consumer experience of being acted upon by the bio medical model. I have come to understand of myself, that I am observing the mental health environment as a nurse artist from another perspective or another place. 
In the same way that I explore this place of otherness that I occupy in relation to my colleagues, I also observe that the mental health field environment is a place of otherness in relation to health practices and services of general medicine, surgery, paediatrics, and midwifery. I will introduce some key writers and thinkers and describe the systems of social order that define and constrain the mental health field environment, and the people that are held within it.

The individual who seeks personal freedom, and the institution that controls personal freedom have a tension that exists between them. Individuals, whose behaviour has transgressed societal norms, seek voluntary admission, or are forced by law to accept treatment, safety and support imposed by the health institution. The institution, since the advent of medical consumerism in the early 1990s, must operate as an economic business unit and constantly seeks to discharge the individual back to their specific jurisdiction whether that be into the care of others or their own care.

Somewhere between these two tensions are the people who receive care for severe and enduring mental illness, and the staff who are responsible for delivery of that care.

In the context of this thesis I am interested in modernity as the place of the genesis of current mental health practices, because the concepts which created modernity still principally direct the legislation and enactment of mental health care as it is delivered in Aotearoa New Zealand. Despite post-modern influences and the assertion that there are many truths, when the circumstances of an individual versus the mental health system are exposed, there is a declaration by the mental health system that there is only one truth and that truth is held by the administrators and senior medical staff of the day.

I can remember a woman who was very well known to the mental health services. She was required to demonstrate her return to 'normal mental state' following a manic episode by the adoption of a style of dress that, in the doctor's opinion, was 
not 'flamboyant'. From the psychiatrist's perspective this was considered to be an early warning sign of returning or static mania state.

She showed me that she had two different shoes. Although not too dissimilar to look at, the shoes were of two different sizes. The reason, she argued, was that she had two distinctly different-sized feet. This necessitated her, from her small budget, buying two pairs of different second hand shoes. One circumstance, yet two apparent truths. For the woman, however, the psychiatrist's opinion prevailed and she remained judged as manic. Had she been attending the local drop in centre she may have been complimented on her colour and style.

This story had a wonderful mirror in that one day, in the morning staff meeting called "hand-over", a member of the medical staff looked down in horror to realise that she was accidentally wearing two black but different shoes. The look of horror and amusement all at once on her face was quite something. One of the hazards of getting dressed in the dark no doubt, but solved for her by a quick trip home.

\section{A History of Ordering}

The alternative mode of ordering expressed in a heterotopic site (could be geographical or textual site) is a mode of ordering based upon some idea of social improvement. For Foucault, such utopian thinking is not just about the good society and the freedom it offers the individual, it is also a modern way of thinking about social control

(Hetherington, 1997, p.54).

The following section is based on historical accounts of the work and understandings of Michel Foucault. The concept of heterotopia in relation to social ordering was not perceived by Foucault as unconstructive. "Foucault regards himself as a critic and ontologist, but his ontology is the ontology of his own language, and he views 
criticism not in the conventional sense of a project design to bring us to a haven of understanding, but in the post structuralist sense of to put into crisis" (Megill, 1985, p.183). I put my critique forward in the post structuralist sense then, of putting into crisis that which sits in an artificial haven of understanding. I want to create criticism as a result of project design, that is an alternative to everyday crisis, which is a feature of the mental health field environment.

Foucault, who is considered a postmodernist and a poststructuralist, considered himself to be a participant in the tradition of modernity:

Foucault sought to account for the way in which human beings have historically become the subject and object of political, scientific, economic, philosophical, legal and social discourses and practices. But Foucault does not take the idea of subjectivity in philosophical isolation. It becomes linked with - and even produced by knowledge and power through-dividing practices where, for example, psychiatry divides the mad from the sane

(Horrocks \& Jevtic, 2004, p.6).

This division of peoples into groups of 'deserving' and 'un-deserving' closely aligns with my experience of the mental health field environment. An example of this division is where a person with a diagnosis of mental disorder spends their entire life in a closed and different part of the same city than those people who do not have a diagnosis of mental disorder. A person moving from hospital, to residential accommodation, to supported employment, to sheltered workshop on foot or by hospital or non government organisation owned car does not access the same facilities and resources as everybody else.

For clinical experience to become possible as a form of knowledge, a reorganization of the hospital field, a new definition of the status of the patient in society, and the establishment of a certain relationship between public assistance and medical experience, between help and knowledge, became necessary; the 
patient has to be enveloped in a collective homogeneous space

(Foucault, 1973, p.196)

Foucault observed that the utopian ideals of an ordered society were, in fact, an ordering of society created by the effects of knowledge and power. What he saw in studying history, without judgement or passion, was the way in which the end of Feudalism and the beginning of Capitalism created a group of people who were then not acceptable in the new order.

In writing about the beginning of capitalism Bauman ( cited in Hetherington, 1997) describes:

a period of 'dense sociability' of pre-modern feudal society breaking down as a result of population increase, agricultural revolution and the expansion of urbanbased capitalist markets. Many people were being removed from the land and from their villages and forced to become vagrants and migrants, known in the discourse of the time as 'masterless men'. Old patterns of rights and duties as well as one's place in an established social hierarchy was no longer certain

In using the expression 'masterless men' I cannot help but compare the removal of men and woman from the Institutions in New Zealand in the late Eighties and early Nineties, which very closely resembles this 'putting off the land' and into forced vagrancy. A particular character that I knew for years, whom I will call Adam, was a strong figure in the context of the hospital institution that he inhabited. He had been rejected by his influential family as an embarrassment to them, and was thus not able to stand in his rightful place on his home marae (focal point of settlement for Maori). He had made the hospital social buildings such as the hall and church the location of his own personal marae and there he loved to open social events with great oratory, flourish, and ceremony. His words in powerful running chains were made up of his rudimentary knowledge and memory of the Maori language and other guttural sounds that fitted the required length of speech and formality. It was like listening to 
someone speaking in tongues, witnessing another person's spiritual phenomenon outside of my understanding. Adam's speeches gave me a sense that I could understand every word he said. I was able to be inside it with him, and so were other listeners.

Years later, after the closure of the hospital and relocation of patients to residential housing, I was in the city going to have an early morning coffee at a café and found Adam huddled in a doorway opposite the cafe. He had a too small brown tweed men's suit jacket on and a pair of blue women's tights and rubber soled shoes with white laces. His nose dripped from the cold and he held the sides of his coat together. He was hours early for the opening of the community organisation that had been assigned to manage his money, but waited patiently outside, knees under his chin, to get the five dollars he was due for allocation for the day. I imagine that passers-by may have found him strange and threatening in his tights with his shock of white hair, and with mucous on his face. I knew so much of this man that I looked with love at him and spoke to him, and my heart was heavy as my early morning coffee treat came to more than five dollars. Within the local streets and city shops Adam's mere presence had the power to invoke distrust, revulsion and a shying away from him, as he had by virtue of his diagnosis and consequent dishevelled and unkempt look, lost his place in an established social hierarchy. I wonder whether, if his family had not rejected Adam in the first place, would he have become a victim of the mental health system? And so the question could be asked: was Adam's dysfunction a threat to his family, which led to his rejection? or, was Adam's rejection and then dejectedness a symptom of his family's dysfunction?

Bauman (as cited in Hetherington, 1997) observes that the result of this rejection from previous familiar domains of land, work and place, was an emergence of “social anxieties" (p.59):

Masterless men, vagrants, criminals, witches, Gypsies, Jews, madmen and so on became the representative and personification, the scapegoats, of this social ambivalence or lack of order. 
Through their lack of integration within society they came to represent the breakdown of order; they were perceived as its cause rather than its victims and this made them appear as a threat to the newly emerging social order

(as cited in Hetherington,1997, p.59).

This so called 'newly emerging order' was in fact the separation of those people who were charged with exhibiting social ambivalence or a lack of order, from those who had been granted approval by virtue of their social status and were integrated within an accepted and ordered social group. Anyone outside of this accepted group came to be considered a threat and the cause of breakdown in law and order.

Whilst this emergence of social anxiety was a feature of fifteenth century England, it can be seen repeated in the mental health environment that I have practised in since 1986. Medical consumerism was highly valued at this late 1980s and early 1990s time, and resulted in the closure of the asylums as places of sanctuary. It was assumed that the newly emerging social order of integration of people with experience of mental illness into 'normal society' would dilute, and perhaps eradicate, some of the features of the behaviour of patients who had previously been grouped in institutions. The theory was one of 'divide and water down', or that exposure to 'normal' people by everyday association, would raise the performance of those people considered aberrant.

There was further loss of stabilising factors for these displaced peoples, as Bauman believes "The sanctions of the local community and church, were no longer effective over a mobile, migrant population moved off the land by agricultural enclosure and the development of the distinctly capitalist arrangements" (as cited in Hetherington, 1997, p.59). 
The major purpose of the modern state, according to Bauman is to:

order and regulate society by policing, controlling and confining those who come to be seen as the source of its ambivalence; not by exiling them beyond the city walls but by locking them away in some special place that comes to represent order

In our society one place has become the locked mental health inpatient adult acute service buildings. These environments within all Aotearoa New Zealand central cities have become the representation of order and control over perceived irrational, dangerous and erratic behaviour that the public demands exist for the housing of those individuals who transgress rules of social order.

Bauman (as cited in Hetherington, 1997) describes how:

the Enlightenment philosophers, and later intellectuals, promoted themselves as potential legislators for this state...As the experts of reason, they were able to decide what order meant, separating it off from the chaos or ambivalence of superstition, opinion and prejudice. Reason became the principle upon which social ordering was to take place. It defined what was to be ordered and how this should occur

Bauman's view becomes critical to my understanding of the basis of the ordering of modern society, and/or understanding the principles of confinement of people with an experience of mental illness. Foucault's observation of the treatment of people with a mental illness during the classical age: the end of the sixteenth and the seventeenth and eighteenth centuries, led him to describe the processes of ordering and classifying of people who were incarcerated in asylums. 


\section{Surveillance as Ordering}

Foucault wrote about the prison and the panopticon as features of an incarcerating society. The panopticon, as a mechanism of power, was designed by philosopher Jeremy Bentham in 1791 to observe (opticon) all (pan) prisoners without the prisoners being able to know whether they are being observed or not (Horrocks \& Jevtic, 1997). Thus "the seeing machine has become a transparent building in which the exercise of power may be supervised by society as a whole" (Horrocks \& Jevtic, 1997, p.118). Foucault wrote " $\{\mathrm{He}\}$ who is subject to a field of visibility, and who knows it, assumes responsibility for the constraints of power...; \{he $\}$ becomes the principle of \{his\} own subjection" (pp.202-203). Such surveillance applies to the sense that people who are locked in acute mental health ward areas have, where despite the fact of there being no cameras in most ward areas, there are just enough cameras visible to make the person believe that they are under constant watch and therefore their behavioural response is to closely monitor their own conduct. This is to the benefit of the power structure and at the physical and emotional cost to the person as they are under a level of stress brought about by being constantly watched by themselves or others.

Foucault notices this new technology of surveillance that came to influence the army, schools, and factories, was also used as a supposed means of controlling infection, crowding and proximity in hospital settings. Most importantly it was envisioned as an "open" health care architecture but this "open" design was one-sided in that it allowed the patient to be surveyed but the same was not so for the surveyor ( Horrocks \& Jevtic, 2004, p.118)

Foucault uses panopticism, and its construction, to describe the ways in which power is exercised and knowledge is formed in our society. Foucault (as cited in Warschauer, 1995) argued that panopticism has created "a level at which the formation of knowledge and the increase of power regularly reinforce one another in a circular process" (p.17). He goes on to argue that this surveillance may fulfil a humanitarian role "by immersing people in a field of total visibility where the 
opinion, observation and discourse of others would restrain them from harmful acts" (as cited in Warschauer, 1995, p.17). Foucault proposes that this total visibility may have an indirect beneficial effect in exerting behavioural control yet, in my judgement, the indirect harm caused by constant subjection to the opinion, observation and discourse of others without being able to value one's own discourse is detrimental to the human spirit and, in this situation, hope dies.

The reality for most people who are admitted under the Mental Health Act for treatment and assessment is that they expect that this intensive period of total visibility ends as they become well and are discharged. A large percentage of those initially under the Mental Health Act however, remain on a Community Treatment Order which is, in essence, a long term use of surveillance and control.

\section{Madness as Ordering}

As an historian Foucault was able to describe the:

classical era of the $17^{\text {th }}$ and $18^{\text {th }}$ centuries in Europe to show that madness is an object of perception within a "social space" which is structured in different ways throughout history. Madness is an object of perception produced by social practices, rather than simply an object of thought or sensibility which could be analysed

(Horrocks \& Jevtic, 2004, p.39).

In the Aotearoa New Zealand context, as a nurse, I have had the experience of being part of mental health field services that consider the individual's experience of psychosis, in particular the response by a person to unseen stimuli and 'hearing voices', as purely a phenomenon of diagnosable illnesses such as schizophrenia or mania. This enables society in modern and every-day contexts, despite efforts to educate the public about the diversity of mental illness and cultural beliefs and practices, to continue to exclude the person who is said to have this experience of psychosis from the social group that is deemed acceptable. 
I have also been part of mental health services where the 'social space' is defined by the cultural practices of Maori mental health workers. In this space the response to unseen stimuli or 'hearing voices' is that it is a legitimate experience of the individual who is in communion with their ancestors, and not necessarily reported as illness. In this way I also argue that madness per se is an object of perception produced by social practice. This is at odds with my nursing training and despite a dominant form of social control exerted by constantly checking and observing, stigmatising and discriminating against people with an experience of mental illness in the mental health field environment.

Foucault saw madness or unreason as something by which 'reason' could be defined at particular moments in time. Horrocks and Jevtic (2004) state "for Foucault the only way for madness to live "in itself" outside of authoritarian reason, is through art and philosophy" (p.46). This is an interesting thought when many mental health consumers in the present day argue the sanctity and value of their experience of madness in their overall life journey. Lee states in "Kia Mauri Tau!: Narratives of Recovery from Disabling Mental Health Problems" (Lapsley, Nikora \& Black, 2002):

The other day we were talking about woundings in life and, I mean, I'm not comparing myself to Jesus (laughs) but...this experience has given me wounds that makes me maybe accessible to people, that people who haven't got the wounds aren't accessible

The practice of dividing the social placement of people who experience mental illness from people that do not, can be demonstrated in the limited comparative movement within the mental health field environment of those who have a history of using the mental health services, and those in society that do not carry this label. Social restrictions are placed upon people with an experience of severe and enduring mental illness which result in forced occupation of marginal spaces. The spin off 
from not being able to qualify for work, for example, necessitates a Work and Income New Zealand (WINZ) benefit. This minimal weekly allowance results in a lack of funds for transport to go anywhere, or for decent clothing to put on to go, and a no entry fee to places that most other people access regularly such as restaurants, bars, concerts, and movie theatres. In general places of recreation, education and entertainment are the domain of those considered 'normal'. By default or design people who do not transgress societal norms are rewarded by permissions to enter and have access to, interesting and desirable places. It has also become important to be seen in these interesting and desirable places as part of the modern "spectacle".

\section{Capitalism as Ordering}

Spectacle is a term that Guy Debord wrote about in 1967 in "The Society of the Spectacle". A translation of the original French version made by Donald NicholsonSmith in 1994. (boy, a.h.s., 1996, p.1.) argues that "Debord's intention was to provide a comprehensive critique of the social and political manifestations of modern forms of production and the analysis he offered in 1967 is as authoritative now as it was then". Debord wrote:

\footnotetext{
"Thesis 1

The whole of life of those societies in

which modern conditions of production prevail

presents itself as an immense accumulation of

spectacles. All that was once lived has

become mere representation."
}

(1995, p.12).

In Thesis 10, Debord (1995) argued that the Spectacle is that phase of capitalism which "proclaims the predominance of appearances and asserts that all human life...is mere appearance" but which remains, essentially "a negation of life that has invented a visual form of itself "(p.14). The irony of the person with an experience of 
mental illness being referred to as a consumer would not be lost on Debord. In a way it is finger pointing by a society that lives to shop.

Debord has been proved to be right in his judgement of the progress of modern conditions. He also sought to direct us in surpassing the spectacle by resistance, in theoretical and "practical struggle" that is brought about by the desire for consciousness $(1995$, p.154). I have attempted in this thesis to heed his words, by surpassing the spectacle of modern mental health care systems, where mental illness is sold to us as commodity and mental health as a product. I proceed with utter consciousness and intent on forming a basis of resistance to the emptiness of habitual and marginalised treatment presented as care.

It could be said that uncovering, in the archaeological sense, was a feature common to Foucault and Debord. Foucault's intention was to show that the basic ideas which people take to be normative and permanent truths about human nature and society change in the course of history. Whilst Debord, as a Situationniste, focuses on the role of appearances and representation, the spectacle is seen as "both cause and result of distinctively modern forms of social organisation" (boy, a.h.s., anticopyright 1996, p.1). Foucault uncovered, archeologically, the relationship between power, knowledge and social ordering, while Debord predicted what social ordering would occur as a result of our burial in the vast mounds of products that represent capitalism. He also offered practical and revolutionary resistance as a means of digging our way out. He said that Spectacle is not an optics of power but an architecture.

The relevance of the relationship between power, knowledge, and social ordering to my thesis is that I ask the question which environment contributes to mental health? I have become aware of the architecture of the environment that contributes to the cause (or prolonging) of mental illness. The mental health spectacle is both the cause and the result of modern forms of social organisation, which seeks to exclude those individuals deemed to create 'social anxiety' in the general population. 


\section{Separation as Ordering}

In my judgement, the understanding of the value of separation in the pursuit of the utopian society, is revealed both by Foucault and Debord. "Central to Debord's analysis of spectacle (alongside Foucault on surveillance) is not a concern with the allure of images or signs but its role in constituting a society based on a principle of separation" (Hetherington, 2002, p.7). "The spectacle is a massive and complex apparatus which serves both the perpetuation of that separation and the false consciousness necessary to make it palatable - even desirable - to the general population" (boy, a.h.s., anticopyright 1996, p.2). Here the example of the national mass media campaigns to sanitize certain chosen forms of mental disorder, such as depression and bipolar disorder, are presented in formulations based on personal reliability, family values and work ethic that is uninterrupted by the presence of the illness. The fact is that people with the experience of these illnesses are detained in institutional care, being unable to find suitable accommodation in the community, gainful employment, or even basic social acceptability. In the past the community wanted to 'put people away', and there is no evidence to suggest that this has changed or that the community wants to support people with an experience of mental illness.

The critical outcome that separation has, as an operant condition of ordering, is in effect a double separation of the mental health field environment and the group of people who experience severe and enduring mental illness, from the rest of society. "Debord insists that spectacle is the development of a technology of separation. It is the inevitable consequence of capitalism's restructuring of a society without community" (Hetherington, 2002, p.7). There are verbal references made to the 'mental health community', but I propose that its suits the state and society to separate, as much as is economically possible, individuals who, through being identified as being ambivalent to social mores, cause social anxiety and consequently are diagnosed as mentally ill. Rather than ambivalence to social mores this diagnosis, relegates individuals, as another expression of a power structure that legitimises the knowledge of some individuals over others? 


\section{Background to Heterotopia}

"Thomas More first coined the term Utopia in his literary satire of sixteenth century society"( Hetherington, 1997, p.viii). Utopia is made up of two Greek words put together. Eu-topia which means good place and ou-topia which means no-place or nowhere. Hetherington says:

this is what modernity has been all about trying to create the perfect society, by turning the nowhere into a good place, more specifically trying to create a society that is ordered and stable and governed properly as well as one in which the principle of freedom is upheld

This pursuit of the perfect society was the result of a minority of intellectuals who reasoned that it must be possible to create a sort of heaven on earth through the enforcement of a set of predetermined values for living, to which all those who wished to belong to this perfect society would adhere. As an intellectual one would, of course, be far removed from the realities of disease, unemployment, poverty, hunger and other such challenges to human effort, to conceive of the simplicity of government as a cure all for the simple fact of peoples lives who were not privileged in society by birth or inheritance. This notion of a utopian society is critical in relation to the fullest understanding of the term heterotopia and its association with Otherness. Utopia professes individual freedom and autonomy, but at the cost of free thought, as all individualism is managed by a power directive of a governmental body of people who make up the rules. 


\section{Places of Otherness}

Foucault introduced the term heterotopia meaning "places of otherness" in a lecture entitled "Of Other Spaces" in 1967. Interestingly it was a term he borrowed from the field of medicine ("MedFriendly.com", 2001). "He used it to identify sites - in linguistic or physical space - where the incongruous and the incommensurable are brought together in tense, unsettling and often transgressive juxtapositions" (Johnston, Gregory, Pratt, \& Watts, 2000, p.236).

Foucault (1967) comments that, perhaps, our life is still governed by a certain number of oppositions that we regard as simple givens: "for example between private space and public space, between cultural space and useful space, between the space of leisure and that of work." (p.2). Certainly we are governed by the notion of the oppositions of normal and abnormal, sane and insane, community and inpatient. Where it will be established that the mental health field environment constitutes heterotopia, I intend to show that in the unsettled nature of this space an opportunity exists for a place of otherness that is not bound by opposition or ordering. Incompatibility, rather than being a reason to separate, exists as a benefit to the elements of play and creativity. The practical desanctification of contemporary space that Foucault (1967, p.2) suggests might occur such as "formalizing it or delimiting it" might help us to appropriate space for people who are in otherwise marginalised heterotopia, as places of otherness, become a possibility for health, play, and gain.

\section{Heterotopia as Ordering}

Foucault described the six principles that distinguish heterotopia from all other spaces. 


\section{First Principle}

All cultures manifest heterotopia: some as sacred places like cemeteries and some as profane like gardens, museums, and ships ("Defining Heterotopia”, 2004). They can be classed in two categories:

\section{Heterotopia of Crisis}

These are places reserved for individuals who are, in relation to society and to the environment in which they live, in a state of crisis (Foucault, 1967). As privileged or sacred or forbidden places an example of this in so-called primitive society would be the menstruation hut.

\section{Heterotopia of Deviation}

Heterotopia of deviation are "those places in which an individual whose behaviour is deviant to the required mean or norm are placed. Such as rest homes, prisons and psychiatric hospitals" (Foucault, 1967, p. 4).

Heterotopia of crisis, then, are those places that are set aside within our communities, historically in rural areas, where people are 'sent'. The removal of the person who has offended the sensibilities of their family or society, is thus out of social view, and returns order and calm to the group. They have the option to visit that person without the person having the reverse privilege.

\section{Second Principle}

Heterotopia have a precise and determined function that may shift over time. A given example is a cemetery. Where once they were beside churches in the middle of town, with the threat of the spread of disease, they were placed in the suburbs (Foucault, 1967). In the mental health field, an institution is a heterotopic site that fits this description of changing in its positioning, in relation to the unfolding of history. Where once people inhabited buildings in the cities, as the numbers of the 'mad' grew they were sent to isolated country institutions that were ex-sanatoriums or returned serviceman's hospitals. Then with deinstitutionalisation all of the residents of these institutions was moved back to the towns and cities. Interests in real estate were peaked as urban investors saw the opportunity in buying residential 
accommodation with guaranteed rents from [ex]-patient tenants, or rural investors looked forward to the sale of large plots of rural land for development.

The institution remains connected to society through an association with it and yet is distant from it, in its social isolation. Institutions, as asylums, have existed for a long time but have held different functions. From poorhouse, to prison, entertainment centre to sanctuary, hospital, and guardian, home to house or flat, to a place of forced practices. Inpatient, outpatient, acute, forensic, long term, intellectual disability, psychiatric surgery, electric convulsive therapy, physical and chemical restraint. These remain heterotopias because they immortalize the deviance they represent.

\section{Third Principle}

"Heterotopias are capable of juxtaposing in a single real place several spaces, several sites that are in them selves incompatible" ("Defining Heterotopia", n.d., p.1). The most obvious example of this is the notion that people are told prior to their first admission that they will be admitted to hospital to restore their health and, upon arriving there, find that they are submitted to a number of experiences of institutionalisation which imperil their health further. The notions of freedom and confinement are the most broad in relation to mental illness when considering the juxtaposing of spaces. Some juxtapositions that exist within the mental health field environment, particularly within the inpatient setting are:

\begin{tabular}{|ll|}
\hline FREEDOM & CONFINEMENT \\
\hline Door & Lock \\
Reception & Police entrance \\
Bedroom & Cell \\
Safe environment & Places to attack, hang, set fires \\
Garden & Ashtray \\
Nursing care & Surveillance \\
Intensive care & Seclusion \\
\hline
\end{tabular}

Table 1: Mental Health Field Environment Heterotopic Juxtapositions 


\section{Fourth Principle}

Heterotopias are often linked to slices of time, as in the functions of a library which is an example of ever-increasing accumulation of time represented by the collections of "all epochs, all forms, all tastes," (Foucault, 1967, p.5), Cemeteries or hospitals are other examples. "These spaces always presuppose a system of opening and closing that both isolates them and makes them penetrable" ("Defining Heterotopia", n.d., p.1). Heterotopia begin to function at full capacity when men (sic) arrive at a sort of absolute break with their traditional time" (p.5). The advent of an illness creates this absolute break with traditional time, which is further compounded by hospitalisation and the initiation of the clinical record that stretches out over time as a meticulous notation of the progress of the illness. In the case of mental illness the perpetual and indefinite accumulation of material is recorded about the passage of the illness across a person (time) in an immobile (or mobile, as this is a nationally based record able to be shared between clinicians in separate towns and cities) place. Within this there are flowing transitory precarious aspects of time. These records can be short, as in the case of the weekly clinical review of twenty minutes or so, or long as in the case conference where the person's whole life is perused in periods of hours and, following break time for coffee perhaps, the next period of time is spent devising a new and improved life path for the individual, who in many cases will not have been invited to join in on this in-depth exploration of their situation.

\section{Fifth Principle}

"Some heterotopias (sic) require rites of passage while others appear to be publicly accessible but hide curious exclusions" ("Defining Heterotopia”, n.d., p.1). "The entry can be compulsory as in barracks or prison, or else the individual has to submit to rites and purification" (Foucault, 1967, p.5). These heterotopia are represented by the special conditions that result in an admission to the mental health services. A person can enter voluntarily but must get permission from the Doctor to leave, so that the voluntary nature of the admission is in fact questionable. If the admission is not voluntary, a person is said to be 'admitted' or 'placed' in a ward by legal process. They are 'committed to' the ward. Leave, or permission to get out, is granted by the 
doctor in 'full' status or 'restricted' status which dictates where they can go, with whom and for how long. The rites and purifications are the submission to a mental state examination a physical examination and the taking of measurements or analysis of the heart, breathing, blood, urine, temperature, weight, skin integrity, and so on. At such a time a person is noted to be sitting, standing, lying, restless or settled, eating, drinking, sleeping, defecating, menstruating, to have head lice, abrasions, cuts, and other treatable conditions. A curious exclusion to these areas are that if the person is a staff member who has become unwell their admission is very unlikely or, if the person has adequate personal funding, they may access a private facility at another site. A person may also be excluded if they are seen to be trying to trick the system into believing they need to be there. This is called malingering and in some severe cases entry is so strongly sought that the conclusion is made that the person must really be ill.

\section{Sixth principle}

Finally, "heterotopias (sic) function in relation to all other spaces that exist outside of them. At the same time they mark a culturally defined space that is unlike any other space, they also act as microcosms reflecting larger cultural patterns or social orders" ("Defining Heterotopia", n.d., p.1). There may be "heterotopias of illusion" which create a space of illusion that exposes real space, to partition even more than usual the sites into which human life is divided. Or, as "heterotopias of compensation" which create another real space as perfect and well arranged and meticulous, as ours is messy, jumbled, ill constructed" (Foucault,1967, p.7). In my judgement, mental health field environments act as heterotopia of disorder so that society can refer to itself, by comparison, as 'ordered'. Conversely the lives of people held within this environment are regulated to supposedly mimic society's normalisation. The result is a concentrated, constructed culturally defined space, in which the social ordering of madness is to take place. The heterotopia of illusion is the setting up of environments of containment that are called care facilities, such as hospitals or community residential homes which, upon examination, reveal the real desire that society has to separate itself from those deemed to be anxiety provoking. 
It would be too easy to say that the heterotopic control represented by mental health services and the health industry was all bad, and that the heterotopic freedom represented by sites of consumer resistance who have snatched their own freedom from the jaws of the mental health system, is all good. I think this has what has made it untenable for so many good nurses to stay in this work. In Hetherington's words "I am trying to find a middle way, seeing places of Otherness neither as panoptical spaces of total control nor as marginal spaces of total freedom (Hetherington, 1997, p.18). I want to be able to stay in the mental health environment and not be compromised as a person to do it.

\section{Heterotopia of the Hospital Environment}

As a staff member I need a key to get in and out of this environment. This key is a representation of my power, and over the years many staff members have literally worn their keys as a symbol of their authority hanging from long looped chains in the pocket in prison officer style or from a safety pin at the belt. The staff member's satisfaction of hearing the keys jangle had quite the opposite effect upon the person they were used to detain.

As a prospective or long time consumer of mental health services a declaration of certified madness is required to get into this environment, and a certified return to normality in the form of safety assurances, is required to get out.

It is at once a place of work and a place of detainment. The purpose of my presence there is to provide freedom. I am encouraged to accumulate experience, to exercise original thought, which can add to my freedom of personal and academic movement. Clients are encouraged to reduce their freedom and movement, since they are required to assimilate into a society that prefers that they have no original thought and demands that they have no deviant thought.

My personal wealth and purchasing power increases. Their personal wealth decreases as jobs are lost, contracts fall away, and people are reduced to the unemployment benefit, sickness benefit, or hospital rate of benefit. 
I am bound by the rules and regulations of relationships in a framework of healthcare, which firmly captures me in a specific position in relationship to all other people who are there. Whereas the Client is expected to be without control as a consequence of a passage in madness and that control must be taken by the staff on behalf of that person.

Time is divided into a series of intervals based on treatment and employment and administration of the bio-medical model. The arrival of meals, for example, is a much-awaited event as, for the client, it is a relief from boredom and an opportunity to relate to the body when all other activity is centred on the mind. From the hospital's perspective this meal is more a treatment as its provision centres on duty of care, regularity, nutrition, and hydration. The social element of eating, as a connecting point for humanity, is lost in the rejection of food by patients, as a representation of another thing they did not choose and which is therefore indigestible. Or alternatively, is jealously guarded and compared with the next person in terms of size, quality and as something to obtain for oneself where other opportunities for personal development are lost to them. In hospitals you hear food before you smell it and taste it because it arrives on trolleys.

\section{Heterotopia of Community Mental Health Field Environment}

Community residential housing and, in fact, the hospital facilities for clients who use mental health services are heterotopia of crisis as Foucault describes. Places where people are placed to be normalised as they have been judged by the community to not fit into society.

People who are placed in community residential environments can be likened to being within individual cells of what is a larger cellular building within a community. I see it as a large hospital that has been sectioned off in economic units and then seeded within the city environment. The person is attempted to be normalised and the house attempts to be normalised also, however the residential 
accommodation house, is really only socially and practically connected to itself and other houses of the same nature.

The idea is to create a home, although most of these environments must stop short of being a family home as staff are discouraged from overtly taking on positions of parental responsibility, but are always expected to maintain a professional role and distance. Residents or 'ressies' as they are sometimes referred to, are related to each other not as siblings of a family or customers of a hotel but as dependants of the residential provider and the mental health system. The position these buildings are allowed to occupy is the space of boarding houses, flats, hostels, ex-motels, essentially those of the migrant, or a transient person passing through. The scale of practical organisation and appearance is greater-than-family and less-than-institution but is nevertheless run on bulk provision that allows for economy of cost. While not seen as a private home they are not a public establishment either, and often belong to no particular owner, being run by trustees or governmental agents who have the benefit of returning to something they own at the end of their administrative day.

\section{The Desire for Inclusion}

It was revealed to me by consumers of mental health services, who were making art, that some people with an experience of mental illness do not have the same sense of permission to enter spaces that require a 'self inclusion test'. For example the glass door, security guard, coat and baggage check-in, ribbon barriers, and finally the layout of major art gallery entrance ways can be enough of a challenge to keep some people out, despite the fact that they have as much right as the next citizen to enter.

Marginalised people gravitate between other marginal spaces to socialise with other marginalised people and to the hospital for appointments.

In summary then, the most powerful observation I have made recently is something that perhaps has passed quite unnoticed by many of my staff colleagues. A pathway which led to the wall mounted cigarette lighter receptacle (locked ward inpatients are 
not permitted to have lighters) had become deep with mud in the winter and large wads of dirt were being brought into the carpeted areas on peoples' shoes. When the weather settled a contractor came to dig out the grass and inlay concrete within the existing borders. At the time the courtyard was locked off so that patients could not use this area for fear they would interfere with the concrete. Sometime during that chemical process of concrete being liquid and then hard, a staff member went to that area and using their oversize institutional door lock key pressed it twice, at the beginning and the end, into the concrete. When a patient wants to go across to the lighter now, they must walk over two impressions of the symbol that holds them captive in this space. This is a sign of the heterotopia of deviation, it is also a sign to me of the validity of difference when one must endure this environmental sign as well as endure the experience of living this sign. I asked around and was told by the person who made the sign, that the key was a symbol of hospital history that is valued by staff. I also believe that it is a symbol of the persistence of these countersites now and into the future of people whose destiny, as dictated by society, is to inhabit the heterotopic site. This peculiarity of the mental health field environment establishes it, in my judgement as a heterotopic site, a place outside of all places.

This chapter has so far considered theoretical and philosophical understandings about the mental health field environment as a place of Otherness. I will now go on to discuss the possibilities for investigation of human experience within this field and the ways in which we are influenced by acquired characteristics which are a product of social conditions. 


\section{Dèrive In Text}

\section{Loneliness and the Spectacle, Moustakas and Debord}

I was most interested to discover Moustakas' 1961 book entitled Loneliness. To read in this small but brimming book a sustained, almost meditative, exploration of what it means to experience loneliness and what loneliness means. Moustakas (1961) writes:

The loneliness of modern life may be considered in two ways; the existential loneliness which inevitably is a part of human experience, and the loneliness of self-alienation and self-rejection which is not loneliness at all but a vague and disturbing anxiety

I related to this text on many levels. First was my own experience of loneliness. This began in my early childhood and I became accustomed to this through a process I adopted of reassuring myself. For this reason I believe the source of my own early loneliness was this sense of "self-alienation and self-rejection" which led to a background sense of personal anxiety. I consciously creatively interpreted things around me that I gave personality and life to in order to promote inner calm and conditions of safety.

An example of this is the fear I had of the driveway that connected my Grandmother's house to my house. I had to run home at nightfall from my Grandmother's house along this drive. A lone owl that lived there would cry out and add to my terror. I invented a set of rules for my safe passage, of car lights passing gaps in the farms hedges that corresponded to my progress from tree to tree up the drive. If I could reach that tree by that flash of light ...I'd be safe. I realise in recalling this memory that in times of extreme crisis in my nursing care of another person I have "lent" them this technique, of progressing moment to moment through agonising physical or mental uncertainty using signs or symbols of safety. 
As I have become an adult the first consideration Moustakas makes of loneliness, of the "inevitable and real loneliness of genuine experience" has become more of a focus. Here Moustakas (1961) says:

It takes creative courage to accept the inevitable, existential loneliness of life, to face one's essential loneliness openly and honestly. It requires inner fortitude not to be afraid or overwhelmed with the fear of being and the fear of being alone

He draws on the writings of Wolfe (cited in Moustakas, 1961) who believed that:

loneliness is an essential condition of creativity, that out of the depths of grief, despair, and the shattered feeling of total impotency springs the urge to create new forms and images and to discover unique ways of being aware and expressing experience

Moustakas goes on to say:

The experience of separation or isolation is not unhealthy any more than any condition of human existence is unhealthy. Ultimately each $\{$ man\} is alone but when the individual maintains a truthful self-identity such isolation is strengthening and induces deeper sensitivities and awareness. In contrast, selfalienation and estrangement drive one to avoid separation. The fear of loneliness is a sickness which promotes dehumanisation and insensitivity. In the extreme, the person stops feeling altogether and tries to live solely by rational means and cognitive directions. This is the terrible tragedy of modern life- the alienation of $\{m a n\}$ from \{his\} own feelings, the desensitisation of \{man\} to \{his\} own suffering and grief, the fear of \{man\} to experience \{his\} own loneliness and pain and the loneliness and misery of others 
There are similarities in this to Debord's Society of the Spectacle (1995) discussed earlier. Both Moustakas and Debord have noticed the effects of isolation but from differing perspectives.

Moustakas points out that there is nothing to fear from a sense of loneliness; that, in fact, this has vast benefits to the individual and to the whole of society. Being able to be authentic and to live an authentic life cognisant of the richness of human experience is a strong foundation for resilience in the face of the challenge of mental illness. For Debord (1995) the commodity capitalist-driven modern society has the 'good life' represented to it as a series of desirable and purchasable goals of socialisation. In fact what really happens, Debord argues, is that people are isolated and immobilised in their commodification, which produces an underlying internal sense of loneliness (as internalised anxiety) that seems to have no basis in the person's outward projection of a 'perfect purchasable world'. This is disturbing to people since they are unable to name why they feel lonely when they are to all intents and purposes surrounded, and even immersed, in the things that they desire: the things which have the power to make them desirable, and the people that they desire to be with who also have desirable things. This subliminally felt self-alienation and self-rejection, experienced as loneliness with no obvious basis, creates an anxiety in the person subjected to modern life, which modern life only serves to increase. This is subsequently problematised as stress and when this stress escalates it is medicalised into an anxiety category of mental illness.

The story of loneliness for people who have an experience of mental illness is somewhat different to those who have never had this experience and remain judged to be normal. It can become evident in one of two ways, the first is an inside perspective.

People who are not able to meet society's norms, have been or become categorised as deviant and are placed in prison or hospital environments of separation. One might think that this would reinforce the feeling of isolation and loneliness, and it does. 
Paradoxically, what can happen is that the circumstances of being separated from society also separate one from the constraints of the spectacle. If you have a mental illness you may no longer be welcome to contribute at an economic level, since the potential to secure employment is limited if one has a medical history of mental illness. Thus, a modern life-produced sense of separation and loneliness is reduced, and what is left is the companionship of others who have felt this sense of, as Moustakas describes, 'genuine isolation', which can lead them to an inner strength. Could this separation also lead to a desire for more, since one has so much less? I was interested to be immersed in the experience of art being made by many individuals, together on a large scale in a common studio. Where one might think that artistic temperament and the desire for solitude would interrupt this arrangement, I found that the sense of making art in company with others who have a similar unspoken history of mental disorder and social exclusion forged bonds of solidarity and inventiveness and genuine joy in another's achievement which was unparalleled in my previous experience in any other art setting.

Meanwhile, from the outside perspective, society continues to amplify the sense of isolation through alienation and rejection felt by consumers of mental health services. Society needs to separate and monitor those that are thus alienated from society as they are thought to be of risk to the spectacle. As Foucault (1971) describes, historically these people in their deviancy are seen to be ambivalent to society's ordering and thus need to be monitored and controlled. They pose a direct threat to this order that motivates social ordering.

The sense of loneliness, through which one might develop resilience and identity, is not afforded to people with severe and enduring mental illness because as a group of people labelled deviant by society, they perform a service to society in establishing the 'other' normal group. In order to prevent people becoming well through experiencing genuine loneliness, the experience is discouraged at best and pathologized at worst. R.D. Laing (1970) captures 'we' as the societal normal group of included individuals, and the group of people labelled deviant and excluded individuals as "other" accurately in his book Knots. Laing refers to someone who 
"has something the matter with him" (p.5). According to Laing's word-knot, the male referred to in the relevant paragraphs does not think he has anything the matter with him. Which is, according to everyone else, one of the things that is the matter with him. He, on the other hand, thinks there is something the matter with us "for trying to make him see there is something the matter with him" (p.6). The group of included individuals assures us that:

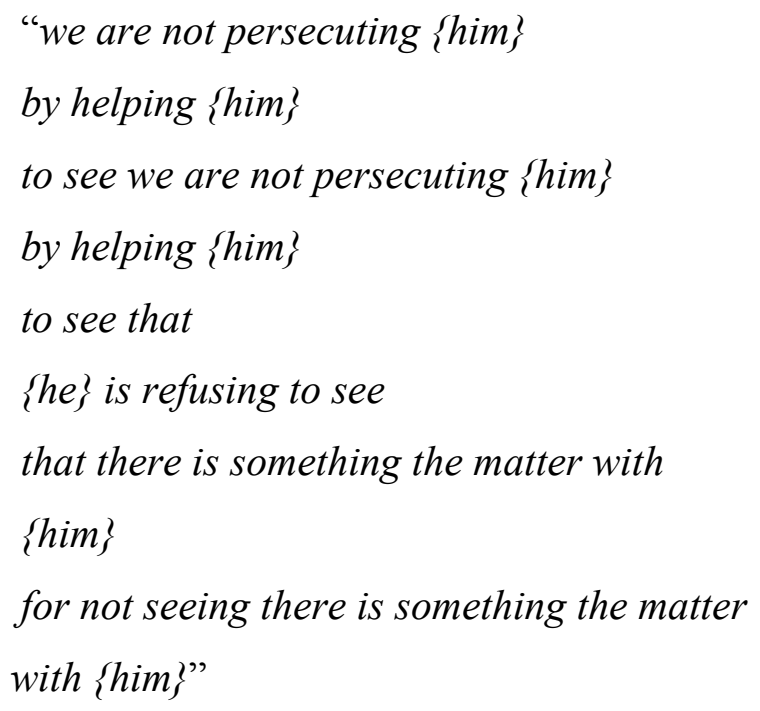

(Laing, 1970, p.6).

The word-knot continues, that it is obvious to see there must be something the matter with him, because he is "not being grateful to us for at least trying to help him". He apparently can't see there is something the matter with himself and so it is almost our duty to inform "him". The "we" ends the self-assured soliloquy with " that we never tried to make him feel grateful".

Laing hopes to have shown within this word pattern enough of the experience of human bondage, so that the reader can refer back to the experience from which they derive. I have certainly been part of countless scenarios where this question of lack of insight is pointed at the individual who is being observed by many staff. Yet they are not so specific that we cannot "divine the final formal elegance in these webs of maya" (Laing, 1970, preface). I think this webbed elegance is the ability that people have to convince themselves that they are worthy of privilege above others. That 
they are more entitled, to freedom of expression and movement than others. That they are more entitled to human experiences, such as loneliness, than others, and by default outsiders are deviant and are to be watched.

People labelled 'loners' in the community, are kept under surveillance by nurses, doctors, sometimes families and neighbours. The encouragement to be involved in life and to not isolate is so extreme that I have known people in the mental health field environment to be locked out of their own bedrooms from 9.00 am to $3.00 \mathrm{pm}$ so that they cannot achieve solitude. Moustakas had the experience of being escorted home by the police with lights flashing, as his solitary night walks in pursuit of immersion in his question about loneliness, aroused police suspicion and censorship (Moustakas, 1990).

Moustakas (1961), in discussing society's reticence to allow people to be solitary, seems to agree with my assessment of the mental health environment. He writes:

We escape our own discomfort and pain, and contribute to the unrealised loneliness of the other person by surrounding \{him\} with company, by talking $\{$ him\} out of \{his\} deep depression, by getting him into other experiences as quickly as possible ( therapies), by assigning \{him\} tasks which will get \{his\} mind off \{his\} plight

In the clinical setting the act of being alone is sometimes referred to as being 'isolative' and can be seen as a risk factor for unpredictable behaviour, or a sign of the person becoming unwell, which generates even closer monitoring and more aggressive treatment. Moustakas comments on the organic nature of loneliness and its necessity for human growth:

Loneliness is as much organic to human existence as the blood is to the heart. It is a dimension of human life whether existential, sociological, or physiological, whatever its derivatives or forms, whatever its history, it is reality of life. Its fear, 
evasion, denial, and the accompanying attempts to escape the experience of being lonely will forever isolate the person from \{his\} own experience, will afflict and separate \{him\} from his own resources so that there is no development, no creative emergence, no growth in awareness, perceptiveness, sensitivity. If the individual does not exercise \{his\} loneliness, one significant capacity and dimension of being human remains undeveloped, denied

Because society fears having a truly genuine experience of loneliness, loneliness has been projected and pathologised, through fear, to the domain of mental illness. Thus placed outside of us we can fear seeing it in the patient and also have the satisfaction of expecting to see it in the patient.

What might it be like, if when in moments of real emotional turmoil as a person admits that sense of deep loneliness, we congratulated them on their achievement instead of admitting them to the nearest secure mental health environment? In preventing and pathologising loneliness do we, as mental health services, essentially prolong or create mental illness?

Moustakas (1961) discusses the loneliness-inducing experience of hospitalisation, and asks why, when we know that clinicians as strangers in hospital environments appear to care more about the medical procedures than the person, can't they (the patients) have at this time, those people with them, who can help them bear this loneliness? Without this support Moustakas describes that the loneliness is perceived as abandonment. He posits that:

The loneliness which the child experiences even when the parent is present is painful enough because in the end there are certain experiences which the child must face alone. There are times when \{he\} will realize how alone \{he\} is as an individual. This is the inevitable loneliness of human existence. But when the child is abandoned, $\{$ his $\}$ terror lives inside. $\{$ He\} will always remember the lonely, isolated hours of abandonment. \{He\} feels that if his parents really loved \{him\} 
and cared for \{him\} they would not have left \{him\} to face \{his\} pain alone...And when a child calls and the mother is not there to answer, then what terror does the child experience in his heart? This terror of the heart is something a person can understand only if \{he\} opens himself to it. Every nurse and doctor would want the parent to remain if \{he\} knew the meaning of the child's desperate existence when \{he\} lay in bed at night, terrified and alone

(pp.38-39).

Might not we, as nurses and doctors in the mental health field, want the (parent) loved one to stay when we diagnose a heart that is filled with terror as the usual starting point of our ministrations, not even as a possible consequence of treatment? Yet we use the physical environment of seclusion to separate a person in every way from the remotest chance of having someone they love or even like, or even another human being with them, as they lie on this seclusion floor or mattress at night and, as consumer feedback tells us (Helm, 2004), terrified and alone.

Of course people normalise to expected behaviours after being in seclusion for hours or days, as the terror of the experience in the heart overcomes the terror of being amongst the people that would isolate you in your hour of need. We seem to have confused the benefits of solitude with solitary confinement. Moustakas' description of a person who is denied loneliness is vivid:

Without any deep and growing roots in the soil of loneliness, the individual moves in accordance with external signals. $\{\mathrm{He}\}$ does not know $\{$ his\} place in the world, \{his\} position, where $\{$ he\} is or who \{he\} is. \{He\} has lost touch with \{his\} own nature, $\{$ his\} own spontaneity

This is an apt description of many people, that I have seen and cared for who have been institutionalised as a result of the diagnosis of (severe and enduring) mental illness. 
A second level of interpretation of this text called Loneliness, which I found fascinating, was the possibility of focussing on something, which could seem at a surface level isolative, and yet further investigation by Moustakas reveals the absolute connectedness of the emotion and state of loneliness that binds us to all nature, things and people.

\section{Investigating Human Experience, Moustakas and Johnstone}

I was greatly encouraged by this work Loneliness in the narrative detail expressed by Moustakas (1961) of the hospital environment.

This intimate story, from my point of view, allowed me an entry point into this most personal of experiences with absolute relevance to my own experiences. I began to see, reading this text, that it could be possible to describe some of my mental health field and nurse artist experience. In the very personal light of my life story and its meaning to me, I could speak without self consciousness or trepidation [for the reception of my good intention which was] to be generalist through relating the specific. To relate to/connect with other nurses, in practice in the mental health field environment, by the revelation of my practice.

Moustakas acknowledges that his developing ability to investigate human experience began with this publication Loneliness in 1961. However by 1990 he had published further works exploring this question which culminated in the text "Heuristic Research: design, methodology and applications".

The methodological phases of heuristic research that Moustakas describes in this text are the basis of how I came to focus on my question and also describe the way in which I began to formulate my ideas. This is discussed in depth later in this thesis in Chapter Five where I describe the project design.

Moustakas named heuristic research as he sought to clarify his own processes of investigation. Heuristic comes from the root meaning of the Greek word heuriskein 
meaning to discover or to find (Moustakas, 1990). "It refers to a process of internal search through which one discovers the nature and meaning of experience and develops methods and procedures for further investigation and analysis" (p.9).

Searching is a mutual experience of knowledge growth, because as the researcher comes to intimately know and illuminate the field of her/his interest, so does the researcher experience growing self-knowledge and self-illumination. Moustakas argues "the process leads investigators to new images and meanings regarding human phenomena, but also to realizations relevant to their own experiences and lives" (p.9).

Moustakas wrote, " If I am investigating the meaning of delight then delight hovers nearby and follows me around" (p.11). The possibility of these types of very lovely experiences are achievable, but he does not promise that it is all so lovely.

I can relate to this feeling, that the thing I am investigating hovers nearby and follows me around. I have been investigating what environment contributes to mental health? The contributing environment in this day and age is generally a physical and mental construction of coercion and normalisation. It is not so easy to have this, at times, dark subject hover and follow me around.

I am sometimes troubled and dogged by this, and uncomfortable in body and spirit by the ways in which this construct gives rise to treatments and behaviours that are performed on people with an experience of mental illness. Yet I stay in this environment to look more deeply, to try to understand the meaning of this, and to search for the good in it that comes from essential relationships with people who I form a connection with. I transcend the nurse patient relationship that is based on the nurse performing tasks and the patient receiving treatment. I specifically choose to go to this place where my being present, as an authentic person and not a representative agent of a system, reduces the pain people feel in being held there. One of the most disarming things I have done in the face of threatened violence borne of real anger and frustration is to simply apologise. 
As Ann Helm (2004) describes:

The fine tuning required to strike an empowering attitude of care is a delicate thing... what really helps is the acknowledgement of our own resourcefulness and innate talents and capabilities. What is needed for such real relationships to happen is a certain humility...Sharing what you know and what I know needs to ebb and flow between us. The reward for relatedness is that we learn from each other

(pp.10-11).

My ability to enter into relatedness with people in the mental health field environment, particularly those with an experience of severe and enduring mental illness, is my sense of Self as being complete with all of my creative attributes coexisting with contrary attributes that mirror them. I am confident and full of fear. I am an educator and a learner. I am directed and I am aimless. I am a practitioner and I am practised upon. I am a nurse and I am a patient. I am an artist and I am a lump of wood.

Subtle forms of social engineering, beginning in our school years, model that we should strive to be successful and to do this only hold positive traits. Any embracing of contrary activity or emotion is counterproductive and thought to "not get you anywhere". Parents, teachers and health professionals see more assertive forms of contrary activity as anti-social.

Rather than accepting being steered away from my contrary nature I have embraced it and called myself artist and, with this, I have discovered a form of social acceptability of my lifestyle that, lived by another name, could have been judged negatively. Within the cultural context of the arts the writer's ability to commune with nature or quite literally talk to the trees is not judged as mental illness. This form of 'letting go' without fear has inherent properties of personal empowerment and insight. I do not differentiate the ways in which I receive information or 
experience emotion as being 'normal' or 'abnormal' in the same way that the biomedical model categorises information. Rather things are represented as signs and symbols of universal significance ordered by their relationships with one another. I have an ongoing expectation of change rather than a fear of it. I can therefore relate very well to the following statement included in Moustakas' book.

Roads (as cited in Moustakas, 1990) entered into a dialogue with his environment, and heard nature speak with him. He said:

how can we write of unseen realities, hint of unheard concepts, or even demonstrate the practicalities of inner truths, without disturbing, the slumbering Self within? The answer: Let go and fall into the river. Let the river of life sweep you beyond all aid from the old and worn concepts. I will support you. Trust me. As you swim from an old consciousness, blind to higher realities beyond your physical world, trust that I will guide you with care and love into a new stream of unconsciousness. I will open a new world before you. Can you trust me enough to let go of the known and swim in the unknown current?

Moustakas (1990) describes this swimming in an "unknown current" as being the most striking feature of heuristic beginnings. "The dawning of awareness may be refreshing and peaceful, or it may be disturbing and even jarring" (p.13). My personal writings regarding loneliness gave me strength because, despite feeling disturbed and jarred, I was willing to submit myself to the phases of heuristic research - in essence I was willing to submit to this process of transformation. These six phases are said to "guide unfolding investigations and comprise the basic research design" (p.27). They are: the initial engagement, immersion in the topic and question, incubation, illumination, explication, and culmination of the research in a creative synthesis.

While this formed the basis of my reflective process I did not go on to use the heuristic method as my foremost tool of data gathering. The reason I felt that this 
method stopped short of offering a final solution to my method search was because of the context of my question and because of the other people and things present in the mental health field environment. I sincerely cannot generalise my experience as a human being to the experience of another person who is held in this environment, when, I as a nurse, am free to come and go.

I was also concerned about the reliance on an "internal frame of reference" that was dependent on understanding the "nature, meanings, and essences of any human experience" (p.26). Moustakas was able to address what can happen if we simply make an assumption about the internal frame of reference of another person. He writes:

our understanding of another person's experiences is distorted when we fail to recognise the phenomenal world of the experiencing persons, when we fail to seek to understand individual's behaviour and experiences through their perceptions and feelings and the meanings that they attach to their activities

He did not say, however, what I should do if I am able to perceive that the internal frame of reference of another person, or even of myself, was institutionalised as a result of an imposed doctrine. In the presence of this anomaly, what challenges are there to the validity of the heuristic research method? Moustakas suggests that this can be overcome by the pursuit of immersion in the question. He refers to Blau's study of anger:

my essential connection with anger has been tampered with and is now entangled in layers of ingested messages. I want to recontact and connect with my natural experience of anger. To do so, I need to look directly at the experience itself; not just my thought processes, bodily aspects of this emotion, or the specific 
behaviours that are emerging. I must consider the full and complete experience to arrive at a deeper more genuine understanding

This is as close as Moustakas comes to acknowledging the possibility that the researched expressed internal frame of reference may be an external locus of control that has been internalised by the person.

I wanted to search for something deeper that gave me a sense of being assured that what I was listening to, and expressing in terms of data, were the essential person 'I', and my lived experience and perception of my world was not just another version of someone else's rules for living. I was not satisfied with the level of rigour in ascertaining authentic voice.

Interestingly, despite much of his work being about the creative possibilities of loneliness when expressed as the power of one, Moustakas does not condone the notion of a heuristic research project with one participant other than in theory (Moustakas, 1990). All of the heuristic research methods are described in detail as the possible quest of the individual but in the final analysis he preferred groups of up to fifteen co-researchers involved in long and extensive interviews. He believed this would achieve "richer, deeper, more profound and more varied meanings" (p.47). While I acknowledge the weight of the crowd, I do not believe the voice of the individual to be less profound.

There is another critical aspect of heuristic research that is both potentially advantageous and problematic. This is the phase of presentation and handling of the data that involves creative synthesis. Here the researcher is, in Moustakas' (1990) words, given the opportunity to be "scientist-artist...the researcher taps into imaginative and contemplative sources of knowledge and insight in synthesizing the experience, in presenting the discovery of essences" (p.52). 
Potentially problematic is that I have a mental image of the lived experience of the People and Things in the mental health field environment, being absorbed through the 'scientist-artist' of the researcher, and synthesized as the researcher sees it. Some of the data may be presented verbatim and thus stand as direct testimony of the People and Things, whilst other data are subjected to three levels of extrapolative synthesis - composite depiction, exemplary portraits and finally creative synthesis.

The positive advantage is the:

free reign of thought and feeling that supports the researcher's knowledge, passion and presence; this infuses the work with a personal, professional and literary value that can be expressed through a narrative, story, poem, work of art metaphor, analogy or tale

(Moustakas, 1990, p.52).

This aspect of heuristic design is the detailed supporting evidence on which I began to formulate my research design.

When considering my position as researcher I was able to build on my self-imposed and longstanding title of Nurse Artist. I substituted in the heuristic research context, 'nurse' for 'scientist' from Moustakas' suggestion of scientist-artist as described in the paragraphs above. The researcher as nurse-artist is given the opportunity of tapping into imaginative and contemplative sources of knowledge when seeking to elucidate meanings and patterns of experience relevant to the mental health field environment.

Moustakas also did not comment on what to do if one is driven, in conscience and political awareness, to make a change to this lived experience that I am seeking to make meaning of. The heuristic quest is said by Moustakas to be "the recreation of the lived experience; full and complete depictions of the experience from the frame of reference of the experiencing person" (p.39). There is no sense of redress or 
'troubling' for the research question that has the potential to raise awareness or burst through/rupture oppression.

This insight revealed the potential research problem of connecting "an intensive and timeless experience of self'(Moustakis, 1961, p.ix) with my need to acknowledge the story of the other person/s present in this environment with me. Particularly when a few people are filled with power and sanctioned to have the dominant voice and many others are disempowered, stigmatised and have no voice.

I had been visited by critical moments of experience and simultaneous insight which allowed me to be as if a shadow, or a mirror, to the life of the person with an experience of mental illness. The lived experience of that person came so close to mine, in me being that shadow or mirror, that I could 'all at once' see what it might have felt like and was then also able to see a possibility for creative change of that experience. This 'opening of the way' would be what I shadowed or mirrored back to the person, to critically stay with her or his own lived experience and yet bring a healing to it.

My life, in being a shadow or mirror companion, within the mental health field environment was such that my lived experience always changed depending on who, or what influences, I came into contact with. There are daily experiences, recoveryable practitioners and powerful events which are very positive and yet there are also too many experiences that are damaging. The personal effect upon me as a nurse artist of experiencing so many acts that created or prolonged mental illness was that I wanted to know what were the elements of this environment that could be separated out as beneficial or creative, which would contribute to mental health.

I needed to find a way to ask the question, which had so powerfully consumed me as I worked in the mental health field environment. I found myself, in truth, not wishing to reveal the sanctity of the darkness of experience that is the intellectual property of the person who experiences mental illness. I was drawn to a much broader idea of 
exemplars, to borrow a nursing term, or artistic representations which had an element of social justice, healing, turning and transformation, within them.

I found a strong point of connection with the work of Johnstone on Reflective Topical Autobiography. Johnstone describes the steps of Reflective Topical Autobiography, which adapt heuristic research methods, and phenomenological research approaches. The connection between this research approach and Moustakas' 1961 work is that 'loneliness' has been described as a 'reflective topical account' (Johnstone, 1999 p.25). Johnstone's work, drawing on Moustakas parallels his phases of immersion, incubation and illumination. Moustakas' other phases, in particular the phase of creative synthesis, are inherent within the process.

The reflective topical autobiography quality of open-ended ness makes it possible for me to return again and again, even within this thesis, "to re-read, re-vision and re-tell the story in the light of new insights, understandings and interpretations of meaning acquired through ongoing lived experience" (Johnstone, 1999, p.25)

Reflective Topical Autobiography has the potential to advance nursing inquiry and knowledge since it has as its project what is described as "turning point experiences", an illumination of what has been, for the researcher, "a personal challenge and puzzlement in the search to understand one's self and the world in which one lives" (p.28). This importantly serves the purpose of making lived experiences directly accessible to others. Told as a self-life-story as research and not as the only or end story it gives an "account of the lived experience of the self that advances shareable understanding of common human experiences" ( p.25).

The autobiographies of mental health consumers of the 1950's and 1960's showed the potential for richness in self-life-story. Nurses have been involved as documenters in telling these stories as the biographers of the life stories of others. In this thesis I have particularly chosen the qualities of this method in being able to more accurately record the stories of 'the self'. If I am able to consider my own experience and thus connect with others' experiences it may be possible through a 
personal parallel reflective process, which gives deep introspective information of the self, to make interpretive responses which align with others' interpretive responses. The 'topical' reference in the term reflective topical biography refers to the snap-shots in time, which are available to me from my awareness of the landscape of topical interest that makes up my experience. These snap-shots invite comparison and I am able to revision them by my ongoing experience. There is an open-endedness and creativity about this ability to revision one's experience, which allows the possibility of a re-contribution to "shared sociological projects of investigation and increasing understanding of the commonality of human experience" (Johnstone, 1999,p.25). This is, therefore, a ceaseless project that never claims to have told the whole story for myself or anyone else.

\section{Habitus and Cultural Safety, Pierre Bourdieu and Irihapeti Ramsden}

I am shaped by the mental health field environment and I seek to reshape what I am part of, because it is intolerable to me to simply observe this mental health field environment without feeling the desire to begin the turning and the changing of it, to reduce its capacity to prolong or cause mental illness. Yet I must walk a path that is divided. A path of acceptability and boundaries of role, challenged by interpretive creativity and expression of role.

I also sought a way of overcoming the impulse to blame myself, or other individuals, within the mental health environment, for the occurrence of acts of oppression which resulted in stigmatising of people with an experience of mental illness. Guilt is not a helpful basis for action.

This is reinforced by Ramsden who insists that all forms of abuse must be recognised and named. Her focus is cultural abuse but the principal remedies remain the same for other abuses. "With honesty, self-examination and professionalism, much of what is happening can be stopped and reshaped" (Ramsden 1994, p.19). Her grace, generosity and insight as a Maori woman who has experienced cultural abuse first hand, reveals the desire that she had to find a workable solution to abuse. "Personal 
guilt for past activities must be avoided since guilt is not a useful creative base. Each of us should accept responsibility for informed future actions personally and institutionally" (Ramsden 1994, p.19).

I always understood that the solution was in the ability of the individual to change their practice but the cause was to be found in the forces that created the haves and have-nots the, normalised and the abnormal, and other power/knowledge imbalances.

Maori comment that the actions of some pakeha who ingratiate themselves out of guilt are far more likely to be perceived as racist than someone who is just purely ignorant of cultural mores. An aspect of this debate was emphasised in the New Zealand media by coverage of pakeha insisting on answering corporate and private telephones with the greeting Kia Ora (hello, thanks, good health) and adopting the wearing of culturally significant but mass produced bone jewellery. Similarly, those mental health workers in the field that act from a foundation of guilt or sympathy are far more likely to re-stigmatise people with an experience of mental illness. My personal experience of this as a nurse is when people congratulate me for my ability to 'work with those people' because they 'couldn't do it'.

A progressive and freeing form of thinking which may overcome some of this personal 'troubling' and possibility of acting from guilt, is to be found in the work of Pierre Bourdieu writing on Habitus. Bourdieu explains for us that the definition of habitus is as a "system of dispositions, that is of permanent manners of being, seeing, acting and thinking, or a system of long-lasting (rather than permanent) schemes or schemata or structures of perception, conception and action" (Bourdieu as cited in Hillier \& Rooksby, 2002, p.27-28).

The relationship that I identify between the literature and thinking of Bourdieu and Ramsden is that they both recognize the same source, where the seeds of this abuse are sown. This is in the socially engineered education system.

For Ramsden it is the neo-colonialism that obtains or retains influence over countries by economic, political and other means. Here she states, "what is offered to Maori 
students throughout the primary and post-primary education system is a powerfully reconstructed version of history utterly deprived of the vigorous truth of colonial and subsequent Maori, Pakeha and Crown interaction" (Ramsden 1994, p.19). "Ignorance is the main requirement for the creation of competent racists" (p.20).

Can we understand, through Ramsden's insight, more about the abuse felt by people who have an experience of mental illness by realising that ignorance is the main requirement of a competent stigmatiser? The education system has priorities and directions that are selected to fulfil agendas, and fails to equip people with the skills to make informed and balanced decisions (Ramsden, 2004).

Bourdieu (as cited in Salerno, 2004) gives another way to see this problem. He asserts:

significant cultural systems such as educational systems present us with ways of looking at the world and making sense of it. This is done through imposing the use of language and other cultural symbols by those in power on the rest of the population. Through this symbolic system, dominance is maintained over society by a relatively small group who secure legitimacy. This legitimacy helps to obscure the power relations, but it also bolsters the position of those in power. The educational system, in particular reproduces and sustains the existing class and power relations

He does however give us an interesting insight into how these positions of power and subordination are maintained by both groups.

Firstly however we must grasp the concept of field as Bourdieu intended. Ramsden discusses field as 'the colony'. What was tribal land of her whanau (family), hapu (sub-tribe) and iwi (tribe) becomes a colony under the influence of colonisation. Bourdieu intends us to understand field as "a structured system of social positions occupied by individuals or institutions. Each field is a network or social arena in 
which there is a concentrated struggle over specific resources or outcomes" (Salerno, 2004, p.220).

Ramsden might agree with Bourdieu's description of field in the light of the current struggle between Crown and Maori to retain ownership of the foreshore and seabed. Bourdieu might agree with Ramsden in the light of the attempt of the coloniser to 'rub out' the cultural capital of the indigenous owner thereby reducing the power of the voice of dissention. I can agree with Ramsden and Bourdieu in light of the concentrated struggle between physician and consumer to own the resource of intellect and intellectual property and mindfulness and the outcome of mental illness and mental health.

The interesting point that Bourdieu goes on to make in regard to habitus is that a number of fields constitute a society, and a number of people who have had personal and social parameters set by cultural conditioning in "outlooks and opinions, personal deportment, and even bodily posture" (Salerno, 2004, p.220) as habitus, will comprise a class society.

The important recognition, for me, is the way in which Bourdieu is able to describe the nature of the locked-in cycle of this field to habitus, habitus to individual, and individual to field. This does explain the way in which I am part of this system and the importance of this study in being able to recognise that I am both a product and a producer of my experience.

Each field has its own particular logic, value, and belief systems, and is characterized by a hierarchy of institutions or individuals engaged in power relationships; and each has a relevance that is simultaneously a producer and a product of habitus

(Salerno, 2004, p.220).

My attention now turns to how this field operates and I am able to reflect on the work of Debord on Spectacle and the field as described by Bordieu. The Spectacle [or 
social field] is where society has been reduced to the mere relationship between production and consumption. Bordieu's field is also subject to market forces. This market has its own "producers and consumers of goods and sees the struggles within and between fields as centring on four types of goods: economic capital, social capital, cultural capital, and symbolic capital" (Salerno, 2004, p.220).

Economic capital is about money and the building of wealth and one's access to wealth or, in the case of mental health consumers, the ways in which wealth is denied to them. Social capital is the social relationships and links that we have and maintain with each other. Cultural capital is "legitimate information and knowledge", specific in Aotearoa New Zealand terms to indigenous and colonial peoples and thought to be "frequently the sources of domination through which intellectuals produce culture" (Salerno, 2004, p.220). Symbolic capital is the amount of honour or prestige, or mana in Maori culture, possessed by each actor in the field. For this is where:

Positions of dominance and subordination within each field are determined by the amount of cultural capital possessed. When one's possession of cultural capital is thought to be more valuable than the capital of one's competitors that agent gains the right to impose its values on others. Conquest is the imposition of one symbolic system on a group by another through the use of symbolic violence

(Salerno, 2004, p.221).

Rather than the effect of determining our response before we begin to act, Bourdieu points out the possibility that this concept could help us overcome some of the vicious cycles that exist in our sped-up world that demand from all of us rapid adjustment and multiple roles. He uses the example of architecture where the structures we build and inhabit create the habitus we display (Bourdieu as cited in Hillier \& Rooksby, 2002). My example is the vicious cycle that exists between diagnosis of mental illness as architecture of illness and the structuring of perception, conception and action that might become habitus of the person inhabiting this geographic and social illness space 
What Bourdieu says about habitus is that we exhibit, within a given field, a style that makes us like the people that are around us. Staff as a group have elements of behaviour which have something in common. Clients that inhabit this same space also have a common or systemic behaviour unto their own group. The social and historical purpose of the environment as a panopticon is oppositional, staff coerce by observation and treatment and clients are coerced by perceiving constant observation and receiving treatment. The habitus displayed by the two groups is generally oppositional and both groups remain locked into this as a vicious cycle, however, as an adaptive response some clients come to display the habitus of staff and staff display the habitus of clients. Habitus is not normally something that we are aware of and therein lies its success and its danger. For as much as we are not aware of our behavioural elements, we are also not aware of where our ideologies originate, and how they are maintained.

Curiously, though, the staff group are suspicious of any client who becomes too comfortable in the ward environment for, as I interpret, the required notion of habitus in the mental health field environment of the patient is to be oppositional. Therefore if a person becomes too comfortable, too quickly, they are seen as personalitydisordered or, interpreted in Bourdieu's theory, they are disordered in their habitus. Anyone exhibiting 'staff-like' habitus traits is viewed as untrustworthy, sly, and dangerous in a way that is much more than physically violent. They may be seen to be seeking attachment and creating dilemmas of transference and countertransference amongst staff and patients.

The danger of this, in terms of staff, is that the staff peer group ostracise any member who is seen to "cross over" to patient sensibilities. The staff member is seen to be no longer effective if they don't value their habitus over the patient habitus. Essentially it is a form of censorship: professional and social control.

Habitus "as the Latin indicates, is something non natural, a set of acquired characteristics which are the product of social conditions and which, for that reason, 
may be totally or partially common to people who have been the product of similar social conditions" (Bourdieu as cited in Hillier \& Rooksby, 2002, p.29).

Bourdieu considers the ways in which we are a product of history as social experience and education. If habitus is not inborn and natural, might it be possible to change history? "That is by new experiences, education or training... any dimension of habitus is very difficult to change but it may be changed through this process of awareness and of pedagogic effort...The habitus is not a fate, not a destiny" (Bourdieu as cited in Hillier \& Rooksby, 2002, p.29).

Bourdieu gives the example of the correction of an accent. I was immediately reminded of Liza Higgins famously singing "The rain in Spain falls mainly on the plain" and the Dr replying" I think she's got it, I think she's got it" (I can hear the sound of the change in her habitus).

Bourdieu isolates three aspects of vicious cycles of habitus, which produce structure ad infinitum:

The first is the way in which we persist in describing things in opposition to each other: Community/hospital, staff/patient, normal/abnormal. "This closed circle is a particular case, namely, the case in which the habitus operates are very similar to the objective conditions of which it is the product" (Bourdieu as cited in Hillier \& Rooksby, 2002, p.30). You might say a self-fulfilling prophecy.

The second is that habitus is not merely habit. It is a:

dynamic system of dispositions that interact with one another. It has, as such, a generative capacity; it is a structured principle of invention, similar to a generative grammar able to produce an infinite number of new sentences according to determinate patterns and within determinate limits...It is a principle of invention, a principle of improvisation. The habitus generates inventions and improvisations but within limits.

(Bourdieu cited in Hillier \& Rooksby, 2002, p.31). 
This is an exciting notion when I consider that despite the traditional power of the institution to reinforce and teach habitus of illness, that even within limits there is possibility for change. I see here the direct correlation between the nurse who is an employee within the confines of the nurse-client relationship as it is held by the health system, and the nurse who can be present and act as healer. This might be a way to describe the level at which I effectively practice.

Thirdly, habitus cannot be considered in isolation from the field in which it operates. Described thus:

as a space of forces or determinations, every field is inhabited by tensions and contradictions which are the origin (basis) of conflicts; this means that it is simultaneously a field of struggles or competitions which generate change. In such fields, and in the struggles which take place in them, every agent acts according to \{his\} position (according to the capital he or she possesses) economic capital, social capital, cultural capital and symbolic capital and \{his\} habitus, related to $\{$ his\} personal history. $\{$ His\} actions, words, feelings, deeds, works and so on, stem from the confrontation between dispositions and positions, which are more often than not mutually adjusted, but may be at odds, discrepant, divergent, even in some sense contradictory

(Bourdieu cited in Hillier \& Rooksby, 2002, p.31)

This shows that I am a product of whence I have come, in every sense of the word. It is my journey but also the journeys of my ancestors and my inheritance of birth which partly account for who I am as a nurse artist. Like my grandmothers before me I have set sail on a ship and left the land of my birth to inhabit a place of Otherness.

In such cases, as one can observe in history, innovations may appear, when people en porte-á-faux, misfits, who are put into question by structures (operating through the positions) are able to challenge the structure, sometimes to the point of remaking it. It means that it is possible to understand and explain the most extraordinary intellectual or artistic revolutions on condition that one takes into 
account (and accounts for) both the subversive habitus of the revolutionary agent... and the field to which they are confronted, the relation, the tension, the dynamic friction between them

(Bourdieu cited in Hillier \& Rooksby, 2002, p.31-32).

Neither nurse nor artist and yet both, I am well placed as a misfit of health and arts culture to bring a rupturing to both of these structures and to challenge them.

Chapter four, which follows, is a consideration of Theoretical and Philosophical Understandings - Another Way. Where Chapter Three considered heterotopia as places of Otherness, loneliness and habitus as a means of viewing the mental health field environment, Chapter Four enters the mental health field environment from the perspective of the researcher involved in the literary psychogeographical method and as a nurse artist, and from the perspective of narrative as a research method of enquiry. 


\section{Art Interval}

Coastal Brew , 2003, oil on canvas, 450mm x 550mm 


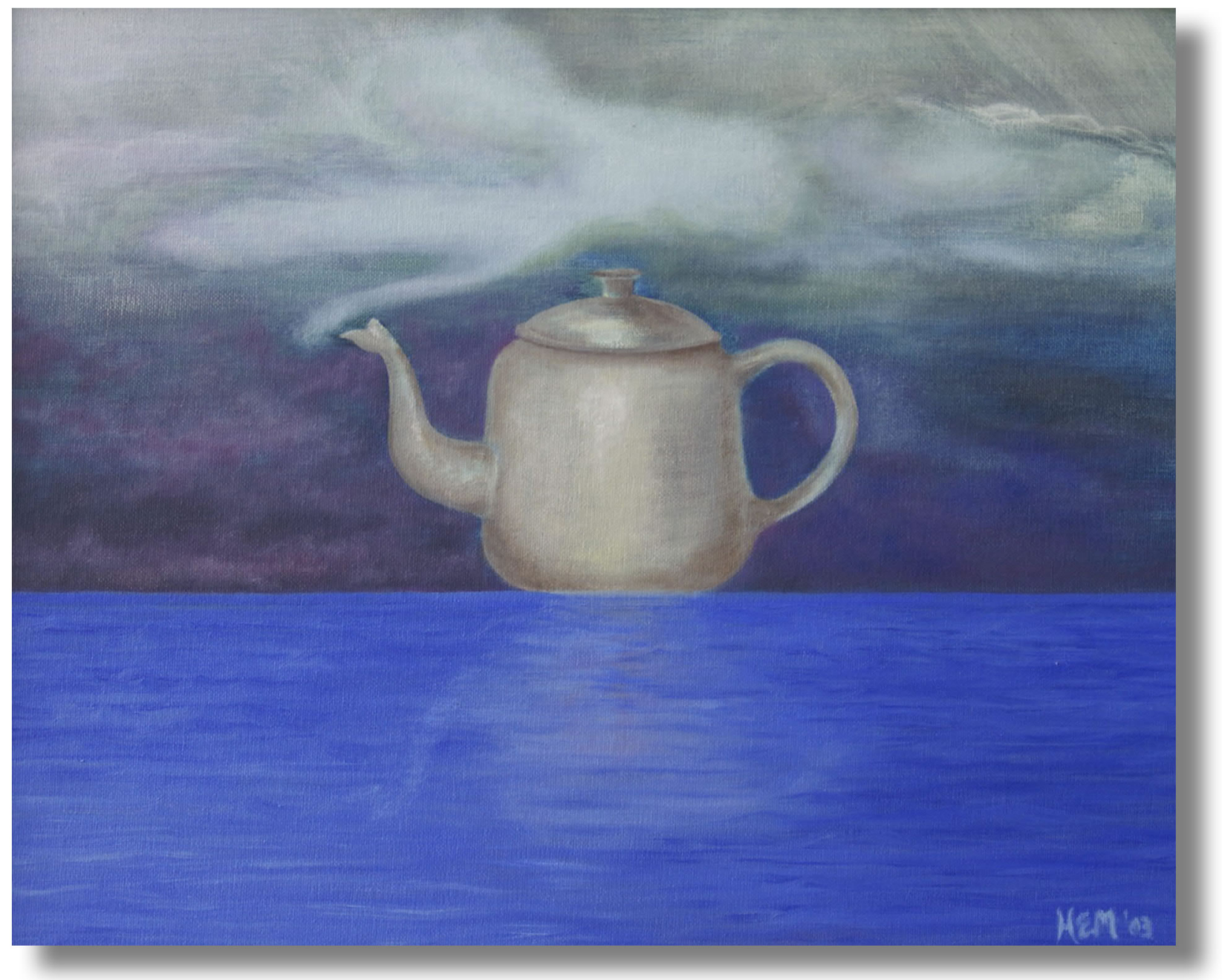




\section{CHAPTER FOUR}

\section{Theoretical and Philosophical Understandings - Another Way}

\section{Literary Psychogeography In Nursing}

Literary psychogeography, as I have stated previously, is a source of awareness that is produced from studying the collection of textual expressions of an age or an era. Some of these expressions are generated by me as a result of direct and indirect personal experience, and others are generated by other people with experience of mental illness. They are also generated from texts by Government agencies, private organisations, media sources, authors, and others who have a particular stake in the metal health field environment. Literary Psychogeography, in this study, is preceded in most cases, by psychogeography in the sense that I have initially immersed myself in the study of the environment as a means to generate a textual resource for the purposes of this thesis. I will now begin to describe to the reader my observations in the field. This produces, by necessity as this is an academic framework not including exegesis, a textual record of this description which in turn can contribute to a further literary psychogeographical analysis.

How do I map the mental health field environment using Psychogeography? This next section of writing suggests the influence that psychogeography has on my observation and thinking about mapping Identity and Environment, People and Things. I have capitalised these terms to identify them as specific subjects of interest in the context of their presence in the world around me, and also as key areas of interest in my research.

I asked myself would it be possible to find a method of observation and inquiry that would allow me to describe my experience of working as a nurse artist within the mental health field environment? As a sculptor I trained and honed my skill in thinking, observing and creating in three-dimensional space. As a nurse I am an 
expert practitioner in thinking, observing and practising in a holistic space which includes the dimensions of physical body, spirituality, family /social context and the mind.

These sensibilities and skills lend themselves to a personal passion for, and specialisation in, the form and creative development of People and Things. This can be defined as; movement of People and Things, and movement of People and Things within space, and movement of People and Things within space over time, and movement of People and Things in space over time and within place. Each of these domains exists in their own right and in connection with the other domains.

I am aware of my exclusion at this point in mentioning animals. The study does not include a description of their influence and presence specifically, however I am loath to not indicate my deep connection and relationship with some animals and recognition of the importance of animals in Peoples' lives. In fact there are some animals that are amongst my favourite group of People and some people that are, by their own word and deed, very Thing-like.

I should also like to mention the role that stray hospital cats have had in enriching the lives of People who live and work in institutional settings. Cats are drawn to the environment to benefit from miles of warm pipes, scraps, vermin and the occasional saucer of milk. Many lonely people, who cannot own a pet due to this not being permitted, I have seen reach out and tame the most wild kittens born under Villas and ward blocks.

Ducks that fly in over the fence for bread from the kitchen could be said to have achieved voluntary admission to the services where, having decided what they need, they come and get it, are fulfilled and sustained, and then leave.

The element that is missing from most mental health environments is the potential of the client to drive the admission. Some wards, however, have adopted the Strengths Model (Rapp, 1998) perspective of care and introduced the concept of a Green Card 
or right of immediate admission to the inpatient ward. This is utilised to great effect, as people don't feel so powerless to get help in the time and manner they wish. The Green Card was described to me (P. Liddy, personal communication, May 10, 2005) as being in use in Timaru Hospital (New Zealand) mental health services, where the management has fully adopted the Strengths Model, based on Charles Rapp's (1998) work, which embraces recovery principles. It has been said to reduce overall admissions significantly, and to reduce the length of stay and severity of the acute phase of illness experienced by the person. The Green Card was introduced by the Timaru staff when noticing that a greater proportion of admissions to the acute unit were by a lesser proportion of the known client group. They began this 'right of entry' card in an attempt to be more responsive to this group who sought frequent admission. Now what happens is that the person contacts staff with a view to readmission, but then declines it since having made the contact seems to be enough.

\section{Defining the Domains - Environmental Field and Elements}

People contribute from their form and creative development to their environment and Things, such as a desk, contribute from their form and creative development to their environment.

Movement of People and Things - organic and other matter is enlivened with chemical, molecular and spiritual energies. There is gross and molecular movement of People as matter, and Things as matter. Within space, People and living and enlivened Things, move in relation to the environment in which they find themselves. Some are apparently physically inert and others are highly mobile. Environments are designed and manipulated to restrict or encourage the movement of People and Things.

Appadurai in The Social Life of Things (1988) notes that even if our approach to things is the conditioned belief that Things have no meaning apart from what is given to them by humans, this does not explain the way in which things themselves have a perceptible historical circulation. An example of this might be the passing of a family heirloom from generation to generation. "female associated Things" tend to be 
passed down female lines and "male associated Things" are passed down male lines. The Thing, in this situation, can be said to have a life history.

Life history is also evident in the circulation of hospital equipment, pieces of which over time become a macabre and curious exhibit in hospital corridor display cases. These Things tend to become objects of nostalgia. The notion of a heroic medical frontier, that has parallels with the Wild West won by the railway, encourages medical cowboys to push deeper and deeper into the human body with advancing technologies. People look back on the steam train and the scalpel as 'something we once did' and the tasks they achieved become a way of glorifying the humans involved and lauding society's progress at large. The movement of Things also has the capacity to effect mediation between people. An example of this is the glass and mercury thermometer which once held a position of Person-Thing-Person. The mercury thermometer required insertion in either oral or anal orifice, or under the arm, requiring a level of development of trust towards intimacy and education between the people involved. The latest thermometers can be inserted in the ear utilising a throwaway plastic cover and requiring a comparative minimal amount of interaction. Medical and hospital-orientated Things also find their way into being second hand store relics and garden items of curiosity.

Appadurai (1988) says that to follow historical circulation of Things:

we have to follow the things themselves, for their meanings are inscribed in their forms, their uses, their trajectories. It is only through the analysis of these trajectories that we can interpret the human transactions and calculations that enliven things. Thus even from a theoretical point of view human actors encode things with significance, from a methodological point of view it is the things-inmotion that illuminate their human and social context

Movement of People and Things occurs within space over time, People and Things are affected by the passing of time in unpredictable and predictable ways. The predominant form of description and interpretation of Being-in-the-world is through 
historicism. In the mental health field environment People and Things become identified by their propensity to be predictable or unpredictable over time. This then dictates the design of the environment that they are permitted to inhabit. Unpredictability engenders closed environments and dependence. Predictability engenders open environments and autonomy of movement.

Movement of People and Things in space over time always occurs within place. People and Things in a particular place take up the valuing or degradation of context and culture, which is highly dependant on environment and time. The effect of historicism on place is the rising and falling of economies. These are commodity driven, political, economy of scale, or cultural. For example, in New Zealand, the response to the rising cost of housing large numbers of people considered to be state dependents in Institutionalised settings which were nearing the end of their viable physical lifespan, was to introduce deinstitutionalisation. A term meaning the introduction of dependents on the mental health services into community based accommodation, and the non-admission of those newly diagnosed. The political and cultural markers of this change were that other governments in western nations had done this as a response to their own perceived problems of overcrowding and financial burdens. The place that received these people who were considered dependents, was invariably the nearest city to their institution of origin since so many people had been lost to, or rejected by, families that 'hometown' often had no relevance for individuals in this group.

\section{People Contribute from their Form and Creative Development to Their Environment}

Form constitutes the physical attributes one has. The senses and physicality of the body that grows and moves is the container for the heart and soul and Self. Creative development is the experience of being in the world as a responsive and interactive life form that reacts to such simple things as hot and cold, and hunger and pain, and can also respond to complex emotional feeling, intellectual reasoning, beauty, and dreaming. 


\section{Things Such as a Desk Contribute from their Form and Creative Development to their Environment}

\section{Thing}

Form and creative development are changing constantly in response to the environment of the Person or Thing. I consider that other living things (not human beings) of the natural world are able to respond to environment in form and creative development. For example a tree feels hot, cold, hunger, and pain and I reason that if a tree can look beautiful and inspire intellectual interpretation and dreaming then it must contain these things. If a tree is milled and then made into a desk, the desk then contains the properties of whence it came, the tree. Things however, are subject to commodification and become marked as a certain kind of Thing. This is dependent on their social value. Two similar desks, one made of pine and one made of oak, do not hold the same value.

As an artist it is important to be able to feel and capture the essence of a thing when it is being rendered as sculpture, drawn or painted. I know that it might be said that I personify the Thing, that I breathe into it and enliven it, with my own persona being projected on to it. I understand the potential that I have to create Things in my imagination and also, in a physical sense, in the world. This is the actual experience of the producing artist.

This awareness is certainly present in my observation of things in the world, but I have always been able to, even as a young child, send my awareness back and around a three dimensional object to 'see' it from the other side. This seeing extends to a sense of the thing in terms of its form and creative development. I am thus also aware of the otherness of the Thing and, in this way, I cannot wholly attribute personification to the Thing. When a separation between it and myself are made, the Thing appears to retain and generate its own qualities. I have come to consider that 
this perception is of a fourth dimension and may be an innate or learned faculty of the person who has accepted their inner artist.

\section{Jug as Thing}

The way in which I am able to view the world then leads me to think about the Things I can see. One particular favourite is the beleaguered stainless steel hospital jug now cast out in favour of plastic.

Heidegger talks about the jug as a Thing, or rather the Thing that could be a jug. He observes "As a vessel the jug is something self sustaining, something that stands on its own" (Heidegger, 1971, p.166).

I make a comparison between the hospital jug that was cast out at the time of deinstitutionalisation, and the person who lived in the institution who was also similarly cast out at exactly the same time. They seem to me to both stand in this way, but not with the ability to stand on their own in a self sustaining way as Heidegger's jug does. In fact the hospital jug and the hospital patient are both dependent - standing in groups defined by outside forces, and sustained by outside forces. Held in relation/ship with the hospital environment, through social context.

When I think about most items in the hospital environment that I am so familiar with, they are all referred to as equipment and supplies. There is really no such thing as the use of usual terms for furniture. We make a clinical quasi-domestic atmosphere for people out of equipment that no one person owns, and yet it is all labelled hospital property.

For example a bedside table is a called a locker, and an over-bed table is called a nightingale and, if the item is not known by a clinical title, then it belongs in a clinical area. For example the chair is a dining-room chair, or a day-room chair or a clinic chair. The chair's existence has become dependent on its label and is institutionalised. 
Heidgger asks the question about the jug, "what does it mean to say the container stands on its own?" (Heidegger, 1971, p.167). He discusses the nature of the Thing in terms of its functionality and its relationship to the person who made it, its proposed use, and the body of the jug as space compared to the space it holds as space. I very much enjoy his argument and have taken my own interest in the jug as a Thing, a step further than Heidegger's function and relationship discussion when he looks at the loss of the true nature of the jug as defined by science's knowledge. I have considered function and relationship but also placed it in a particular space, in a biomedical scientific-oriented environment, which is the environment of the institution or hospital:

To what non-appearance of the thing is thing due? Is it simply that man has neglected to represent the thing as thing to himself?"... “\{Man\} can represent, no matter how, only what has previously come to light of its own accord and has shown itself to him in the light it brought with it"... "Has the thing never yet come near enough for man to attend sufficiently to the thing as thing? What is nearness? We have already asked this question before. To learn what nearness is we examine the jug near by. In what does the jug-character of the jug consist? We suddenly lost sight of it - at the moment, in fact, when the illusion intruded itself that science could reveal to us the reality of the jug

(Heidegger, 1971, p.171).

\section{An example of Deceptive or Premonitory Proposition Détournement of this paragraph...}

To what non-appearance of the person as person due? Is it simply that $\{\operatorname{man}\}$ has neglected to represent the person as person to \{himself\} ?...[Diagnosis] can misrepresent, no matter how, only what has come to light of its own accord and has shown itself to the services in the light it brought with it...Has the [person] never yet come near enough for $\{\operatorname{man}\}$ to attend sufficiently to the [person] as [person?]...What is nearness? We have already asked this question before. To learn what nearness is we examine the jug near by...In what does the [person]-character of 
the [person] consist? We suddenly lose sight of it - at the moment, in fact, when the illusion intruded itself that science could reveal to us the reality of the [person].

\section{Placement of The Thing}

Therefore in my thinking the chosen action must also be considered. The action of placing the jug, as a thing, within a mental health field environment and the action of removing it from a mental health environment.

\section{Placement of the Person}

This has further implications for my consideration of the action of placing people within mental health field environments and also removing them from mental health field environments. Otherwise known as admission and discharge.

\section{Can Things Help Us Understand People?}

Kopytoff (as cited in Appadurai, 1988) says:

A society orders the world of things on the pattern of the structure that prevails in the social world of its people. What also happens, I would suggest, is that societies constrain both these worlds simultaneously and in the same way, constructing objects as they construct people

Maybe I can learn more about what it means to be placed within or removed from a mental health field environment as a Person by considering the experience of a Thing, such as an institutionalised dining room chair. 


\section{Stained}

Always set off at an angle

And trying to appear to have flair

Sorry that my legs are dirty

I'm a hospital dining room chair

I'm light to prevent fatality

Material period stained

Pale plastic and apologetic

I wait constantly strained

Because People [who represent systems] create places and control Things, these are a direct reflection of our state of mind, culture, attitude, resource, expectations and controls. Nature also responds to people's behaviour. It has become evident to scientists that the continued rate of burning of fossil fuels within the earth's atmosphere has created global warming. Predicted dire consequences are already registered amongst populations of animals whose ecological systems are most susceptible to this effect caused by human actions. We expect that the earth will forever support our greed for production of commodities. We do not consider the ecological cost but only consider the profit margin.

Even where there are wild animals, such as ducks that might be said to be voluntarily admitted to the environment, if people have regularly fed them, they too can become a People/Thing within the environment. Things point very clearly to how People in that same environment are treated.

\section{People and Things that are Captured Within Hospital Environments}

\section{Jugs In Hospital Environments}

Once upon a time every person had a bedside table called a locker and on the locker sat the hospital jug. The jug contained water or cordial and was monitored by myself, 
as a nurse, in relation to the daily fluid intake of the person. It was also a routine/ised job of myself, as a nurse, to do a 'fluid round'.

The jugs were particular in their nature because the men in the onsite workshops of the institutions and hospitals manufactured them; therefore they had the quality and aesthetic of the maker inherent in them. For example because the body of the jug was fabricated out of a single sheet of stainless steel, the jug retained roundedness at the base and always had a single high point of contact with the flat surface of the locker which made it roll around a bit. By contrast welded seam jugs have a circular shape cut out for the base and they sit perfectly flat.

These jugs were identifiable as a servant of the health system and, as such, became institutionalised along with every other thing and person who was in this mental health field environment. A hospital jug as such, when removed from the hospital, cannot easily blend into other environments. Its closest cousin being the barrista jug used for heating milk with the coffee machine. Thus I have been drawn to and used the hospital jug as a symbol of affection towards all things I associate with my career and also as a symbol of all peoples and things institutionalised and then deinstitutionalised, only to stand alone and unable to blend into the new environment.

It should be noted that the 'fluid round' was not performed as a routine task in the mental health institution. No attention was generally paid to the functions of the body to note such things as thirst, as all effort was focussed on the workings of the mind. Passing of urine was documented where it required the constant changing of bedclothes and thus additional effort on the part of the caretaker. The jugs were not assigned to the bedspace of a particular patient in mental health environments but mainly circulated on the food trolleys. At the end of a historical period of hospital life, such as with the moving or closing of a ward or hospital, these metal jugs were discarded for plastic. One could say that the hospital jug had been deinstitutionalised. Some found their way to opportunity shops and antique stores along with sister jugs from the NZ Railways Corporation and the Hotel Corporation. These jug Things finding their way to the community was a spin-off of devolution of social and 
economic functions of the government into privatised control, in the same way that people found their way into the community or were forced there by economic stringencies. Metal jugs, like people, were turfed out of environments that provided true asylum, and given plastic jugs and community inpatient or residential care, a much cheaper version, because they were never adequately funded.

\section{Nurses In Hospital Environments}

Nurses have an ability to sense the nature of the ward as a Thing and the People within it. When performing the task of keeping the lives of up to thirty or more patients safe at any given shift, twenty four hours and seven days a week, they are guided by what some call a sixth sense or intuition. As the dérive describes, nurses are drawn to Things and People who need their help and are similarly repelled by or excluded by them. They have an investment in this skill of vigilance over People and Things and spatial awareness, as they rely on this awareness to extend their powers of success in averting disaster. This ability of intuition is not inborn to nurses but develops as part of their progress, as Benner (1984) describes, from novice to expert.

\section{Expert Nurses In Hospital Environments}

Benner describes how expert nurses speak of being drawn to a particular patient's bedside in the night when they have been in the office on night duty, and discovering a situation of life or death that required their attention. Their attention was attracted and gained by sending their three dimensional and perhaps four dimensional senses 'around the space' of the ward. Expert mental health nurses are able to sense danger and safety issues within their field environment. Mental health nurses tell stories of 'having a feeling' about a space (such as a shower cubicle) in the hospital environment only to discover and intervene in self harm attempts such as cutting or hanging. 


\section{Movement of People and Things - Organic and other Matter is}

Enlivened

\section{Nurse Artist In a Hospital Environment}

Heidegger sent his awareness around the jug in a somewhat different way than which I describe myself doing. He sent his intellect around the jug and, as a nurse artist I send my feeling/touch around the jug. This is a way I have developed within my self of sensing the surface of a person or thing with my emotions. As I have developed this skill I have been able to penetrate the outer surface of the person or thing so that I can know the thing as an artist, and the person as a nurse, from a gross level and from a molecular or cellular level.

\section{Development of Feeling/Touch}

I first discovered this in/sight when being taught to meditate, coincidentally at a livein body energy workshop in 1980 at Porirua Hospital, long before I considered working at any institution such as this. In my meditative state I saw myself walking on the hillside outside of the building I was in, and in front of me was a sheep (I may have observed the sheep's presence earlier in the day). Instead of going around the sheep I let myself walk through the sheep and my energetic-being passed through the internal physical nature of the sheep's being. I could see its internal bodily functions in microscopic and cross sectional form such as rushing blood, digestion and electrical activity, there was very loud rushing sound also. Then I stepped out through the sheep onto the grass at the other side of it. My body in psychic form was able to comprehend the similar nature of living beings. I could see there was no real difference, energetically, between the sheep and myself. This was a formative moment in my nurse artist development.

\section{Nursing Development of Feeling/Touch}

If I gather my focussed attention and direct it on a person I am able to detect where in their body they have a thickening of energy that might indicate tension or disease. 
Dolores Krieger (2002) taught a scientifically proven technique to nurses which she referred to as Therapeutic Touch. If I also use my hands in this Therapeutic Touch method at the level of the person's energy field I can be more accurate and my hands are pulled towards the tension or disease in the same way a divining rod is pulled to water. My fingers are more sensitive for accuracy of place than the body of my hand - like the fingers of the divining rod being the pointer.

\section{Development of Feeling/Touch in the Arts}

Creatively it's a bit like the sensation I have had at art school $1983-1985$ when learning to pull clay for a handle of a cup. If there is an inconsistency in the body of the clay even though the outer surface may look smooth as I run my hand, pulling the clay (like milking a cow teat), over the surface I can feel this thickening. In the same way as this thickening may be unhealthy to the person, the thickening may result in the handle not going through the firing process evenly and the handle may be brittle, unstable or break in the firing stress (heating and cooling). I can detect thickening (or thinning) in the body or psyche of a person and, when I have permission, I 'geographically-like' survey them by feeling/touch and with nursing knowledge intellectually I can make an educated guess at a nursing diagnosis and proceed to suggest where appropriate, a person-centred intervention based on my nursing awareness.

\section{Nurse As Psychogeographer}

I believe I am a type of geographer. I think or function in the mode of a geographer. Where a geographer might study the science of earth's form, physical features, climate, or population I, as a psychogeographer, study the art (form and creative development) of People and Things that are to be found within, and in association with, the earth's form, physical features, climate, population and so on. More specifically I study the art of these people as they move into, are within or subject to, and move out of, the mental health field environment. I utilise this powerful form 
and creative development observation to modify my behaviour and action in my nurse artist practice.

\section{Movement of people and things within space - living things, inert and mobile move in relation to the environment in which they find themselves}

\section{Mapping Movement within Environment}

I became interested in the idea of people moving within their environment as an expression of the pressure that they are placed under by the forces of deinstitutionalisation. Later in the progress of my thesis I became aware of the co morbid forces of capitalism (consumption of products) and medical consumerism (production of illness) that relies on the self-disciplined habitual movement of people. In fact what once was a "mobile, kinaesthetic and sensuous individual as part of a crowd" shifts to an "audience, where we learn to look or gaze upon an image effectively as well as ourselves" (Hetherington, 2002, p.4). Above all, this idea is based on culture's role in the disciplining of the body. Furthermore Debord (cited in Hetherington, 2002) describes the spectacle of society as the "development of a technology of separation. It is the inevitable consequence of capitalism's restructuring of society without community" (p.7). People become responsive to noncoercive forms of power that are covertly operational. Rather than the staff at the institution forcing you to shower as part of the expectation of the patient group, now the person is more likely to be subjected to social pressure to conform, and this is confirmed by the displaying of such habits as showering which is then documented as part of the patient record. The pervasive sense of being watched, as people sit in their single roomed accommodation, is what drives 'normalised' behaviours and is a much more cost effective method than custodial care. These are the movements within environment, which are more evident in the post-deinstitutionalised era of today. However where there are staff members in care settings who worked in institutions of the past, the patterned movements of task nursing can still be identified as described below. 


\section{Social Segregation and Forced Social Cohabitation}

This interest in enforced movement/enforced stasis developed directly from my observation of the enforced and limited movement within urban environments which clients of the mental health service make in comparison to other citizens. The person with an experience of mental illness is systematically blocked and channelled into making a limited series of segregated movements: movements that effectively segregate them from other citizens of their communities. This segregation, and these segregated resultant movements, are made as a direct result of this person being labelled with a mental illness. Forced cohabitation and zoning of these houses occurs as a result of communities shunning people with an experience of mental illness, and more particularly those people with severe and enduring mental illness.

\section{Movement and Identity - Past and Present}

My work experience within two New Zealand mental health [illness] institution settings contributed to my view and understanding. I developed an acute awareness of segregation that was also highlighted by the patterned wanderings of clients that resulted from their adherence to daily routine rather than their own desire to go here or go there.

The points of geographical detail of the hospital villas were nicknamed. An example of this at one particular hospital was the seat outside the bathroom area being named the 'bus stop'. The Bathrooms were utilised in a way that maximised the speed of clients passing through the showers for the benefit of the staff. The clients had to assemble at the bus stop in a queue and were undressed sometimes outside or just inside the bathroom door to proceed to be showered and once washed, stand to be dressed and file out. The use of this 'bus stop' seat during the day made an irony of its name. People who sat there had no hope of making a choice about their use of real public transport and, in fact, the person was likely to be going nowhere. 


\section{Routinisation of Movement and Care}

The caring act of a nurse's practice to provide the means to achieve a hygienic state of environment and body can become something that is done to the person rather than with the person: Hygiene of body or hygiene of sleep become a routine; the body and its functions are routinised. The washing of the body or the getting to bed at a reasonable hour with a milk drink, becomes driven by the need for the nurse to be able to state that she/he has completed the required daily tasks rather than something that is offered to the client. The routine becomes more important than the task it was established to accomplish and then the habituation of movement through time and space occurs.

Alavi (2005) argues that "it is not the routinization per se which is potentially a problem, but only that when routines are empty and not part of an embodied exchange between the nurse and patient is routinization problematic" (p.296). This risks the self, as nurse/person being viewed as separate and distinct, and ultimately concern for others in the patient/person role will compete with self interest.

Alavi (2005) describes, "controlled caring" (p.296) which is clearly visible in the routinization of movement and care within the mental health field environment. There is a clear expectation by society that mental health support workers will not only manage, but also control the behaviours of patients. The 'work of caring' for patients with experience of mental illness is perceived as a highly technical and exclusive skill carried out by special people who tolerate close contact with 'those people'. The desire by society for secure containment is also prioritised.

Comments suggest that the more important emphasis of choosing a staff team by skill-mix is not in terms of nursing expertise, but in terms of male to female ratio of staff members. Valuing of technical skill with an emphasis on male strength removes the need for intimate involvement with the patient. If patients are managed by controlled care through their day, without incident, this is perceived as a desirable 
outcome. When the patient is objectified in this way then poor quality of life results (Alavi, 2005) and the self-interest in quality of life for the staff group is given priority.

Not only is the person controlled and segregated into a defined area of society, but their daily life is segregated into sections in which shift changes of staff occur and doctors arrive or leave. This is important to note as a separate item of routine movement because nothing significant happens for a person backward, forward or sideways unless the doctor says so. This is not recognised over time as the effects of routinisation on people are interpreted as 'everything is running smoothly'. Anyone who expresses original thought or individuality may therefore be marked as a troublemaker. Unsafe behaviour or aggression by a patient that interrupts this smooth routinisation may then be more harshly responded to than if they were viewed as an individual.

As Alavi (2005) states "Where the self is viewed as relational then concern for others contributes to a view that one can care and be expected to be cared for" (p.296). Routinization of organisation of the health care system and routinized delivery of health care practice is counterproductive to concern for others. Concern is centred on the nurse's need to perform, thus the relationships between Nurse and Client become routinized and not present or real.

\section{Movement of People and Things within Space over Time - People and Things are Affected by the Passing of Time in Unpredictable and Predictable ways}

Clients with experience of severe and enduring mental illness are particularly affected. The stock phrase of some nurses is 'in a minute' and it can be heard parroted so often in a ward environment that it becomes meaningless, and indicates the endless waiting and wanting for something which may, or may not, happen. The difference between a hotel and an institution is the length of time it takes to be responsive to a client's request. In an institution a client may ask for something and 
the effect of institutionalisation is that they begin to expect never to achieve their expressed goal. The staff member also hears the request, and is able to devalue it by in turn thinking that the client never expects to get it straight away anyway, so the request can be delayed. This produces enormous frustration and anger which, combined with boredom, is expressed by irate behaviour. The bio-medical model neatly puts this down to presentation of illness and 'lack of motivation to help themselves'; a blame the victim response. Staff are not exempt from this and experience the frustration and anger and lack of job satisfaction as stress. There is a particular relationship in the health services between timeliness, responsiveness and motivation that remains largely unexplored

Movement of People and Things in Space over Time within Place People and Things in a Particular Place take up the Value or Degradation of Context and Culture, which is highly dependent on Environment and Time

\section{Movement Influences Identity}

The tendency to create these areas of habitual movement and use of the environment may have changed as the institutions closed and residential community housing was offered in the late 1980s and early 1990s. I now observe, however, that the environment was never the only culprit and the people who had a tendency to use the environment in this routinized way were relocated along with everyone else into the community. The effect was to close the large institutions and to create many more smaller versions of the same thing - small institutions.

This 'behaviour' of blocking and channelling the movement of people who are receiving mental health services into a segregated region is the physical enactment of a societal mind set that requires the separation of the person who exhibits 'abnormal' behaviour from the person who exhibits 'normal' behaviour. As Goffman says: 
"The simplest sociological view of the individual and $\{$ his $\}$ self is that $\{$ he $\}$ is to $\{$ himself $\}$ what $\{$ his $\}$ place in an organization defines $\{$ him $\}$ to be" (Goffman, 1961, p.280).

The consequent observation of a "prepatient", now referred to as a "voluntary admission" has not changed since the writing of Goffman's book in the 1960s. In my judgement the following description of movement into the institution is experienced identically today:

Like the neophyte in many of these total institutions, the new inpatient finds \{himself\} cleanly stripped of many of \{his\} accustomed affirmations, satisfactions, and defences, and is subjected to a rather full set off mortifying experiences: restriction of free movement, communal living, diffuse authority of a whole echelon of people, and so on. Here one begins to learn about the limited extent to which a conception of oneself can be sustained when the usual setting of supports for it are suddenly removed

(Goffman, 1961, p.137).

\section{Social and Legal Constraints for Patients}

Regardless of a person's circumstance, context, precipitating forces, or predisposing factors, once behaviour judged to be 'abnormal' has been exhibited and has been officially (being brought to the attention of the health authorities) noted then this person who becomes a patient with a diagnosis would be segregated from society. This action, in turn, has been normalised into being called an assessment and treatment period. If the transgressive behaviour being exhibited is a contravention of the societal understanding of what constitutes harm to self or others, or self neglect, treatment is compulsorily imposed.

There has been a need to have a national campaign to reduce the effects of discrimination and stigma directed towards those people who experience mental illness. Mental Health Commission directives seek to undo the damage done by 
society and health professionals that would allow them to treat another person as a non-citizen in the presence of a psychiatric diagnosis.

It is possible for people who have experienced this segregation to reach a stage of wellness where they may 'pass' in society without being detected as a person who experiences/experienced a mental illness. However if they suffer any ailment of a physical nature the retrieval of their National Hospital Number will reveal their status as a person who has a Psychiatric file. This is flagged by the indicator of a field on the patient computer profile when information is sought on all general files that contain notes of a medical, surgical, or obstetric nature.

\section{Freedoms for Staff}

As comparison for example, I do not at present have a mental illness which has come to the attention of the mental health services. I inhabit the same environment of mental health service delivery as clients might, however as a staff member I only need to take a lunch break to step outside of this into a "staff only" tearoom. I have the freedom to proceed to my car and thus any part of the city which is in turn accessed by my money, influence, social standing, social acceptability, 'normal' appearance, clothing or general attire, body posture, body hygiene, computer or written record about me able to be accessed by others to assist me or further my interests ....and so on.

In summary then this section of writing about the mental health field environment explicates the cognitive mapping that is possible using a psychogeographical method, where psychogeography is a means to investigate the effects of the mental health field environment. Critical notice of vortices and exclusions enables me to explore a location and its attributes where original and unique responses are made to People and Things [and animals] that I am attracted to, repelled by or excluded from. Cognitive mapping shows the knowledge that I gain of the People and Things and assists in organising concepts, and relations between these concepts are elucidated. Acquiring and storage of knowledge is not the key principle of cognitive mapping in 
the psychogeographical method; more importantly drift and awareness are the desired principles as recall and decoding of this information thus leads to exposure of these effects as a basis for resistance.

The following section of writing in this chapter addressing Theoretical and Philosophical Understandings - Another Way, explores the role of the researcher and strategies of research enquiry. Testimonio as narrative method and discourse reveal my narrative position in critical relationship to the mental health field environment. Reflective Topical Autobiography also contributes as a narrative method emphasising critical reflection, reflexivity and total immersion in the research experience. Whilst writing my own narrative I also study the ways in which the mental health field environment as a dominant culture narrative challenges the voice of Other. 


\section{Narrative As Inquiry}

\section{Introduction of the Researcher}

In order for you the reader to know me I may need to describe in what way I come to know you. Because a narrative after all, calls me to give account of myself and I do not exist but in relation to you, my reader. Beverley (2000):

suggests that the predominant formal aspect of the testimonio is the voice that speaks to the reader in the form of an "I"... a real, rather than fictional person... This is a voice that refuses to be silenced, and the person speaks on behalf of others

(p. 556).

In this discussion on strategies of research inquiry Denzin and Lincoln (2000) comment "unlike autobiography testimonio which involves an erasure of the concept of author. The testimonio uses a voice that stands for a larger whole. This creates a democratic, egalitarian form of discourse (p.375).

I believe that the erasure of the concept of an author in this discussion of what testimonio as narrative, method and discourse describes, can be compared to what the signature on an artwork asks of the audience. To see the artistic intention through the artist's medium but always interpreted by the viewer's eye.

This is in comparison to what the author of a written work asks for. Books, whether fact or fiction, are judged by what the author has taken responsibility for writing.

I present my narrative as text, like a painting, as an object of interpretation. Denzin and Lincoln (2000) point to the 1984 work The Testimonio I, by Rigoberta Menchú where the reader is asked to "identify with the text, and believe in the truth of the text, as the text asserts its interpretations of the world" (p.375). 
Beverly (2000) goes on to say:

The testimonio is an open-ended interpretive work. It may contain passages and reflections that are social constructions, fabrications, or arrangements of selected events from the actual world. These constructions may deal with events that did not happen. In this sense, the testimonio is an object of interpretation. It is not a mirror of the world; rather it stands in critical relationship to the world of actual events

Therefore I put forward my narrative with the greatest respect for the confidentiality and privacy of people who have been present with me in the mental health environment. I do not hold a view like a camera does, taking a photographic record of these times and places of witness that I have been part of. The snapshot in time is a small segment of the topical record of my ongoing experience of these places.

I stand, however, in a position of being able to articulate through my critical relationship to the mental health field environment those practices which might prolong or cause mental illness and those practices which create ground for recovery.

I can absorb something that passes between two people in the time it takes me to walk past a doorway and this fragment of human interaction, the colour and sound of it, the emotion of it, can become a small piece of a larger work that is interpreted by paint or poetry or narrative. If I haven't witnessed the totality of the experience in the same way as might be required of a person if they are a legal witness to an act, this does not make this experience less whole or less valid.

I see myself as being at once, a witness, activator, and a participant in a stream of action, consciousness and behaviour that I am part of and yet separate from. I sift through ready to make the decision of whether or not to make sense of this, to make it fit. Sometimes it is important for the collective narrative of the mental health 
environment that I enter the space of the interaction between others and participate, but at other times it is more important for me to observe the falling of the events and words like leaves falling from a tree in autumn. The pattern and coloured carpet they create is at once random and yet disciplined as circumstances and natural order dictate.

\section{Thinking Narratively}

Narrative inquiry is aimed at understanding and making meaning of experience. Clandinin and Connolly (2000) describe the experience of the narrative enquirer who is in the field and agree with my experience of narrative enquiry: that the experience is always a dual one, of being part of the experience directly and being part of experiencing the experience as the researcher. "The complexity and depth brought on by composing field texts in a three dimensional inquiry space" (Clandinin \& Connolly, 2000, p.80) is an interesting way of considering the nature of this inquiry space. In my enquiry field, texts are cognitive maps which assist in the moving back and forth between full involvement in the mental health field environment, its locations and attributes, and finding distance from this immersion. I suggest that the psychogeography method is operating in a multiple dimensional inquiry space because of the potential of the researcher to be drawn to, repelled by or excluded from elements in this inquiry space which elicit an emotional reaction in the enquirer, but also that the emotional response from within the enquirer can contribute to the research where a discovery of existential relationship with place is recorded.

Several tensions exist in relation to narrative thinking. Firstly, in narrative thinking, temporality is a central feature, but I have intentionally moved away from the notion of recording an event, in most cases, so that it is not recorded with the implication that the event is someone's experience of treatment in the mental health field environment, but rather as an expression of the way people are treated generally in time, history and in space. 
Secondly, in relation to temporality it is also important to acknowledge the people present at any point in time are in the process of personal change. From a recovery approach point of view "it is important to be able to narrate the person in terms of the process" (Clandinin \& Connolly, 2000, p.30).

A third tension centres on how an action is seen as a narrative sign. In the presence of recovery and mental disorder, where constructs of patient care can be at odds with each other, a single expression taken as a narrative sign can be misleading. Without recognition for the narrative history of madness and civilisation, the significance or the meaning of the sign remains unknown (Clandinin \& Connolly, 2000). It is imperative to understand the significance or meaning of the expression as it appears within the field of knowledge and power. As Clandinin and Connolly (2000) discuss in narrative thinking "there is an interpretive pathway between action and meaning mapped out in terms of narrative histories" (p.31).

Importantly in the mental health field environment, where narrative histories of the consumer may have been colonised by the mental health system, the psychogeography method enables the nurse, as part of that power structure and as nurse researcher, to be aware of the multiple presentations of action and meaning.

A fourth tension is centred on certainty which closely aligns with the notion of one truth or multiple truths. "In narrative thinking, interpretations of events can always be otherwise" (Clandinin \& Connolly, 2000, p.31). Rather than just adopting the position of knowing that other possibilities, other interpretations, other ways of explaining things are possible, this is an active moral and aesthetic base of this research project. The creation of space for Other is not an apology for doing 'ones best' where uncertainty reigns, but a response to a call for action where disparity and discrimination exist.

A fifth tension is centred on context, which in this thesis has been addressed fully in other aspects of the description of the mental health field environment. In narrative thinking, the context where it is necessary for making sense of any person, event, or 
thing, prioritises the person (Clandinin \& Connolly, 2000). In this study, however, there are some examples of inquiry into the way in which the context of the Thing reflects the prioritising, or lack of it, given to the Person where that Person has an experience of mental disorder. In my judgement the mental health field environment has the unique ability, beside other heterotopia of crisis and deviance to prioritise events and its own context over Things and, at the bottom of the heap, over People.

\section{Narratives in the Mental Health Field Environment}

People who work in mental health field environment disciplines are 'handed over' patient information from shift to shift [nurses work shifts] and duty to duty [doctors are on duty] that orientates them to the stream of action and divides it, between people, in relation to their patient status. ' $\mathrm{C}$ ' level clients are on proximal (at elbow's distance away) observation, and other clients are given freedom to roam at leisure which is called ground leave or unescorted leave.

In my nursing role I participate in this 'handing over' process and am sometimes required to read patient files, and thus, when I walk into the mental health environment whether it is an acute inpatient setting or community based service, I cannot always take the environment and people at face value since I have been given preconceptions and am privy to information which has already coloured and shaped my view of others. I am already consecrated as a staff member, as the powerful one, and the other person as a consumer walks in hostile territory.

In the main however I am able to refocus my attention on the here and now, that is to bring my eyes to the other person's eyes in warm greeting without judgement, and to say my name and to ask theirs. I greet people in this way that reduces the burden of the diagnosis as part of my awareness.

I learnt to do this to avoid the psychic tearing away I felt when, as an inexperienced nurse or artist, I introduced myself using prior knowledge of the person. It occurred to me after some dismal failures that people sense the approach of others and our 
senses tell us friend or foe, whether to stand or fight or flee. My approach starts before my words, and is a reaching out done in asking spiritual permission to approach into the space and presence of the other person. People felt me approach and accepted me as friend until I opened my mouth and 'staff words' came out, not the words of an unmet friend.

There is nothing so tearing away of the fabric of human contact than to approach a stranger person and already know things such as their [unsaid] shame and pain, age and [said] occupation and whereabouts of their home, and to use this information to mentally construct and say a first hello. Trust walks out the door. This is the practice of the person who is only aware of his or her own narrative in any setting.

I have learnt how to invite trust to stay, I weave some threads of the fabric to be cast between us, I narrate a little non-verbal and verbal story of myself as a gift, an offering. My ability to recognise and overcome my typecast position within this mental health environment gives me a unique view from which to record my narrative.

My sense of self in this environment changes as I am subjected to the responsibilities, ethics, and professionalisms that are inherent in my multiplicity of role. I am at once an artist and a nurse, and a woman, friend, colleague and a researcher. I may not immediately be able to say if my eyes and ears that I witnessed/experienced something with at a certain time, are the same eyes or ears with which I perform a grouped or divided set of roles. Reflection, dreaming, thinking and making art are the places that this knowledge becomes apparent to me, and from which I learn where I have been.

I can however assert that the environmental constraints and paramount responsibilities of safety to clients and to staff, and that I am ultimately an employee of the health service, make it clear that I am often required to behave and act within the requirements of policy and procedure. 
As a nurse within a team I do not always act in a way that the client sees as being beneficial to them at that time. There may be recognition of beneficial effects at a later time. A note on the thank you board in an acute ward says...Received a phone call from (name withheld) expressing her thanks to staff on the ward... She said she felt on her last admission to the ward she felt well cared for and supported and wanted staff to know she was appreciative of the care she received. Sometimes I don't know if it has been a therapeutic experience for people, but sometimes we are directly told of the benefits received. My sense of self is dependent on my involvement as a nurse in a client's care being an experience for that person that does not prolong or cause mental illness.

\section{Challenges to the Personal Narrative}

In the mental health field environment there is the challenge of a dominant culture narrative that precludes the personal narrative. Sometimes team decisions and actions that I am part of, are as a result of a dominant culture narrative, whether that be of a medical or socio-cultural nature. What a person has thought can be affected by the presenting illness and their circumstances of coming to the notice of the police or health care agencies. What a person thinks is affected by the circumstances of the admission, whether they be suffering from psychotic delusion, or under the influence of drugs or alcohol. If medication was administered under compulsion, or in a restraint hold, their version of events versus the voice of authority's version of events will inevitably differ.

We, who have a collective staff narrative, pick up and transfer the narrative of the person with an experience of mental illness to accommodate them more acceptably in society. We also intervene in situations of harm to self and others, which would have changed the course of the client's individual and collective narrative.

On an individual basis though, and as a nurse, I am much more confident in my ability to deliver care that does not prolong or create mental illness. As an artist in the mental health environment I have even more confidence in my therapeutic 
contribution to individual narratives. When Clients greet me I encourage and respond to my sometimes recognition as "oh you're that artist lady". Perhaps the presence of the artist enables me to address the possibility of becoming a nurse who contributes negatively to another's narrative.

Staff who may act in a manner not congruent with their moral conscience probably behave in this way which arises out of the environment of litigation that we now work in (staff charge clients with assault and vice-versa, and staff can be charged with negligence of duty and care), but also the desire to do no harm or see no harm done is great. I believe, however, the requirement for more than just physical safety but also cultural safety and creative safety are now part of my nursing practice. Some may comment that these additional safety standards are more in the artist domain than part of a health gain, however I assert my belief that these are critical in health recovery.

The strong influence of the mental health field environment subtext, of who is 'a client' and who is 'staff', has ultimate bearing on freedoms of movement and permissions of presence within this environment. It also includes me, as a nurse or artist, and excludes me from certain conversations and social groupings.

For example, clients may gather to discuss matters of significance to them and exclude those who do not declare a personal experience of mental illness. Some conversations between clients are about the rights and wrongs of treatments and decisions involving their care. It is not OK to talk about this in front of staff, as there is a consumer solidarity that prevents inclusion of staff (even if they are a consumer of mental health services themselves). Other repercussions could be, where the report of a persons' mental state, their compliance or their diagnosis will be based on or changed by the observation by staff of their interaction with other clients where this leads to anti staff sentiments and outright oppositional behaviour.

On the other hand I could not enter groups of staff that are, for example, gathered in the nursing station chatting if I was not a staff member. At the approach of a client, 
doors are closed or conversation is suspended, regardless of the general or inane topic of conversation.

If I am observed and distinguished as an artist by the client group I experience being more likely to be included than if I were seen as a nurse. Nurses however are much more likely to be accepted and trusted when an interchange occurs on a one-to-one basis. The pattern seems to be that groups of nurses working with groups of clients sometimes invoke oppositional forces but individual nurse's experience of working beside people who are acutely or chronically unwell, is that generally relationships can be successfully achieved when a relationship is built between two people. Therefore, how I am perceived and grouped affects the experiences and information that I am privy to and this affects my personal narrative.

Some activities of nursing are directed by medical protocol, or directly by medical staff which they are not directly part of, or are usually absent from. These prescriptions of care, such as restraint and seclusion and the delivering of intramuscular medication against the person's will are, I believe, responsible for the distrust clients instinctively have of groups of nurses. When we wish to deliver these prescriptions we always approach in groups. Clients may have observed this happening to a fellow client and fear this for themselves.

The distrust, which nurses have of groups of clients, is that the staffing levels are always so low so that if everyone of the client group decided to leave we would be overpowered. Everybody is actually held within the mental health environment by a steady and almost invisible acquiescence to stay: both staff and clients. This is because the society at large which we all might choose to leave or escape to, rejects the presence of mental illness, and the presentation of someone with this disorder as 'normal' and compliant. Should everybody decide to leave at once, the clients would be returned, and the nurses would be returned, to continue this somewhat uncomfortable but symbiotic relationship. 
I have observed support from clients extended to include a person when it is known they have been inside an institution or have received treatment, but usually a personal declaration of survival of the psychiatric system is required before acceptance to the consumer group is given.

The same goes for the fraternity of nurses who may strongly protect the clinical environment that is perceived as their domain of excellence, and the nursing activity that goes on there. They may also need the solidarity of their nursing colleagues in order to continue to return to an environment that is quite punishing every day. Nurses are caught between the bio-medical model and the consumers' rights movement but are still expected to deliver to both oppositional and opposed groups.

In my judgement the difference that other nurses experience in their nurse role narrative to mine is evident when I am either consulted, or a request for my input is made. My suggestions may seem challenging, way out, or weird. For example the provision of a one dollar confectionary or fizzy drink purchased by the service for a reward in a behavioural development plan is seen as extravagant, or as singling out one patient over others, when the alternative is the emotional cost to the patient as well as the economic cost to the service of hundreds of dollars for provision of seclusion. People stare at me in disbelief and say “but we haven't got any ward funds".

This also works in reverse where my difference to other nurses in professional/political position is highlighted by the vetoing without consultation, or undermining of my planned nurse artist-to-client activity. Jokes about clients and derogatory remarks are made in my presence. Some things I can laugh at too, because they are funny, and all of this place without laughter would be unbearable. But some laughter is done with a cynicism and self-assuredness that people can only express from a staff member's position. A smugness that can only be afforded if that person thinks they will never be on the receiving end of the mental health services. What we know about the mental health field environment is that no one has a guarantee of exception. 
I am not the same from day-to-day and moment-to-moment and I may adopt a variety of roles in any given situation as enactor or observer. The effect of time also has a part to play, as events that affect my personal narrative may be strangely repeated in the inevitably recurring nature of the psychiatric system. I get my coat caught in the 'revolving door' that people with an experience of mental illness go round and round in, and suddenly it can be all the same for me too. Maybe, for this reason I seem to repeat myself in different ways throughout the thesis.

\section{Progress of the Narrative - Temporality}

I am not able to deliver a progressive narrative of events from the beginning of my research until I finish writing this thesis, as I am deeply affected by events that happened in the mental health field environment that I inhabited in 1986 and these events continue to change who I am today and how I respond to events. Therefore my narrative is not as a statement of fact but in critical relationship with the mental health field environment. As Bruni (2000) writes "the post structural conception of subjectivity rejects the conception of a coherent, rational self" (p.27)

\section{Reflective Topical Autobiography as a Narrative Method}

I have made some comments on investigating human experience through the methods of Moustakas and Johnstone. Johnstone promotes Reflective Topical Autobiography as an under-utilised method of enquiry for nurses. Johnstone (1999) believes that Reflective Topical Autobiography teaches students the art of investigating subjectivity, where both novice and veteran researchers may take this opportunity to advance nursing enquiry and generate new nursing knowledge (p.29). Reflective Topical Autobiography adapts "research approaches that emphasise critical self reflection, reflexivity and total immersion in the research experience (Johnstone, 1999, pp 27-28) and draws directly from the methods of Moustakas in discovery of a realm beyond what that person has known into a recognition of the unique and incomparable nature of existence (Johnstone, 1999). The phases of this 
method which are derived from six phases of heuristic research advanced by Moustakas, became a way for me to enter the mental health field environment:

Immersion: The researcher maintains a sustained focus of concentration which includes the strategies of deep and systematic introspection, introspective narrative and self-dialogue such as those commonly used in heuristic psychology (Moustakas, 1990). I had a physical experience of this immersion process one day as I walked down a steep hill leading from my childhood home into the town below. I felt myself sinking down and down deeply settling into my being/thinking and understanding of my field of interest. This important experience I directly attribute to the conscious effort that I made to achieve immersion in all of my waking and dreaming states and creative explorations. Data collection flows in response to immersion and the experience of turning points or existential moments. Johnstone's description of "a collision with another horizon (experience, world view)" (1999, p 28) gives rise to a cascade: of decision making, emotional response, strategising to cope with stresses associated with the turning point experience, the symbolic environment in which it took place, problems and the experience of having the experience. Recommended sources of data include diaries, visual art-work (drawings and paintings), and literary works (creative fiction, poetry) which fitted well with my personal capacity and skill. I was interested in the reflection that Johnstone documents based on Denzin's work, that a challenge to all researchers of subjectivity is "to learn how to write visually, in a way that reflects how what is seen is felt, knowing then that seeing is feeling"(Denzin cited in Johnstone, 1999, p.29). I believe that the essence of my enjoyment in creating this thesis has been the experience of writing visually as a means to create an experience of feeling for myself and for my reader.

Incubation: This is the process in which the researcher draws back from the "intense concentrated focus on the question... to enable "another level of the expansion of knowledge and understanding to take place" (Moustakas, 1990, p28). This phase feels like it sounds. There is a sense of a body of new knowledge that is forming, turning and developing in an internalised place, and yet the focus is somewhat removed from the seat of this development to a broader and more expansive place of 
openness and nurturing. Protectiveness of this incubation phase was important and I learnt to be discerning so as to not expose myself to any random form of external creative influence that would pull me away from this important centring and growth stage. Paying more attention to my own dreaming and allowing streams of thought to intermingle, with the awareness that previous immersion in my research questions had produced a fertile research field.

Illumination: The researcher experiences "a breakthrough into conscious awareness of qualities and clustering of qualities into themes inherent in the question" (Moustakas, 1990, p.29). Following a contemplation of the illumination, relevant deep introspection and reflective examination of the meanings of the various layers of consciousness begins (Johnstone, 1999, p 29). It was at this point in my progress that I began to actively engage in the psychogeography method of dérive and détournement as another means to create or collect data. In some cases however it would be impossible to say whether the steps of reflective topical autobiography or the psychogeography method preceded one another or followed one another and, at times, their utilisation may have been, or was concurrent. Any limitation that reflective topical autobiography may have had as an exploration method of self-lifestory, in answering the question what environment contributes to mental health recovery? was addressed by the possibilities inherent in literary psychogeography as an exploration of critical space and Other space.

The following Chapter Five: Project Design features the elements of reflective topical autobiography that contribute to the overall research project. These are: the articulation of practice in text which reveals the 'turning point experience' which are the moments of connection and experience which have been powerfully symbolic and which I then associate with this challenge to my life's meaning; the use of a diary or journal which became a point of reflection as well as data collection including the textual inspiration of others in the field; practice stories which were a source of data and then provided further realisation of yet another turning point which revealed itself as new data -a re-visioning or re-storying of the original insight; the self-life-story of others as dialogue in partnership; the incubation process that is 
possible in drawing back to travel or move in different physical and different referential (ontologically situated) field environments, or altering one's position in the world so that I can have a different view the simplicity of looking up or down or sideways as a means of shifting or concentrating focus; the use of performative language and environment as an exhibition space for the illumination and contemplation of research as a performance art or instillation; and finally the use of the research design itself as a means to holding space and knowledge over time for the purpose of a sustained and deep look at a particular question. 


\section{Art Interval}

Spirit Under the Mountain , 2003, oil on canvas, 450mm x 650mm 


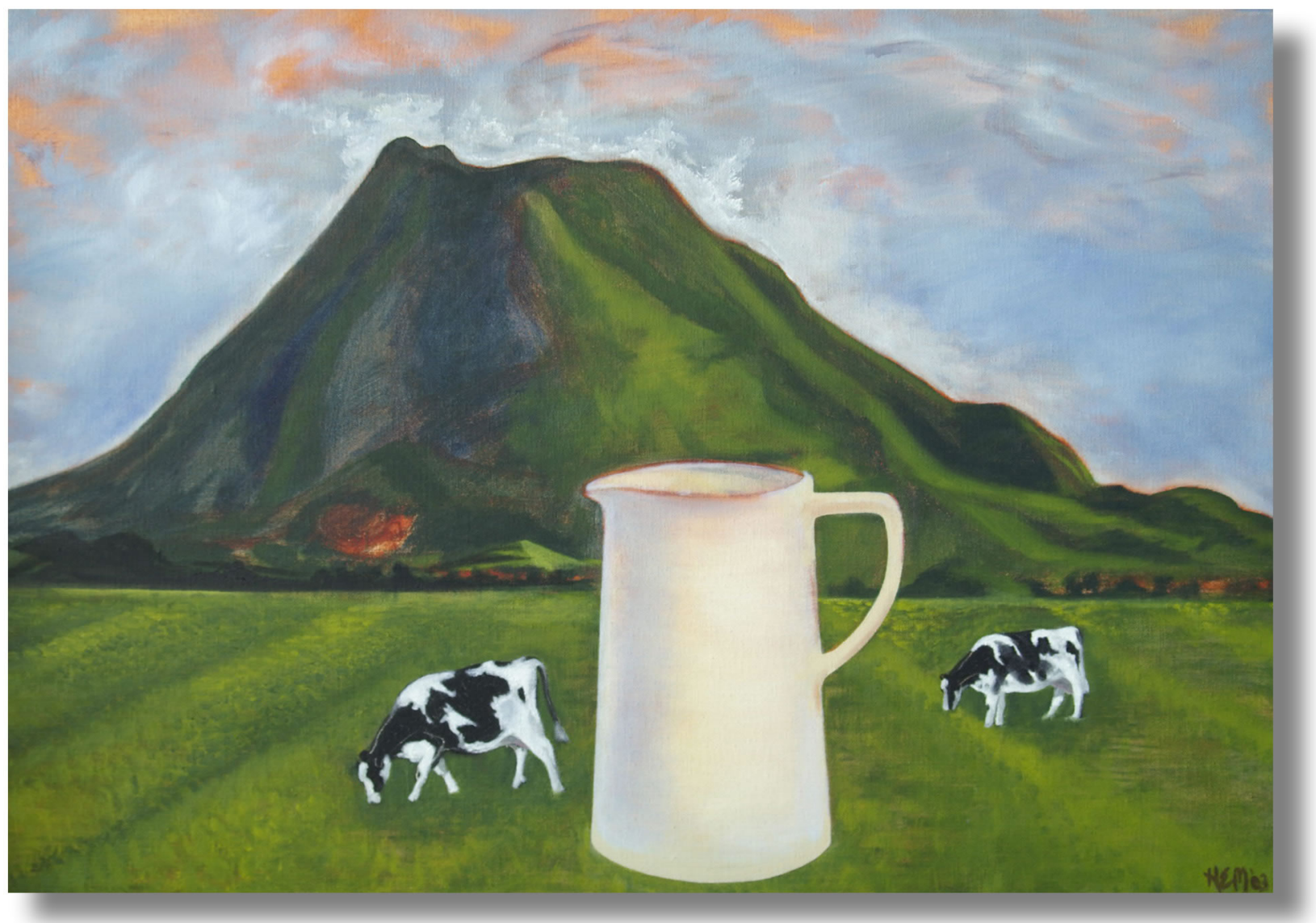




\section{CHAPTER FIVE}

\section{Project Design}

This chapter is dedicated to providing the reader with information that documents the background process involved in creating this thesis. There were a number of project phases which, overall, contributed to the handling of data and development of the thesis. This critically assisted in situating the writer in optimising continuous constructive development within a given framework of academic space and time. These phases are presented as major headings in the following order: Aesthetics and Design - logo to the project; Development of Scholarship in Writing; Clinical Practice to the Page (practice stories); Partnership and Consultation as Design; Environmental Inspiration; Inspirational Writings of Others; Conceptual Positioning of Self; and finally, Locating Meaning by Design.

\section{Phases of Project Design: Aesthetics and Design - Logo as Map}

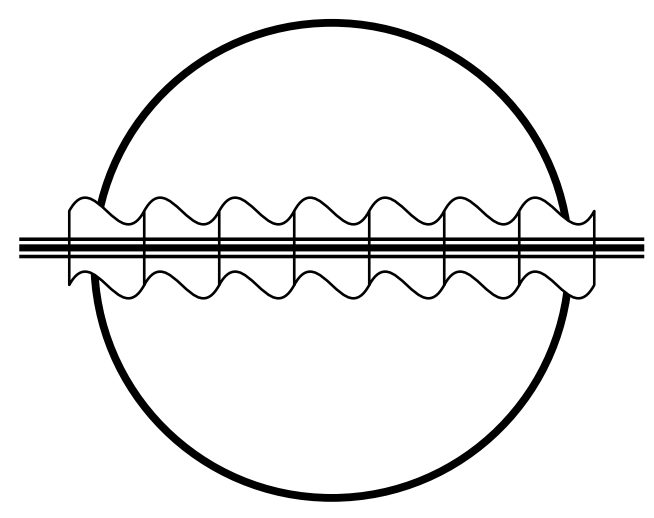

This logo is a symbol of my circular journeying between the conscious and the subconscious worlds; between the known and the unknown. It represents Art and Health; the distance that I have journeyed to discover the circle of understanding of my topic; and the interface that is the bond between these two fields. 
Creating this in 2001, the logo came to represent my Self as a nurse artist and also to brand my written work. In the same way that a signature on a painting is a sign of the artist the logo is a sign of myself as the writer. Wherever my work has been shown in presentation, or conference, this symbol precedes the body of my work.

My intention is to use the logo to indicate to the reader the place in which they find themselves; as if the thesis were a map of a landform or environment over which she is traversing. The possibilities of this travel, are however, not limited to a linear trajectory and are not bound by direction dictated by the progression of time or the march of history. One might start at any given point and travel along the lines of a star burst which emanates from this one point, exploring in any three-dimensional direction to intersect with another starburst that has spread from a different point.

The logo signifies an opening to and temporary ended ness of this written work and also heralds the beginning of each of the Chapters One. As such, it appears as a sign of my personal engagement with the reader, and as a seal of good intention and good fortune for an endeavour undertaken. This thesis is a piece of an ongoing and larger creative work.

Where the reader can determine the known as the field of health, the unknown becomes the river of art, or of personal creativity, into which we dive. The dive takes us from the top 'known' portion through the wave into the 'unknown'. In exploring creativity through the materials of art a contribution is made to our health state. As we surface once again into the 'known', a sense of wellbeing is gained with knowledge of the creative self.

This logo is based on an insight that I gained about the field of Mental Health knowledge through being in it. I set about exploring and endeavouring to articulate in the world what I know and how I practise. I also began to value the sense of realisation and discovery that there is in not knowing; there being a difference between what I absolutely do not know and what I know but do not yet real/ise. At the interface between these two spaces is a horizontal plane wherein the movement of the circle between known and unknown a mirror exists. 
What we know leads us to the unknown: what we did not know is revealed. The seventh wave pattern alludes to the powerful and ever present force of nature of which I am part, and the waiting/watching that I do in the belief that the seventh wave will come and lift me over and beyond any barriers that I may imagine or encounter in my imperfect state of being a student of art and health, between the known and the unknown.

\section{Phases of Project Design: Scholarship In Writing}

\section{Writing As Research -Articulating Practice in Text}

In the year 2000 I became a student of the Graduate School of Nursing and Midwifery and through my studentship in the Postgraduate Certificate In Advanced Nursing (Mental Health) course I began to experience the freedom and the power of writing my experiences from the heart and from my head.

I began to realize that it was possible to have an original thought and to assert original practice as a nurse artist, which sat beside or inside other writers and thinkers' theory and practice. I had a sensation of a great production and release of energy as I utilized my creative skill as an artist and, more particularly, as a sculptor and painter in a new medium, that of the wordsmith. Like breathing in and breathing out a fresh new air that pleased my lungs and made my nose warm and my fingers pink.

I wrote a paper that was accepted for the Australian and New Zealand College of Mental Health Nurses and had my first experience of delivering a paper to an audience of peers in Brisbane, Australia. There is nothing quite as exacting as having to stand up in front of other nurses and people from other disciplines and state your case, be entertaining and informative all in the space of the allotted time. I was very nervous before this experience but found myself entering a state of heightened perception as my nerves gave way to exhilaration. I found I absolutely love 
presenting to an audience and, as a consequence of the concentrated effort required to produce this paper, it catapulted my thinking and work ahead at an accelerated rate.

During this formative year I began to reconcile my desire for Partnership that I would wish for with Maori, against the fact that the circumstances of colonization and health statistics showed me that no such thing as an unconditional partnership/relationship was possible; that all of the conditions which controlled me as a pakeha, female, middle class, nurse, created a gulf between myself and a potential client or Maori colleague. I had to fully understand historical, political and economic forces before I could begin to bridge the cultural divide by simply nursing or making art. I had to find a way to proceed that was honouring of Partnership, developing of trust and freeing of guilt. To continue to fulfil my responsibilities to Maori, by engaging in Partnership under Te Tiriti $O$ Waitangi (The Treaty of Waitangi).

During this year I also acquired some practical skills such as learning how to construct and deliver a PowerPoint presentation, and how to control information such as saving of files, recording source material, and searching for new information using the resources made available to me as a student.

\section{Writing for Presentation - Articulating Practice for Audience}

The year 2001 was a consolidation year of completing papers towards my Master of Arts (Applied) in Nursing.

I took as an option an Individual Contract for research enquiry. The proposal centred on Art Process as Research Enquiry. I carried out an exploration of an art piece I created which accompanied the paper. I attempted to generate knowledge through an explanation of the artistic process as inquiry from both the perspectives of nurse and artist. This enabled a journey to, and arrival at, a place of new knowledge. I intended to convey the powerful potential of imagery, and embodiment of metaphor in 
artwork made by nurses, as a means to contributing to the growing body of knowledge which validates and inspires nurses to live their experience of their craft.

I submitted a portfolio and took into consideration the course objectives, which were to critically consider a range of nursing research activities and their importance to the discipline's growth. I learnt to use skills in the critical evaluation of research reports and research-based journal articles to generate informed debate about the "state of the art' of health research in nursing, and to gain deeper understandings of the process of research including framing of questions; methodological choices; rigour and the importance of the evidence of rigour in health research. This was my first experience of thinking in a way that posed questions and considered the conceptual mapping and development of a theory of my practice.

\section{Writing for an International Audience- Articulating Practice with World Peers}

In 2003 I wrote a paper that was accepted for an international conference. I attended the ECArTE - European Consortium for Arts Therapies Education $7^{\text {th }}$ bi-annual European Arts Therapies Conference entitled “Arts Therapy: Recognized Discipline or Soul Graffiti? Approaches, Applications Evaluations" which was held in Madrid, Spain during September 2003.

My paper "Korero Wairua: A nurse artists expression of soul in the mental health environment" was streamed into a training issues group and came under the heading of "verbal and non-verbal implications for interpretation and supervision". My purpose in going to this conference was to compare my approach and experience of practice with a group of practitioners who could be my peers in terms of practice issues. This was an important exploration of the work that I had been doing as a nurse artist in Aotearoa New Zealand. With no group of nurse artist peers to compare my work with, I wanted to know if I was creating something that could have meaning in another geographic and cultural context. I wanted to know if my thinking was naïve, en-cultured, or in step with other workers in the mental health field. I was 
curious to know of other mental health conditions and practice and, most of all, I needed to know if I could go so far away from home and survive. This was my first major journey and I was away from everything familiar to me for a month.

The conference was fascinating to me as I was surprised how much the Arts Therapists were bound by the psychiatrists' codes of practice and methods. For example in a large Mental Health Institution in Madrid two woman artists described their arts session which was then followed by the individual participants having compulsory interviews with the psychiatrist in which the work, or participation in the group, was analysed. I found other artists work to be very subservient to psychiatry and psychiatrists' practice.

I compared my experience of being up at 5am in the morning with my parents and participants to lay the hangi (traditional Maori steamed food cooked in an underground oven) for the day's arts project. Walking through the town centre bright banners flying, to gather and warm the site of the new residential accommodation house with a circle prayer. Then joining the inpatient unit staff and consumers for a celebratory concert and serving of the feast. I discovered my experience to be, quite literally, a world away from the other people present.

When hearing the presentation of the woman involved with people with an experience of cancer, I felt their practice most resembled my own. This session was held in the stream entitled "Art therapeutic interventions to special symptoms" and the phenomenon was cancer. Where the outcome was free of intention to 'fix' the person, as in the case of people with cancer who were being treated in all states of acceptance and advancement of their illness, there was a greater emphasis on the ability of the individual to direct their art exploration of Self. 


\section{Writing Consistently By Journaling - Articulating Practice from Reflection}

Relevant excerpts now follow the previous descriptions of development in writing scholarship from my journal, as examples of the reflective development process of the thesis. In April 2002 I began a process of journaling, which I have continued throughout the years of the project.

I wrote my journal in two places. The first, while at home, was a computer diary and the second when away from home, was in a Chinese handmade book with rose petals imbedded in the paper, which I always carried with me. The computer journal came to reflect what people wrote about and what I wrote about. The rose-paper book reflected what I heard other people say and what I had said or seen. Drawings came into both journals equally.

\section{Journaling as a Source of Textual Research}

Below is a selection of relevant and dated journal excerpts. I developed a key that enabled me to follow trains of thought, quotations and new ideas by sign, italics and plain text.

Key:

Original Idea in raw state $-\approx$

Quotations - in italics

Personal writings - Plain text

Table 2 : Key to Research Journal

The excerpts have fallen into a number of naturally occurring headings that give exemplars of the benefit of journaling. The layout and information, including referencing in this section, have been left in a raw state to give you an idea about 
how I freely wrote these entries, and thus demonstrate the authenticity of my journaling. Drawings were transposed from art paper to computer graphics.

\section{April 2002}

Where to start is my question? There is no beginning place that I can quite accurately pinpoint. I feel the directions hanging in space around me as if I were a Christmas tree covered in decorations. Each adornment sparkles and lures me in a different trajectory from the heart of the tree. I hear words spoken to me: yes read, yes search but above all else always write... just begin to write. And so today I begin my journey of words and images. I am led by the evolution I see unfolding in my painting. It already exists as witness and proof and gives me hope that my vision will be true. I had never realised the power of the visual work in its solid proof of creativity. I leave it, and when I return it is there to greet and reward me for my effort in creating it. I constantly delight in the rhythm and colour of it and the folds of mystery that it contains. It is this assurance that a reflective journal offers.

$\approx$ Like a rumpled sheet on a bed, in the day after my sleep a new landscape of ideas and meaning is revealed, the aspects between the folds remain hidden. I sleep and awake to newly revealed folds of meaning. Does the turning of my unconscious mind [symbolized by the turning of my sleeping body in the night] play with the possibilities that it can choose to reveal to me? Or does the passage of time reveal layer upon layer of meaning which, when looked through, reveals a three dimensional reality that cannot be carried in the two dimensions of paint on canvas. Is my subconscious gathering meaning and playing 'through me'? What is the impact of my will? Is the turning of meaning trying to reach me with a message of truth? What if I should be separated from this painted image, would my mind still seek to caress its nuance and shape? If locked in a cell would I try to draw this in the dust or carve it into the wall? How important is this image to me? Where did it come from and what is my response to its arrival? It is an outward sign of the possibility in me, a sign that what I have felt to be true for others, can be also true for me. The nurse is 
an artist, the nurse artist is me. Where I have offered others the confidence to begin to create I now offer myself this same encouragement.

\section{Provisional title $-\mathbf{2 0 0 2}$}

"Canvas is to the artist as skin is to the nurse: Painterly narratives of the nurse/artist practitioner in a mental health setting". Provisional thesis design also put in place at this time

\section{Exploration of Method: Congruent Methods}

\section{Beverly Taylor}

Beverly Taylor states in her book Nursing Research Process: an Australian perspective (Roberts, K. \& Taylor, B., 1998 p. 169) "that in qualitative research, there are usually attempts to ensure that the methods by which new information is collected are 'in tune' with the particular theoretical assumptions that underlie the kinds of knowledge that are being generated in the project. Being 'in tune' is another way of saying that methods and forms of knowledge need to be congruent... this is an issue to be faced if you believe that your research questions might be answered well by a qualitative approach". Congruency between methodology and method extends in my opinion, to knowing that the methods used to collect new knowledge are in tune with the philosophies of my practice. Where qualitative research adds value to lived experience it will also be a value added experience if the research sits well with my personal ethical practice. For example I do not read Client notes, as my knowledge of their hospital record relating to their illness is not the most important part of our contact (except in circumstances of safety issues). As my present practice does not require this, it would not be 'in tune' for me to design a research project that required me to specifically do this. Reading Client notes prior to meeting the person colours my view of them and gives me knowledge/power over the person. I choose to begin our relationship by not stacking the power differential in my favour. 


\section{Nancy Diekelmann}

Nancy Diekelmann visited the Otago Polytechnic School of Nursing some years ago and I attended an evening lecture that she gave from her manuscript in preparation entitled "Narrative Pedagogy: Caring, Dialogue and Practice". There is a significant aspect of teaching and learning involved in my work as I offer art materials to Clients that may not have had any experience with these mediums before. Nancy's "Concernful Practices of Teaching and Learning" seemed to capture the essence of my practice both as an artist and as a nurse and in my commitment to honouring the principles of the Treaty of Waitangi.

\section{Concernful Practices of Teaching and Learning}

Gathering: Welcoming and Calling Forth

Staying: Knowing and Connecting

Presencing: Attending and Being Open

Creating Spaces: Keeping Open a Future of Possibilities

Safeguarding: Reading, Thinking, Writing, and Dialogue

Caring: Engendering Community

This became a very early and basic way for me to begin to understand the process of immersion in the project. There is some correlation here between Dieklemann's practices and the methodology suggested by Moustakas.

\section{Jean Watson}

Basic premises of the interpersonal-transpersonal-spiritual in nursing (Nursing: Human Science and Human Care, 1985).

-A persons mind and emotions are windows to the soul

-A person's body is confined in time and space, but the mind and soul are not confined to the physical universe

-Access to a person's body, mind, soul is possible as long as the person is treated as a whole

-The spirit inner self, or soul of a person exists in and for itself

-People need each other in a caring, loving way

-To find solutions it is necessary to find meanings 
-The totality of experience at any given moment constitutes a phenomenal field

$\approx$ I feel that all of these subheadings have particular personal meaning, as I ascribe to these statements and have felt this way all my adult life, although I did not use this same terminology. I am looking at others' work, as much to understand their theory development as to learn new terminology

\section{Phases of Project Design: Clinical Practice to the Page}

\section{Practice Story February 2003}

A funny thing happened... I asked a Nurse where a Client was, and he said the "Escort Yard". My hackles rose and I said to him “ you mean [in] the garden!". Later I recounted this to the Clinical Nurse Educator as an example of the frustration I have with some [poor] language that is used. She looked at me steadily while I said it and then repeated that yes they had been calling it the "East Court Yard" for a while. Made me laugh at myself and showed me how I am not [positively disposed] to some...did I hear what I wanted to hear?

\section{Practice Story December 2003}

I arrived to take B. for her session and I found she'd had an 'incident' the preceding evening and been put in seclusion overnight. The Nurse relayed his decision to 'let her out' and how he wouldn't recommend my session went ahead as he had very little leverage as it was, to elicit good behavior. The implication being that getting out of seclusion must stand as reward in itself for 'good behavior' and that an arts session with me would be seen as a reward.

Weekend leave was identified by the client as something she looked forward to, and was consequently interpreted by the Team as the key goal of the care plan and therefore must be 'earned'. Leave had been revoked due to the incident the night before and despite the fact she had spent the night in seclusion, leave remained an 
impossibility. The situation was, the client must suffer instantaneous and total loss of privileges for exhibiting unsafe behavior, and yet the staff had the right to extend the negative consequences of this for the client for an indefinite period.

I was frustrated, as I knew a trip home at the weekend was the client's passionate goal. Having lost all there is to gain; the process of building safety and trust should begin again, in preparation to gain the next weekend leave. Yet the Nurse was prepared to offer nothing and removed freedom of access to the client's bedroom by locking this off, and removed other personal items such as lighter and wallet.

He saw the removal of items as the goal of the nurse in achieving control over the client's behaviour. This is carried out by the systematic confiscation of items of personal meaning and identity to the client. Whereas I had previously negotiated with the client to add value, activity and reward, to work towards the weekend leave. Nurses working in a custodial and incarceration style may only consider removal of privileges. What about adding opportunity and reinforcement of sought enrichment as privilege, thus creating agreeable and safe behaviour as a result of a mutual endeavour towards the goal? I developed this visual chart (Figure 2) to show the nurses the process of adding leverage not taking away control, as a practice development tool.

\begin{tabular}{|c|c|c|c|c|c|c|c|c|c|}
\hline \multirow{4}{*}{$\begin{array}{l}\text { Begin } \\
\text { Cycle } \\
\text { From } \\
\text { return } \\
\text { Following } \\
\text { W/E } \\
\text { Leave or } \\
\text { after } \\
\text { incident }\end{array}$} & \multirow{4}{*}{ 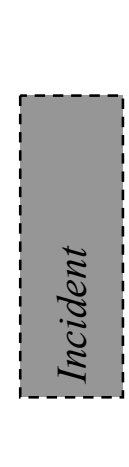 } & & & & \multirow{4}{*}{ 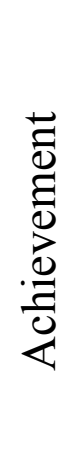 } & & \multirow{4}{*}{ 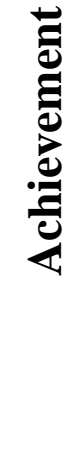 } & $\begin{array}{l}\text { Add } \\
\text { Activity }\end{array}$ & \multirow{3}{*}{ 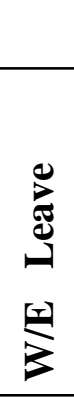 } \\
\hline & & & & & & $\begin{array}{l}\text { Add } \\
\text { Activity }\end{array}$ & & $\begin{array}{l}\text { Add } \\
\text { Activity }\end{array}$ & \\
\hline & & & $\begin{array}{l}\stackrel{艹}{0} \\
\stackrel{0}{0}\end{array}$ & $\begin{array}{l}\text { Add } \\
\text { Activity }\end{array}$ & & $\begin{array}{l}\text { Add } \\
\text { Activity }\end{array}$ & & $\begin{array}{l}\text { Add } \\
\text { Activity }\end{array}$ & \\
\hline & & $\begin{array}{l}\text { Add } \\
\text { Activity }\end{array}$ & $\frac{0}{0}$ & $\begin{array}{l}\text { Add } \\
\text { Activity }\end{array}$ & & $\begin{array}{l}\text { Add } \\
\text { Activity }\end{array}$ & & $\begin{array}{l}\text { Add } \\
\text { Activity }\end{array}$ & \\
\hline
\end{tabular}

Figure 2. Nursing Practice Development Tool 
The service delivery framework of weekdays and weekends and 'good' behaviour and 'bad' behaviour, often binds the patient's life when subject to behavioral management practices as part of treatment. Weekends and weekdays are critical time periods bound by the availability of workers that are employed on rostered duties or weekdays/weekends off. A shift between behaviors is often heralded as an 'incident'. This conceptual map expressed as a chart, attempts to locate within these frameworks of institutionalization, the real cycle of significance which is the recognition and reward of a persons struggle towards achieving their expressed goals. In the mental health field environment the weighting of importance of the institution over the individual is expressed in subtle and undermining ways. For example should an incident happen at a weekend period often the outcome of discussions around the progress of the individual towards their goals is put on hold until the weekdays, so that key people managing the development programme can attend. This effectively has the individual in 'waiting mode' for what cumulatively can be large chunks of their life. The situation arises that the individual is so anxious and wound up in their need to get to their goal that behavior considered unacceptable by the staff called an 'incident' is inevitable. I proposed that all staff working as part of a team have the capacity to know and understand the stepped goals of a person, which can lead to achieving their big aim. Thus whoever is on duty, at whatever time of the week, can be responsible for assisting that person to show achievement and ultimately reach their aim. Rather than staff who are not associated with that person's programme just valuing knowing what the outcome of an incident is- that you report the incident and you wait (hours or days) until the key person tells you what to do...all staff are enabled to participate in a positive direction. This is a reward system and not a punishment system, which is unfortunately how things end up being orientated. This is an example of how the knowledge of the planning of patients lives is represented, and then put into the hands of professionals such as psychologists (particularly where it involves behavior development) who hold power over the persons' life which is counterproductive to recovery and produces dependencies for which the person is ultimately blamed. 


\title{
Phases of Project Design: Partnership and Consultation as Design
}

\author{
$13^{\text {th }}$ Feb 2003 \\ Meeting with Po Te Atatu (from Darkness to the Light) - Maori Mental \\ Health Team
}

I was asked some very good questions like...

What is art?

The reply came from one of the group..."Art is expression".

How will my studies benefit Maori?

If I had to write what I do for Clinical [practice development], how would I describe it?

I had a satisfying time encouraging others to write and talking about research, as I knew it to be based on my experience to date, which is a skill many others have.

\section{$20^{\text {th }}$ March 2003}

Teachings from Arama Perika - Kaumatua to Po Te Atatu (elder of the Maori Mental Health Team)

Following the presentation I did for Po Te Atatu after my panel interview, I was invited by Arama to join him in discussing the Maori concept of art and creativity. This will take place in several discussions and Arama has intimated we may never get to the end of this discussion because that is its nature.

\section{Elements of the discussion: Language, the Wairua of Maori culture, and the spirit of the art (in a conversational style).}

So he said... "That this thing that I work with is without measure. Measurement in the strictest sense is detrimental to Maori. For Maori there is no clinical connotation or scientific explanation, as art is seen and interpreted by the individual and the individual also wonders how the artist felt, it is not measured by a machine, mathematics or scientific means. 
It is not measured with the mind but with the heart. Heart measure is:

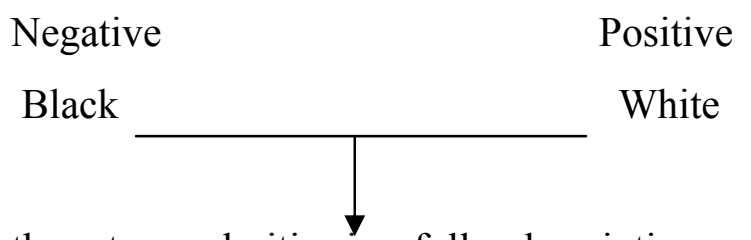

Between these two polarities is a fuller description and satisfaction

\section{Color emanates sound}

Color emanates time - time immemorial, Tuku iho (passed down) the pride and joy given to us by our parents.

We use the same measures as our parents did in their time but each generation has its own ability and need to assess the situation.

Color, hue and sound is assessed and determined in my life-time

This has come as a gift from our ancestors. The waka (vehicle) that brought it to me is the wairua (spirit, soul)

How can I bring 'it together' [my practice and my understanding] to the point that $\underline{I}$ can use the term wairua?

[Wellspring or inner being are the words used by printmaker and friend Marilyn Webb. Could these terms be more appropriate for me to use, as they have been passed to me by a pakeha woman artist who originally comes from Opotiki near my home?]

Arama explained, that I had begun my cultural journey a very long time ago and this is why I am recognized as being able to understand Maori.

I asked about having permission to use this word wairua, and Arama explained that I can only really make comparisons with Maori and their use of the word, as I am talking to people about me.

Wairua is a passion

Wairua is about decisions

Wairua is about what part of our body makes the decision Spoken from the heart, joy emanates from the heart

Hue, colour, balance, and healing comes out of colour, plus sound and time. 
Wairua is about making decisions,

It is about energy and passion, which must find its balance in the law and by compliance, in order to make other people happy (or to not bring down their wrath). Memory resides in other parts of your body, not the brain.

Maori often make decisions not from the head, which can lead to trouble, because they are being measured in their action by someone else's standard.

Wairua Korero...to speak from my wairua

Me as an individual

My culture

My background

This is not about my qualification

Arama asks, Maori from a Maori perspective will always be a Maori, how do we retain this when we have been told to do things as a pakeha?

When a Maori moves away from home from their culture and becomes transient, you make whoever is with you your family. Some Maori have taken their culture with them and removed it from their birthplace e.g. Moved to Australia. Maori have no right to inflict their culture on someone else.

You must always know where you are from and what you have left behind.

Leaving your birthplace to never return there robs your birthplace of your unique contribution and robs your children of their birthright.

\section{Phases of Project Design: Environmental Inspiration}

\section{$27^{\text {th }}$ April 2003}

\section{Reflection}

I have been away visiting the mountain Taranaki. I realized when I traveled around it that I could see it from all these different angles and that it had a very different presentation from different places. If a problem... or say, my thesis as a center of concentrated effort is like this mountain and I am only looking at it from one angle 
then I am not seeing it fully. If it were a problem then I can only see it in one light and from the perspective of the presenting facet. I have resolved to walk around my thesis mountain and to see it from its every face. I am on a hikoi (special journey, usually walk) which is to register my recognition of this 'thought mountain' by having different stand points around it.

What facilitates creativity in the mental health field environment?

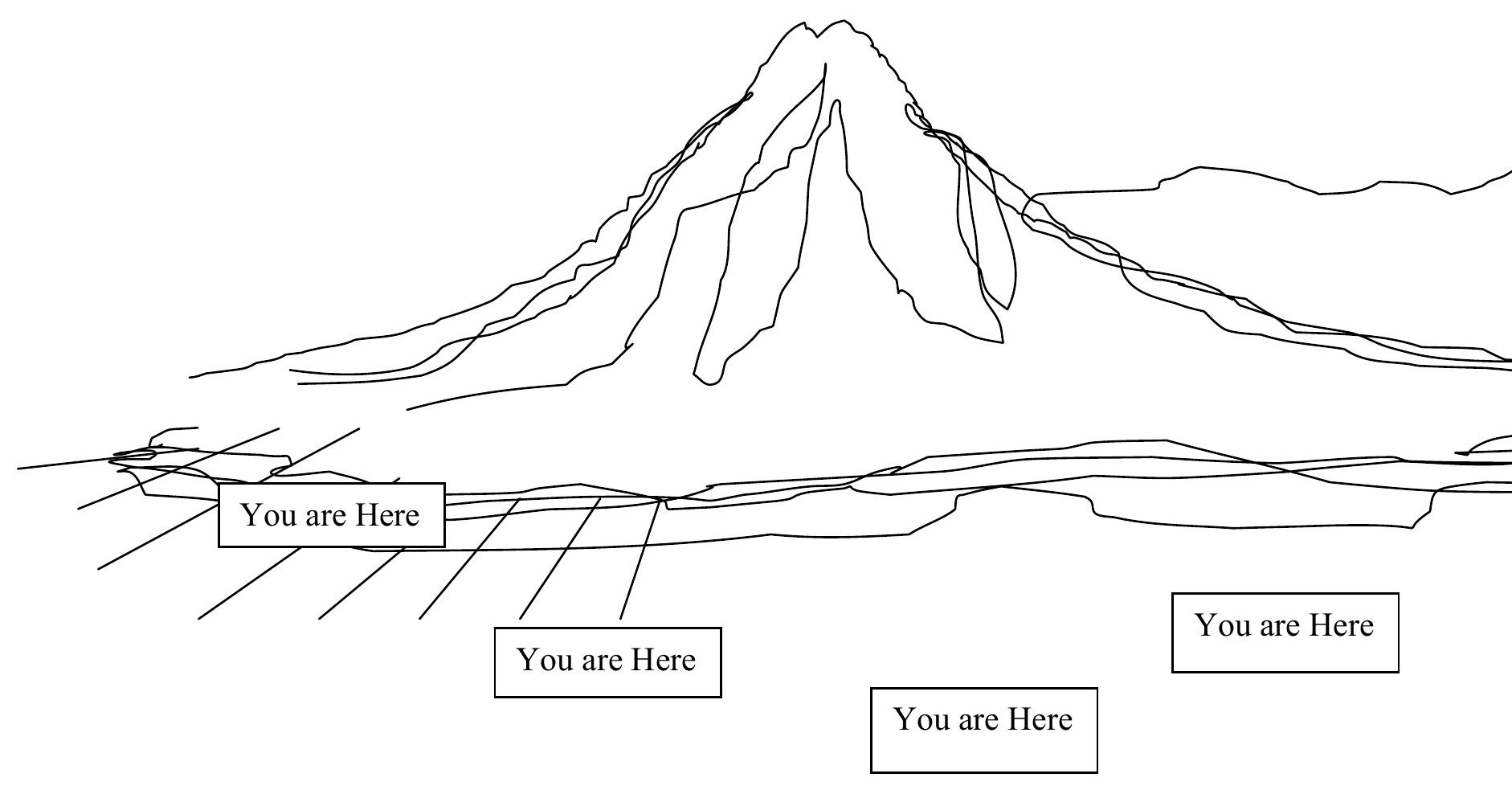

Figure 3 : Thesis As Mountain - Side View

$\approx I$ could use the concept of differing standpoints "You are Here", as a motif throughout the thesis to signify walking around the thesis, seeing it as the reader from differing perspectives as well as the writer presenting differing views? 
What view of the mental health field environment is possible from above, looking down upon it?

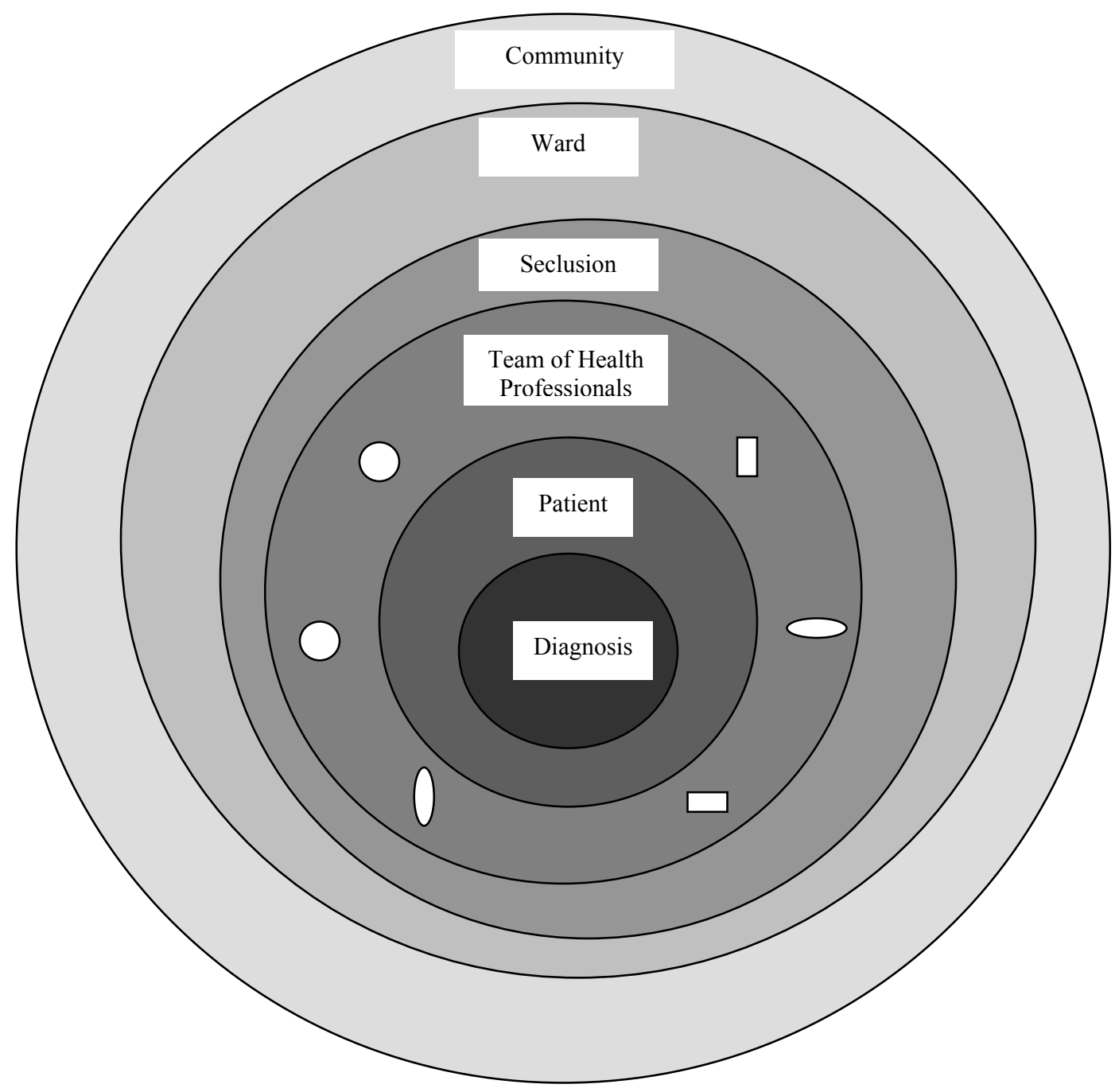

Figure 4 : Mental Health Field Environment as Mountain of Separation - Aerial View

What I can see as I move around this thesis mountain is that the Mental Health Field Environment as a mountain of separation is... 
... Actually a vast hole that one descends into, with a lid on it like a pothole cover which divides the underworld below the street from the activities of the world above it.

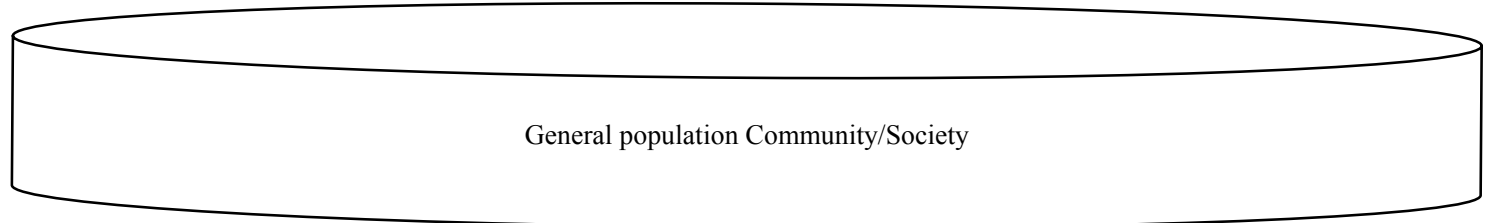

Poverty, Stigma, Discrimination, Residential Group Homes, Social Ghettoising, Visual/sensory ghettoising, pyramidal effects, no transport, no speech...

\section{BARRIER/ GAP}
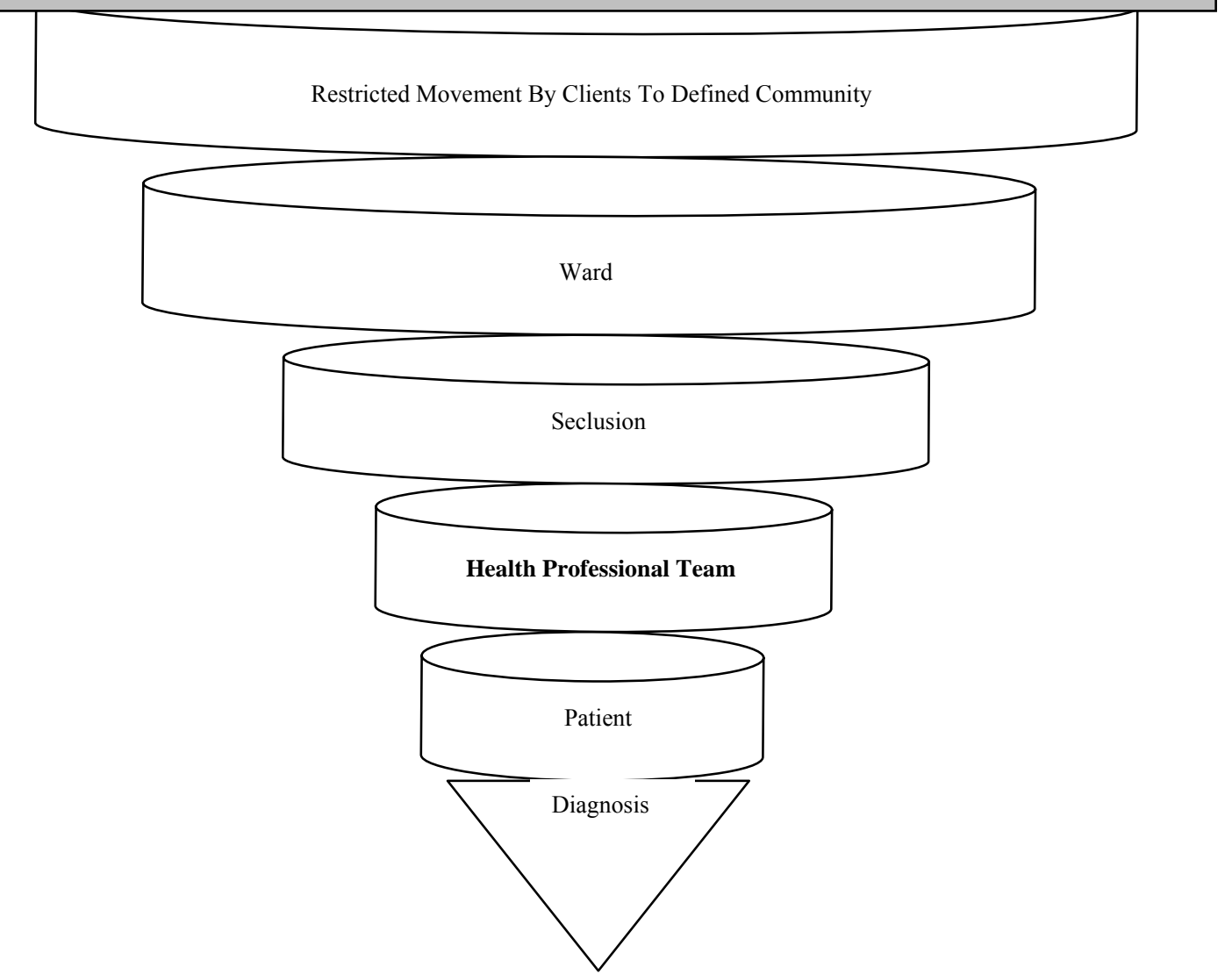

Figure 5 : Mental Health Field Environment as Mountain of Separation - Underworld View 


\section{Inspirational Writings of Others}

\section{Journal Entry}

Writer Rick Moody cited by Margie Thomson In the Weekend Herald 'Canvas' magazine, May 3-4 2003, Article The Right Stuff by Margie Thomson p. 15

Moody writes to make sense of the world or, in Black Veil, to make sense of himself. As he wrote, he found his main theme became the veil that must always exist between one person and another. "Concealment is essential for identity," he says. "What you call eye-opening personal exposure is actually, just a constructed candour," he says. "I think the most honest thing you can really say to a person is: 'I will do my best to be honest with you', but there are limitations on what I can say. People are always concealing and revealing at the same time, and memoirs, as the products of people, are the same way. Its marketers who try to tell you that reading a memoir constitutes some relationship to the truth. Memoirists would likely all admit that the memoir form always has some strategic elements of fiction buried within".

$\approx$ Is it possible for the person with an experience of mental illness to undertake concealment as an essential part of revealing identity?

\section{$16^{\text {th }}$ May 2003}

Received a full text journal article from Victoria.

Holohan, C. (1974). Experimental investigations of environment - behavior relationships in psychiatric facilities. Man-Environment Systems. 4: 109-113.

I can hardly believe that someone carried out an empirical experiment on seating arrangement and behavior in a psychiatric hospital. I don't know whether to be dismayed or pleased. Interesting comment however.

It is not our intention that physical environment be viewed as a treatment procedure in its own right. We do, however, stress that poorly designed physical milieu in a treatment setting will inhibit therapeutic progress, while a setting 
designed with therapeutic goals in mind will facilitate therapeutic ends (p.113). Psychiatric patients have been trained to be "outer-directed," while training for self-directed social encounter and environmental management has been greatly neglected. Allowing patients to arrange their own dayroom furniture appears unprofitable without prior training in self directed environmental management. Past tendencies to ignore the behavioral impact of physical settings and to perceive hospital environments as unalterable should not be allowed to present an insurmountable obstacle to productive and therapeutic environmental change (p.111).

The acknowledgment of the importance of environment is made here, but very interesting to note the stigmatizing way of contributing to client choice. Rather like experimenting on people. Also, merely moving the furniture, has been medicalised into an action called "self-directed environmental management".

\section{Patch Adams Practice Story- On being admitted to a Psychiatric Ward}

Talking to Rudy I realized the importance of love and the people who loved me. I had been surrounded by love but hadn't let I affect me. I perceived a deep personal truth: I needed to be open to receive love. Without it I was not a strong person. And I realized that if I continued living as I had been-without tender, human love - I would end up like Rudy. He represented the ghost of Christmas future that I would become if I refused to surrender to my needs. That moment was a spiritual awakening to the power of love. My destructive use of science, math and reason to disprove whatever was not factual had, in fact, left me lonely. I talked to the other patients on the ward and found similar threads of loneliness and lost dreams. It became obvious through the tears, that these people weren't crazy or inane. There was no switch in our heads for "normal" or "abnormal". I was the same person I had always been; so were they. Maybe that was what was so painful. These supposedly “crazy” people had merely responded to life's complexities with fear, anger, sadness, and despair to such an extent they-weneeded protection from ourselves." (Adams, 1993, p.6-7 ). 


\section{- Patch Adams Practice Story - On Becoming a Doctor}

During my freshman year the school offered an optional three-hour course called "Man and His Environment." The professor made a great effort to introduce us to life and health care situations outside of the hospital. Only 20 to 40 percent of my classmates signed up, and the next year the class was dropped. The whole idea of a person's life - its quality, diversity, and complexity - was relegated to psychiatry. But the psychiatry texts did not discuss any aspects of healthy, happy life, much less suggest how to attain it. Instead, they were filled with pathology and case histories of bizarre mental disorders."

(Adams, 1993, p.11)

\section{Patch Adams Practice Story - On Arts Practice In Health Environments}

I drew upon the skits we had improvised at home since the mid-1970s "We linked the skits together to make an actual show about the elixirs of life; wonder, nutrition, humor, love, faith, nature, exercise, and community." ... "This show was an advertisement for wellness and an excellent description of what Gesundheit Institute was all about. We later added a second show featuring eight more magic elixirs; hope, passion, relaxation, family, curiosity, creativity, wisdom, and peace."

(Adams, 1993, p.21)

\section{Patch Adams Practice Story - On Psychiatry}

In psychiatry - ironically, the specialty that should deal with matters of the mind and spirit - the need for professional distance was magnified multifold for fear of the dreaded "transference". In group discussions, we students sometimes showed too much vulnerability in front of an attending physician or resident. Whenever we showed any regard for the patien's pain, we were sharply criticized for "getting too involved" (Adams, 1993, p.34). 
Doctors should not buy into the lie of professional distance. Medicine is an intense profession. Medical personnel daily see such profound human suffering that "distance" may be another word for repression". " Transference is inevitable. Every human being has some kind of impact on another.

(Adams, 1993, p. 3).

\section{Patch Adams Practice Story - On Being a General Practitioner}

Often I am asked, "What kind of a doctor are you?" I generally like to say, "I'm a caring, fun doctor." This response catches people off guard because they are really asking "What is your medical specialty?" then I explain that my first hope for a patient is to be a friend, to learn and care about the patient. I also encourage the patient to be active in creating a healthy life. I try to be open to many perspectives and to never give up, at least not when comfort and intimacy are involved. By this time the discussion is interrupted by the questioner concluding, “oh, you're a psychiatrist!” Actually I'm a general practitioner who sees the above qualities as fundamental to the family physician."

(Adams, 1993, p.51)

\section{Guy Debord - The Spectacle and Oneself}

Sometimes everything is in just one word. Like a gift out of the blue I was introduced in 2002 to a term I had never heard before. As part of my Master of Arts I was preparing a research proposal and delivering my presentation to student colleagues. After much conjecture about the way to proceed a quiet but wise voice came from the group ... "sounds like psychogeography". As a result of this single moment and this single word, critical insights that I have gained about the mental health field environment in my nursing and arts career, found a context that resounded with my own theory of the diminishing ability of people to affect influence over their own destiny (gain recovery from mental disorder). Through subsequent research I became aware of Guy Debord and his extraordinary book entitled "Society of the Spectacle" 
first published in 1967. Individuals according to Debord become less of an individual and more and more a consumer. Key insights afforded by subsequent readings of information by writers who utilised psychogeography as a means to explicating their own questions and viewpoints represented a turning point in my research development and personal development.

\section{Phases of Project Design: Conceptual Positioning of Self}

I recall the work of an Associate Professor of the Victoria University of Wellington New Zealand Graduate School of Nursing and Midwifery, who would stand in class using the floor space to step out, pace and turn around in, in order to better emphasise positioning of the self in the project. Her demonstration of thinking-aboutby-action is my inspiration for this section of writing.

As a researcher it is important to fully understand and describe the positioning of my Self as part of the project. This is in part the elucidation of the experience of the experience. I can stand outside of the project as the director of action and progress. I can also stand completely within the project as a performer and follow the script for dérive according to Literary Psychogeography sources.

There is however a third position which I was able to take up as the project progressed. This was situated between director and performer as a participatory and involved audience-of-one. I found myself being in an observational and participatory state of watching and listening to the flow of information back and forth between the role of director managing the progression of the thesis as a project, and data from the role of performer immersed in the raw experience of being drawn to, repelled or excluded by the mental health field environment. The Director may be seen to sit in the Nursing Research domain and the Actor in the Nursing Practice domain. This thesis that contributes to practice development seeks to describe the ground between them as observed/ witnessed/intuited by the central position writer, myself. 
The following conceptual map gives an overview of the positions of nursing research in relation to nursing practice with the placement of Director, Performer and Participatory-Audience-Of-One in the context of the thesis. This Conceptual mapping describes the parallel process advanced by Moustakas in his six phases of heuristic research and incorporated as the research method Reflective Topical Autobiography. The immersion phase relates to the Project Performer - Artist, the incubation phase relates to the Project Director - Nurse and the illumination phase relates to the Participatory Audience of One.

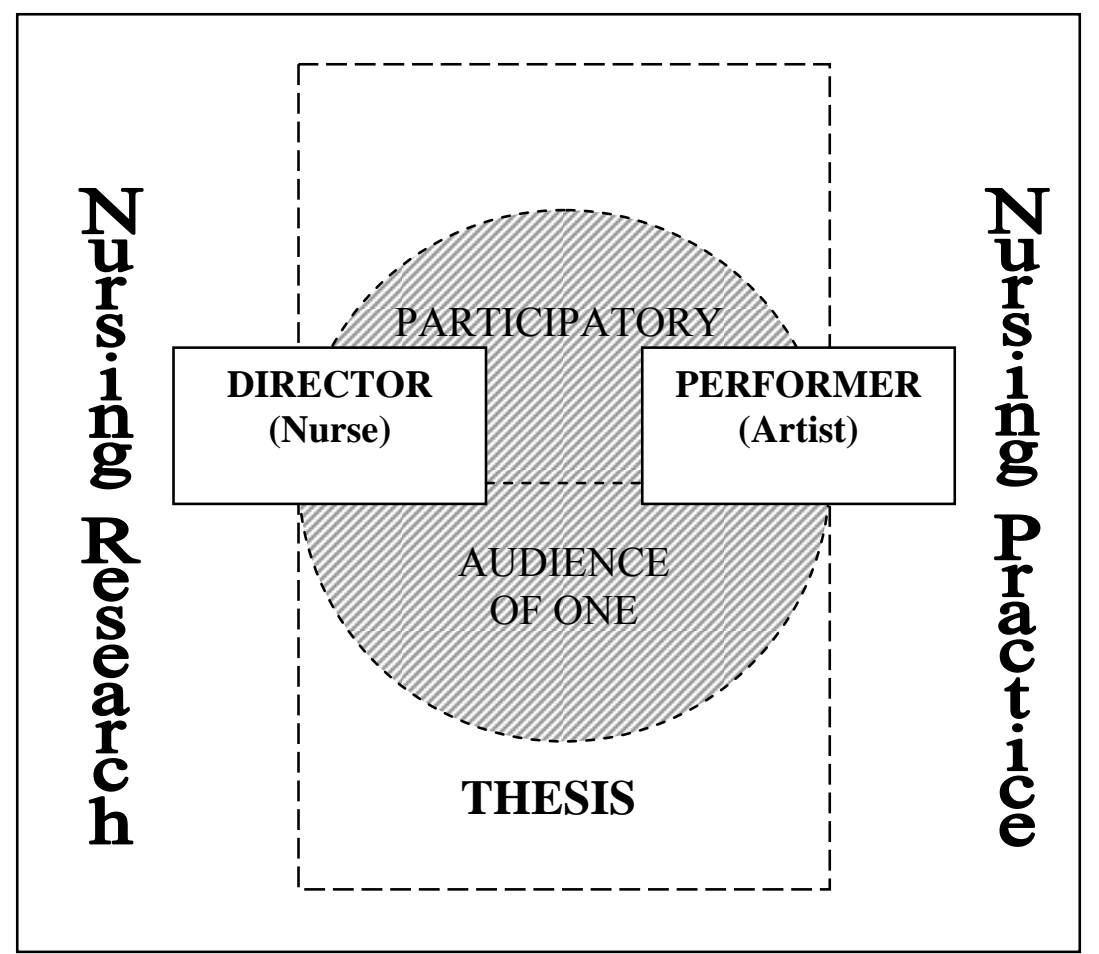

Illustration 2 : Conceptual Map of Positioning of Researcher

\section{Project Performer - Dérive}

At some time and as a necessary part of the creation of the project and subsequent thesis there must be the recognition of the will to act and this is followed by action, which is followed by reaction, and ultimately reflection on action and so on.

...WILL TO ACT...ACTION...REACTION...REFLECTION...RECOGNITION... RECONSTRUCTION...REDIRECTION...WILL TO ACT... 
The act or will to act can be born of the external senses or as a result of internal sensing. I may see something that motivates me, and I may feel something that motivates me. I may be according to (literary) psychogography drawn to or repelled by or excluded from the environment. In this way the performer has to be cognizant of the external world of experience and the internal world of experience. As the Director Self points the way the Project Performer must negotiate the terrain. As Michael White (narrative therapist, Napier New Zealand) points out the map is not the terrain and therefore as the Performer I must give feedback to the Director Self constantly. This is a geographical project. I move across the mental health field environment and the data is produced in response to this movement.

The Project Performer is the writer and the written about. The one that goes into the mental health field environment and experiences being attracted to, repelled or excluded from certain elements and being able to give an account of this experience. The performer is the first hand witness to events that occur in the Mental Health Field Environment that shapes nurse artist practice. In many circumstances the performer is the enactor of moral and ethical stance and also the enabler of reflective practice. This excerpt from the rose-paper journal is an example of the beauty and movement within the performers world...

\section{March 2004}

I know a man who was deeply in grief and despair. His unexplained withdrawal from family and loved ones had created a gulf into which he saw love, life, work, marriage disappear. After the experience of being told this was mental illness and wandering in the wilderness for days and raging at the edges of this void, he awoke one morning to a message.

It fell from the Hubbards muesli packet and told the story of another man who by chance met a group of students. These students said come walking with us in the bush. Then later come tramping with us, and then come mountaineering with us. The man from the muesli packet story found himself in a new place with new friends and a new outlook, because he had taken the first step. 
Miraculous at this time was the fact that this message of hope came from the muesli. Buddha said: to hope is to be in pain and to expect something makes one edgy. Maybe as health professionals we do forget the pain of the first step and the magic places messages can be found.

This exemplar shows the recognition given by to me by this person and returned to him, as he experienced a very painful time in the inpatient ward, and the communication that was possible between us. The bio-medical model hasn't got a lot of room for messages of hope and where they are to be found, and especially not in muesli boxes. Yet this was the actual experience that gave this man an encounter with hope and also what made it more important was the fact that I was there and receptive to hear his story. To hear it in its meaning for him and then to acknowledge what hope the muesli message had when he applied this logic to his own life. The Buddha statement was gleaned from a Film Festival movie I saw at the same time as these events were taking place in the ward. It shows the way in which my life as a professional is woven with the things that happen in my other performance states.

The project performer is involved with practice at the point of engagement with Other and is also responsible for giving an account of the experience of being in the mental health field environment.

\section{Embodiment of The Project - Entering Deep Self-Life-Story}

An important role of the performer is the ability to dérive as this is experiential at a very deep level. I am at one time both conscious to place myself in the most acute focus, but also to hold the space with an unconsciousness which produces the freedom to notice [the ordinary]. I feel that I had been using this technique before the beginning of the project. The method has strong links to Nursing as an art and the strength inherent in reflective practice. The method also has strong links to the process I employ as an artist when conceiving of and designing a piece of art. In this way I found it not a difficult task to learn the discipline of the dérive. My recollection 
of beginning to commit to this process is one of free falling without fear. I have a memory of walking down a hill from my home to the township below. There was an incredible feeling as I progressed down the hill of descending ever more deeply into the meaning and context of the project. The air on top of the hill was warm and heavy and the air as I descended the hill through the bush and road cutting became crisp and light. I moved from the familiarity of my home to a place of exploration in cold air and emerging from the steps into a slice of cosmopolitan and sunny busy culture. I knew deep within me that the time of immersion into the project had come and I did not feel fear despite my very acute sense of sinking into the unknown through temperature change, altitude and environment. It felt like an upside down rocket launch. The rocket would normally be pointing skyward and launching upwards, this rocket of immersion went down and down and down, and strangely the feeling of acceleration into forward space that one might feel was an immense feeling of acceleration within [backwards] and down to a type of ground- or at least in search of a bottom to this incredible void. My heart came up into my throat. There was a sharpening of my vision to crystal like quality of the trees and I could smell the earth. I felt glad to be alive and lucky to have my own adventure to embrace and thrilled that the adventure had embraced me back.

\section{Project Director - Détournement}

This aspect of my Self as researcher is responsible for the overall design and sense of the writing up of the project. Responsible for the holding together of the threads of the information as they are revealed. Direction of the action within the Mental Health Field Environment is important, as without an over view it would be possible to disappear into the depth of a certain aspect or position that I have discovered during the project.

At several points of project development and thesis writing I have recognized the importance of checking back with the original intention using my abstract as a framework for the development and innovation of accurately placed ideas. Where there have been major shifts in my thinking the Director has been able to integrate 
the shift into the overall design, or to lift up and move other aspects of the project forward, to match the movement or change in thinking.

There are levels of thinking and a breadth of thinking, which have relevance to the core of the project and yet need to be able to take up positions in a global sense. Not everything is critical but relevance between peripheral subject matter can lead overtime, to a strengthening of the core. The Director has to be able to hold this entire small universe of moving and rotating and shimmering objects in the air and allow the performance and the Performer to continue, whilst listening to the Participatory Audience of One.

\section{Participatory Audience of One}

The Participatory Audience of One is a unique place of observation and comment, aware of the positions and views of the Director and Performer, the Participatory Audience of One is free to critique and engage in the field of action. Emotionally and physically caught up in the action, I can hardly keep my seat when I see an obvious point arising that can be something the Director self could not predict and something the Performer Self did not intellectualise and yet it arose from the intuitive. This state is observational because often I could be aware of a possible effect of an experience of the performer on the overall project, but it was not until I had reconsidered the implications of these data from the perspective of the direction of the thesis that its significance and placement was found or rejected. The state was also participatory because, as with any audience, I was not unaffected by the knowledge of the overall story and the impact of the events of the action as they unfolded.

The position of participatory audience is also integral to the progression of the story dependent on the director's anticipation of the effect of the story on the audience; like wanting to take the audience along with the story, and wanting to elicit emotion and response, and wanting to create flow between elements of the story to not create jolts between storyline and events. But to also keep the audience interested and keen to see more of the story developing. 
The position of participatory audience is also integral to the progression of the story dependant on the performer's freedom to elicit direct or indirect contact with the audience. As the performer I also had to learn to cope with hecklers. These hecklers were internal; self doubt, conformist and anti-anarchists. The thoughts that I have had in the middle of the day or night that tell me I'll never be able to do this thesis and what is the point of trying to change things anyway. External hecklers have been people that have not had the benefit of university support and learning and who think that academic hierarchy and accolade is worth nothing in comparison to an honest person doing an honest day's physical labour. There have been other people that said they could have done a PhD but just chose not to, because they couldn't see the benefit in attempting it.

I have only been able to counter these heckler thoughts and unbeliever individuals with the confidence of the performer who believes in the validity of the craft to uncover the multiple truths in the final analyses. Also my mother has always said "I can do anything if I want to" and I firmly believe her.

\section{Phases of Project design: Locating Meaning Through Design}

\section{Creative Synthesis or Psychogeographical Map}

In the location of creative synthesis within my thesis I have made a metaphorical comparison between the opening and closure points of a necklace and the opening and closure of this thesis as a project of research design. The art works and poetry stand as the creative element of the demonstration of the literary psychogeography of myself as a nurse artist. The textual narrative stands as the synthesis of the literary psychogeography of myself as a nurse artist. 


\section{The Clasps}

In the use of this metaphor I intend to gather both the creative art works that are my narrative together with the synthesis of researched material and create a circle of knowledge. This closure of the necklace naturally defines the area of [new] knowledge that has been generated by my inquiry. The balance and the mastery in the writing of this thesis is to only create as much as can be synthesised. Creation for its own sake in this context does not help to illuminate my process, and synthesis of knowledge that is merely reliant on a search of the known, does nothing to add to the debate.

A necklace without the clasps perhaps is not a necklace at all, as it cannot be applied to its purpose. The opening and the closure of something that is designed to fit the body, involves a specific design for the placement and removal of the adornment from this décolletage area. In the same way I have identified a type of practice within a specific and defined area. It is no accident that this necklace pays homage to that part of the body that is closest to the heart and the creativity shakra. The place on the body where we display a statement that speaks of our Self. And so I make comparison between the necklace and the narrative.

The Clasp

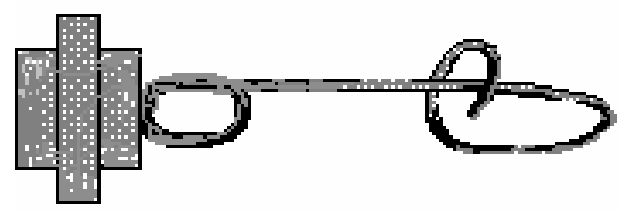

Figure 6 : The Clasp as the Creative Hook

"Creative - imaginative, inventive, inspiring, original, stimulating, visionary"

(McEldowney, 2002, p.1) 
The clasp end of the necklace that is generally known as 'the hook' has an openness that is the essence of its nature. This simultaneously occurs with convoluted-ness, which is also essential to its nature. It cannot perform its job unless it has both. It is a locking device and an opening. It is a way, to make the whole, and an undoing. The clasp at this end of the necklace is a paradox. What seems complicated is simplicity itself. The clasp operates on natural law that the direction of the ends of the necklace will be divergent to each other, that they pull away from each other as the necklace sits on the curve of the neck and falls away, drawn on by gravity. For the necklace to come apart it requires the intervention of a force. The fingers of a person that first relieves this natural pull and creates slack. Then this person must intentionally spiral the opposite end of necklace though space along the wire and changing direction allow the clasp action [in reverse] to undo.

The creativity of this clasp embodies the way in which originality; imagination and the desire to reach a practical and aesthetic solution to one's dilemma can be found in the smallest and most powerful artistic expression. This is what I sought in my project.

If I had sat down to solve this creative problem myself I may have never come to this solution without the inspiration of creative elements around me, and yet two people who work towards a goal that are separated half a world away from each other can create exactly the same thing. In synchronicity our humanness is echoed, and our human processes, needs and desires. Our deep symbolism and connection with each other across time and space can be found and wondered at. In the spiral and the open symbol of the 'creative clasp' we find release and embrace in coexistence. 


\section{The Clasp}

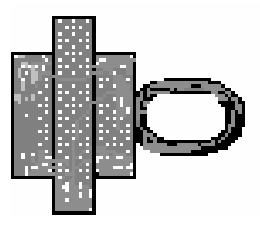

Figure 7 : The Clasp as Synthesis Eye

"Synthesis - amalgamation, combination, integrative, welding, blending, combining, fusing, uniting"

(McEldowney, 2002, p.1)

The clasp end that is generally known as the 'eye' brings together the necklace. Its circle provides the absolute safety on which the closure of the necklace is founded. Where the clasp end that is the hook contains elements of release and embrace, this end of the clasp is receptive and uniting. The nature of the circle is integrative and completing. It is affirming and engaging and brings the necklace always in the direction of/towards 'together'. Even when the necklace is undone the clasp that is the eye seems to beckon to closure, to unite is its primary purpose. 
Psychogeographical Map of the Thesis Design

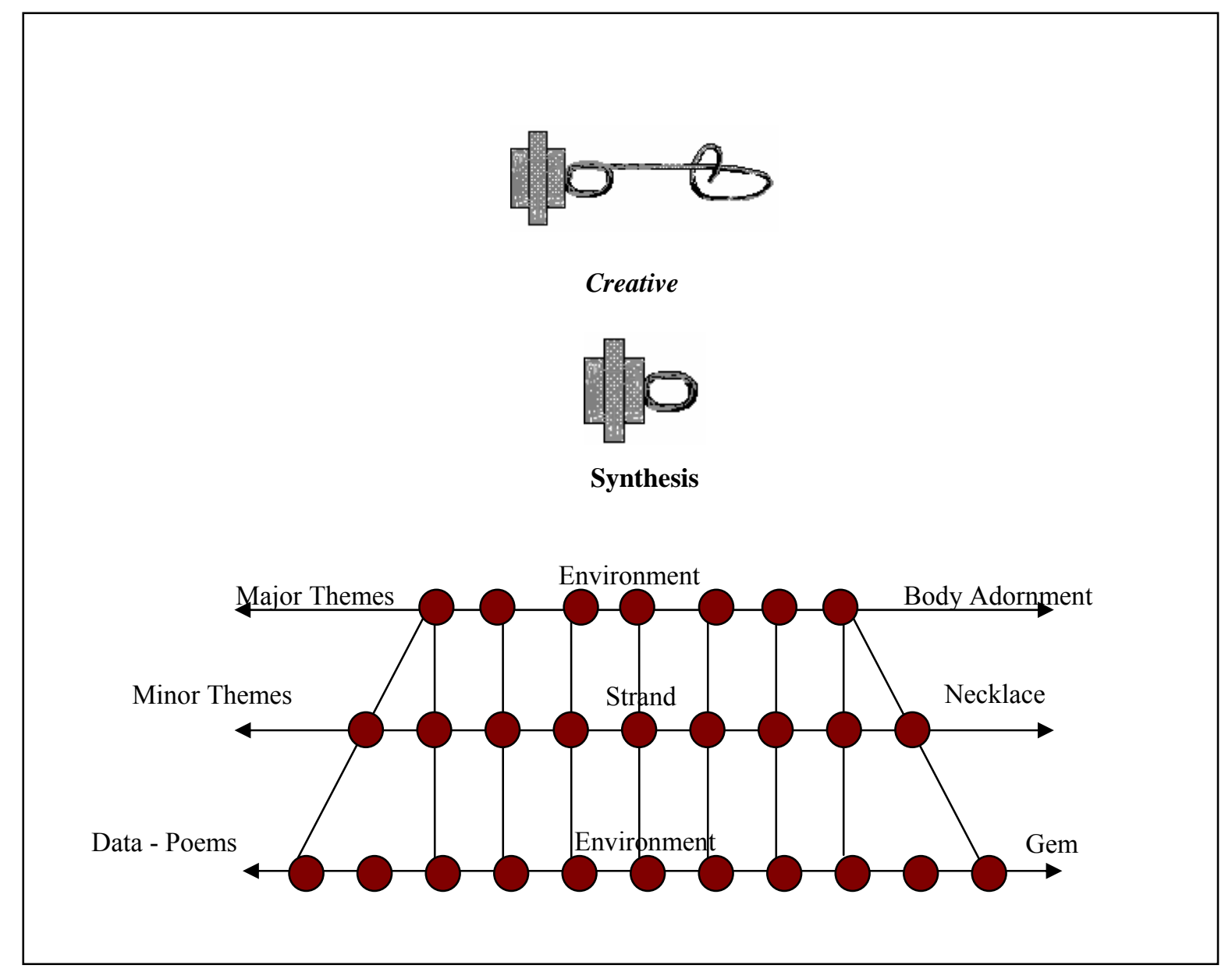

Illustration 3 : Psychogeographical Map of the Thesis Design 


\section{Phases Of Project Design: Psychogeographical Mapping of the Thesis}

\section{Psychogeographical Map of the Thesis Design - Another Way}

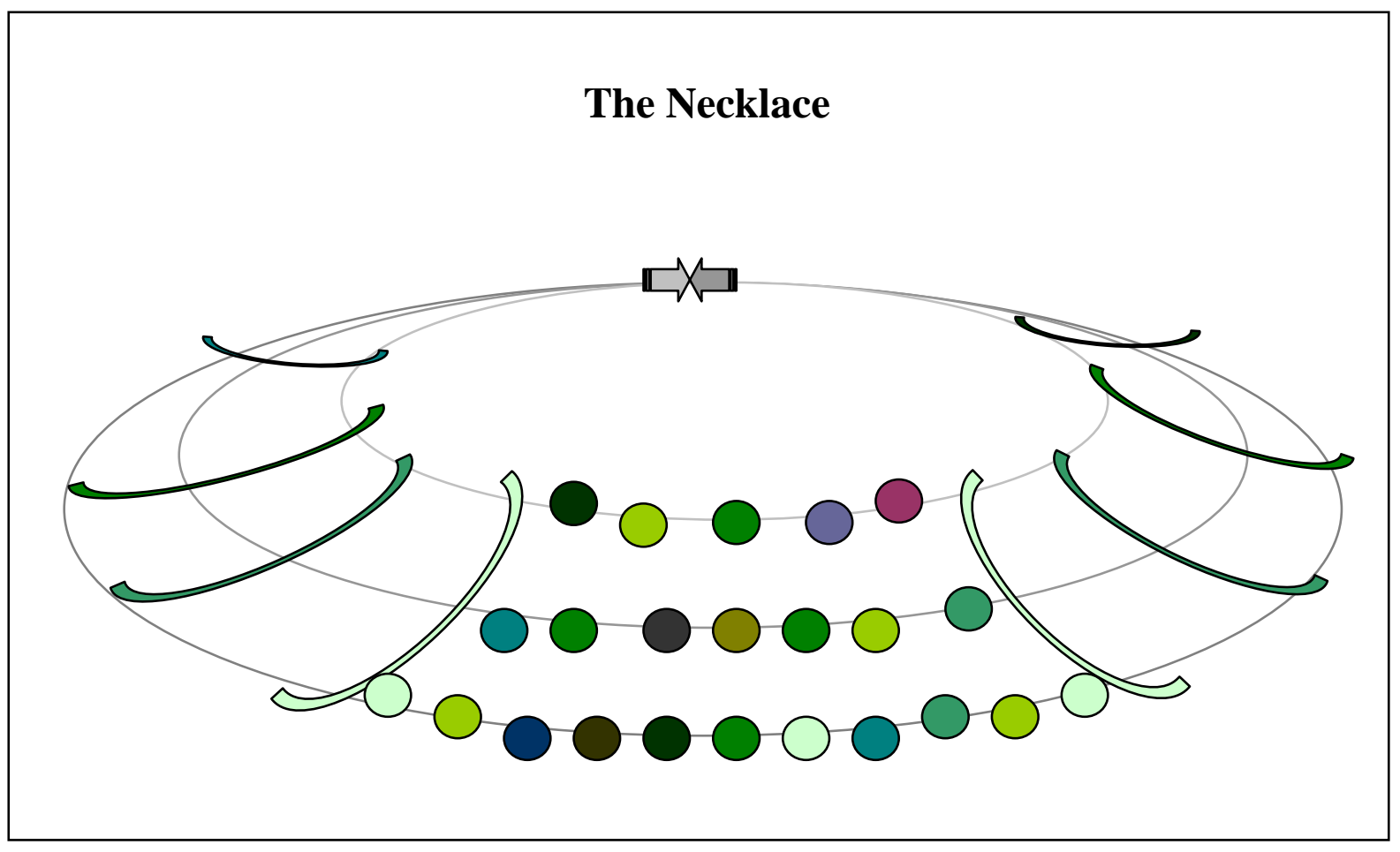

Illustration 4 : The Necklace, Psychogeographical Map - Another Way

I will now proceed to Chapter Six: Gathering Meaning, which demonstrates the thesis design. Poetry as data leads to the development and mapping of minor themes and then major themes. The reader will be further introduced to the literary psychogeographical method and invited to dérive the poems noting the influence of the physical surroundings as recorded in the literature of the poetic text. Cognitive mapping draws comparisons between the insights of the researcher between the periods of 2002 and 2005. 


\section{Art Interval}

Bird Rock Cafe, 2003, Acrylic on canvas, 600mm x 500mm 


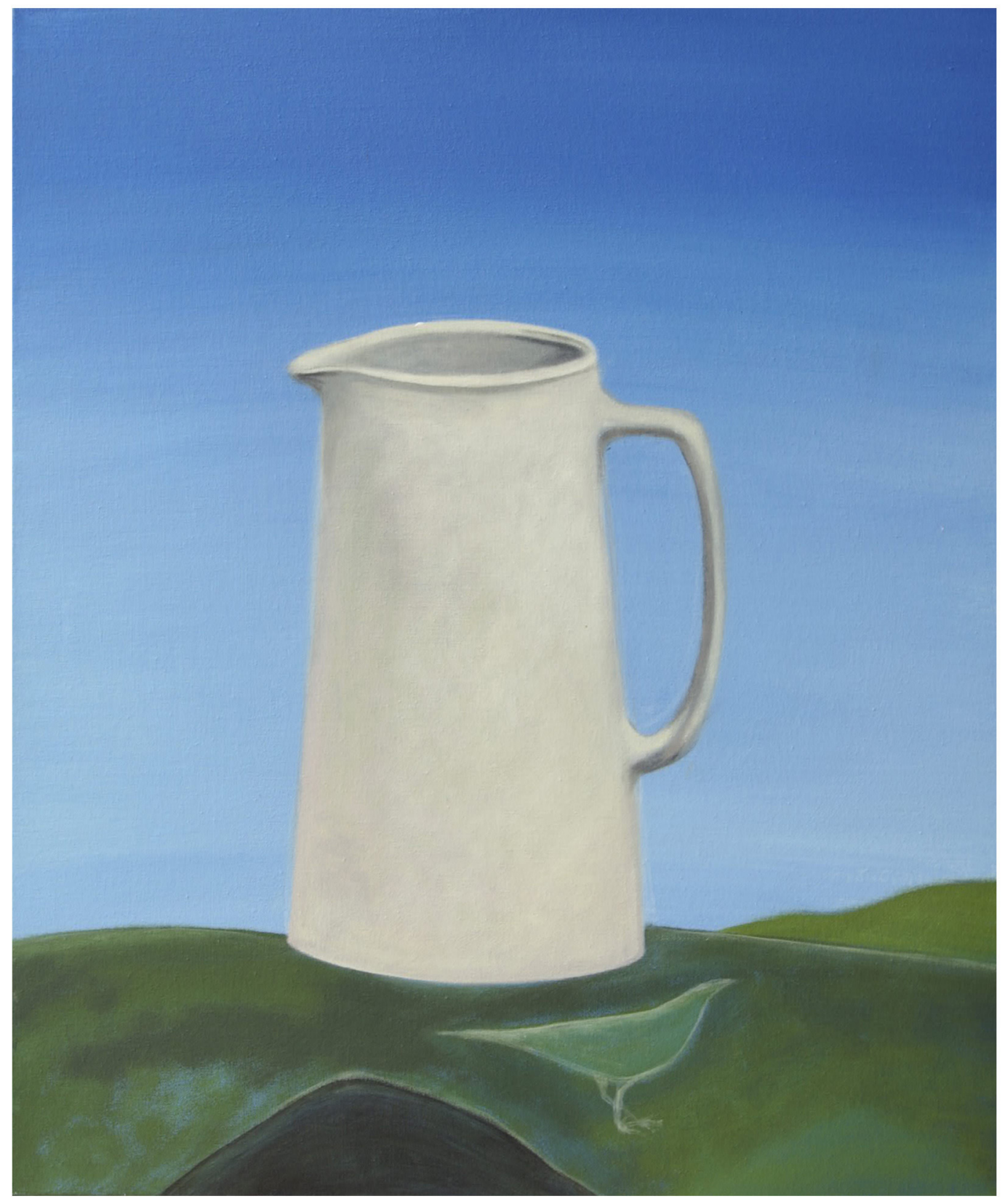




\section{CHAPTER SIX}

\section{Gathering Meaning}

\section{Map Fragments}

\section{Literary Psychogeography Method}

To dérive is to rediscover the existential relationship that I have with the mental health field environment. To wander with critical notice, yet with an unconsciousness that allows me to be drawn to, repelled, and/or excluded by this environment. The cognitive map which results is derived from noticing locations and their attributes. Text in the form of poetry and paintings as a cognitive map, allows the transfer of information about the Mental Health Field Environment gained through the dérive from myself to others for the purpose of influencing, resisting or rupturing passivity and acceptance which is an "expression of the relations of power within a capitalist society" (Hetherington, 2002, p.13).

the practice of détournement, like the dérive within the city [mental health field environment] is concerned with a rupture, a punctum, in the spatializing of time and the pseudo-history provided by the city planners [health industry] and film directors [politicians] in their different media [health policy]. As a source of intervention, it seeks to bring movement into what it sees as a condition of stasis that encourages isolation, separation, and passivity in its audiences [patients]

(Hetherington, 2002, p.19).

Psychogeography is to analyse the subjective relationship that I have with the mental health field environment as I rediscover that place. Literary psychogeography is a term denoted by van Tijen (Shaw \& Tijen, 1991) in 1979. His intention was to utilise literary psychogeography "as a means to exercise a positive influence on one's own physical surroundings" (Shaw \& Tijen, 1991, p.6). Most importantly in this study, 
literary psychogeography enables me to record the mental health field environment in text which, as historical and spatial data, can then provide a means to shape the future of this environment by explaining the past.

Literary Psychogeography is an examination of the "influence of physical surroundings on the instinctive behaviour of individuals, as recorded in literature, literature being understood here in its widest sense of all written records left by a people or an era" (Shaw \& Tijen, 1991, p.3). Poetry is an acceptable source of literature including non-literary text (paintings), as what is important is whether or not the text contains some "psychogeographical element as may occur in a quotation describing physical surroundings and their impact on the mind" (Shaw \& Tijen, 1991, p.3). It is also possible that the text may evoke a mood produced by the physical surroundings (Shaw \& Tijen, 1991).

I invite you the reader to dérive in your own way with the poetry where you may select certain words or phrases that you are attracted to, repelled by or excluded from and by doing so create a conceptual map and personal response to these poems. Having gained an insight to the geographical and literary features of the terrain of these data you can then proceed to détournement, which is to incorporate new elements that retain the essential nature of the original text but that also take it to a point of new insight, understanding or expression. What do you see? As this field was mapped out by the poems what emotional response did you project onto the mental health field environment? And what effect did the 'city of the poem' mental health field environment as captured by the text have upon you?

This poetry is movement, it is action by myself as a nurse artist towards recovery through the recognition of strengths that asks What can I do? rather than, what can I think or what do you think of me? This represents a rejection of passivity, isolation and immobility in our constructed positions of mental health worker and patient. 


\section{Hospitalised Poem}

My sentence broke off.

My full stopped.

I clumsily dropped, the line.

My writer's blocked.

My linkage hindered.

I'm a/sham/ed/ly longwinded, and raw.

My syllables are stressed.

My past tenses.

I'm image dense, language poor.

My para-phrased.

My rhythm is flat.

I'm overly fat, not justified.

My thought trailed off.

My poet repeated.

I'm close to deleted, written off. 


\section{Hospitalised Poem}

\section{Dérive of the Poem}

Broke off...my full writers ashamedly raw...I'm image...dense...rhythm justified...thought...poet...written off...

\section{Literary Psychogeographical Analysis - Minor Theme}

[I used to have a handle on life but then it $]$...broke off...my fullness poured out into words...ashamedly raw and dense...yet the pulse and rhythm of it so beautiful and colourful...and in time...I am justified...sanctified...unified...I'm poetry personified...I am in my time a written image of myself...shimmering and lifting off...

\section{Détournement to the Major Theme}

The beautiful flawed Self....

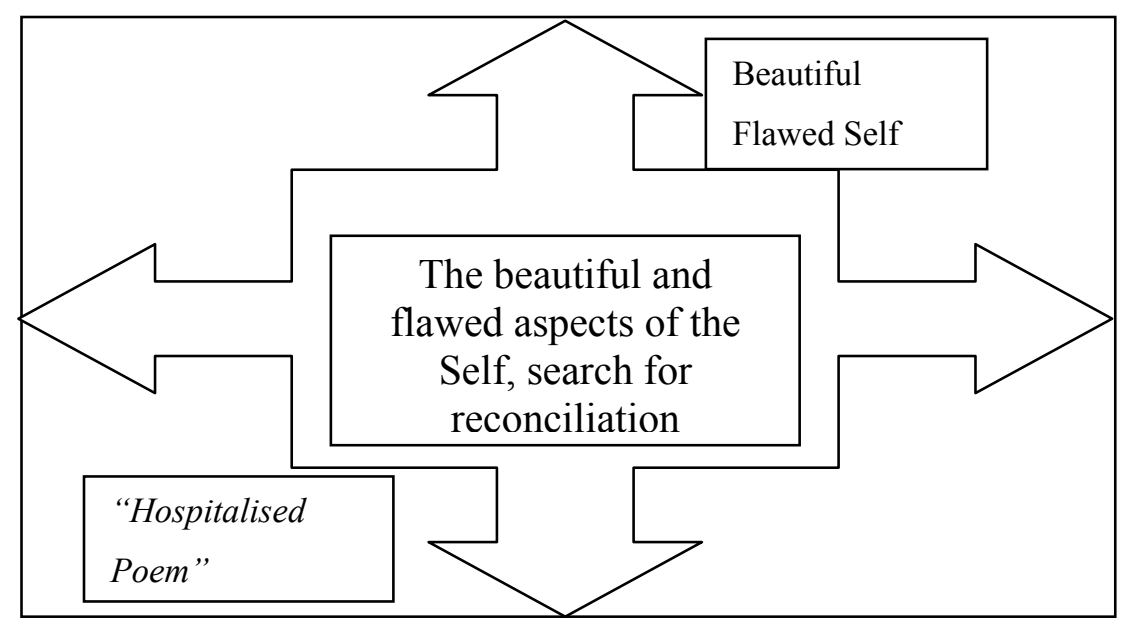

Figure 8 :Cognitive Site - Map Fragment 


\section{Jerk}

I recall a male nurse counselling a young woman in the no-mans land of the open ward space, as she spasmodically writhed and cried all at once, body twisted into an ' $\mathrm{s}$ ' echoed by hands and forearms grasped around each other, in a hug with no-one else in it to stop a jerk.

carrying a formal conversation of "when will it stop?" in the best way she could, like a surgical patient asking when will the stitches come out?

The privacy was missing, I shied from the witness of it. Where were the drawn curtains? Other patients get to ring the bell. Those in the mental health ward have to come out of their room and find a staff member, it all happens in the open you see.

He reassured her that the levels would be titrated to therapeutic, and not toxic, over the next few days.

My heart went out to her Though she never knew.

I wanted to hold her, while the shakes subsided until she trusted her body again. when just being there, meant her mind had betrayed her also. 


\section{Jerk}

\section{Dérive of the Poem}

Nurse Counselling...open ward...cried...echoed by hands...a jerk...and carrying...come out...the privacy...witness of...patients...mental health ward...staff member...open you see...my heart...hold her...to trust her...betraying her...

\section{Psychogeographical Analysis - Minor Theme}

Nurse guardian...opening ward closing ward ...like asthmatic lungs...opening eyes...echoed by opening hands...jerking open and carrying tears...please see me otherwise I cease to exist ... but then don't show me to others...privacy for my body is lost when you stare into my brain...seeing other patients genitals and thought trails...all laid bare...I witness my jerk...then the other jerk...all in the same boat...we are the ship of fools...cast off into a therapeutic dose...loved by many cared for by none...holding her down...we betrayed her...

\section{Détournement to the Major Theme}

Physical and Mental Privacy....

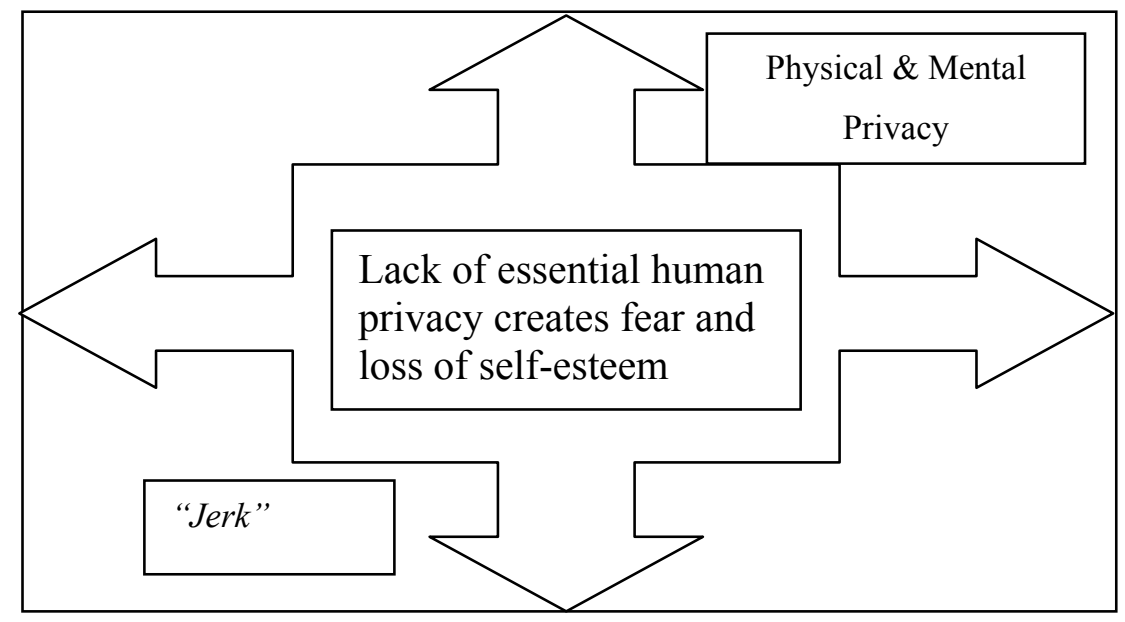

Figure 9 : Cognitive Site: Map - Fragment 


\section{Carrier}

The hand, black and purple

$$
\text { a lump of sore }
$$

seeks refuge under the bean bag,

lying in the crook of the opposite arm accidental damage to the body.

The result of a disorganized mind a clash of wills, forced the hand, held at this time in this place when no other clasp will do.

You've got me fast I'm beaten adopting a dying pigeons pose when viewed,

useless and near lifeless, and wincing from touch.

Hand! hold the hurt for every part. carry it for everyone even the heart. 


\section{Carrier}

\section{Dérive of the Poem}

Forced...beaten...heart...dying...pose....clash...wincing seeks...refuge...disorganised...mind...hold...hurt

\section{Psychogeographical Analysis - Minor Theme}

Injury at the hands of others...Loss of personal control...Experience of torturous pain...needing refuge even from oneself.... violence of self inflicted pain and injury... Self-preservation...continued existence or near death are close to each other...Surviving ones own mental illness...surviving the result of ones own illness...surviving the response of others to ones own illness...surviving a life threatening experience...transferring mental pain into physical pain as a means of exercising control...inflicting/preferring/owning ones own pain in preference to the pain inflicted by others

\section{Détournement to the Major Theme}

Survival....

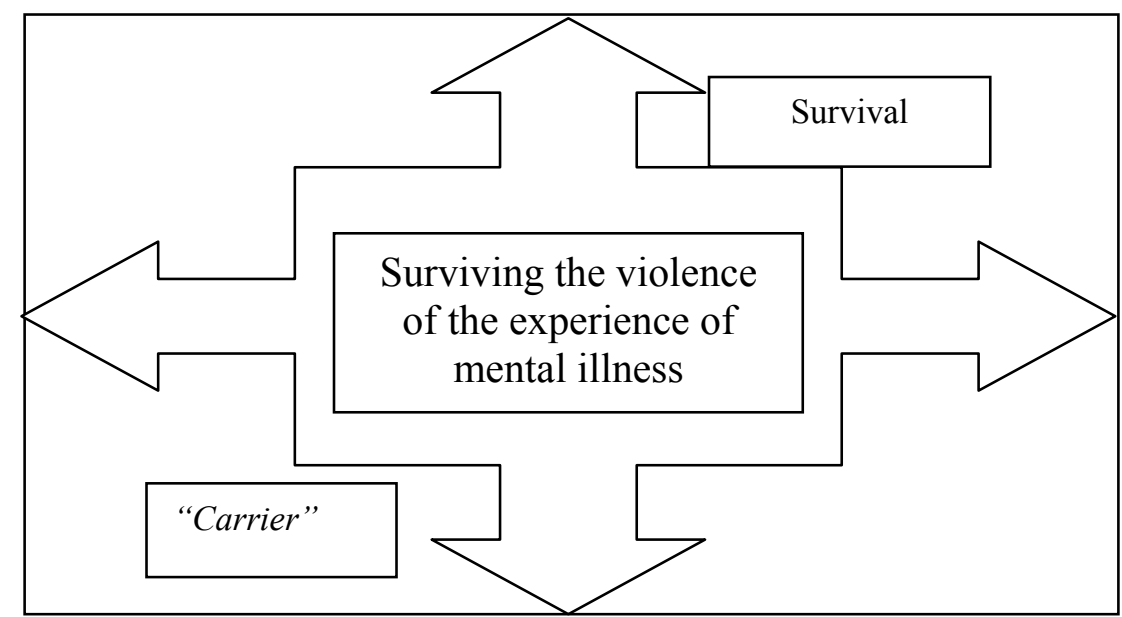

Figure 10 : Cognitive Site: Map - Fragment 


\section{Pink Slacks}

I looked from crutch to ankle

at the pink stretch trousers,

the type with the permanent press seam.

at the wet trail of urine

not steaming but damp and raw on the skin,

hard to meet the eyes,

Madge trying to convey

the hopelessness of it all,

in really wanting a brand new dress

and being told the pee,

was just another attempt

at getting different coloured trousers,

from the store. 


\section{Pink Slacks}

\section{Dérive of the Poem}

The type...of urine...damp and raw...convey...hopelessness...brand new dress...getting different...store

\section{Psychogeographical Analysis - Minor Theme}

Cast in a hospital play... with no wardrobe mistress... [accused of] using body fluids to communicate...I want something that is just beyond that locked door...can you clothe me without dressing me down...can I clothe myself...please...I want something just beyond that locked door a new me to put in the old dress...old dress and new me can go up town...I'm wearing something wet...I want to change...

\section{Détournement to the Major Theme}

Freedom to change....

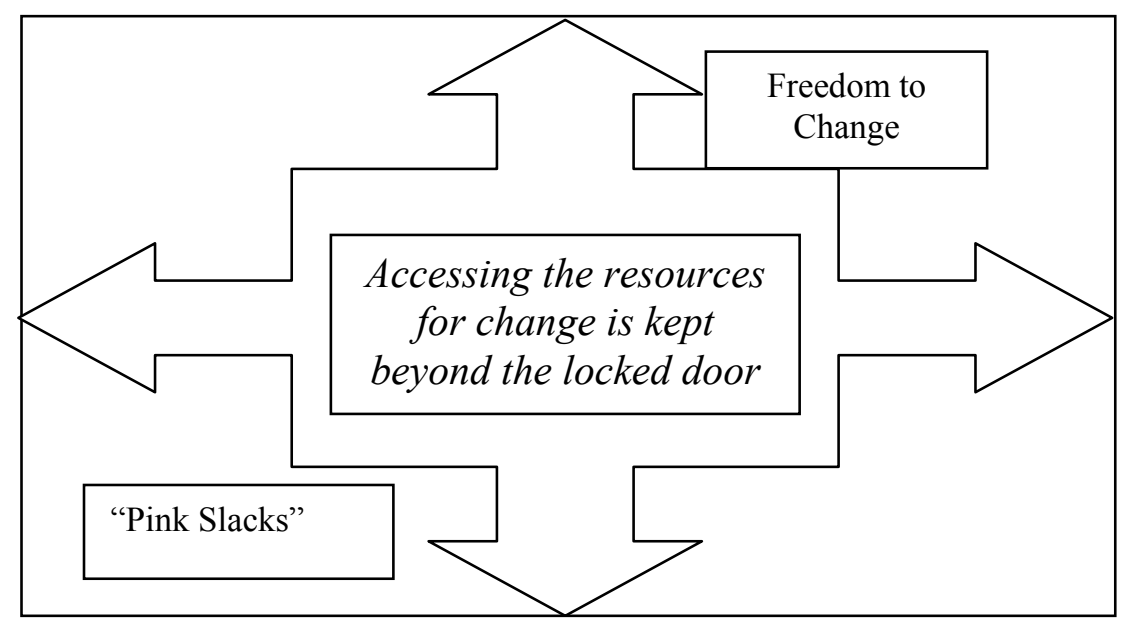

Figure 11 : Cognitive Site - Map Fragment 


\section{What Ifs and Butts}

Every psychiatric facility has the

piles of butts, smoked to within an inch of their life.

You can always tell the butts that have been dragged on down to the filter, what once was a cigarette becomes a stick of charcoal under the toe of the shoe, drawn back to extinguish the smoulder.

The streak solid and deep black tells another story, of a habit that takes food out of mouths and medicine from bodies.

The roll-your-owns lie there like curled dry whitebait, the length not for want of smoking that last puff, but all that protects the lip from a blister.

They become light in the breeze

swirl in circles and gather in mounds with the leaves, never quite able to pass themselves off as a natural object. 


\section{What Ifs and Butts}

\section{Dérive of the Poem}

Psychiatric facility...dragged on down...under the toe...extinguish a smoulder...habit...mouths and medicine...not for want...with the leaves...never quite able...natural object

\section{Psychogeographical Analysis - Minor Theme}

A building paints a thousand words...oppression is the antonym site of maintenance...smoulderings are extinguished below, overhead the fire rages on...oral routes are for compliant patients...wanting a cigarette plugs the other wantings...smoking is reachable, giving up and holidaying in a year is beyond my reach of knowledge of myself...you tell me big plans might be dangerous, what about a smoke?...its natural that I should smoke, then the harm I do is to myself...the objective in smoking is to avoid personal expression and choice which might present a greater risk to others...my smoking is preferable to my direct expression of self...indirect expression is preferred...

\section{Détournement to the Major Theme}

Expressing Desire....

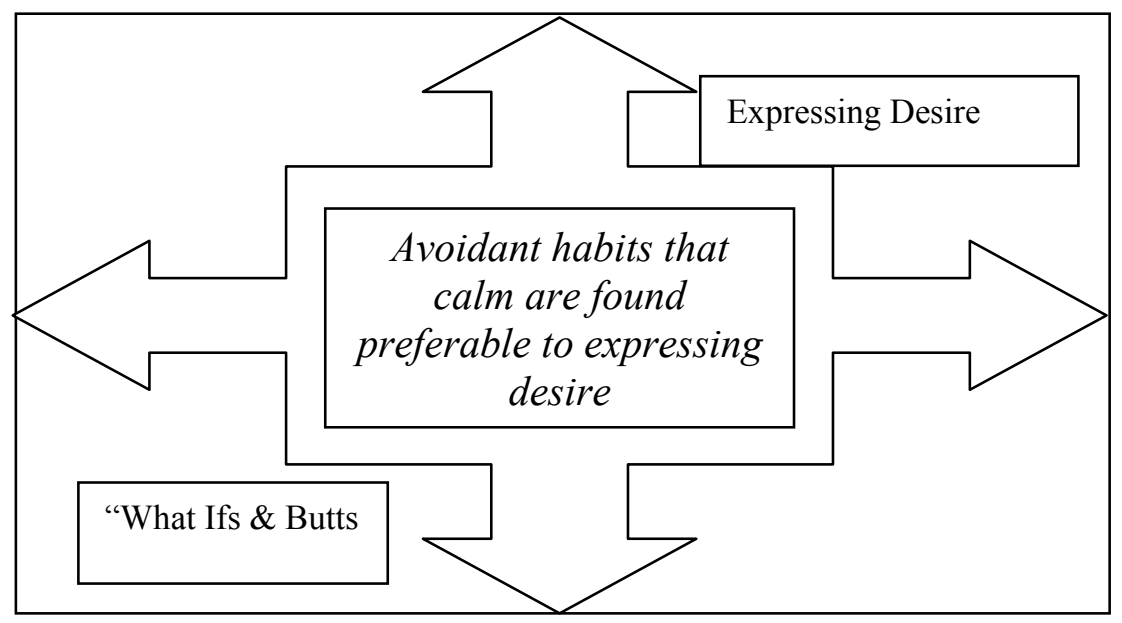

Figure 12 : Cognitive Site - Map Fragment 


\section{Shame}

The talk circled high in the air buzzard like above her head she's invited to her meeting and the subject of discussion instead What to do with the difficult case?

Heat shimmer made discharge a mirage Planning for getting out is different than planning for going home And the talk circles again this time with doubt she'll make a mistake and do it soon.

Ears burnt off in shame white heat. There's nothing I'd like better than to let you go but you're too great a risk.

Over to you, and the high language comments flow she wants out, but only goes out the back.

Tongue cracking for lack of space at the font.

Our knowledge in this situation must overbear your wishes, prove to us how safe you are that you'll get up and do the dishes. so when it's all said and done who's killing who.

Slumped over the edge of a poisoned water hole, makes everything we try, look so sick 


\section{Shame}

\section{Dérive of the Poem}

Subject of discussion...discharge a mirage...

mistake...shame...risk...overbear...slumped over...

\section{Détournement of the Minor Theme}

Being talked about, not talked with...being seen as a medical case...language of discharge from hospital mirrors/copies language of release from prison...mistakes are not something to learn from but something to suffer for...mistakes are not able to be made as they have dire consequences...mistakes are unacceptable...shame goes unnoticed...mistakes are noticed...risk is particularly noticed...shame is minimised...mistakes bring the consequence of solitary confinement...normal behaviour is prized...normal behaviour brings inclusion...anything but normal behaviour is a mistake... anything but normal behaviour brings consequences... what are we doing... where are we going with this...give us a sign of your normality...give us a sign...exhaustion... an exhaustive exclusion

\section{Major Theme}

Social Exclusion...

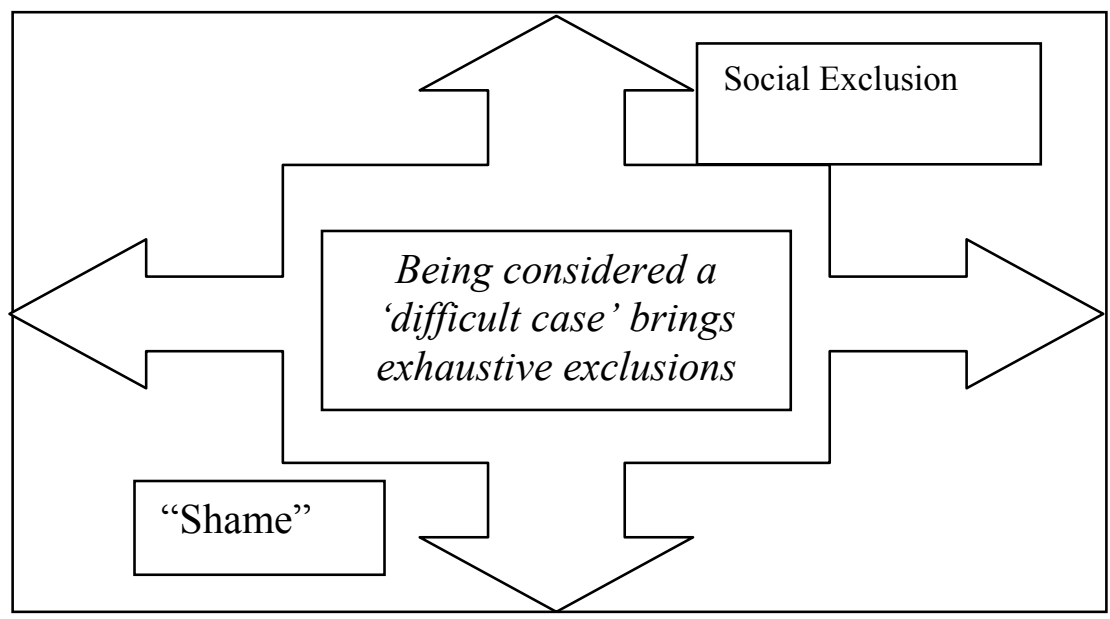

Figure 13 : Cognitive Site - Map Fragment 


\section{Belonging}

Longing to be

a householder

with green

wheelie-bin.

To get a glasshouse

to grow some

good tomatoes

in.

To wear a ring

attached to

a wife my

love.

I want a few

simple ordinary things

that other people

have.

Longing for

a door

I lock on the

Inside.

A chair I

can leave

my body print

in.

A cat that waits

a child that plays

somewhere to end my

days. 


\section{Belonging}

\section{Dérive of the Poem}

Longing...grow some good...wear a ring...my love...ordinary...longing...I can leave...cat that waits...end my days...

\section{Psychogeographical Analysis - Minor Theme}

Always paying out or losing never receiving...like a conduit that family life and domestic assets pass through but never builds or has an anniversary or gains capital...Domestic unbliss...no quarter acre dream...unsafe sex for money...unsafe sex for drugs...money for drugs and alcohol...drugs for food...no wedder...no gift showers...landlords profit...SPCA feeds pets then uplifts them...CYFS feeds baby's then uplifts them...if I died today I'd leave a stain not a mark...gone in the first rain...Domestic purpose is a benefit...

\section{Détournement To The Major Theme}

Domestic Purpose....

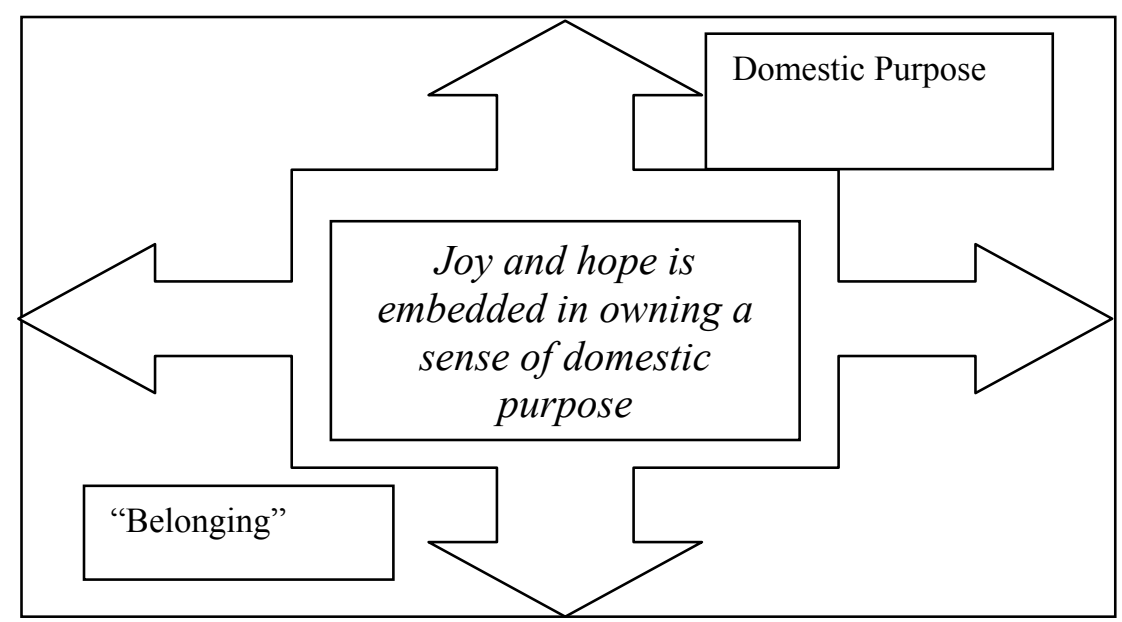

Figure 14 : Cognitive Site - Map Fragment 


\section{Space Suit}

In this space suit I fill

called pyjamas,

I feel the cloth.

my eyes dance

on patterns of autumn,

focussing more closely

to find I am property,

of the hospital board,

over and over

in diagonal slanted

ill-fitting print. 


\section{Space Suit}

\section{Dérive of the Poem}

Space...fill...pyjama's...feel cloth...eyes dance...patterns...focussing find I am property...of...health...over and over...ill fitting...

\section{Psychogeographical Analysis - Minor Theme}

A space to fill...pyjamas as cloth hold open the space....as my eyes dance then focus...on finding the pattern to ownership...property rights to my health are sold over and over...its fitting that I'm ill...

\section{Détournement to the Major Theme}

Illness Prophecy....

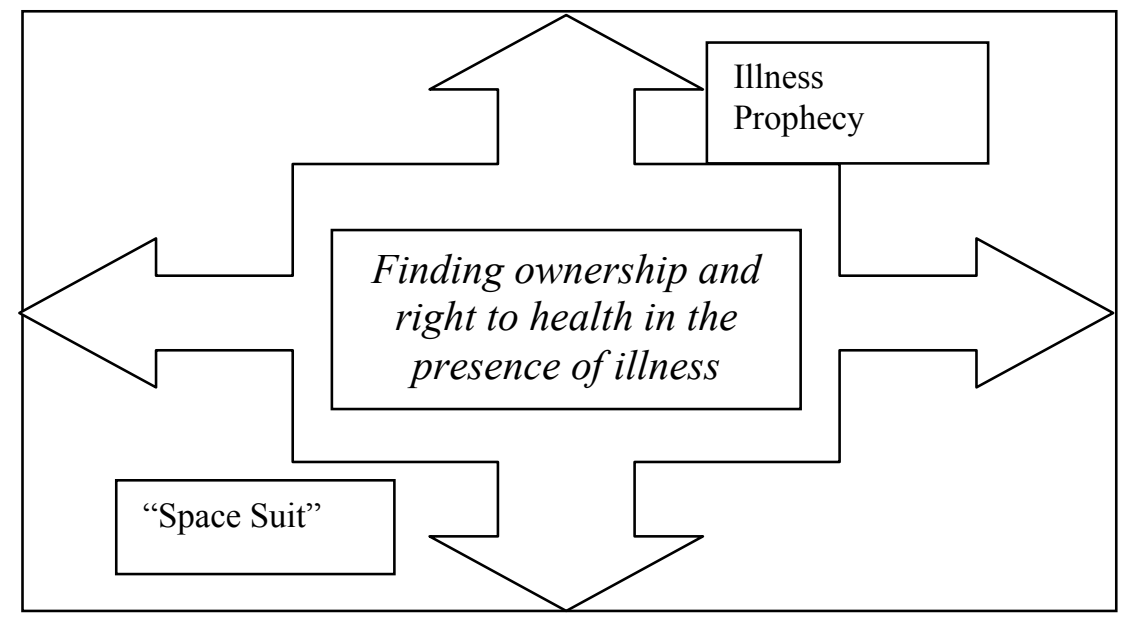

Figure 15 : Cognitive Site - Map Fragment 


\title{
Charge's Desk
}

\author{
I bear a burden \\ It's the patient's files, \\ I'm wooden and Government Issue \\ no frills, no style. \\ I have a similarity \\ to people that pass the door, \\ most of me is insignificant \\ but for one locked drawer. \\ knocking at the door \\ the patients come pleading, \\ I need a smoke \\ my heart is bleeding. \\ I'm hurting from the sorrow \\ of being forced to hear, \\ the details of people's habits and bodies \\ the status fights and fear. \\ I live in the charge's office \\ left of the main door. \\ all my family live in the same place \\ except for the spares in the store. \\ If I had the use of my legs \\ I'd run a mile if I could, \\ out of this Charge Nurse's office \\ and go and hide in the wood.
}




\section{Charge's Desk}

\section{Dérive of the Poem}

Burden...files...no style... similarity...pass the

door...insignificant...locked...patients come...heart is bleeding being forced...status fights...live in...left of the main... all my family...spares...charge nurse's office...go and hide...

\section{Détournement to the Minor Theme}

Files of files...rooms of files...files of lives...files in basements...de/basements of patient lives...overheard whispers...bleeding heart stories...charge nurse passing the door...comments on insignificant style...your side of the door...and my side...my left side...I'm left...you are right...you're always right...my family despair...coming to see charge nurse in the office...I go and hide...patient files...burden patients

\section{Major Theme}

Illness Burden....

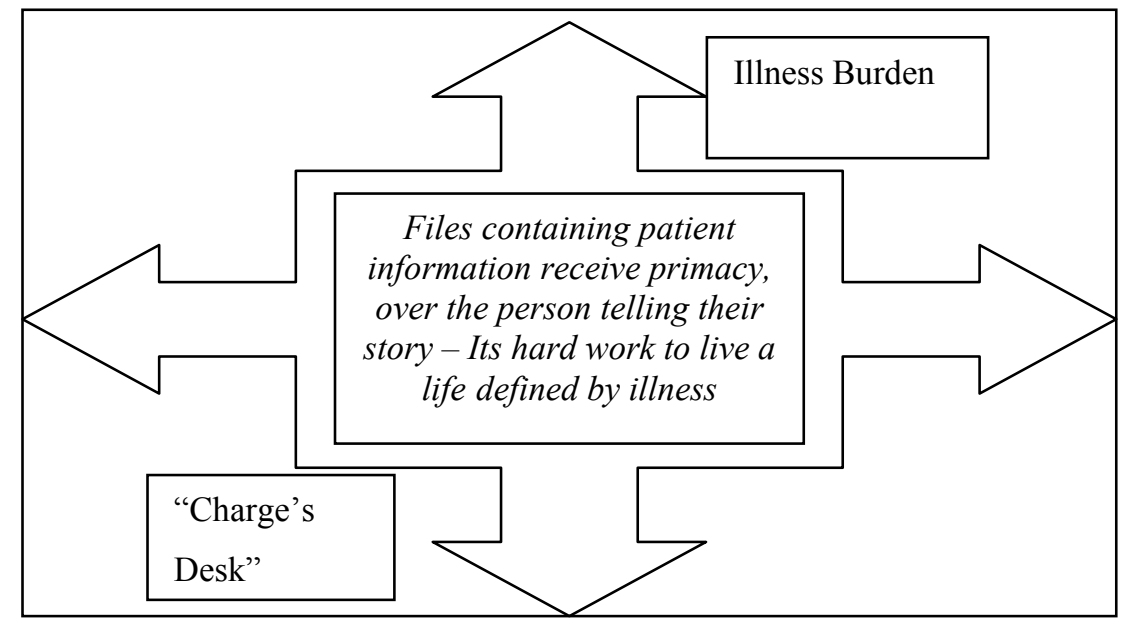

Figure 16 : Cognitive Site - Map Fragment 


\section{Map Fragments}

\section{Cognitive Mapping of the Mental Health Field Environment}

In this section I will compare a cognitive map made at the time of the beginning of my research and a further mapping that was carried out in the later part of my research. It is an accurate record of the movement of researched information from the centre to the margin. From constructed position of staff member in power over patient, to the struggle for a view that is not fully realised as a result of my position of power but as a result of making space for Other.

The information that we possess as workers in the mental health field environment is privileged not just because of privacy issues but because we look, as a voyeur, directly into the [presumed] experience of an individual held in absolute control by coerced surveillance, assessment and treatment. My research reveals an interesting tension between what the 'educated' mental health worker may attempt to constitute as recovery and what appears to be a further construction of the mental health field environment in the pursuit of workforce development that produces a less brutish or monster-like, caregiver. A mental health worker who does not cause or prolong mental illness via social injustice, unresponsive services, or traumatic events (Mental Health Commission, 1998).

The following map records the view that I held of the mental health field environment, at the time of my envisioning the research project through the use of the poems. It represents the opportunities and limitations not only of the actual field but also my own ability to perceive this field at this point in time. My understanding is based in my preconception and grasp of the field from my constructed position of mental health worker within a milieu that seeks to engender recovery in the person with experience of mental disorder through the recognition of identity-claims. This milieu however, is "based on a risk paradigm in which the investigation and identification of pathology emphasises vulnerabilities" (Morgan, 2001, p.15). 
Therefore I propose that the ability of the individual to seek and be compelling in their own recovery and the "mental health worker to believe in their own power to make a positive difference" (Mental Health Commission, 2001) is limited, and that this limitation becomes part of the expectation society holds for that person in overcoming mental disorder.

What is apparent to me from studying this 2002 map over the research period is that it looks encouraging when viewed with the expectation that these identity-claim markers will be able to be realistically sought and achieved by people with an experience of severe and enduring mental illness. The reality is that these identityclaim markers are what I had hoped to be able to engender in people or what I might expect to see in a recovering individual, rather than what they had hoped for themselves. 


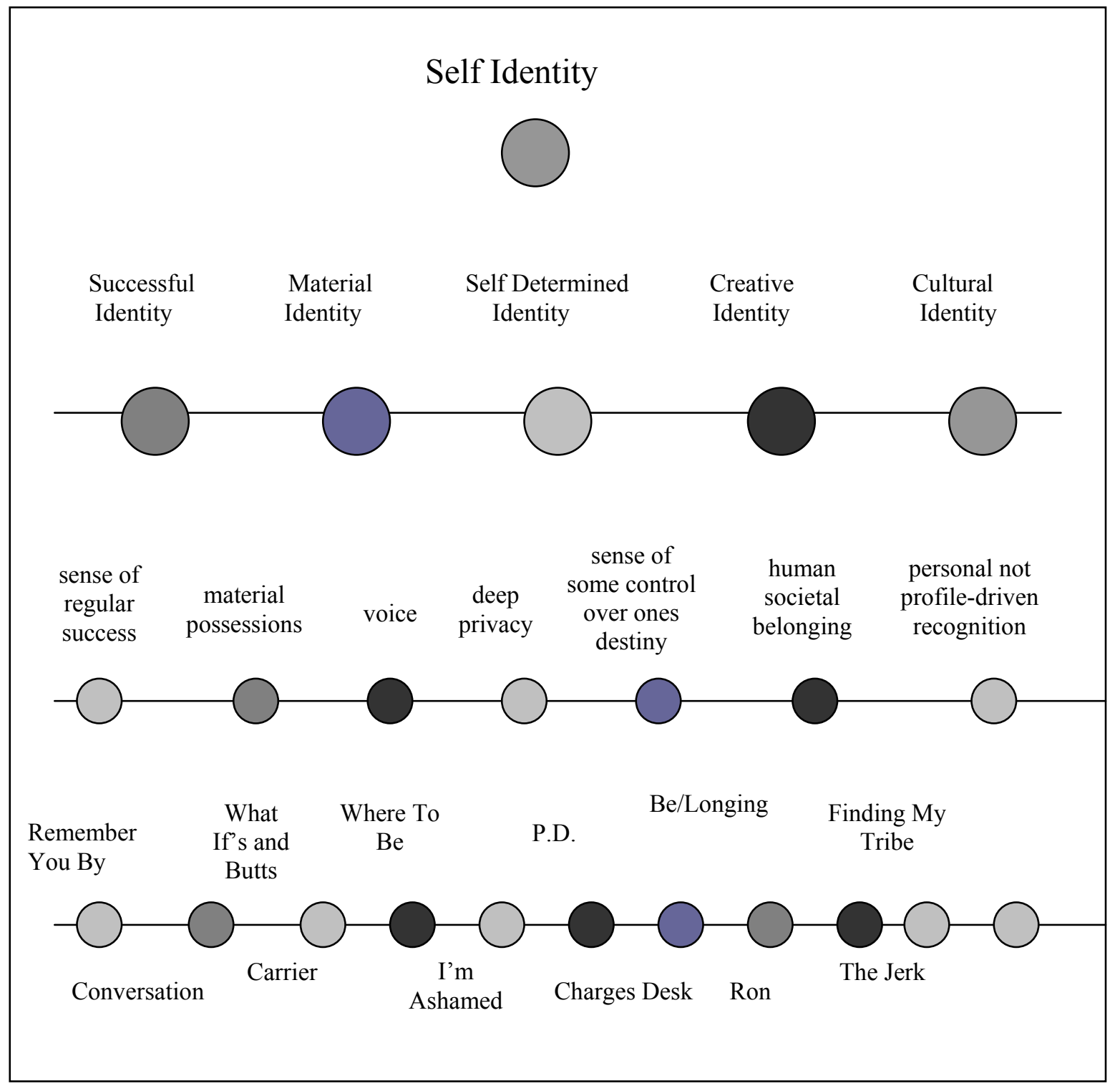

Illustration 5 : Cognitive Map of the Poems - 2002 
The second cognitive map (p.198) was created with the utilisation of the psychogeography and literary psychogeography method in the later part of the research process when, as researcher I had gained experience and understanding of the research method. It reveals a shift in my awareness and a more subtle and tentative stating of understandings, which seems to be discovering less of a stated position and more of an explored space. Importantly, the understandings are more relevant because I came into realisation that the first map (2002) was as a result of what I thought I was attracted to, repelled by or excluded from, in the mental health field environment. The second map (2005) is what was revealed after I actually carried out this enquiry. If I had not carried out this investigation, as a mental health worker I would not have been able to be aware of the way in which my view, as recovery focussed as (I thought and other health workers told me) it might have been, was merely as a result of what I thought, through a constructed view, rather than what is there through a psychogeographical method. What more is there for me to see? 


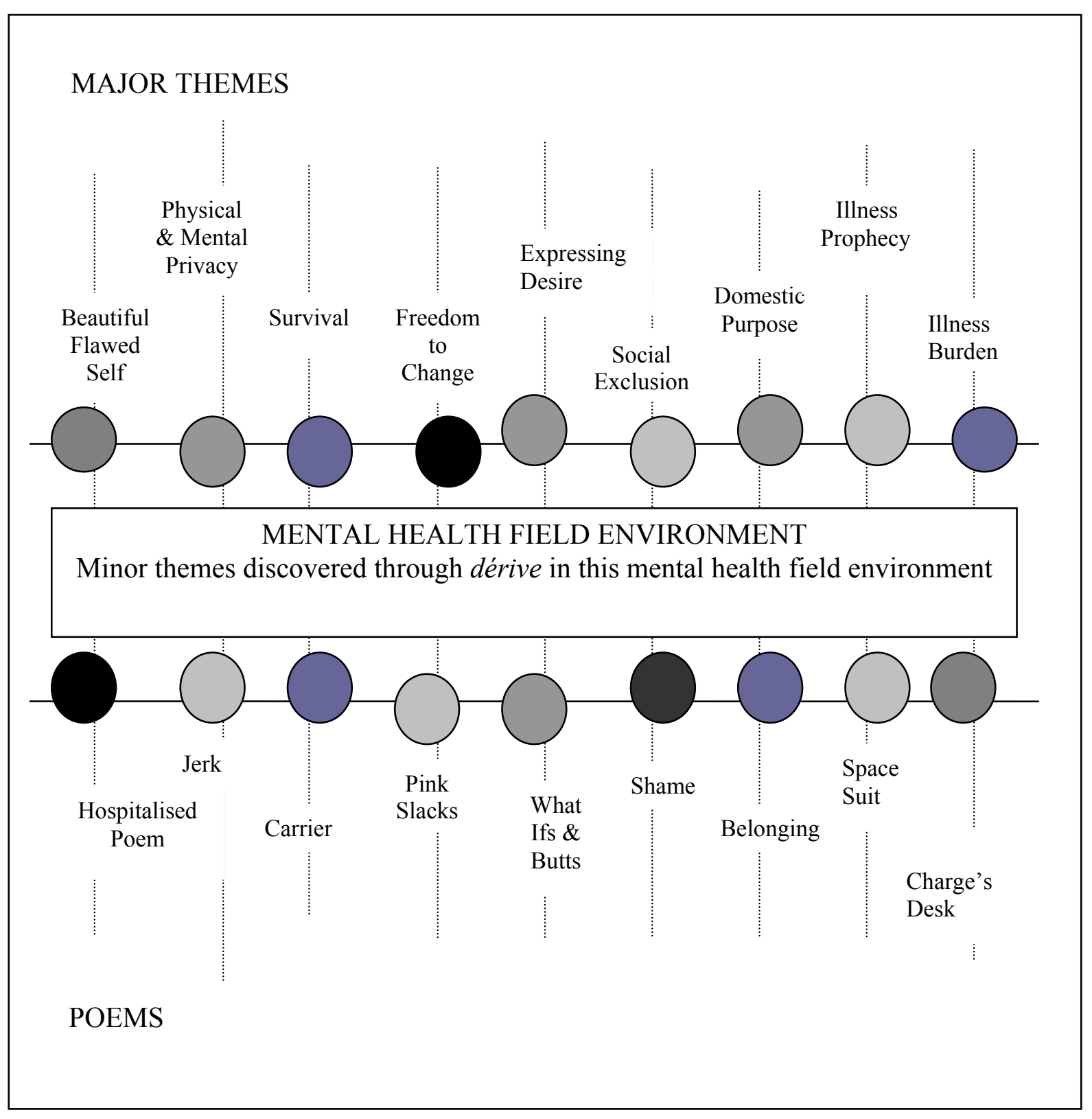

Illustration 6 : Cognitive Map of the Poems - 2005 


\section{Identity-Claim versus Agency}

As I indicated in the previous section the cognitive map of 2002 revealed my main concern of recognition of identity-claims as a means to development of Self. The reason for my earlier notions of the importance of identity-claims was due to my awareness of the overwhelming emphasis of the mental health services on "the "risk paradigm' in which the investigation and identification of pathology emphasizes vulnerabilities" (Morgan, 2001, p.15). This emphasis has been at the loss of any real headway made by national campaigns to reduce discrimination encountered by people with experience of mental illness, and the introduction of widespread recovery approach practice in the mental health workforce.

I was also influenced by mental health promotion models that emphasize that "the building of resilience is directly linked to that of meaning-making, for the building of competence or capacity comes about through an exploration of identity" (Morgan, 2001, p.15). Community-based health promotion projects have found that strengthening of "developmental factors, such as a sense of identity, autonomy, accomplishment and belonging enhanced individuals' capacity to face the ever changing and challenging realities of life" (Morgan, 2001, p.15). These views, put forward by health professionals working in the mental health field environment progressing mental health promotion, have a different timbre than identity-claim commentary that has been gained from people with psychiatric diagnoses. Goffman, (1968) differentiated between people "whose stigmatizing features are public knowledge - the discredited, and those who can conceal their stigmatizing characteristic - the discreditable" (p.57). People who have severe and enduring mental illness are in the group who become the discredited. Stefan (2003) conducted a survey of people who perceived themselves as psychiatrically disabled, and who had a diagnosis of serious mental illness, or who thought others perceived them as psychiatrically disabled. In choosing sites of survey she says "I essentially concentrated on outlets serving people who are discredited" (p.7). Stefan's findings 
showed that people experience a variety of beliefs about, and reactions to, a psychiatric diagnosis:

Very different reactions to the experience of emotional suffering, the experience of diagnosis and treatment, and the issue of identity itself create a difficult situation for a group that decades of social science research confirms is subjected to enormous discrimination. In order to assert that one is being discriminated against because of membership in a certain group, one must both accept membership in the group and externalize negative experiences. In other words, one must be able to recognize such experience as discrimination, rather than deserved treatment. This acceptance and externalization are crucial to seeing one's identity in a political context. Externalisation, however, requires that one have sufficient self-esteem and internal resources to believe social difficulties are primarily the result of unfair treatment by others, and that the generalizations made by those in power about the group to which one belongs are at best mistaken and at worst purposeful oppression. A claim of discrimination is obviously a political claim of unjustified treatment on the basis of membership in a certain group. Both the recognition that the treatment is unjustified and the question of identity (defining who is a member of the group) are critical to a political movement

(Stefan, 2003, pp.3-4).

I began to see that one of the ways in which we sap energy from people, and keep people with experience of mental illness in limbo, is to allow the ongoing struggle about identity-claims to continue. This struggle, ultimately, becomes a way of deflecting the real issues of stigma and discrimination, as consumers argue with consumers about the membership of the consumer group. The push for strengths model and recovery approach practice encourages the consumer in gaining self esteem and the mobilization of internal resources, only for them to come up against the hard fact that it is not only the actual illness that they have to battle with, but the unfair treatment of themselves. In some cases the unfair treatment is being meted out to them by assigned caregivers. The external societal view of consumers who 
struggle and suffer with issues of unfair treatment produces residual elements that feed the notion that these people as a group need containment, observation, treatment and care. I was able to recognize that, as a mental health worker, I had been involved in the support and search for identity-claims that perpetuated the stigma and discrimination against people with experience of mental disorder. Allowing people to establish identity in recommended and directed ways keeps health workers in the picture [and in employment]. People establishing their own identity-claims and recognizing experiences in the mental health field environment as experiences of discrimination rather than deserved treatment, without the need for verification of this by health workers, produce some disquiet and mobilize services to create 'safe' treatment areas. Political movement based on group membership and political stance based on identity-claims appears to have become one of the primary modes of conceiving of ourselves and relating to one another as human beings (Hutchins, 1999). Although identity-based education of the general population in New Zealand about the group of people who experience disorders such as bi-polar disorder and depression has reportedly (Mental Health Commission, 2004c) created general tolerance and appreciation for the human experience of illness, and need for community support, this approach has also allowed the continued view of 'us' and 'them' in terms of exclusion. This conundrum is exemplified by the choice of television advertisements which first used 'famous people' who identified as having mental disorder. This was a highly successful campaign but created further gaps in identification and reducing discrimination as 'ordinary people' then excluded themselves from this group focussing on the famous personage rather than the mental disorder.

Identity-based politics too often bolsters attitudes of 'us' against 'them'. 'Those' people that are mentally disordered, or I am 'normal' because I am not 'mentally disordered'. " 'Them' is silenced. 'Them' always stands on the other side of the hill naked and speechless... 'them' is only admitted among 'us', the discussing subjects, when accompanied or introduced by 'us' " (Alcoff, 1991-1992, p.6). Thus people who do not wish to be seen to belong to the group of people who experience mental disorder rely upon their opposition to this group for their own definition. Rather than 
moving towards rupturing the status quo and creating a basis for resistance to stigma and discrimination "non-hegemonic identities may be understood not as essential differences, but as cultural constructions, which even when used in resistant ways, may continue to reify hegemonic powers of definition and binary categorization, reinforcing the universalizing tendencies of dominant positions" (Hutchins, 1999, p.2). Identity claims become nothing more than "political manipulations of people who share one characteristic and therefore it is a sort of roll call concept" (Landry \& Maclean, 1996, p.294). What mental health field environment contributes to mental health?

\section{Agency Follows Identity?}

There is a wider debate that is shared by other subaltern groups that appears to be focussed by identity-based claims. These "deconstructive critiques of essentialized identity categories take place in postmodern, feminist, queer, postcolonial and other academic conversations" (Hutchins, 1999, p.1). The assumption is that once identity has been established then the natural course is to establish personal and group agency since agency follows identity-claims. In my judgment the mental health field assists in identity-claims but the relationship of dependence upon services by those who receive a psychiatric diagnosis that is built into the health care delivery system does not encourage, indeed does not allow, agency. Whilst there are many varieties of agency Spivak (as cited in Landry \& Maclean, 1996) says " the idea of agency comes from the principle of accountable reason, that one acts with responsibility, that one has to assume the possibility of intention, one even has to assume the freedom of subjectivity in order to be responsible. That's where agency is located" (p.294). Therefore it is important to establish what kind of agency is critical in reducing stigma and discrimination. This agency must not be confined to the desire for the reduction of stigma and discrimination against people with experience of mental disorder but as a desire for the end of stigma and discrimination directed at all peoples of difference. Spivak (as cited in Landry \& Maclean, 1996) invokes this by saying "if we engage ourselves not only in the end of exploitation of our own community, but for the distant and impossible but necessary horizon of the end of 
exploitation, then we will not be confined within fantasmatic and divisive cultural boundaries" (p.296).

The location of agency in the mental health field environment might be found in the words of Deegan (2001) who with personal experience of stigma and discrimination is well placed to speak as a voice of Other. She describes a popular misconception that recovery is portrayed as being about restitution of a life or person that once was, before a diagnosis of mental disorder. She asserts:

For those of us who have struggled for years, the restitution storyline does not hold true. For us, recovery is not about going back to who we were. It is a process of becoming new. It is a process of discovering our limits but also it is a process of discovering how these limits open up new possibilities. Transformation rather than restoration becomes our path....

Transformation narratives emphasize the agency of the self in the healing process as opposed to crediting professionals with curative powers. In this light, the task of mental health professionals becomes one of supporting people and helping them build skills and a sense of agency. Helping people to become self-directed as opposed to compliant, is a goal of the recovery process.

As a mental health worker, then, I must apply accountable reason to establish what kind of agency is critical in reducing stigma and discrimination and not simply assume based on my already ingrained impressions of [the needs of] Other. It is vigilance in my own practice which generates agency on the inside of an interaction where the Other person has likely sacrificed both privacy and freedom. In particular vigilance where, as a mental health worker in a position of privilege, I speak for, or on behalf of, people with experience of mental disorder. "Yet to replace both 'I' and 'we' with a passive voice that erases agency results in an erasure of responsibility and accountability for one's speech" (Alcoff, 1991-1992, p.11)..."Who is speaking, who is spoken of, and who listens is a result, as well as an act, of political struggle" (p.15). 


\title{
Meaning Making - Exposé of Data: Detail and Relevance
}

\author{
The Performativity of Poetry
}

Language takes on a non-ordinary meaning in order precisely to contest what has become sedimented in and as the ordinary.

Judith Butler (as cited in Hutchins, 1999, p.8)

In the section of presentation of poems and their analysis I have used the literary psychogoeography method to further explore the environment using the record of People and Things that inhabit this environment. The purpose of this research is to provide a challenge to the stasis of the mental health field environment that causes or prolongs mental illness: what has become sedimented in and as the ordinary. "Nonordinary meanings of language are useful for subverting or complexifying normative meanings (Hutchins, 1999, p.1). For Judith Butler whose quote with which I begin this section of writing, the "excess" of poetry "involves that which is systematically denied by the traditional philosophical notion of fixed, volitional subject and by the habitual processes of categorisation that characterise language and thought [and diagnosis]" (as cited in Hutchins, 1999, p.5). I return to an earlier quotation (Chapters One) from the Mental Health Commission (1998) that crucially notices the effect of what environment contributes to mental health recovery:

Some people believe the origins (or at least the prolonging) of mental illness does not lie in the person with the illness but in the world around them. It may be their family, social injustice, unresponsive services, or a traumatic event. In these cases recovery does not just need to happen in the individual; the people and systems that contribute to a persons illness also need to change to enable that person to live a better life 
My contention is that like the theory of the spectacle proposed by Guy Debord, the spell that the commodity [services of the mental health field environment] casts is not one of fulfilling some unconscious sense of lack, but of making people passive, isolated and immobile and the commodity [provision of services] thus becomes their way of connection with a sense of community, action and self. (Hetherington, 2002, p.21). This is essentially what people are forced into, being defined by their illness state in relation to the services as a commodity of health rather than to health itself [which comes from within the individual and not from the services], being unable to engage with their own resources of recovery. This is what causes mental illness and prolongs it.

Poetry is a useful method for extending anti-discrimination and anti-stigma insights and understandings and particularly for bringing into being a valid form of data collection from my position of nurse artist within the mental health field environment. Data collection that does not fabricate or deny what I am attracted to, repelled by or excluded from:

In a unique way a poem inseparably links "what it means" and "how it means", offering a concrete glimpse of how meaning "performs" itself in and through language. In addition, the "excess" of poetry, its affective, imaginative, musical and category breaking dimensions, can extend, expand, and exceed the limits of categorical, definitive language in ways that conventional academic genres and language usage do not

(Hutchins, 1999, p.1)

Poetry offers the opportunity of holding in tension the experience of being within the mental health field environment and also of observing it for the record of research. I record a view that might be considered anti-foundational bio-medical discourse and yet I must always acknowledge that mental health worker recovery competency is inseparable from and "constructed in inseparable relation with concrete cultural forces always already embodied or performed in by particular contexts and events" (Hutchins, 1999, p.3). 
I was asked by a woman as we set off from the ward for a walk "are we here as friends or are you observing me?" (name withheld, personal communication, January 19, 2005). This is an example of the tension that exists in the mental health field environment relationship. Regardless of our similar nature, experiences, and connection as individuals, and the mutually beneficial effect of the walk we share together, when the walk is over I must record in the patient (sic) file the conduct and mental state of this woman. In terms of assessment and treatment goals the reason for going on the walk at all, is due to the drivers of the treatment programme. As this was her first walk outside the hospital in weeks I was responsible for reporting how she tolerated this sudden expansion of her world. I could have avoided this opportunity leaving it for someone else to take her, knowing that I then wouldn't have to analyse this event. However I chose to be the one to go, knowing that I would look for a space of Other. I chose to be the one to occupy this space of being with her and not being with her. I verbally acknowledged what I must do but asked her would it be possible for us to find a position where we could still enjoy each other's company. She offered me lollies from her dollar mixture and I found a piece of blue and white crockery that she said was a sign she was in the right place. We found a place of Other, so that we would not be self-conscious of each others positions of nurse and patient (sic) in our being together. She lay on her belly on the grass feeling the sensation of lying on mother earth and 'being out'. These and Other experiences are the place from which my poetry has come. This performativity of poetry as a record of an age or era of the mental health field environment is unique:

As bridges, or hinges, poems may be able to swing open to a wider accessibility the abstractions of critical theory, expressing and expanding the insights of theoretical, academic discourse about "identity", "the subject", "meaning”, and the creative and constraining power of the motion of discourse itself

(Hutchins, 1999, p. 4). 


\section{A Dérive of the Major Themes}

\section{Beautiful Flawed Self}

\section{The beautiful and flawed aspects of the self search for reconciliation}

The best mental health workers are those in which the healers find the wounded within themselves and the wounded find the healers within themselves. Almost always this comes about through human compassion. The human touch.

(Leibrich, 1998, p.4)

Flaws (failings) as human traits are common to all. Society generally allows breathing space for people to make mistakes or just to exist with those flaws as part of their make up. The intent of this theme is in personal growth that occurs from self realised struggle and achievement.

In the mental health field environment mental disorder is formally recognised as an illness, but as a particular symptom is seen in the context of daily life, it is often interpreted as a human flaw. This is especially so for some of the "negative" symptoms of schizophrenia which are incorrectly interpreted by others as sluggishness, laziness, lack of joy in life, lack of drive and so on. "Positive" symptomatology may be observed incorrectly as criminality where aggressiveness, poor impulse control, and mania, are seen in a person's presentation. It is therefore very hard for a person with experience of mental disorder to consider their attitudes and feelings about their own attributes and failings when the public and the medical profession are so negatively opinionated, and this opinion becomes a matter of public debate rather than private reflection. In my judgement, people are robbed of huge amounts of energy as personal focus goes into reconciling the Self with things that other people have deemed flaws, rather than what the person has the right of reconciling with themselves. Very rarely is there time or energy left for recognition 
of the beautiful aspects of Self. Even if beauty is mentioned it is often 'given' by a staff member and not emanating from the individual.

\section{The Flawed Self as Seen by Others}

Here presentations that are seen at several hospital admissions become interpreted as aspects of the character of the person and therefore become associated with individual human flaws. Also as an example of misinterpretation, a person who exchanges sexual encounters for cigarettes is seen as morally weak, rather than being oppressed by poverty into taking extreme measures for survival.

Health providers may justify the course of clinical action upon the desire to protect the patient from discovering that she has acted in a manner that, in staff members' opinion, had she been in control of her faculties/mental state, she would not have acted in this way. This clinical action may be a confining of the person in a bedroom or intensive care area when a consequence of mental disturbance may be: disrobing; masturbation; urinating; having sexual contact with other patients or visitors; defecation and faecal smearing; shouting; swearing; destruction of property; threats made to staff or other patients; or when harm to self /others occurs. Protection of the patient by the action of confining the person to these areas is decided upon in the event that the person regains their own capacity to monitor and limit their behaviour and realises/remembers or is informed by someone else, of their behaviour /actions which is presumed an embarrassment to them.

The genuine intent of the staff member is to prevent harm or future embarrassment but the means to achieve this are often by removing the person to a place of "absence of the company of others" or seclusion. If the person cannot "maintain themselves" in this environment with the door unlocked, the room may be locked. In this way the concern of staff to protect the dignity and essential human privacy of the individual is managed by what many consumers perceive as punishment. This is a concentrated example of the wider social control that is exerted to bring the flawed aspects of self, as perceived by others, into line with behaviours/social interactions that are 
acceptable to others. This misperception by others, of people who experience mental disorder does not allow for, and often crushes the beauty of, individual nature creative expression and free will.

A person I know, was evicted or 'lost his place' in a residential house because of a variety of things but primarily the example given was of him not adhering to the laundry regime of lining up in a convoy of residents who washed their clothes at a certain time in this prescribed line. Others muttered "well we can't have him behaving like that".

This is an example of the way in which the desire to acknowledge and protect the individual from their flawed self (as a person with experience of mental disorder is always considered flawed by others) by the patriarchal services which separate the person from ever reconciling their own actions and way in the world. The ideal staff hold for the conduct and presentation of consumers is something staff project and often not how people would wish to conduct themselves in their own private life. Yet staff have the benefit of demanding this flawlessness in others'; accurate budgeting; tidy living spaces; moderation in smoking and abstinence in alcohol and illicit drugs; daily eating of meat and three vegetables; planning for tomorrow and the list goes on.

\section{The Flawed Self as Seen by Self}

There is so much criticism of the consumer in the mental health field environment, I always feel an acute sense of privilege if I am invited to witness, or am told of the flaws of a person, by that person, and together we marvel at the beauty of that person in all their ways and being. I have come to love, and be humbled by, the moments where self-forgiveness flourishes despite the burden of mental disorder and the realisation by that person of their categorisation and control by diagnosis. This personal process of the 'flawed self as seen by Self" has been colonised by some recovery approach and strengths model documentation. 
Wellness recovery action-planning is another genuine attempt by services to encourage reflection upon the reconciliation of flawed and beautiful aspects of self. However it is often, or only ever completed, when the person is in a 'compliant state' and not an 'oppositional state' and is usually completed as a progressional part of engagement with health services. One day I presented an Early Warning Sign form to a woman who had earlier signed this form, detailing those signs is a requirement of documentation in the patient file. I thought perhaps that seeing the best course of action (or the course I wanted her to accept) in her own writing, would make a difference to her acceptance of my request. After studying the form she said: " well that's the signature I use when I don't mean it".

\section{Physical and Mental Privacy}

\section{Lack of essential human privacy creates fear and loss of self-esteem.}

This research shows that people who inhabit mental health field environments as patients of health services are subject to intense observation. These spaces may be administered by governmental agencies or non-governmental agencies that are subject to the scrutiny of government. The new 'mental health bed', postdeinstitutionalisation, is rigid in its ability to accommodate individuals with high and complex needs, and there are too few of these beds with waiting lists up to three months duration in some cases. This creates a premium of need and pressure on community residential accommodation to move people on, especially those who present levels of perceived risk. People who regained health postdeinstitutionalisation were moved on, despite believing they were in a home for life. As staff and providers came and went and evolved post-deinstitutionalisation, service availability and categorisation changed to reflect providers' ability/capacity [to attract trained staff] rather than patient need.

People who present levels of perceived risk may lose their community placements almost immediately when hospitalised, as there is always someone who presents less risk, and who is a more desirable prospect to fill the bed waiting in line. People are 
moved to the too few hospital beds, which places resultant pressure on the hospital services to discharge people to the community. People who may be barely ready to mentally survive exposure to community and social scrutiny are discharged to the community.

The patient is subjected to intense pulling apart of the fabric of their mental character and physical health in order to expose their potential, to either be admitted to these too few mental health beds through active harm or neglect, or discharged through any glimmer of returning self-governance. The ability of a person to secure their fundamental right to privacy over thought and experience and action, is lost in the need of the bio-medical model to explore the terrain of the person's psyche and body to assess their ability to be successfully moved through the system. The staff member's employment rests on their ability to get this right every time.

Within the confines of the hospital mental health environments, patients are extensively investigated. A person who is being observed every ten minutes may not be able to shower or toilet without the need for the locked door being opened by a staff member from the outside with a key. Also, the exposure of one patient to the experience of mental illness of another patient, unwanted witnessing of another's pain and anguish in the moment of experiencing ones own illness, compounds distress.

The gaze that sees, even when one is unsure who looks, creates fear. Cameras, observation port windows in doors, windows in walls, one-way glass, torches shone into bedrooms at night, and multi-viewed corridor spaces increase the capacity of the staff to watch. Could it be that the patient (sic) who is said to be 'disinhibited', has lost a sense of expectation of essential personal privacy?

This systemically pressurised system is the legacy of the closure of the environment of true asylum, and the threat and burden of the clients that must inhabit it and the staff that must manage it. The only means available to each is the relinquishing by the patient and taking by the staff, of physical and mental privacy. In this incredibly 
vulnerable and stripped state each person passes muster on a twenty-four hour sevenday basis to hold all of this together.

\section{Meaning Construction}

It would be possible to endlessly derive and uncover layers of information about the mental health field environment each with a nuance that gave the reader an additional insight into what attracts, what repels, and what excludes the researcher. As I further dèrive these major themes I am also aware of the potential for entering a space of reflection upon my own experience increasingly without reference to the experience of Other. With the benefit of positioning in the environment of study and with the recognition of socialized subjectivity that I carry as habitus the research remains valid. It is only through the continued use of the psychogeographical method that my observation stays outside of, or aware of, the influence of socially conditioned systems of dispositions that contribute to my character. Other conditions of habitus are affected by positions of power that I occupy as mental health worker; educated; white; woman; staff member, all of which affect my ability to make space for the speech of Other. Rather than a concealment of my role within the system that prolongs or causes mental illness I am able to find a middle ground between "individual agency and structural determinacy" (Bourdieu as cited in Scahill, n.d., p.3). These deep structural classificatory and assessment propensities which are socially acquired constantly direct my outlook, opinions and embodied phenomena and ultimately the way in which I might judge another person. The habitus enables an agent's collusion within which she is a member. She calls this 'fit' or the sense of 'being at home' in a familiar milieu, an 'ontological complicity' between embodied history in the habitus and objectified history in institutional roles. Habitus however, as described by Bourdieu, is not only a determinant of my "execution of imperceptible yet determinate rules of action" (Bourdieu as cited in Scahill, n.d., p.3), rather it has a creative, inventive and active capacity to produce an appropriate innovation. This capacity of the active agent is often the way in which a mental health worker identified as 'recovery competent' by consumers will be able to 
respond in the moment. In my judgement active individual agency is a critical requirement for safe practice in the mental health field environment.

As the reader I invite you to derive the further seven major themes as listed below. What do you see? What attracts you? What repels you? What excludes you?

\section{Survival}

Surviving the violence of the experience of mental illness

\section{Freedom to Change}

Accessing the resources for change is kept behind the locked door

\section{Expressed Desire}

Avoidant habits that calm are found preferable to expressing desire

\section{Social Exclusion....}

Being considered a 'difficult case' brings exhaustive social exclusions

\section{Domestic Purpose}

Joy and hope is imbedded in owning a sense of domestic purpose

\section{Illness prophecy}

Finding ownership and right to health in the presence of illness

\section{Illness Burden}

Files containing patient information receive primacy, over the person telling their story - Its hard work to live a life defined by illness

The critical point that I wish to make here is that the dèrive is not just a new and trendy way to see things but an alternative way to look at problems in the mental health field environment, particularly for people with severe and enduring mental illness, that don't go away. The derive is crucially a way of looking at problems differently, which can give the opportunity of creating different solutions. 


\section{Art Interval}

Moving On , 2003, oil on canvas, 600mm x 500mm 


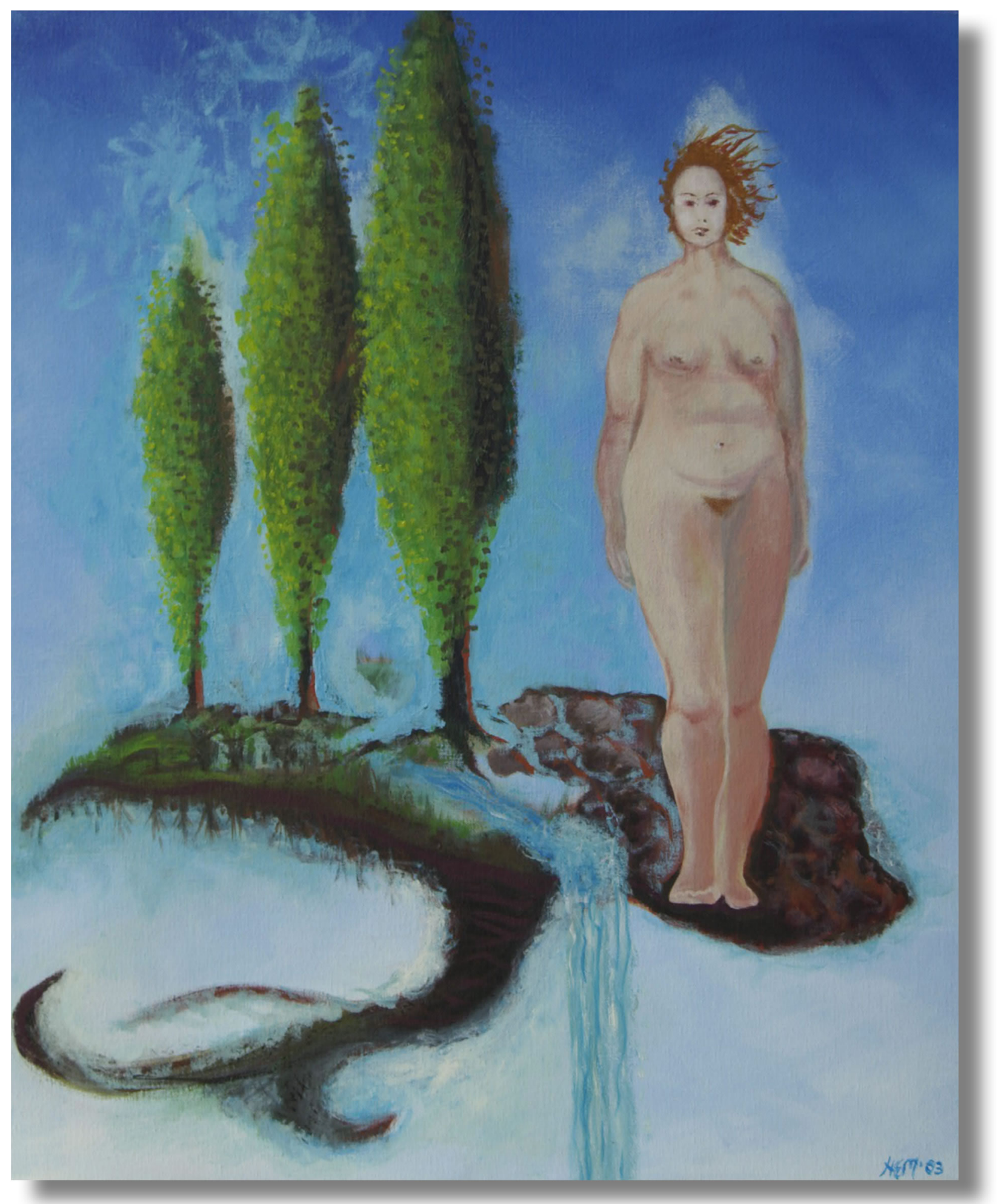




\title{
CHAPTER SEVEN
}

\section{Conclusions and Recommendations for Practice}

\section{Is it Possible to Describe What Mental Health Field Environment Contributes to Mental Health Recovery?}

\begin{abstract}
By categorising aspects of the person (e.g. the mind, the emotions) as a disease, the whole person can easily be viewed and then treated as a disease, reflected in the phrase, "she is a schizophrenic". Diagnosed people then lose control of their own destiny, since the most powerful judgments of them as people are controlled by experts in psychiatry. Because this model teaches that people can be diagnosed through objective classification of their symptoms and scores on standardized tests, personal meaning, or what people, their families, and their cultures think is wrong with them, and the meanings that they attribute to their symptoms are not part of the diagnostic considerations
\end{abstract}

(Hall, 1996, p.3).

This thesis has been motivated by my question: is it possible to describe what mental health field environment contributes to mental health recovery? This question arose, as a government document pointed out that the concept of recovery often lies in beliefs about the origins and nature of mental illness. "Some people believe the origins (or at least the prolonging) of mental illness does not lie in the person with mental illness but in the world around them. It may be...unresponsive services..." (MHC, 1998, p.15) what part does the mental health field environment play in this?

The possibility of unresponsive services being the origin or the cause of prolonging of mental illness is not only abhorrent to me as a human being and a nurse but it is also part of my experience of the past twenty years in this environment. The suffering of Others through stigma and discrimination directed against people with experience of mental illness, in a mental health field environment where I am in a 
powerful position and they [patients] are not, what I seek to change. In order to be able to achieve this I have to be able to perceive and distinguish stigma and discrimination even as I, in a nurse artist role, am part of the system of unresponsive services that causes it. I must not assume knowledge of suffering as it is experienced by an-Other. Even as I do not assume knowledge of Other's experience, I must be acutely aware of the suffering that power differentials in the mental health field environment can cause.

\section{Social Justice As A Recovery Competency}

Ethical and moral practice has 'to do no harm' as its first principle of care. In the mental health field environment the provision of care must be more than being a passive obligation of non-intention to injure, it is fundamentally about active participation in anti-discrimination work that leads to social justice. Social justice from a multiculturalist and cultural diversity perspective environment, has parallels with the mental health field environment, and is based on the principle of equality defined by Dr. King Davis thus:

Social justice is a basic value and desired goal in democratic societies and includes the equitable and fair access to societal institutions, laws resources, opportunities, without arbitrary limitations based on observed, or interpretations of, differences in age, colour, culture, physical, or mental disability, education, gender, income, language, national origin, race, religion, or sexual orientation

(Teasley \& Rice, 1996, p.1).

As social injustice is cited along with unresponsive services, as being "the origins, or at least the prolonging of mental illness" (Mental Health Commission, 1998, p.15) recovery competencies, as actions of mental health workers, must be directed towards addressing social injustice. "As a value of social fairness and equity, social justice should be reactive; it should respond to social conditions to alleviate social problems" (Teasley \& Rice, 1996, p.2). The plight of people with experience of severe and enduring mental disorder in our society remains a social problem that 
does not lessen, since people with mental disorder are viewed by society as less than equal citizens and society places the problem with them, as Other.

The 1998 Mental Health Commission document also challenges the mental health services to recover/transform themselves: "recovery does not just need to happen in the individual; the people and systems that contribute to a person's illness also need to change to enable that individual to live a better life" (MHC, 1998, p.15). Perhaps Bartlett's (1992) comment that "at the core of both the ethic of care and the ethic of justice lies a deep and passionate concern for human dignity, the respect for that in us which cannot be reduced to abstract principles" (p. 87) is an important point of deliberation for mental health services that must consider recovery and transformation. Quite clearly the recovery of some individuals will critically depend on the recovery of the people and services in which they are held or incarcerated. This will not be achieved by services that include a recovery approach in policies, but only at arms length as a set of abstract principles, not translated into practice.

While government documents recognize that some services prolong or cause mental illness, the bio-medical model, recovery approach competencies and communitybased models of service delivery are being defined and carried out by a health workforce that is also being shaped by these approaches and models. Are these approaches and models able to be complementary to one another or are they in opposition to one another?

Deinstitutionalisation since the 1990s has not been able to overcome the continued cry for more exclusional [separating] hospital settings by the public, nor to overcome the difficulty some people have in finding a place to live in the community, some fifteen years later. Simply closing hospitals and moving people into the community does not mean that a community exists that is ready and willing to receive them. "In spite of notions of 'recovery', mental health services remain the product of institutional experience. At the core remain 'scientific' assumptions, which are based on a reductionist model" (Warriner, 2001, p. 18). As a mental health worker the conclusion that can be drawn from these observations is that the system, as it is 
presently set up, does not allow for the change in behavior and attitudes that is required by people who work in mental health services on a day-to-day basis that might reduce their impact in causing or prolonging mental illness.

When considering the mental health field environment it is possible to suppose that environments produced by mental health workers are always-already environments of subjects who create environments of subjection/subjugation. Because of the phenomenon of habitus and the obviousness of always-already environments, without being necessarily aware of how, the mental health field environment causes or prolongs mental illness. People and Things continue to reproduce patienthood in a group of consumers who continue to be subjugated as patients and, despite a recovery approach and competencies in staff, mental health workers continue to hold attitudes of/and behave as subjugators.

In discussing the inadequacies of the system with a woman with experience of mental health services of the past, and now, (A. Helm, personal communication, Nov 2005) she assures me that if her entry into the services all those years ago when she was a teenager, had been like it is for some teenagers today, the course of her life would have been completely different. She was referring to the service's capacity to provide early intervention for people with a first experience of psychosis. Research has shown, and it is not logically surprising, that the initial mental health experience of a young person who is received and cared for in the community by mental health youth specialty services, positively influences the rest of that person's subsequent engagement and their recovery.

This positive outlook does not however extend to those adults who become hospitalised under the Mental Health Act in adult inpatient units, especially if those adults have a diagnosis of severe and enduring mental illness. My own experience reflects this revolving-door situation where returning to a mental health setting after a five year residence in another city, I was able to take up my relationships with people who were in the service and even in the inpatient unit, then as they are now. In observing this I also recognize that myself, and a number of the staff group are 
also still present in the services. It seems that theories proposed by Debord (drawing on Marxist theories) can be applied to mental health services which, despite some changes, continue to fulfill an economic truism "understood in its totality, the spectacle [mental health field environment] is both the outcome and the goal of the dominant mode of production [mental health service provision]...in form as in content the spectacle [mental health field environment] serves as a total justification for the conditions and aims of the existing system" (Debord, 1995, p.13). In this case however the economic consequences are actually human consequences and, as Helm discusses above, lives are irretrievably changed where services are unresponsive.

I have made the choice to respond to the possibility of resistance and change that is inherent in marginality and struggle. Rather than being a catalogue of frustration I intend that this thesis provide some insight into the what and why of unresponsive services and practical methods for mental health workers who have reduced or lost, the capacity to accurately see the mental health field environment due to the effects of institutionalisation.

\section{Side-By-Side Practice as a Recovery Competency}

Side-by-side practice is a means to allow the speech of the Other and the possibility of a reply. I provide space for the emergence of an identity-claim of artist, which leads, through community arts practice, to agency in creative expression. This change of level, in addressing myself as a nurse artist to a layer of material previously having no pertinence to medical model subjective surveillance, makes the previously invisible person seen. This artist recognition is an alternative to patienthood and diagnosis.

The smallest of side-by-side gestures is a powerful antidote to the cause or prolonging of mental illness and remains positively in the awareness of the person who suffers in an unresponsive service. I was asked by a person who was experiencing a period diagnosed as mania if she might touch some of the things in my office space. To her the simple things I had gathered such as postcards, stones, 
small toys, containers filled with pens and dried flowers were a treasure trove. She ran her fingers over the textures and colours and objects with delight. This occurred in the ten minutes she was allowed out of her room. This 'one hour in, ten minutes out' regime had been conceived of as a treatment plan for mania by the reduction of environmental stimulation. It also meant that the period of time staff would be required to interact with her was lessened; she was out of sight and out of mind. As a nurse artist my contention is that environments of low stimulus (bare walls, minimal chairs, no view, no accessible comfort facilities such as running water) are an idea born of the staff need to not have to clean up the result of passionate adult play and performance. I believe that areas of low stimulus so enrage and insult people that the opposite effect occurs. People feel threatened, highly stimulated, jailed and angry, then with no outlet, resort to creative means of self stimulation/aggression ...such as tearing the buttons off the couch or writing on the walls by scratching in paintwork. 'Wilful damage' becomes a blot in their copybook that must be paid for and is written up in the clinical file. Sometimes people just feel exhausted with the effort of attempting to deflect constraint and lie down to sleep. The inference is of course, that the decision to utilise a low stimulus area was a good one.

I strongly advocate a satiation of the person's desire to create something [change something], within a given timeframe and with a goal of achievement. To create something together; a painting, song or poem...even laughter, produces an affirmation of us both in our ability to direct our energy and resources, towards recovery. We move away from the binaries of 'us' and 'them' towards multiplicity of meanings and expressions.

The woman came back to my office space and shyly asked for a handmade soap that was the product of a workshop some months before. Coming to expect refusal the lusciousness she experienced when putting her hand into the basket and taking the soap was palpable. The irony though, is that the environment that I am part of, should have sustained her in this way, but it had also reduced this woman to such joy in receiving permission to take something, by a staff member. What made the recovery-difference in our interchange was the sharing with her of the moment of 
passion for the object, but only as a focus of her intention to have something right then and there. No maybe, no putting off for later, no "I'll have to ask somebody else"...it was just YES. Side-by-side practice is unique in its ability to maintain a relationship where the person may need assistance with mental distress, but it is also to be with the person, rather than act for or on their behalf. There is a heterotopic place, outside of all other places of care delivery in the mental health field environment, which is a space for Other. Later the woman came to tell me... thank you for the soap but she had given it to someone else. Many staff who embark on the first part of a journey of recovery practise [giving], then fall over at the first hurdle because the patient (sic) seems to have no regard for the object [Thing]. I have been party to many comments of genuine confusion or bitterness where staff had talked of trying to 'do something nice' only to have it 'thrown back in their face'. In other words the favour, or gift, has been broken or given to another. This demonstrates the way in which mental health workers follow their best intentions into the very lives of people with experience of mental illness, to monitor gratitude and what they hope will be some sort of responding improvement in the presentation of the person. That they, the patient group, will display a habitus a little bit more like themselves, the staff group. The gift slips into being a bribe for good behaviour, which further reduces the mental health field environment to an economy of wills. This is recovery on the terms of the mental health worker, which is not recovery at all but further subjugation.

Side-By-Side practice is recovery on the terms of the person who seeks recovery. Recovery, understood in side-by-side practice, to be beliefs about the origins and nature of mental illness by the person with experience of it. The concept of recovery can be "easily applied to holistic approaches like the Whare Tapa Wha model which identifies four dimensions of health - taha wairua (spiritual), taha hinengaro (mental and emotional), taha tinana (physical) and taha whanau (family)" (Mental Health Commission, 1998, p.15). When mental health recovery is understood by mental health workers to have multiple dimensionality, multiple solutions to mental disorder challenge are more likely to be found. 


\section{Spatial and Geographical Imagination as a Recovery Competency or Beyond Traditional Dualism}

The description of my position as geographer of mental health field environment throughout the thesis gives a view of my acute awareness of the possibility of opening up and expanding the scope and critical sensibility of my spatial or geographical imagination. Where the material world is focused on the real, then this reality is interpreted in the imagined, a Thirdspace as a multiplicity of real-andimagined places provides the opportunity for deconstruction or radical restructuring of modes of knowledge formation that perpetuate stigma and discrimination against those people with experience of mental illness.

In as much as I have described myself as a geographer or geographical thinker I recognise that space is a culturally constructed entity. Soja encourages us to think differently about the meanings and significance of space. " Those related concepts that compose and comprise the inherent spatiality of human life: [hospital], place, location, locality, landscape, environment, home, city, region, territory and geography" (Soja, 1996, introduction). He suggests that rather than discarding my way of thinking about space and spatiality that I am able to question them in new ways that are "aimed at opening up and expanding the scope and critical sensibility of my already established [interpellated see Althusser, 1984, p.49] spatial or geographical imagination" (Soja, 1996, introduction). Where space was divided in modernity into perceived (physical space/materialism) and conceived (mental space/idealism) space, Soja has identified lived space as a postmodern third aspect to spatiality itself. Might this be a way to consider what mental health field environment contributes to mental health and thus discover Thirdspace (social space/imaginative) as a space of transition in mental health recovery as the "most important contribution of postmodernism to today's geography is the way of looking at each other" (Arentsen, Stam \& Thuijs., n.d., p 11.):

Thirdspaces are created by the effects of a changing culture, and are spaces of transition; transition between localities and over time [deinstitutionalisation]. 
They elude the reflection of a single permanent power structure and are places of simultaneity and transience. They relate to both poles of binary concepts ions of cross-cultural space and yet at the same time entirely transcend them. More than a mental place, Thirdspaces hold the possibility for socio -political transformation.

(Soja, 1996, p.9)

According to Foucault, understanding the development of a worldview of the mental health field environment, means understanding the implications of knowledge and power as a means to create ordering of things or an architecture of power. Also, the understanding of heterotopic sites as places of otherness, which reflect all other sites. This is in opposition to other disciplines and some practices within health services that give unquestioned privilege to historical (temporal) [patient file] and social (or sociological) [bio-medical model] understandings of the world. In this way mental health workers have had the benefit [where they choose to read/critique it] of Foucault's insight into the constructed nature of madness, not as a result of an historical record over time, but as an explanation of mental illness, folly, and unreason (Foucault, 1971). This is just motivation for mental health workers to be ready to embrace a three sided sensibility of, spatiality - historicality - sociality, as in our discipline or field of interest there has already occurred a deconstruction of, or radical restructuring of, long-established modes of knowledge formation. This debate is not about whether modernist or postmodernist approaches, or making practical or theoretical sense, of the mental health field environment will generate mental health, but more about creating an open space for dialogue which is not subject to the dualisms of 'us' and 'them', 'nurse' and 'patient' or 'normal' and 'mentally defective'(sic). Soja asserts that "thirdspace is rooted in a recombinatorial and radically open perspective... a critical strategy of "thirding-as Othering" (Soja, 1996, p.5). Soja attempts to open up our spatial imaginaries to ways of acting and thinking politically that draws selectively and strategically from the two opposing categories of physical and mental space. If Firstspace perspective is focussed on the "real" material world and Secondspace interprets this reality through "imagined" 
representations of spatiality then Thirdspace can be a multiplicity of real-andimagined places.

This view has a parallel with Debord's advance of psychogeography, in that Firstspace might be seen as the material [or built] environment, or in literature all records of an age or era, which are able to be moved through in the experimental mode of behaviour of dèrive allowing critical notice to be made of the influence of geographical surroundings and of those aspects of the environment or text which attract, repel or exclude the researcher/geographer. Simultaneously I will think of ways of changing my surroundings as an act of attempting to disrupt existing representations. Secondspace is mental space where the psychogeographical method allows the construction of a cognitive map to record the observations of the derive and importantly to provide opportunities for psychological transformation through decoding information about the relative locations and attributes of phenomena in the mental health field [spatial] environment. Thirdspace then is a dètournement where elements, no matter where they are taken from, can contribute to the generation of new elements. This generative capacity is critical in escaping binary logic [that mental illness is attributable to a number of classifiable symptomatologies] and creatively resisting by choosing an-Other alternative. "Thirdspace then, is an-Other way of understanding and acting to change the spatiality of human life" (Soja, 1996, p.10). In the creation of this space for an-Other way of understanding and acting, would this then create the space for the speech of the subaltern as Other. Possibilities inherent in recovery competent mental health workers who believe they can make a positive difference to mental health recovery, recovery approaches and consumer led (sic) initiatives for consumers by consumers has not proved to be an adequate response to the ongoing suffering of people with experience of severe and enduring mental illness. As in psychogeography, Thirdspace requires a "strategic and flexible way of thinking that is guided by a motivating project... an effort to improve the world in some significant way" (Soja, 1996, p.22). My motivation is to bring recognition and change where mental health services cause or prolong mental illness and to provide practice development initiatives for mental health workers who have reduced or lost the capacity to accurately see the mental health field environment due 
to the effects of rapid or long term institutionalisation. In developing or reestablishing accuracy of observation, ways of resisting oppression and rupturing the status quo can be creatively introduced.

I present this thesis as a Thirdspace, a space of open/ing ground and an-Other way. I was asked long ago in the process of this research by a Maori health practitioner of Po Te Atatu, in what way will your work benefit Maori? This was the traditional laying down of a wero (challenge) in front of me, for what he was asking was, in what way will your work benefit all people who suffer stigma and discrimination as a result of difference. This is the ultimate of questions because, as I have stated, it is not important what people think of me but rather what I can do. In time I will be expected to return to Rotorua to answer this question. I propose that creative expression in mental health field environments gives an-Other platform from which to view oneself and one's surroundings rather than the sole constructed position of nurse or patient. Always recognizing however, that "when I speak for myself, I am constructing a possible self, a way to be in the world, and am offering that to others, whether I intend to or not, as one possible way to be" (Alcoff, 1991-1992, p.21). I cannot avoid the possibility of 'speaking for' as I recognize the privilege of my position as mental health worker and acknowledge the danger of inaccurate representations of Other, the notion of "speaking to" (Alcoff, 1991-1992, p.23) may be a means of further subjection of the oppressed person. However Spivak suggests that "speaking to" is preferred as it allows for the possibility that the Other [as an oppressed person] will produce a "counter sentence" (In Alcoff, 1991-1992, p.23). I cannot conceive of a life lived without the benefit of utilizing real-and-imagined Open space. Where this might be defined by society as a place of marginality, marginality has the potential to adopt a radical openness.

This thesis with rich use of text in various forms has literally been an-Other space for my creative development and for rethinking the mental health field environment. AnOther place for retheorizing spatiality, not just of aspects of nurse artist practice but also of the mix of forms of oppression, exploitation and subjection that are to be found in this healthcare environment. I want to continue to search for something 
deeper than what others expected of me in my ability to listen, and what I express in terms of data. I must consider the full and complete experience [dérive] to arrive at a deeper more genuine understanding [cognitive mapping] and not be just another version of someone else's rules for living and working but search for the essential person 'I' [détournement].

I therefore conclude with a statement of the impossibility of speaking for others and open-endedness of this research in its intention to not create a final statement but importantly promote further discussion. This is, therefore, a ceaseless project that never claims to have told the whole story for myself or anyone else. 


\section{Art Interval}

Open Hearted Phase I, 2003, mixed media, 450mm x 600mm 


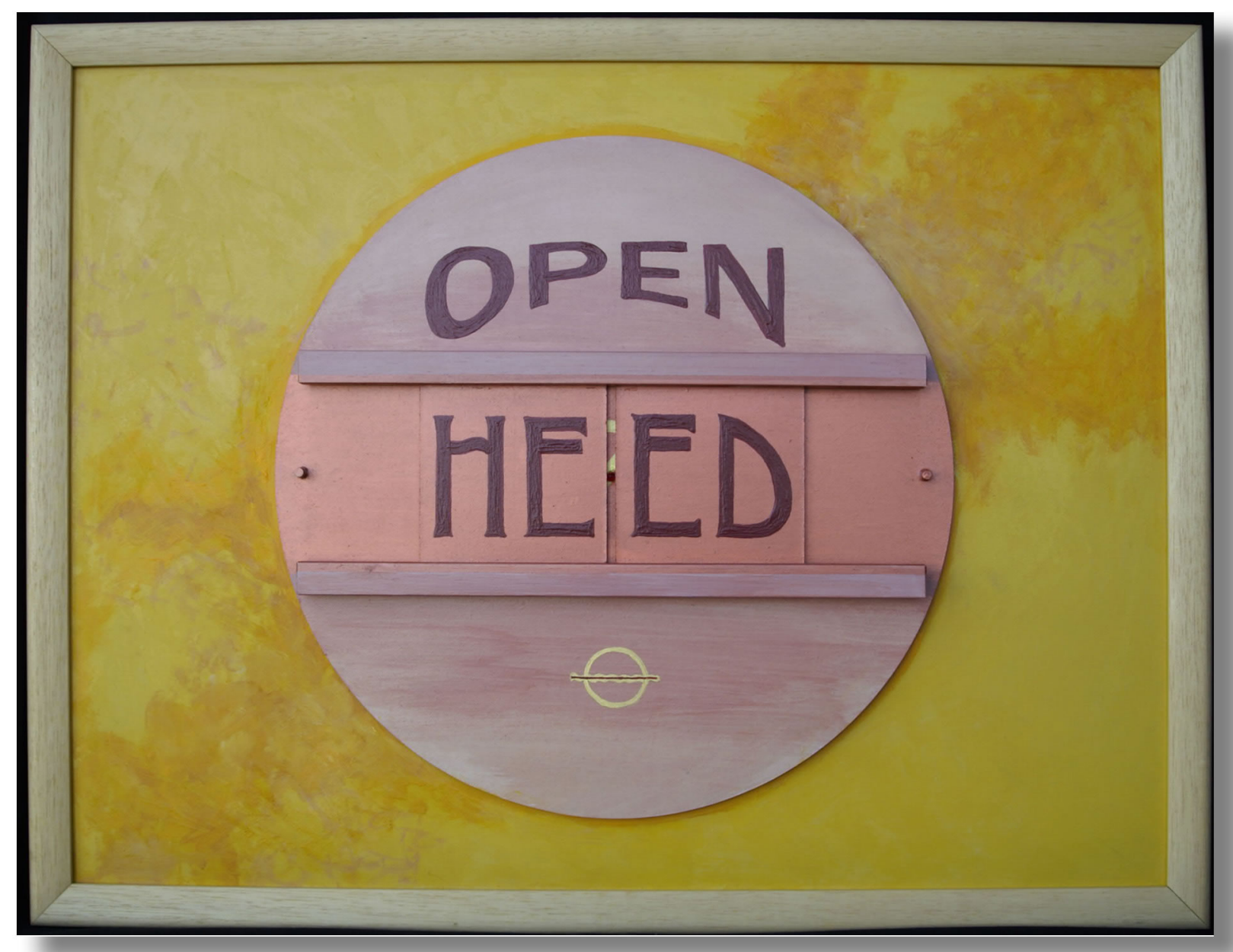


27 April 2004

\section{To Whom It May Concern}

\section{Research Project - A Literary Psychogeography Study of The Practice of a Nurse Artist in Aotearoa New Zealand}

I am writing on behalf of the Lakes District Health Board Clinical Council to give our support to the above research project being undertaken by Heather Martin, in fulfilment of the requirements for the degree of Doctor of Philosophy.

Heather gave a presentation to the Clinical Council meeting on the 6 April 2004. She covered the reason she was undertaking her research, explained the general topic area, outlined the chosen research methodology (literary psychogeography) and then focussed in some detail on the ethical concerns and parameters.

The Clinical Council members were unanimous in giving their support to this project. They acknowledged that Heather is in a unique position as the only 'nurse artist' that we are aware of in New Zealand. Heather's genuineness, her passion for the topic and the importance of the matters she is exploring for Tangata Whaiora were acknowledged. Heather's own wairua and her sensitivity were also acknowledged. As part of her presentation she acknowledged those who had contributed to the birth of her research interest over previous years including the former Lakes DHB Kaumatua Tutanekai Kinita and CEO Ray Watson.

The Lakes DHB Clinical Council is privileged to be able to write in support of Heather's research, and we have also requested the opportunity to hear about the outcomes once she has completed her Doctorate.

We wish her all the very best for her studies.

Yours faithfully

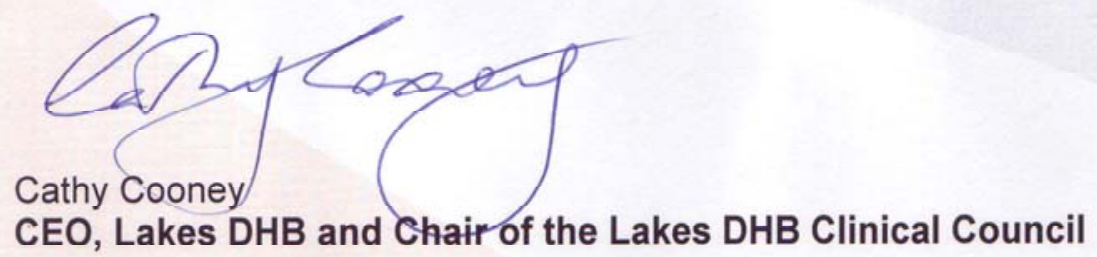

cc: Lakes DHB Clinical Council

Heather Martin 
LAKES DISTRICT HEALTH BDARD

$15^{\text {th }}$ January 2003

Heather Martin

Arts Consultant

Mental Health Services

Lakes District Health Board

Private Bag 3023

ROTORUA

Dear Heather,

\section{Re: Research Project Permission}

In regard to your research project entitled;

"What creative approach supports the development of recovery and partnership in the mental health field (working title)" which is a thesis submitted to the Victoria University of Wellington in fulfilment of the requirement for the degree of Doctor of Philosophy in Nursing with an expected year of submission in 2005.

I confirm that you have explained the project to me and I am happy for you to carry this research project out in this facility.

Yours Sincerely

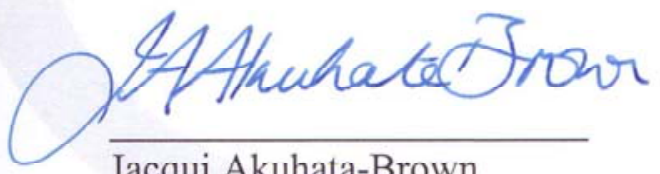

Jacqui Akuhata-Brown

Service Manager : Mental Health Service

Lakes District Health Board 


\section{References}

Adams, P. \& Mylander, M. (1993). Gesundheit!: Bringing good health to you, the medical system, and society through physician service, complementary therapies, humour and joy. Vermont: Healing Arts Press.

Agassi, A. (n.d.@ 2001-2005) (website). Setting and world-building [Electronic version]. Retrieved May 8, 2005, from http://www.foolquest.com/world_building.htm

Alavi, C. (2005). Breaking-in bodies : Teaching, nursing, initiations or what's love got to do with it?. Contemporary Nurse. 18, (3) 292-299.

Alcoff, L. (1991-1992). The problem of speaking for others [Electronic version]. Cultural Critique, 20, Winter, 5-32.

Althusser, L. (1984). Essays on ideology. London: Verso.

American Psychiatric Association. (1994). Diagnostic and statistical manual of mental disorders ( $4^{\text {th }}$ Ed.). Washington, DC: American Psychiatric Association.

Appadurai, A. (Ed.). (1988) The social life of things: Commodities in cultural perspective. United Kingdom: Cambridge University Press.

Arentsen, M., Stam, R., \& Thuijs, R. (n.d.). Postmodern approaches to space. [Electronic version]. Retrieved September 19, 2004, from www.ru.nl/socgeo/html/files/geoapp/Werkstukken/PostmodernSpace.pdf

Barham, P. (1984). Schizophrenia and human value. Great Britain: The Bath Press.

Benner, P. (1984). From Novice to expert: Excellence and power in clinical nursing practice. California: Addison-Wesley Publishing Company. 
Beverley, J. (2000). Testimonio, subalternity, and narrative authority. In Denzin, N ....\& Lincoln, L. (Eds.). Handbook of qualitative research. ( $\left.2^{\text {nd }} \mathrm{ed}.\right)(\mathrm{p} .555-565)$.

.....United States of America: Sage Publications.

boy, a.h.s., Biding spectacular time, Anti-Copyright 1996, all rights declined, (review of Guy Debord. The Society of the Spectacle. 1994. tran. Donald Nicholson-Smith.New York:Zone Books In Postmodern Culture Vol. 6 \#2, January 1996) Retrieved May 8, 2005, from http://library.nothingness.org/articles/SI/en/display/70

Brookes, B., \& Thomson, J. (Eds.). (2001). 'Unfortunate folk': Essays on mental health treatment 1863-1992. Dunedin: University of Otago Press.

Bruni, N. (2002). The crisis of invisibility: Ethical dilemmas of autoethnographic research. Qualitative Research Journal, 2 (1) 24-33.

Burns, N., \& Grove, S. (1997). The practice of nursing research: Conduct, critique and utilization. (3rd ed.). Pennsylvania: W.B. Saunders Company.

Butcher, M. (2003). What is Maori? Who is pakeha? North \& South, August 2003, 36-47.

Cameron, J. (1995). The artist's way: A course in discovering \& recovering your creative self. London: Pan Books.

Campbell, J. (1986). The Inner reaches of outer space: Metaphor as myth and as religion. New York: Harper \& Row Publishers Inc.

Chinn, P., \& Watson, J. (Eds.). (1994). Art \& aesthetics in nursing. New York: National League for Nursing Press.

Clandinin, J., \& Connelly, M. (2000). Narrative inquiry: Experience and story in qualitative research. California: Jossey-Bass Inc., Publishers. 
Cooper, D. (1992). The Cherry Farm Creative Arts Trust. Wellington: Queen .....Elizabeth II Arts Council of New Zealand.

Couser, G. (1997). Recovering bodies: Illness, disability and life writing. Madison, WI. : University of Wisconsin Press.

Cunningham, C. (1998, 7-9 $9^{\text {th }}$ July 1998). Te Ora Rangahau. Paper presented at the Maori Research and Development Conference, Massey University.

Davison, L. (2004). Simply to be let in: Inclusion as a basis for recovery. [Electronic version]. Auseinetter, 20, (1), 10-14.

Debord, G. (1995). Society of the spectacle. (D. Nicholson-Smith, Trans. (C) 1994). New York: Zone Books.

Debord, G. ( n.d.), Methods of détournement. [Electronic version]. (Theses). Les LËvres Nues \#8, May 1956. Retrieved May 8, 2005, from http://library.nothingness.org/articles/SI/en/display_printable/3

Debord, G. (1958). Theory of the dérive. (Essay) [Electronic version]. (Rev.ed.). (K. Knabb, Trans.). Internationale Situationniste \#2, 1958. Retrieved May 7, 2005, from http://library.nothingness.org/articles/all/en/display/314

Deegan, P. (1996). Recovery as a journey of the heart. Psychiatric Rehabilitation Journal, 19 (3), 74-83.

Deegan, P. (C) 2001). Recovery as self-directed process of healing and transformation. Occupational Therapy in Mental Health, (2002) 17, (3/4), 15-21.

Defining Heterotopia,(n.d.). Retrieved September 3, 2004, from http://english.ttu.edu/kairos/3.1/coverweb/galin/heterotopiadef.htm

Denzin, N., \& Lincoln, Y. (Eds.). (2000). Handbook of qualitative research. (2nd ed.). United States of America: Sage Publications. 
Diekelmann, N. (2000). Narrative pedogogy: Caring, dialogue and practice. Lecture presented for the Otago Polytechnic School of Nursing, Dunedin, New Zealand.

Durie, M (1994). Whaiora: Maori health development. Auckland: Oxford.

Durie, M. (1997). Puahau: Five part plan for improving Maori mental health. Wellington: Oranga Hinengaro Maori Mental Health Summit.

Dürsteler, J. (2004). Conceptual maps. Retrieved May 11, 2005, from http://www.infovis.net/printMag.php?num=141\&lang=2

Ellis, C., \& Bochner, A., (2000). Autoethnography, personal narrative, reflexivity: Researcher as subject. In Denzin, N. \& Lincoln, S. (Eds.), Handbook of qualitative research ( $2^{\text {nd }}$ ed.) (pp. 733- 768). United States of America: Sage Publications.

Fenton, I., \& Te Koutua, T. (2000). Four Maori korero about their experience of mental illness (Vol.one). Wellington: Mental Health Commission.

Foucault, M. (1967). Of other spaces (1967), heterotopias (J. Miskowiec, Trans.) (Reprinted from Architecture/ Mouvement/ Continuité, "Des Espace Autres, 1967”, October 1984) Retrieved August 26, 2004, from http://foucault.info/docuents/heteroTopia/foucault.heteroTopia.en.html

Foucault, M. (1971). Madness \& civilisation: A history of insanity in the age of reason (R. Howarth, Trans.). London: Tavistock Publications Limited. (Reprinted from Histoire de la Folie, 1961).

Foucault, M. (1973) The birth of the clinic (A.M. Sheridan, Trans.). London: Tavistock Publications Limited.

Foucault, M. (1977). The eye of power. In C. Gordon (Ed.). Power/Knowledge (p.153). New York: Pantheon Books. 
Foucault, M. (1979). Discipline and punish: The birth of the prison. (A. M. Sheriden. Trans.). New York: Vintage Books.

Freeman,J., Epston, D., \& Lobovits, D. (1997). Playful approaches to serious problems: Narrative therapy with children and their families. New York: W.W. Norton \& Company.

Goffman, E. (1961). Asylums: Essays on the social situation of mental patients and other inmates. Great Britain: C.Nicholls \& Company Ltd.

Goffman, E. (1968). Stigma: Notes on the management of spoiled identity. Great Britain Pelican Books.

Hall, B. (1996). The psychiatric model: A critical analysis of its undermining effects on nursing in chronic mental illness [Electronic version]. Advances in Nursing Science, 18, 3, p16 (11). Retrieved May 5, 2003, from http://infotrac2.distance.scs.vuw.ac.nz/itw/infomark/598/479/37017

Hall, P. (1987). Images of Art Therapy: New developments in theory and practice. In Dalley et al. (Eds.), A way of healing the split. (pp.157-187). London: Tavistock/Routledge LTD.

Heidegger, M. (1971). Poetry, language, thought (A. Hofstadter, Trans.). United States of America: Harper \& Row, Publishers, Inc.

Helm, A. (2004). Recovery and reclamation: A pilgrimage in understanding who and what we are. Proceedings from the TheMHS Conference, Gold Coast, Australia.

Hetherington, K. (1997). The badlands of modernity: Heterotopia and social ordering. London: Routledge. 
Hetherington, K. (2002). The kinaesthetic of capitalism: Fetishism, spectacle and the body. Published by the Department of Sociology, Lancaster University, Lancaster LA1 4YN, UK, Retrieved May 19, 2004, from

http://www.comp.lancs.ac.uk/sociology/papers/hetherington-Kinaesthetics-ofCapitalism.pdf

Hillier, J., \& Rooksby, E. (Eds.), (2002). Habitus: A sense of place. England: Ashgate

Publishing Company.

Holohan, C. (1974). Experimental investigations of environment - behavior relationships in psychiatric facilities. Man-Environment Systems. 4,109-113.

"Home Sweet Home" (n.d.). Works from the Peter Fay collection: A National .....Gallery of Australia travelling exhibition [Postcards]. Australia: n.p.

Horrocks, C., \& Jevtic, Z. (2004). Introducing Foucault. R. Appignanesi (Ed.). United Kingdom: Icon Books.

Hui Whakarongo: Maori health planning workshop. (1984). New Zealand: Department of Health.

Huia Communications (Artist). (2001). Oranga Tangata, Snakes and ladders, Recovery is part of our culture. [three posters]

Hussey, A. (2001). The game of war: The life and death of Guy Debord [Electronic version]. New Statesman14, (671), p.420. Retrieved May 16,2005 from http://helicon.vuw.ac.nz:2065/pqdweb?did=79021454\&sid=5\&Fmt=4\&clientld=751 $\underline{1 \& R Q T}=309 \&$ Vname $=$ PQD

Hutchins, C. (1999). Poetry as performativity and excess: An essay on politics and anti-foundational academic discourse, and seven poems on sedimentation. [Electronic version]. Paideusis - Journal for Interdisciplinary and Cross Cultural Studies, 2, 1-21. 
Internationale Situationniste \#1 (June 1958) (K. Knabb, Trans.). Definitions.

Situationist International Online. Retrieved May 7, 2005, from

http://www.cddc.vt.edu/sionline/si/definitions.html

Intraspec.ca (Website), 2005, Retrieved May 11, 2005, from

http://intraspec.ca/cogmap.php

Johnston, R., Gregory, D., Pratt, G., \& Watts, M. (Eds.). (2000). Human Geography. United Kingdom: Blackwell Publishers.

Johnstone, M-J. (1999). Reflective topical autobiography: An under utilised interpretive research method in nursing. Collegian, 6 (1), 24-29.

Kilburn, M. (1996). Glossary of key terms in the work of Gayatri Chakravorty Spivak Retrieved August 15, 2005 from

http://www.english.emory.edu/Bahri/Glossery.html

Krieger, D. (2002). Therapeutic touch as transpersonal healing. New York: Lantern Books.

Laing, R. D. (1970). Knots. Great Britain: Tavistock Publications Limited.

Landry, D., \& Maclean, G. (Eds.). (1996). The Spivak reader. United States of America: Routledge.

Lapsley, H., Nikora, W. L., \& Black , R. (2002). Kia mauri tau: Narratives of recovery from disabling mental health problems. Wellington: Mental Health Commission.

Leibrech, J. (1998, November 10). Taking off the strait jacket. [Address]. Address presented at The Grand Hall, Parliament Buildings by Dr Julie Leibrech, Commissioner, Mental Health Commission. 
Leibrich, J. (1999). A Gift of stories: Discovering how to deal with mental illness. Dunedin: Otago University Press.

Marin, L. (1984). Utopics: The semiological play of textual places. United States of America: Humanities Press International, Inc.

Mason, K., Johnston, J., \& Crowe, J. (1996). Inquiry under Section 47 of the Health and Disability Services Act 1993 in Respect of Certain Mental Health Services. Report of the Ministerial Inquiry to the Minister of Health. Hon. Jenny Shipley. Wellington: Ministry of Health.

McEldowney, R. (2002) Narrative Inquiry. (class handout). Victoria University Graduate School of Nursing and Midwifery: Wellington

McKewen, S. (2001). The experience of mental health support workers who are themselves in recovery from mental illness. Unpublished Master of Arts (Applied) .....in Nursing Thesis, Victoria University of Wellington, Wellington, New Zealand

MedFriendly.com.(2001). Heterotopia. Retrieved August 26, 2004 from http://www.medfriendly.com/heterotopia.html

Megill, A. (1985). Prophets of extremity. United States of America: University of California Press.

Mental Health Commission. (1997). Mental health commission blueprint for mental health services in New Zealand working document 1977: How things need to be. Wellington: Mental Health Commission.

Mental Health Commission. (1998). Blueprint for mental health services in New Zealand: How things need to be. Wellington: Mental Health Commission.

Mental Health Commission. (2001). Recovery competencies for New Zealand mental health workers. Wellington: Mental Health Commission. 
Mental Health Commission. (2003). Report on progress 2001-2002: Towards implementing the blueprint for mental health services in New Zealand. Wellington: Mental Health Commission.

Mental Health Commission. (2004a). Report on progress 2002-2003: Towards implementing the blueprint for mental health services in New Zealand. Wellington: Mental Health Commission.

Mental Health Commission. (2004b). Our lives in 2014: A recovery vision from people with experience of mental illness. Wellington: Mental Health Commission.

Mental Health Commission. (2004c). Journeys towards equality: Taking stock of New Zealand's efforts to reduce discrimination against people with experience of mental illness. Wellington: Mental Health Commission.

Mental Health Commission. (May 2005). Mental Notes. (No: 11) Wellington: Mental Health Commission.

Mental Health Research Institute of Victoria. (2004) The Cunningham Dax Collection. Retrieved November 6, 2005, from http://www.mhri.edu.au/cunningham_dax.html

Milne, M. (2001). Hui Report: Best Practice guidelines for kaupapa Maori mental health services. Moerewa: Te Moemoea Author.

Ministry of Health. (2001) The National Mental Health Standards. Wellington: Ministry of Health [Standards New Zealand]

Morgan, P. (2001). The potential of creative arts as a medium for mental health promotion in schools: An exploration of meaning-making, belonging and identity using creative processes. Occasional Paper Series One [Electronic version]. Wellington: Mental Health Foundation of New Zealand.

Moustakas, C. (1961). Loneliness. United States of America: Prentice - Hall Inc. 
Moustakas, C. (1990). Heuristic research: Design, methodology and applications. United States of America: SAGE Publications, Inc.

National Gallery of Australia, (n.d.). Travelling Exhibitions: Home sweet home: Works from the Peter Fay collection [Brochure]. Australia: University of Wollongong.

National Gallery of Australia. (2003). Home sweet home: works from the Peter Fay collection. Retrieved November 8, 2005, from http://www.nga.gov.au/HomeSweetHome/Part1.cfm

Parker, R. (1990). Nurses' stories: The search for a rational ethic of care. Advances in Nursing Science, 13, (1): 31-40

Polit, D., \& Hungler, B. (1997). Essentials of nursing research: Methods, appraisal, and utilization ( $4^{\text {th }}$ Ed.). United States of America: Lippincott-Raven Company.

Pouroto, N., \& Way, K. (2001). Te Tiriti O Waitangi: Treaty of Waitangi workshop participant handbook. Auckland: Author.

Ramsden, I. (1994). A challenge to education. Social Policy Journal of New Zealand, $3,18-25$.

Rapp, C. (1998). The strengths model: Case management with people suffering from severe and persistent mental illness. New York: Oxford Press, Inc.

Roberts, K., \& Taylor, B. (1998). Nursing research process: An Australian perspective. Melbourne: Nelson International Thomson Publishing Company.

Rogers, C. (1961). On becoming a person: A therapist's view of psychotherapy. Boston: Houghton Mifflin Company. 
Salerno, R. (2004). Beyond the enlightenment: Lives and thoughts of social theorists. United States of America: Praeger Publishers.

Scahill, J.(n.d.) Meaning-construction and habitus. Retrieved March 18, 2005, from Ball State University Http://www.ed.uiuc.edu/EPS/PESYearbook/93 docs/SCAHILL.HTM

Science Fair Projects Encyclopedia.(n.d.). Panopticon. Retrieved September 7, 2004, from http://www.all-science-fairprojects.com/science fair_projects_encyclopedia/Panopticon

Shaw, J, \& Tijen, van, T. (1991). Literary psychogeography a project in development: Literary psychogeography of the city. Retrieved September 15, 2002 from http://people.a2000.nl/ttijen/Litpsyweb\%20copy/Litpsy91.htm

Soja, E. (1989). The reassertion of space in critical social theory. London:Verso.

Soja, E. (1996). Thirdspace: Journeys to Los Angeles and other real-and-imagined places. Massachusetts: Blackwell Publishers Ltd.

Spivak, G. C. (1988). Can the subaltern speak?. In Nelson, C., \& Grossberg, L., (Eds.). Marxism and the interpretation of culture (p.271-313). United States of America: Illini Books [Board of trustees of the University of Illinois].

Spivak, G. C. (1990a). Practical politics of the open end. In Harasym, S. (Ed.), The postcolonial critic: Interviews, strategies, dialogues. (p.95-112). United States of America: Routledge. (Reprinted from Canadian Journal of Political and Social Theory/Revue Canadienne de Théorie Politique et Sociale, Vol.12, No. 1-2,1988).

Spivak, G.C. (1990b) Questions of multi-culturalism. In Harasym, S. (Ed.), The postcolonial critic: Interviews, strategies, dialogues. (p.59-66). United States of America: Routledge. (Reprinted from Hecate: An Interdisciplinary Journal of Women's Liberation,Vol.12, No.1/2,1986). 
Stefan, S. (2003). "Discredited" and "discreditable": The search for political identity by people with psychiatric diagnoses. [Electronic version]. William and Mary Law Review, Feb,44 i3 p1341 (43). Retrieved May 5, 2003, from Info Trac One File: Thomson Gale Database.

Tangitu, P., \& Cooney, C. (2002). Pohiri poutama Maori model of practice: A guide for staff. Rotorua: Lakeland Health.

Te Puni Kokiri Ministry of Maori Development. (1997). Oranga kaumatua: The health and wellbeing of older Maori people. Wellington: Author.

Teasley, M., \& Rice, J. (1996). What is social justice? [Electronic version]. Perspectives on Multiculturalism and Cultural Diversity VI, (2), 1-3. Retrieved January 14, 2006, from http://www.students.vcu.edu/counsel/MC/justice.html

Theoretical Spaces, Jan-June 2001. Retrieved on September 8, 2004 from http://www.spin.net.au/ mifilito/theoryphd1.html

Thompson, M. (2003). The right stuff. [Review of the book Black Veil by Moody, R.] Herald Newspaper Canvas Magazine, May $3^{\text {rd }}-4^{\text {th }}$.

Tijen, van, T. (n.d. ). A literary psycho-geography of Tokyo \& Amsterdam [Interactive Installation]. Retrieved September 3, 2004, from http://imaginarymuseum.org/LPG/TALPflw1.htm

Ungar, S. (2002). Cognitive mapping and social change-3: Psychogeography. Retrieved September 15, 2002, from Surrey University BSc Psychology Course Lecture Notes Personal Home Page: http://fhis.gcal.cal.uk/PSY/Sun/LectureNotes/ENV4_EnvCog/environ (update) Retrieved May 16, 2005 from: http://www.surrey.ac.uk/ pss1su/lecturenotes/envpsy4/menu.html 
Walsh, C. (1997). Negotiating difference in mental health nursing in New Zealand. In S Tilley (Ed.), The Mental Health Nurse, Views of Practice and Education. pp.172-185. London: Blackwell Science.

Warriner, R. (2001). Defining the future by responding to the shift to community based mental health services. 'Incite' The Mental Health Journal of New Zealand, $1(1), 14-26$.

Warschauer, M. (1995). Heterotopias, panopticons, and internet discourse. Working Papers in ESL 14 (1) 91-121. Manoa:University of Hawai'i. Retrieved on September 3, 2004, from http://www.gse.uci.edu/markw/heterotopias.html

Watson, J. (1985). Nursing: Human science and human care. Norwalk, CT: Appleton-Century-Crofts.

Weinstein, E. (1998). Elements of the art of practice in mental health. The American Journal of Occupational Therapy, 52, (7), 579-585.

Weller, J. (1993). Planting your feet firmly in emptiness: Expressive arts therapy and meditation. Journal of the Creative Arts Therapies Exchange 3.104-105. Wellington: The Learning Connection.

Wells, D. (2001). Mental health recovery competencies: Teaching resource kit [References, Teaching Notes, Overhead transparencies, Class activities]. Wellington: Mental Health Commission.

"What is,". What is psychogeography?. Retrieved February 17, 2002, from http://art.ntu.ac.uk/mental/whatisps.htm

Zoo from inside the parrots cage (1991). The Cunningham Dax Collection : Art, creativity and education in mental health. Australia and New Zealand Journal of Psychiatry, October 2005, 39 (10), 957-958. 


\section{Art Interval}

Open Hearted Phase II, 2003, mixed media, mm x mm 


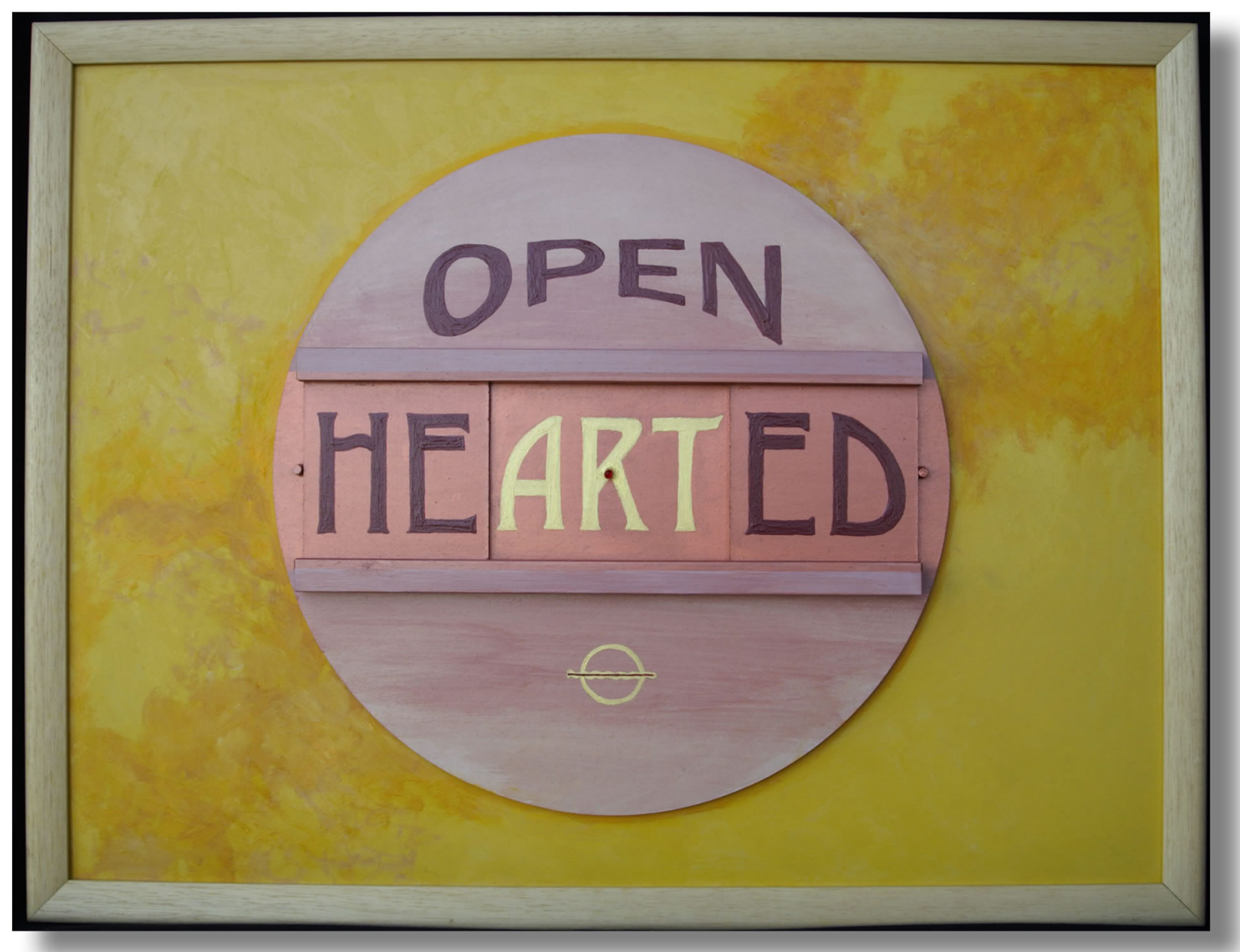




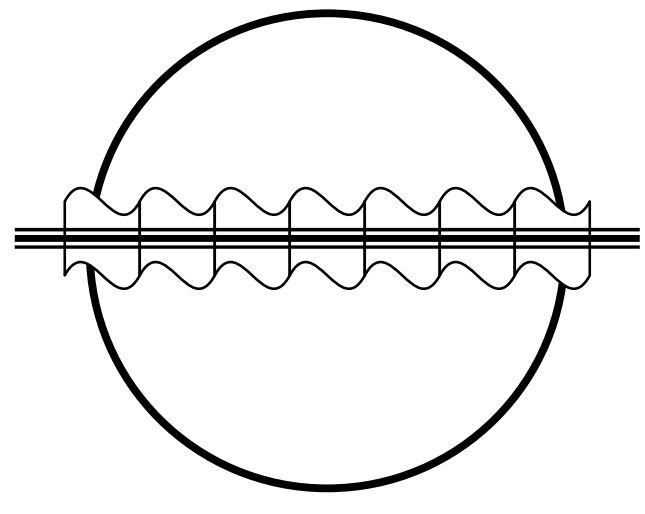

